Molecular determinants for the outcome in gemcitabine-treated pancreatic cancer

\author{
Doctoral Thesis \\ In partial fulfillment of the requirements for the degree \\ "Doctor rerum naturalium (Dr. rer. nat.)" \\ in the Molecular Medicine Study Program \\ at the Georg-August University Göttingen
}

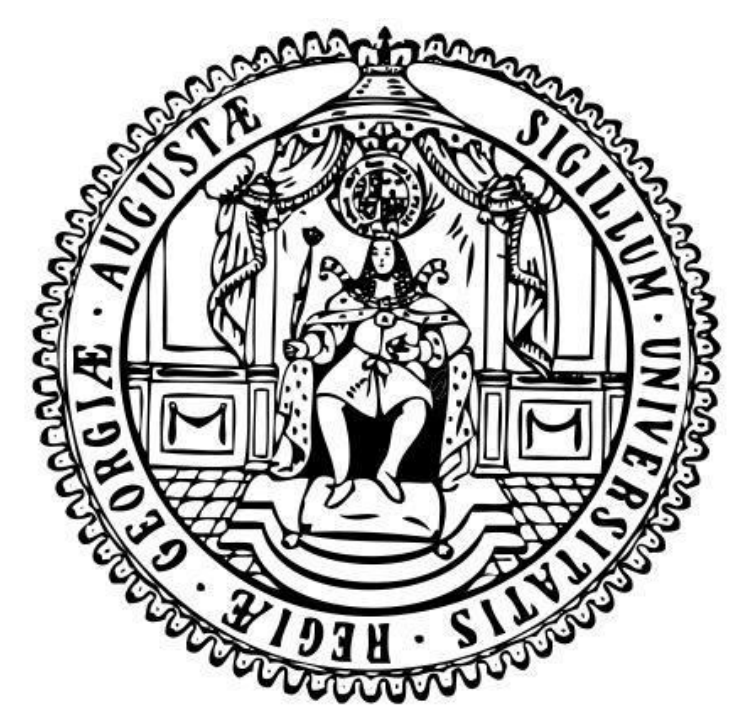

submitted by

Claudia Lüske

born in Oldenburg

Göttingen 2015 


\section{Members of the Thesis Committee:}

Supervisor:

Name, Institute: Prof. Dr. med. Jürgen Brockmöller, Institute of Clinical Pharmacology, University Medical Center Göttingen, Georg-August University Göttingen

Second member of the thesis committee:

Name, Institute: Prof. Dr. rer. nat. Peter Burfeind, Institute of Human Genetics, University Medical Center Göttingen, Georg-August University Göttingen

Third member of the thesis committee:

Name, Institute: Prof. Dr. med. Michael Zeisberg, Department of Nephrology and Rheumatology, University Medical Center Göttingen, Georg-August University Göttingen

Date of disputation: $26^{\text {th }}$ of November 2015 


\section{Affidavit}

Here I declare that my doctoral thesis entitled "Molecular determinants for the outcome in gemcitabine-treated pancreatic cancer" has been written independently with no other sources and aids than quoted.

Claudia Lüske

Göttingen, September 2015 


\section{Table of Contents}

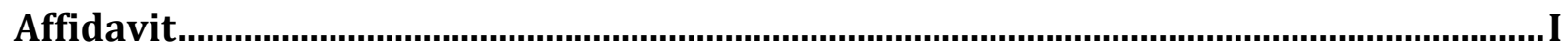

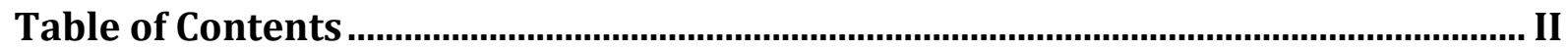

List of Publications.............................................................................................................

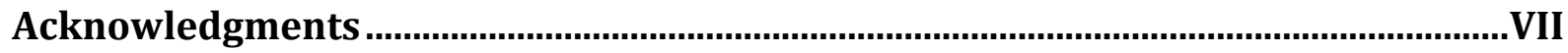

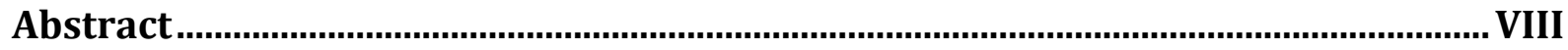

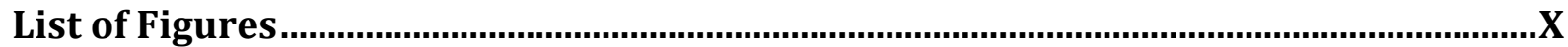

List of Tables and Equations............................................................................................XII

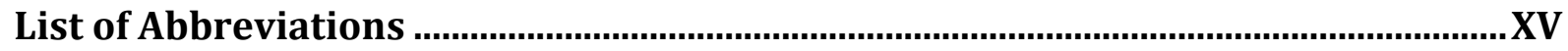

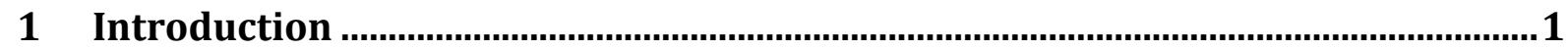

1.1 Pancreatic cancer: Incidence and prognosis..............................................................1

1.2 Molecular features of pancreatic cancer ......................................................................

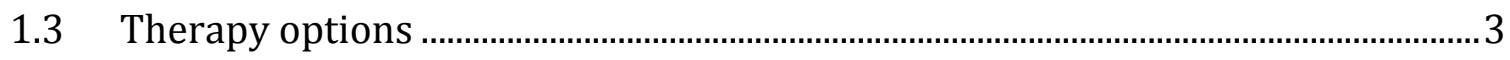

1.4 The nucleoside analogue gemcitabine......................................................................

1.4.1 Clinical indications, administration and toxicity........................................................

1.4.2 Route of gemcitabine ..............................................................................................

1.5 Outcome predictors in gemcitabine-treated pancreatic cancer ...............................

1.5.1 Candidate genes affecting gemcitabine efficacy …………………………………......

1.5.2 Genome-wide association studies (GWAS) .................................................................9

1.6 Aims of this thesis ................................................................................................. 11

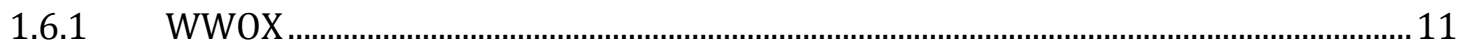

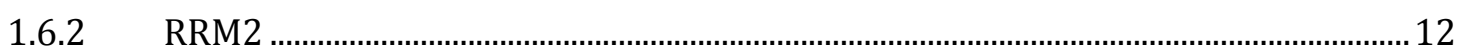

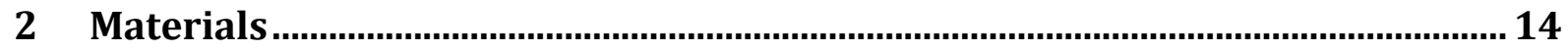

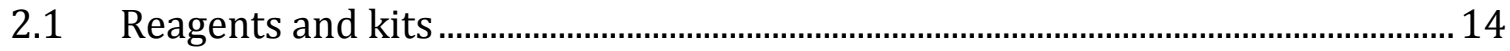

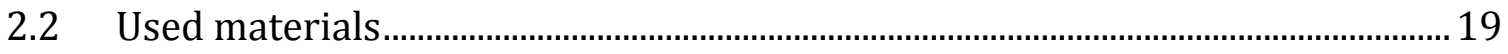

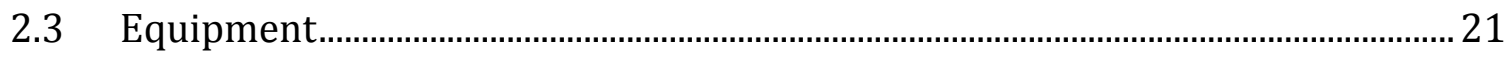

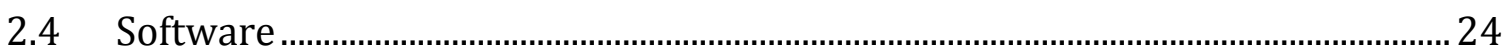

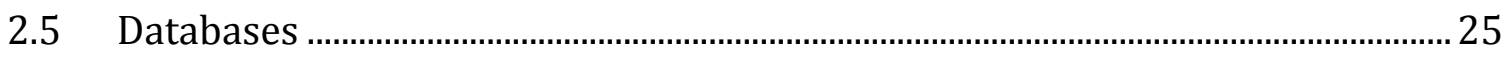

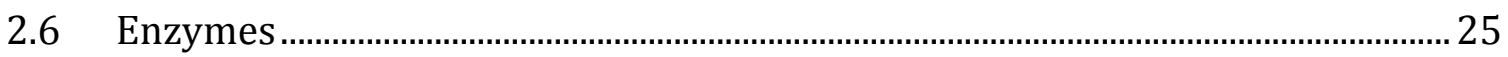

2.7 Strains of bacteria .................................................................................................. 26

2.8 Plasmid vectors......................................................................................................... 26

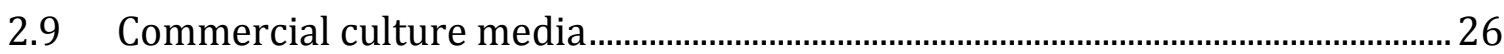

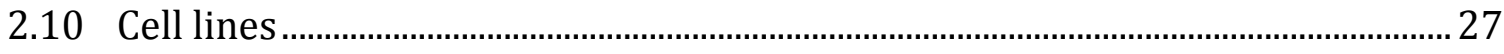

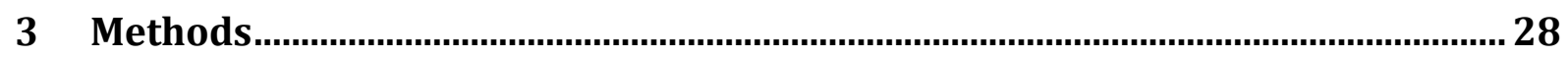

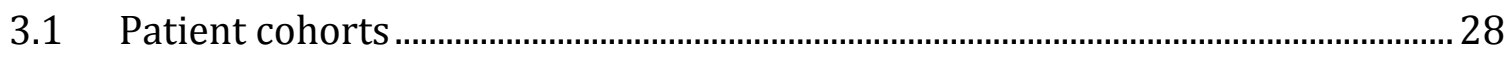

3.1.1 Retrospective patient cohort...............................................................................2

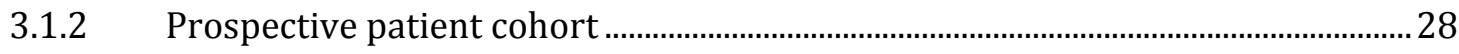




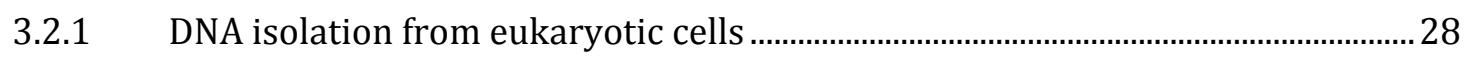

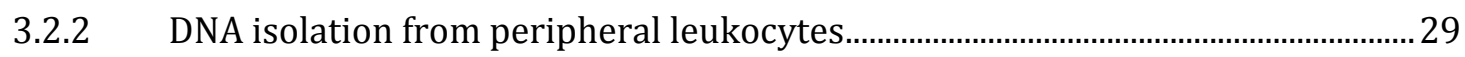

3.2.3 Quantification of DNA...................................................................................... 29

3.2.4 Polymerase chain reaction (PCR) ……................................................................ 29

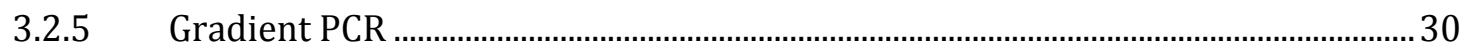

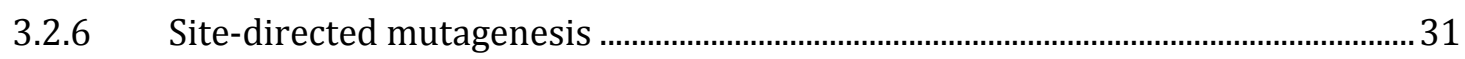

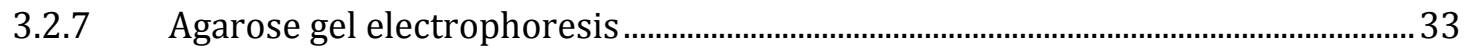

3.2.8 DNA purification from agarose gel......................................................................... 34

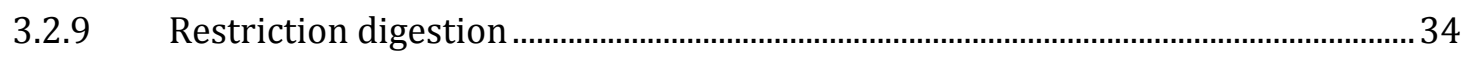

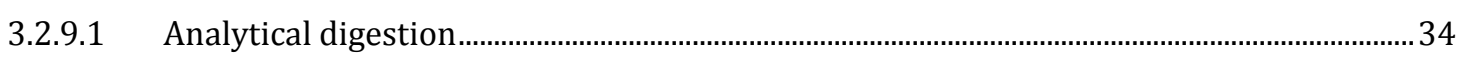

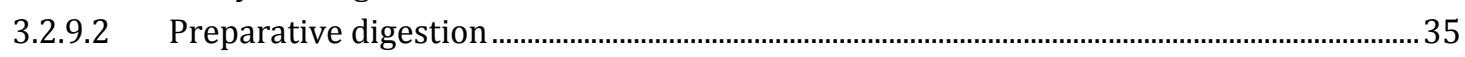

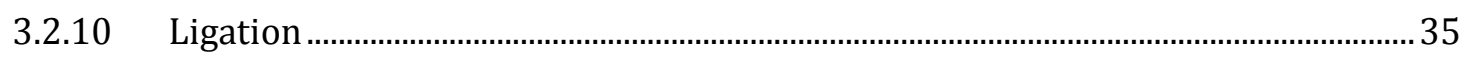

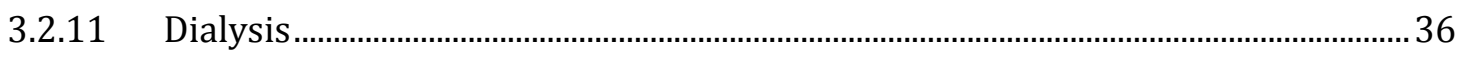

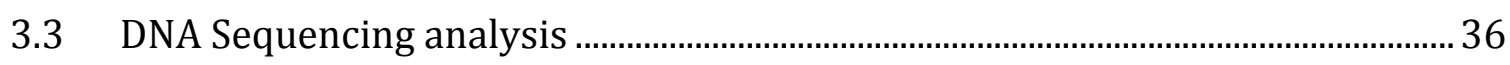

3.4 Genotyping by Single Base Primer Extension Method (SNaPshot ${ }^{\mathrm{TM}}$ ) .................. 38

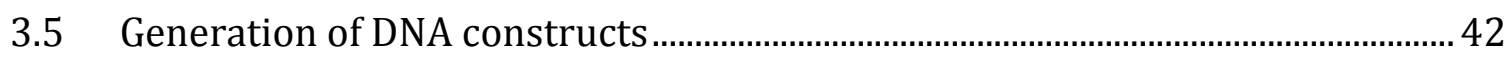

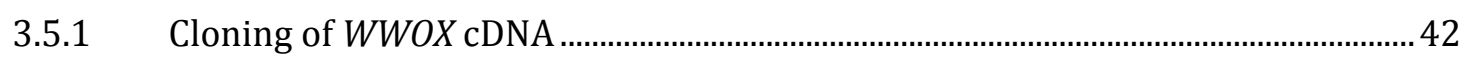

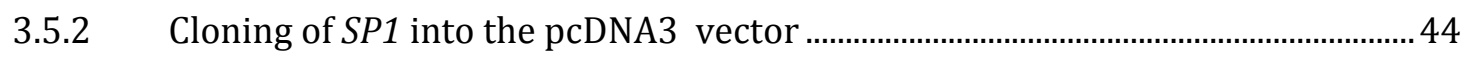

3.5.3 Cloning of eGFP-tagged RRM2 into the pcDNA5 vector......................................... 45

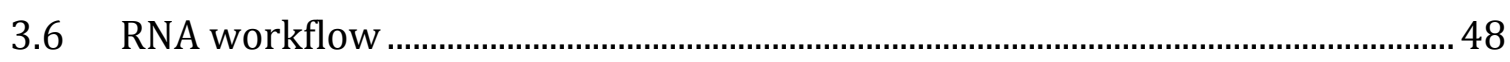

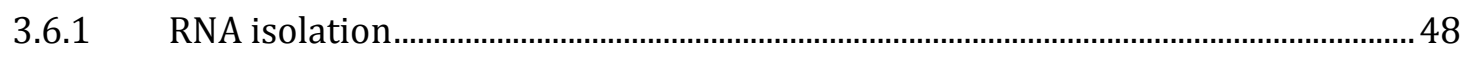

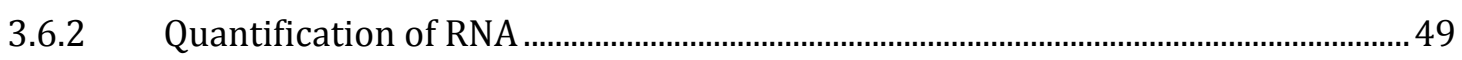

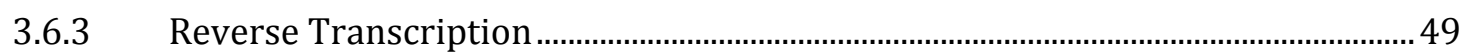

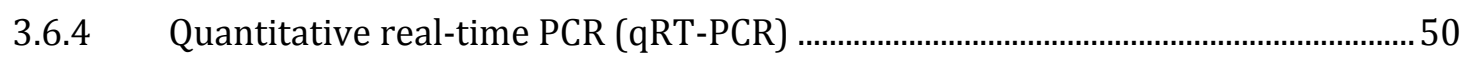

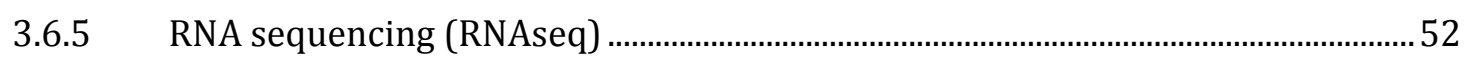

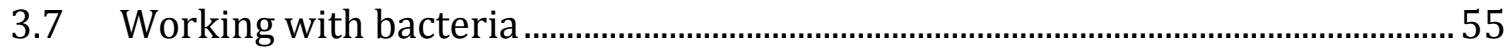

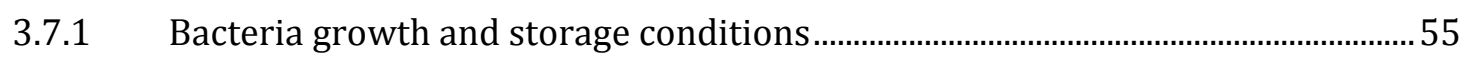

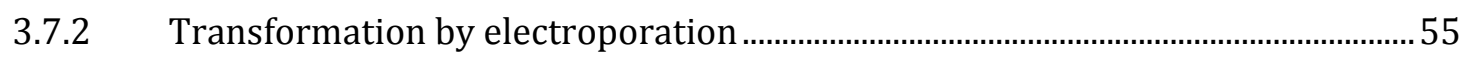

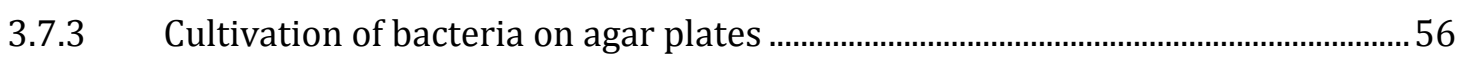

3.7.4 Cultivation of bacteria in solution ......................................................................... 56

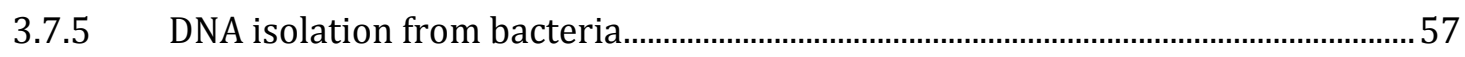

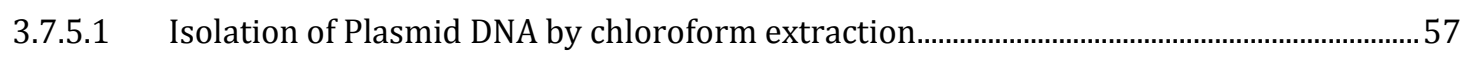

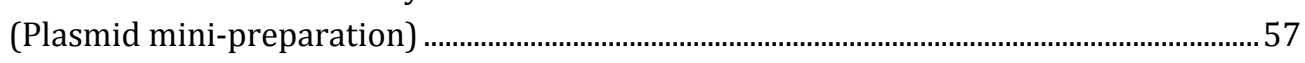

3.7.5.2 Isolation of plasmid DNA by solid extraction .........................................................................59

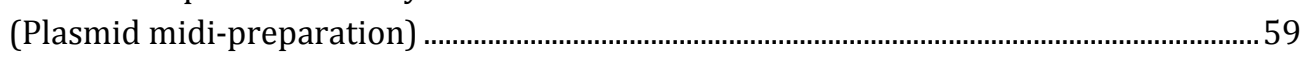

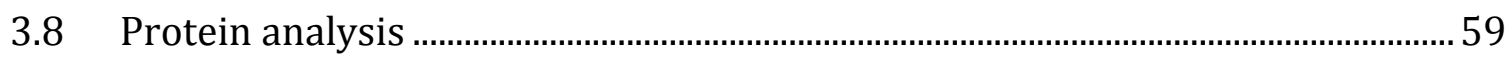

3.8.1 Preparation of cell lysates for Western Blots ........................................................... 59

3.8.2 Determination of protein content via Bicinchoninic acid assay ..............................6 60

3.8.3 Western Blot........................................................................................................ 60

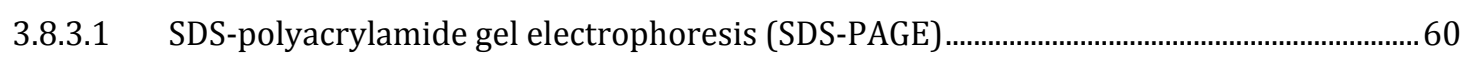

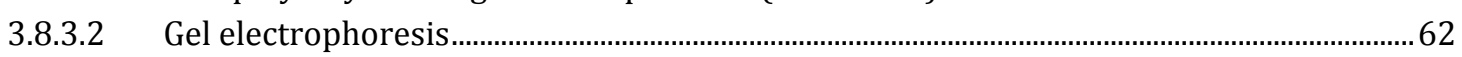

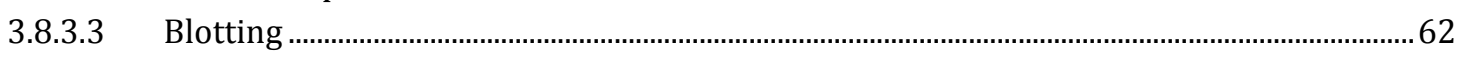




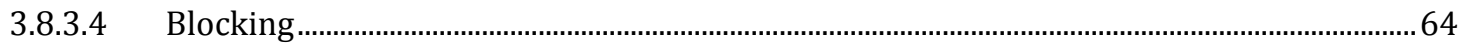

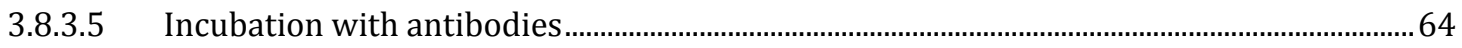

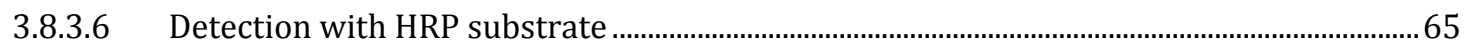

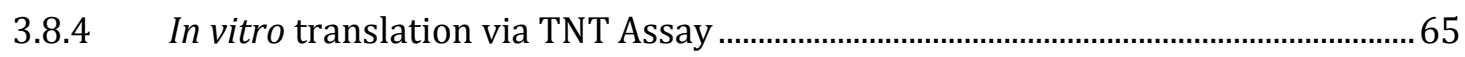

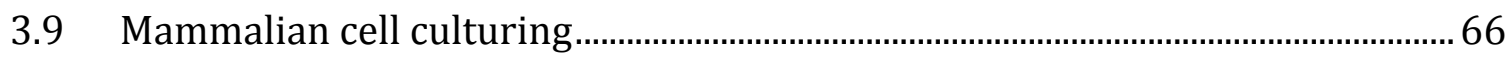

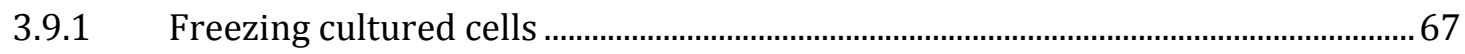

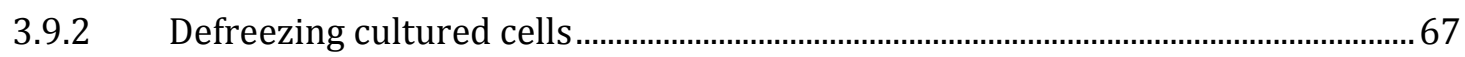

3.9.3 Counting cells with the Neubauer-Cell Chamber .......................................................68

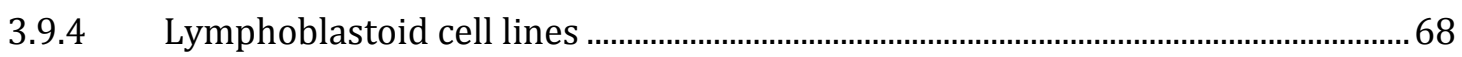

3.9.5 Pancreatic cancer cell lines ................................................................................... 69

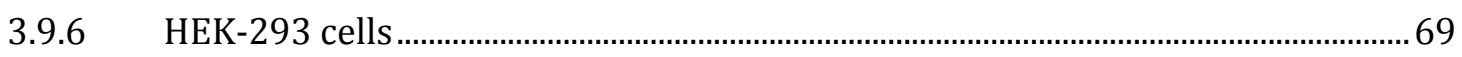

3.9.7 PaTu8988t cells stably transfected with shRNA plasmids against WWOX .........69

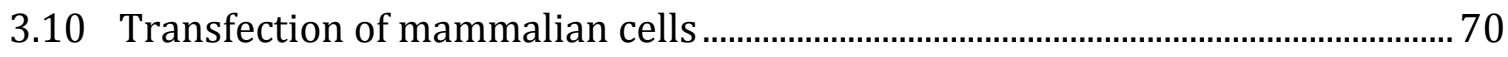

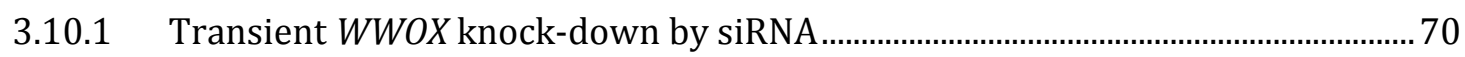

3.10.2 Stable WWOX knock-down by shRNA …………….................................................. 71

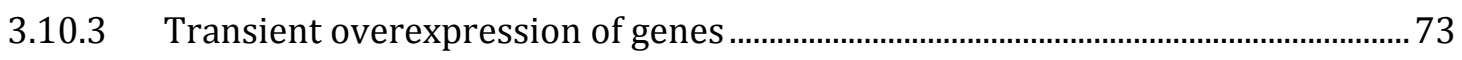

3.10.4 Viability Assay of cytostatic-treated cells ....................................................................... 74

3.11 Sensitivity of lymphoblastoid cells toward gemcitabine .......................................... 75

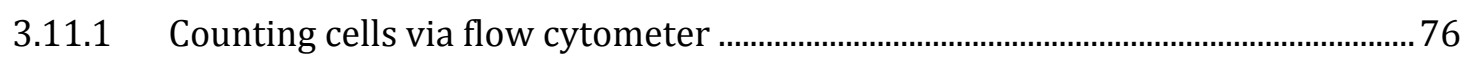

3.11.2 CFSE staining of LCLs for proliferation analysis......................................................77

3.11.3 Flow cytometry preparation................................................................................... 78

3.11.4 Flow cytometry and its measurement conditions ..................................................... 79

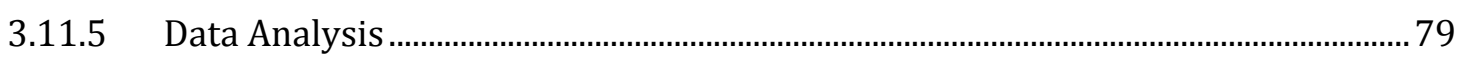

3.12 Electrophoretic Mobility Shift Assay …................................................................... 81

3.12.1 Isolation of Nuclear Protein Extracts …………………………………………..... 81

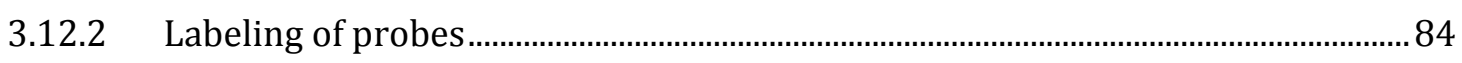

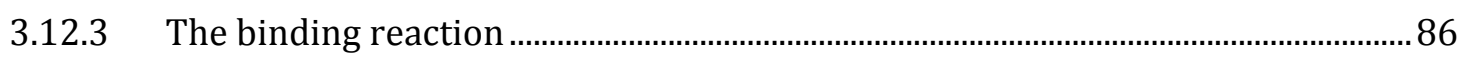

3.12.4 Non-Denaturating Polyacrylamide Gel Electrophoresis .......................................... 87

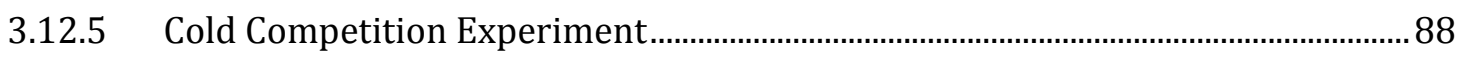

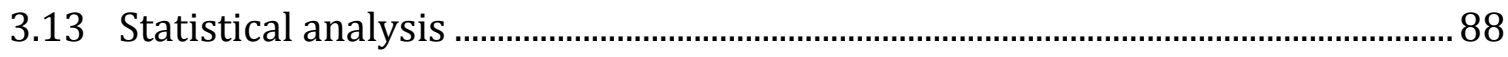

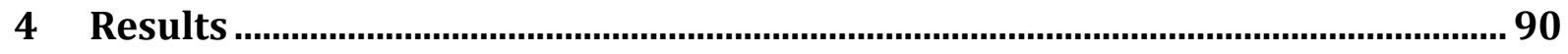

4.1 The SNP rs11644322 association with the overall survival suggesting relevance of $W W O X$ in pancreatic cancer and gemcitabine treatment .............. 90

4.1.1 Modulation of gemcitabine sensitivity by WWOX rs11644322 ............................. 90

4.1.2 WWOX expression in relation to the rs11644322 SNP site ……..............................91

4.1.2.1 Location of the rs11644322 SNP site........................................................................................91

4.1.2.2 WWOX expression of exons flanking the index SNP .............................................................91

4.1.2.3 Impact of rs11644322 SNP on WWOX regional transcription.............................................93

4.1.2.4 Whole transcriptome analysis around the WWOX index SNP...............................................93

4.1.2.5 Global transcriptome stratified for rs11644322 ……………………………..........................94

4.1.3 Consequences of SP1 overexpression for cytostatic drug sensitivity .................... 95

4.1.4 WWOX in the context of apoptosis-related genes ................................................ 99 


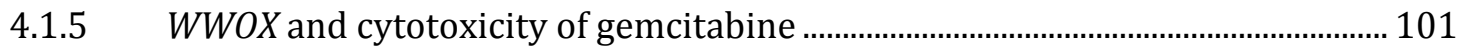

4.1.6 Drug sensitivity upon knock-down or overexpression of WWOX....................... 101

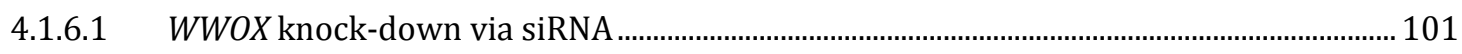

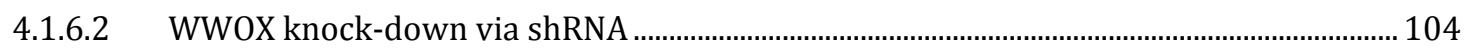

4.1.6.3 Transient overexpression of WWOX

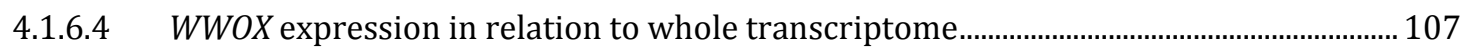

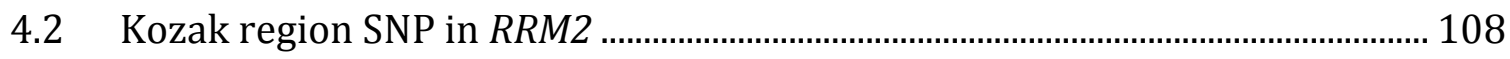

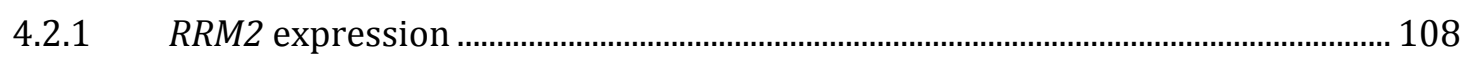

4.2.1.1 RRM2 expression in relation to whole transcriptome upon gemcitabine ......................... 108

4.2.1.2 RRM2 transcript variant expression .................................................................................. 109

4.2.2 RRM2 variant expression upon gemcitabine ........................................................ 110

4.2.3 Impact of RRM2 index SNP on RRM2 transcript variant expression ................... 112

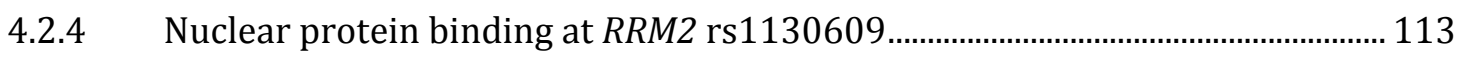

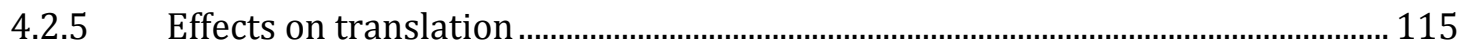

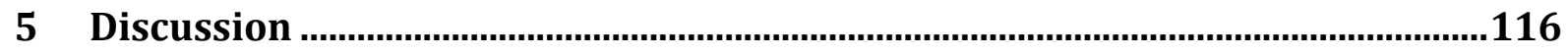

5.1 WWOX

5.1.1 WWOX rs11644322 affects cytotoxicity of gemcitabine but not 5-FU ............... 116

5.1.2 WWOX expression affected by rs11644322 ………………………………....... 117

5.1.3 Consequences of overexpression of SP1 binding to rs11644322 _...................... 118

5.1.4 Rs11644322 located in extraordinarily huge intron: Looping hypothesis ...... 119

5.1.5 Model linking functional and clinical findings for rs11644322 ......................... 121

5.1.6 WWOX knock-down slows cell proliferation and hampers gemcitabine cytotoxicity.............................................................................................................. 122

5.1.7 WWOX in the context of genomic stability and carcinogenesis............................ 124

5.1.8 WWOX in the context of apoptosis induction and DNA damage repair ............. 124

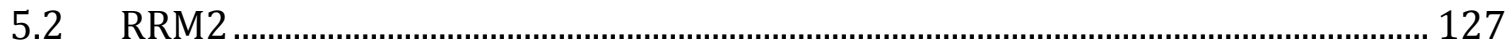

5.2.1 RRM2 expression increases upon gemcitabine...................................................... 127

5.2.2 RRM2 variant expression is differentially affected by gemcitabine ..................... 128

5.2.3 Index SNP affects RRM2 transcript variant-specific expression .......................... 129

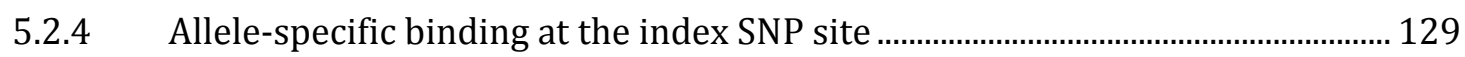

5.2.5 Unifying model how the RRM2 SNP might act...................................................... 130

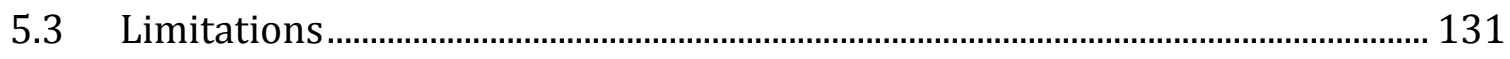

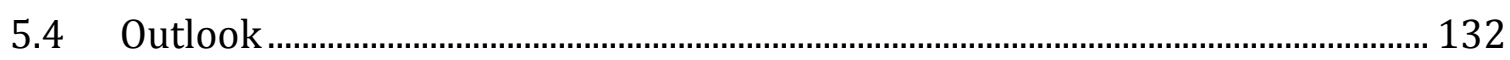

6 Conclusion

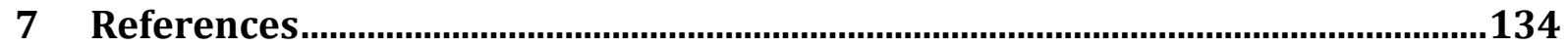

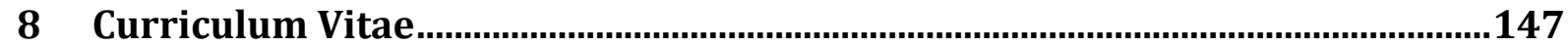

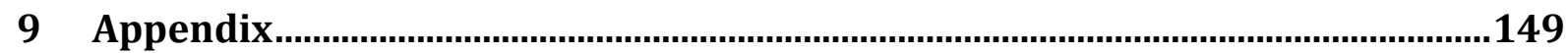




\section{List of Publications}

Groh, I. A., Chen, C., Lüske, C., Cartus, A. T., Esselen, M. (2013). "Plant polyphenols and oxidative metabolites of the herbal alkenylbenzene methyeugenol suppress histone deacetylase activity in human colon carcinoma cells." — Nutr Metab 2013: 821082. 


\section{Acknowledgments}

First and foremost, I want to thank my advisor PD. Dr. med. Markus Schirmer for his scientific support during my whole PhD time. I appreciate all his knowledge, scientific enthusiasm, numerous ideas and the time he spent with me to make my $\mathrm{PhD}$ thesis productive, interesting and ongoing. I am very thankful for his motivation, even during tough times.

Moreover, I want to thank my thesis committee members Prof. Dr. med. Jürgen Brockmöller, Prof. Dr. rer. nat. Peter Burfeind, and Prof. Dr. med. Michael Zeisberg for interesting and helpful discussions with constructive advice and comments during our meetings, which led to progress of this thesis.

I am greatful to Prof. Dr. med. Jürgern Brockmöller, who made it possible to spend my $\mathrm{PhD}$ time at the Institute of Clinical Pharmacology of the Medical University Center Göttingen.

I also thank PD. Dr. rer. nat. Mladen Tzvetkov for his nice and helpful ideas related to molecular questions.

Many thanks also go out to the Transcriptome and Genome Analysis Laboratory (TAL) of the Göttingen University Medical Center, headed by Dr. rer. nat. Gabriela Salinas-Riester, for performing Whole Transcriptome Analysis (RNASeq).

Moreover, I want to thank Prof. Dr. rer. nat. Steven Johnson and his doctoral student Jacobe Rapp (Clinic for General, Visceral and Pediatric Surgery) a lot for their support with regard to RNAi experiments.

I thank all my dear colleagues and friends from the Institute of Clinical Pharmacology and the Institute of Pharmacology for their support, cheering up sessions, open ears, and for all the fun we had during the last three years in Göttingen: Tina, Andreas, Kristin, Nawar, Kate, Steffi, Mohammad, Sebastian, Laura, Jiayin, Karo, Helen, Thomas, Marleen, Svenja, Sina, Brian, Manar, Joao, Anita, Konrad, Sebastian, Simran and Aline.

Another thank you goes to my best friends Luise, Christine, Henrieke and Marina and to all my other friends (TGSO).

My deepest appreciation goes to my family for motivating and being there for me all the time. 


\section{Abstract}

Pancreatic ductal adenocarcinoma (PDAC) is a mostly lethal disease which represents the fourth common cause of all deaths related to cancer. The nucleoside analogue gemcitabine constitutes a currently widely used treatment standard both in a palliative and adjuvant setting. However, variability in response to gemcitabine is high with a substantial impact of genetic variations assumed. Two previously identified single nucleotide polymorphisms (SNPs) associated with the overall survival of gemcitabine treated patients suffering from PDAC were characterized in this thesis concerning the underlying molecular mechanisms: Rs11644322 pertinent to the tumor suppressor gene WWOX, and rs1130609 pertinent to the ribonucleotide reductase RRM2.

A panel of 89 lymphoblastoid cell lines (LCLs) with publicly available genotype information was used as model system to study genomic causes of variable gemcitabine sensitivity. Cytotoxicity of gemcitabine was assessed by flow cytometry-based measurement of proliferation inhibition, and gene expression was determined by quantitative real-time PCR. For extended experiments the pancreatic cancer cell lines AsPC1, MiaPaca-II, PaTu8988t, PancI, and L3.6 were used. Modification of gemcitabine response upon WWOX knock-down by siRNA and shRNA (verified by Western Blotting) or upon WWOX overexpression was ascertained. As the transcription factor SP1 bound to the WWOX rs11644322, overexpression of this factor was conducted and the consequences on WWOX transcription with and without gemcitabine, 5-fluorouracil and irinotecan were studied. Whole transcriptome analysis was determined for gemcitabine effects in AsPC1 and MiaPaca-II cells, in PaTu8988t upon shRNA-mediated WWOX knock down, and in pooled LCLs defined by homozygous wild type and variant allele at the WWOX index SNP site, respectively.

Regarding the molecular mechanisms behind the RRM2 polymorphism, electrophoretic mobility shift assays (EMSA) were performed to discern allele-specific transcription factor binding at rs1130609. An in vitro coupled Transcription/Translation system was utilized to study allele-specific differences regarding protein translation.

In LCLs, cytotoxicity of gemcitabine was reduced in dependence of the number of $A$ alleles at WWOX rs11644322, consistent with the worse prognosis of patients with this allele. No transcripts were detected in close vicinity to rs11644322. However, homozygosity for the $A A$ allele at rs11644322 was accompanied by lower WWOX 
expression of both, the core coding region and of the last exon, separated by $730 \mathrm{~kb}$. A specific gemcitabine-related correlation was identified in LCLs between transcription of WWOX and the growth arrest and DNA damage-inducible gene GADD45A, which was correlated with increased gemcitabine cytotoxicity.

Whole transcriptome analysis in AsPC1 and MiaPaca-II cells revealed that RRM2 expression increased more strongly than any other protein-coding transcript upon gemcitabine exposure. Quantitative relations of the two RRM2 transcripts differing in the noncoding 5' sequence length revealed the major one amounting to 96 to $99 \%$ of the entire transcript numbers, depending on the cell type. This major RRM2 transcript isoform was also increased upon gemcitabine exposure in LCLs and in peripheral blood of patients subjected to gemcitabine-containing chemotherapy. In EMSA experiments

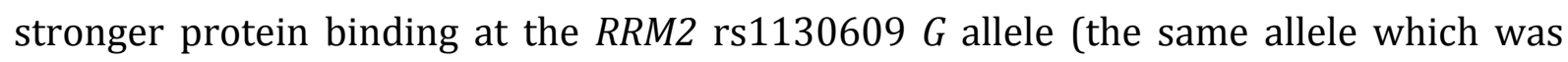
associated with worse prognosis) was identified. However, no impact of this SNP on the transcription of the major RRM2 isoform was seen. In contrast, increased expression of the minor isoform with an extended 5'-region was observed in presence of the $T$ variant allele at rs1130609, intensified upon gemcitabine treatment. Preliminary results for cloned RRM2 suggested less translation efficacy for the $T$ compared to the $G$ allele.

Based on previous data and those of my thesis, mechanistic hypotheses for WWOX and RRM2 are suggested: The variant $A$ allele at the WWOX index SNP might bind SP1 to a lesser extent, resulting in decreased expression probably mediated via interaction with the promoter region by looping. By that, epithelial-mesenchymal transition may be increased resulting in reduced cell proliferation and enhanced resistance to gemcitabine, finally providing a mechanistic basis for worse clinical outcome. Regarding RRM2, phosphorylated gemcitabine can block physiological DNA synthesis resulting in RRM2 transcription induction, primarily of the major variant isoform. In case of the $T$ variant allele at the RRM2 index SNP site, RRM2 protein synthesis is presumed to be impaired, what might stimulate transcription of the minor isoform.

The obtained data provide new insights in functional mechanisms. By corroborating the clinical associations, these data further supported the two predictive SNPs in WWOX and RRM2 as valid biomarkers for gemcitabine-based chemotherapy in PDAC. 


\section{List of Figures}

Figure 1: Anatomy of pancreatic ductal adenocarcinoma (PDAC)........................................

Figure 2: Skeletal formula of desoxycytidine (A) and gemcitabine (B) ..................................

Figure 3: Pathways of gemcitabine $(\mathrm{dFdC})$ transport, metabolism of action and self-

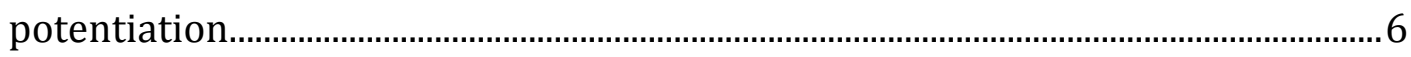

Figure 4: Impact of the inherited RRM2 polymorphism rs1130609 on overall survival ...9

Figure 5: Impact of WWOX rs11644322 on overall survival ................................................ 10

Figure 6: Cloning procedure: Generation of a pcDNA3:WWOX construct ............................. 43

Figure 7: Cloning procedure: Generation of a pcDNA3:SP1 construct ................................... 44

Figure 8: Cloning procedure: Generation of a pcDNA5:RRM2 construct............................... 46

Figure 9: Cloning procedure: Generation of a pcDNA5:RRM2:eGFP construct.................... 48

Figure 10: Workflow of RNA sequencing ………............................................................... 53

Figure 11: Scheme of the pGeneClipTM Hygomycin Vector .................................................. 71

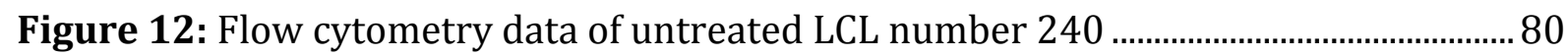

Figure 13: Flow cytometry data of LCL number 240, treated with $10.8 \mathrm{nM}$ of

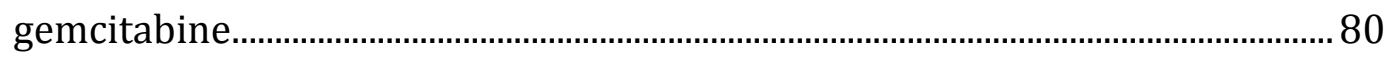

Figure 14: Flow cytometry data of LCL number 240, treated with $76 \mathrm{nM}$ of gemcitabine

Figure 15: Impact of WWOX rs11644322 on cellular gemcitabine sensitivity of lymphoblastoid cell lines 91

Figure 16: Genetic architecture at the WWOX locus 91

Figure 17: Expression of the last exon in relation to that of the core $W W O X$ coding region. 92

Figure 18: Impact of rs11644322 SNP on WWOX regional transcription (exon 4-6/8-9)

Figure 19: Whole transcriptome analysis around rs11644322. 93

Figure 20: Time kinetics of $S P 1$ overexpression 94

Figure 21: Impact of SP1 overexpression on WWOX transcription. 95

Figure 22: Modulation of $W W O X$ transcription by cytostatics upon $S P 1$ overexpression

Figure 23: Correlation of WWOX exon 4-6 transcripts with $\mathrm{EC}_{50}$ values of gemcitabine.99

Figure 24: Correlation of GADD45A transcripts with $\mathrm{EC}_{50}$ values of gemcitabine .......... 100 
Figure 25: Correlation of WWOX transcripts with $\mathrm{EC}_{50}$ values of gemcitabine

Figure 26: Western Blotting for siRNA knock-down in adenoductal pancreatic cancer

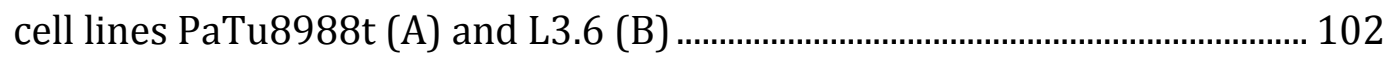

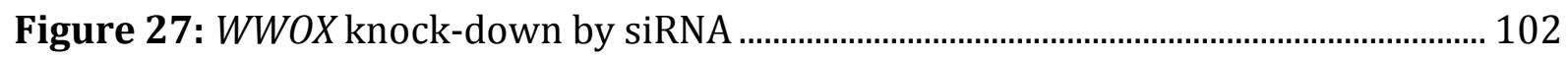

Figure 28: Consequences of WWOX knock-down on cytostatic drug sensitivity ............ 103

Figure 29: WWOX exon 4-6 expression upon suppression by shRNA................................ 104

Figure 30: Western Blotting to demonstrate WWOX knock-down by shRNA................. 104

Figure 31: Gemcitabine sensitivity upon WWOX knock-down by shRNA and in

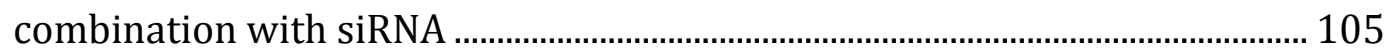

Figure 32: Gemcitabine sensitivity upon WWOX overexpression....................................... 106

Figure 33: Differential gene expression upon WWOX knock-down by shRNA................ 107

Figure 34: Relation of the index SNP (rs1130609) to the two RRM2 transcript variants

Figure 35: Quantitative proportions of RRM2 transcript variant expression ................... 110

Figure 36: Gemcitabine effects on RRM2 transcript variant expression in LCLs............. 110

Figure 37: Consequences of gemcitabine on RRM2 transcript variant expression ratio

Figure 38: $R R M 2$ transcript variant expression in patients' blood during chemotherapy

Figure 39: RRM2 transcript variant expression in dependence on RRM2 rs1130609.. 113

Figure 40: Electrophoretic Mobility Shift Assay (EMSA) for RRM2 rs1130609 with LCL nuclear cell extract

Figure 41: Electrophoretic Mobility Shift Assay (EMSA) for RRM2 rs1130609 with HEK293 nuclear cell extract

Figure 42: Electrophoretic Mobility Shift Assay (EMSA) for RRM2 rs1130609 with nuclear extracts of the pancreatic cancer cell lines MiaPaca-II, PancI, PaTu8988t and CFPac.

Figure 43: Hypothesis linking functional and clinical findings for rs11644322 ............ 121

Figure 44: EMT as a putative mechanism for the effects of WWOX rs11644322 …....... 123

Figure 45: Hypothesized impact of RRM2 rs1130609 on RRM2 transcript expression and protein translation.

Figure 46: Hypothesized interactions of WWOX with p53, EMT and the Wnt/ $\beta$-catenin pathway. 


\section{List of Tables and Equations}

\section{Tables}

Table 1: Standard KOD HotStart PCR reaction ............................................................................ 30

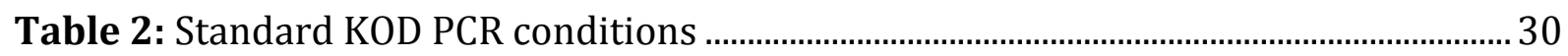

Table 3: Oligonucleotide primers for the Site-directed mutagenesis (rs1130609) ........... 31

Table 4: PCR-reaction mixture for the site-directed mutagenesis........................................... 32

Table 5: PCR consitions used for site-directed mutagenesis..................................................... 32

Table 6: Sequencing primers for the construct pcDNA5-RRM2-eGFP ................................... 32

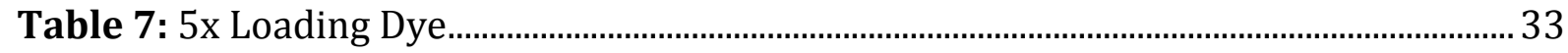

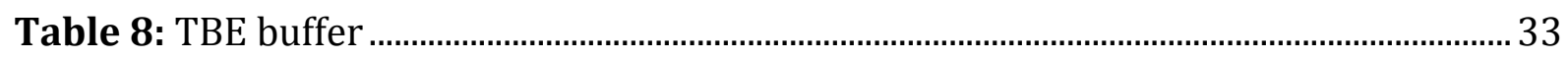

Table 9: Reaction mixture for analytical digestion ..................................................................... 34

Table 10: Reaction mixture for preparative digestion ............................................................ 35

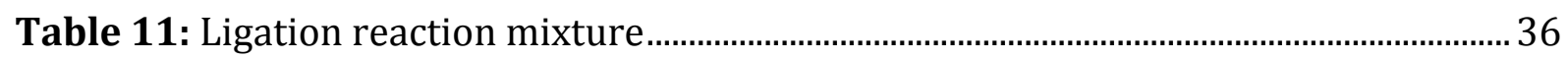

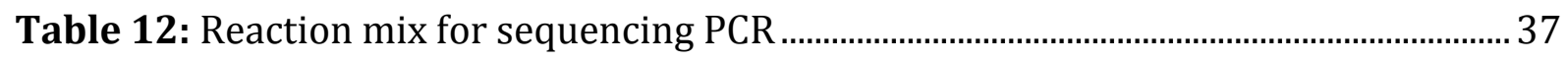

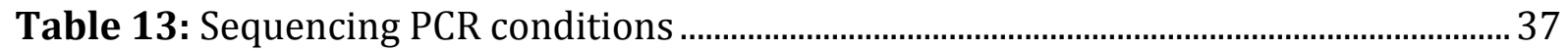

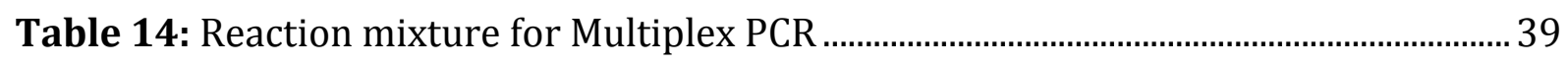

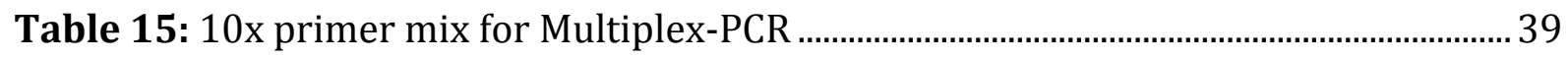

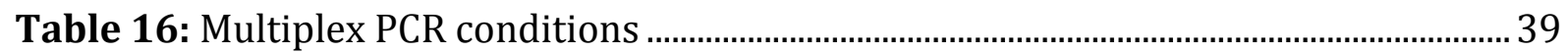

Table 17: Reaction mixture for the first purification step.................................................... 40

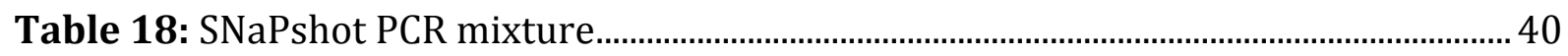

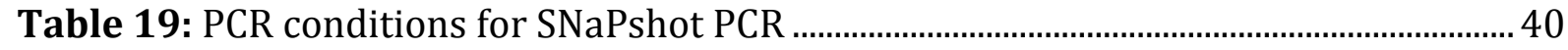

Table 20: SNaPshot Primers ............................................................................................... 41

Table 21: Reaction mixture for the second purification step................................................ 41

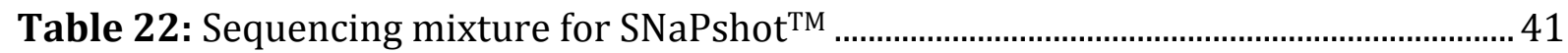

Table 23: Primers for WWOX cDNA amplification .................................................................. 42

Table 24: Sequencing primers to verify the pcDNA3-WWOX construct................................ 43

Table 25: Sequencing primers for the construct pcDNA3:SP1 .............................................. 45

Table 26: Primers to amplify RRM2 out of the pOTB7:RRM2 construct ............................... 46

Table 27: Primers to amplify eGFP out of the pcDNA5/FRT/TO GFP construct ................47 
Table 28: Reaction mixture for the reverse transcription 50

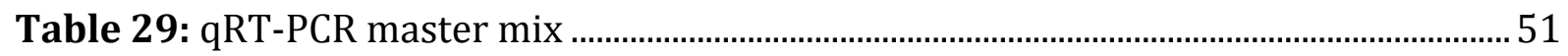

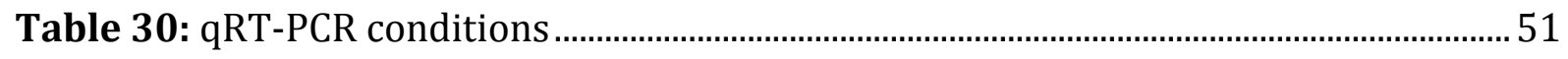

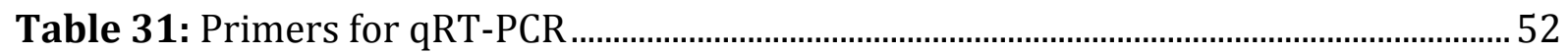

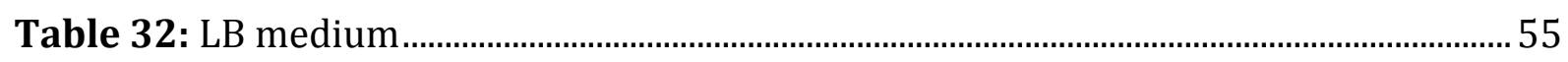

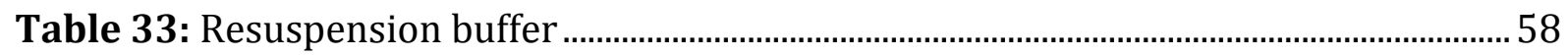

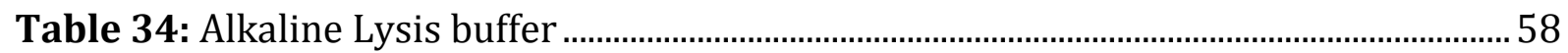

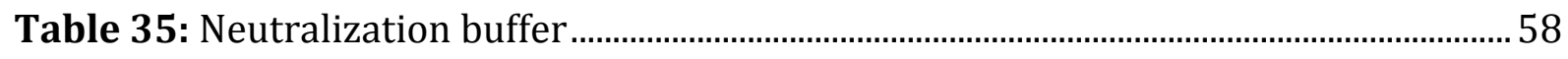

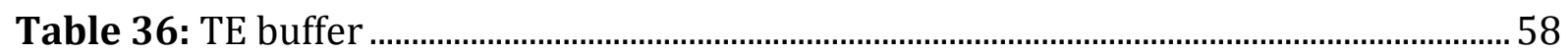

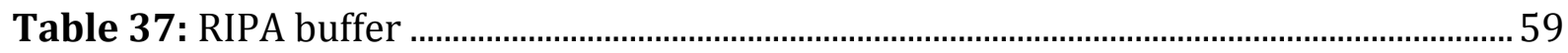

Table 38: 10 \% Separating Gel, mixture for two mini gels ...................................................... 61

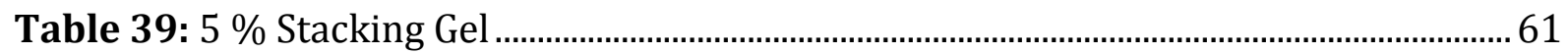

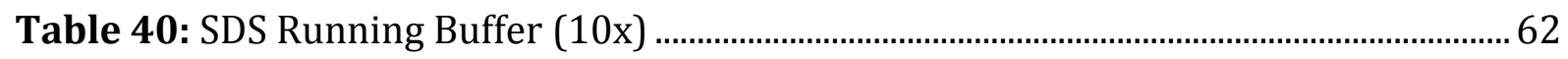

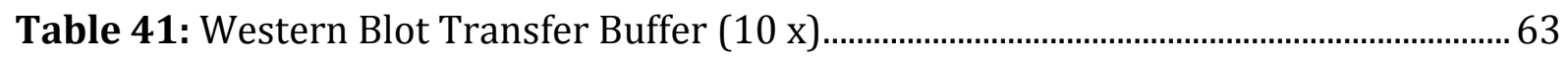

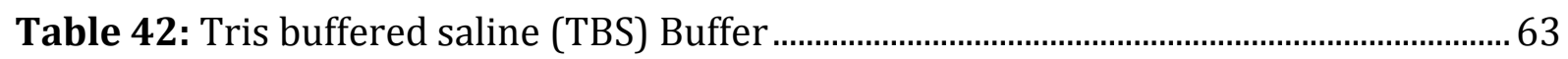

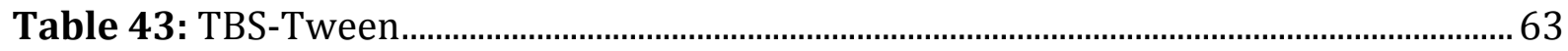

Table 44: Blocking Buffer for the Western Blot membrane .................................................. 64

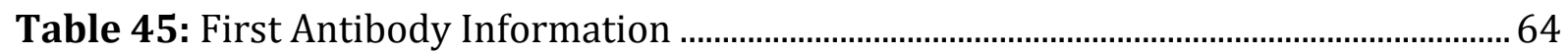

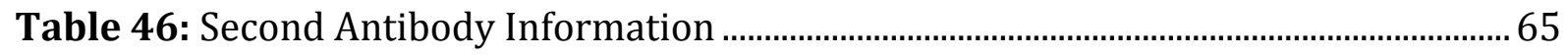

Table 47: Reaction mixture for the TNT ${ }^{\circledR}$ Assay .................................................................... 66

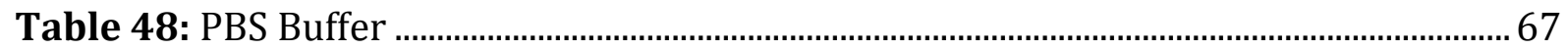

Table 49: ID numbers of lymphoblastoid cell lines from Coriell Cell Repositories ........... 69

Table 50: siRNA transfection mixture .......................................................................................... 71

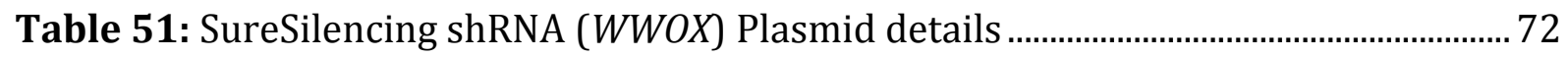

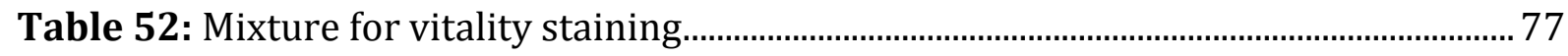

Table 53: Volume of gemcitabine treated samples measured by flow cytometry ............ 78

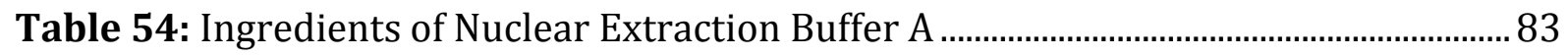

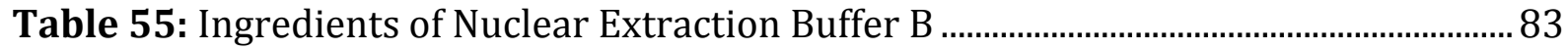

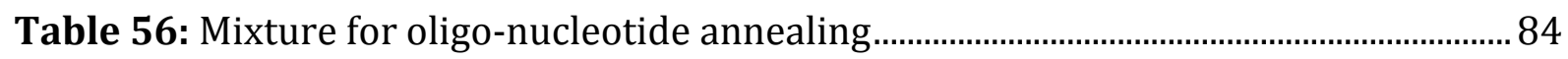




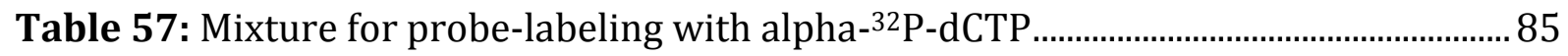

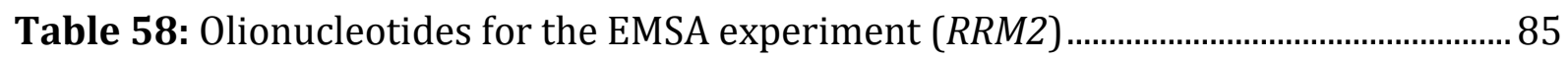

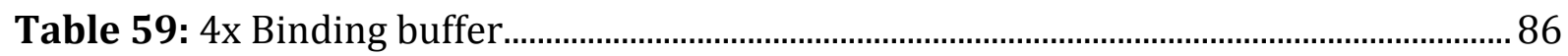

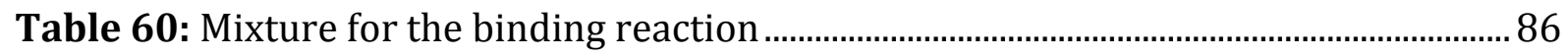

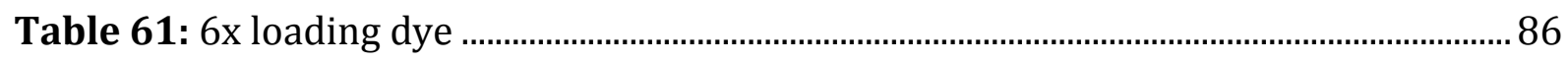

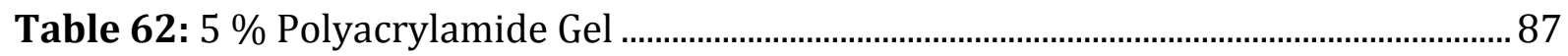

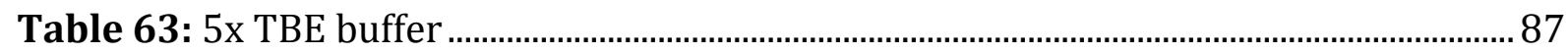

Table 64: Expression profile in LCL samples in dependence of WWOX rs11644322 ...... 95

Table 65: Expression correlation of WWOX with BCL2, GADD45A, and TP53.................. 100

Table 66: $R R M 2$ induction by gemcitabine in relation to entire transcriptome .............. 109

\section{Equations}

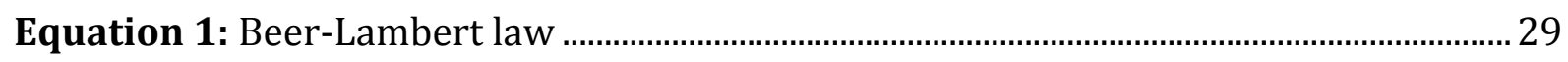

Equation 2: Formula to calculate relative gene expression ...................................................... 51

Equation 3: Calculation of cell concentration per milliliter ....................................................... 68

Equation 4: Calculation of the cell concentration in a cell suspension containing counting beads. 


\section{List of Abbreviations}

$36 B 4$

5 -FU

ADP

APS

AJCC

AMT

B2MG

BCL2

bp

BSA

CAMP

CDA

cDNA

CDP

hCNT

CFSE

CI

CMPK

CRE

d-

Da

DCTD

dCTP

dd-

$\mathrm{ddH}_{2} \mathrm{O}$

DDR

$\mathrm{dFdC}$

dFdCMP

dFdCDP

dFdCTP

dFdUMP

DMEM

DMSO

DNA

dNTP

DPD

dsDNA

DTT

E. coli

$\mathrm{EC}_{50}$

EDTA

e.g.

EGFR

eGFP

EMT
Acidic ribosomal phosphoprotein P0

5-Fluorouracil

Adenosine diphosphate

Ammonium persulfate

American Joint Committee on Cancer

Ataxia telangiectasia-mutated

Beta-2 microglobulin

B-cell lymphoma 2

Base pair

Bovine Serum Albumin

Cyclic adenosine monophosphate

Cytidine deaminase

Copy DNA (complementary DNA)

Cytidine diphosphate

Human concentrative nucleoside transporter

Carboxy fluoresceinsuccinimidyl ester

Confidence interval

Cytidine monophosphate kinase

cAMP response element

Deoxy

Dalton

Deoxycytidylate deaminase

Deoxycytidine triphosphate

Dideoxy

Bi-distilled water

DNA damage response

2', 2'-difluorodeoxycytidine (Gemcitabine)

2', 2'-difluorodeoxycytidine-monophosphate

2', 2'-difluorodeoxycytidine-diphosphate

2', 2'-difluorodeoxycytidine-triphosphate

2', 2'-difluorodeoxyuridine-monophosphate

Dulbecco's modified Eagle Medium

Dimethylsulfoxide

Deoxyribonucleic acid

Desoxynucleosidetriphosphate

Dihydropyrimidine dehydrogenase

Double standed DNA

Dithiothreitol

Escherichia coli

Half maximal effect concentration

Ethylene di-amine tetra-acetic acid

Exempli gratia

Epidermal growth factor receptor

Enhanced Green Fluorescent Protein

Epithelial-mesenchymal Transition 


\begin{tabular}{|c|c|}
\hline hENT & Human equilibrative nucleoside transporter \\
\hline et al. & et alii/et aliae/et alia \\
\hline FACS & Fluorescence-activated cell sorting \\
\hline FCS & Fetal calf serum \\
\hline FRT & Flp (recombinase) recognition target \\
\hline g & Gravity acceleration $\left(9.81 \mathrm{~m} / \mathrm{s}^{2}\right)$ \\
\hline$G A D D 45 A$ & Growth arrest and DNA-damage-inducible gene alpha \\
\hline GAPDH & Glyceraldehyde 3-phosphate dehydrogenase \\
\hline GDP & Guanosine diphosphate \\
\hline GWAS & Genome-wide association study \\
\hline $\mathrm{h}$ & Hour \\
\hline HEK-293 & Human embryonic kidney 293 cell line \\
\hline HEPES & 2-[4-(2-hydroxyethyl)piperazin-1-ly] ethanesulfonic acid \\
\hline HPRT1 & Hypoxanthine-guanine phosphoribosyltransferase 1 \\
\hline HR & Hazard ratio \\
\hline HRP & Horseradish peroxidase \\
\hline ID & Identification \\
\hline $\operatorname{IgG}$ & Immunoglobulin G \\
\hline $\mathrm{kV}$ & Kilo volt \\
\hline $\mathrm{kb}$ & Kilo base \\
\hline $\mathrm{kDa}$ & Kilodalton \\
\hline LB medium & Luria-Bertani medium \\
\hline LCL & Lymphoblastoid cell line \\
\hline LD & Linkage disequilibrium \\
\hline M & Molarity \\
\hline MAF & Minor allele frequency \\
\hline MET & Mesenchymal-epithelial Transition \\
\hline $\min$ & Minute \\
\hline mRNA & Messenger RNA \\
\hline NDPK & Nucleoside diphosphate kinase \\
\hline NER & Nucleotide excision repair \\
\hline NP-40 & Nonyl-phenoxypolyethoxylethanol \\
\hline NT & Nucleotidase \\
\hline ORF & Open reading frame \\
\hline $\mathrm{p}$ & Probability \\
\hline PAGE & Polyacrylamide gel electrophoresis \\
\hline PBS & Phosphate buffered saline \\
\hline PCR & Polymerase chain reaction \\
\hline PDAC & Pancreatic ductal adenocarcinoma \\
\hline $\mathrm{pH}$ & pH-value \\
\hline PMSF & Phenylmethanesulfonyl fluoride \\
\hline PS & Penicillin-Streptomycin \\
\hline qRT-PCR & Quantitative real-time PCR \\
\hline RNA & Ribonucleic acid \\
\hline RNase & Ribonuclease \\
\hline RNAseq & RNA sequencing \\
\hline RPKM & Reads per kilobase of transcript per million mapped reads \\
\hline
\end{tabular}




\begin{tabular}{ll} 
RPMI & Roswell Park Memorial Institute Medium 1640 \\
RRM1 & Ribonucleotide reductase subunit 1 \\
RRM2 & Ribonucleotide reductase subunit 2 \\
rpm & Rotations per minute \\
rs & Reference SNP \\
RT & Room temperature \\
SDS & Sodiumdodecylsulfate \\
sec & Second \\
shRNA & Short hairpin RNA \\
siRNA & Small interfering RNA \\
SNP & Single Nucleotide Polymorphism \\
SP1 & Specificity protein 1 \\
SSDNA & Single stranded DNA \\
Taq & Thermus aquaticus \\
TBE-Buffer & Tris-Borat-EDTA-buffer \\
TE-Buffer & Tris-hydroxymethyl-aminomethane-EDTA-buffer \\
TEMED & N,N,N',N'-Tetramethylethane-1,2-diamine \\
TNM & Tumor classification system (tumor, lymph node, metastasis) \\
TP53 & Tumor protein 53 \\
Tris & Tris(hydroxymethyl)-aminomethane \\
TS & Thymidylate synthase \\
U & Unit \\
UBC & Ubiquitin C \\
UDP & Uridine diphosphate \\
UICC & Union internationale contre le cancer \\
UV & Ultraviolet \\
Var & Variant \\
v/v & Volume per volume \\
Vol & Volume \\
vs. & Versus \\
v/w & Weight per volume \\
W & Tryptophan \\
w/o & Without \\
WT & Wild type \\
WWOX & WW domain containing oxidoreductase \\
\hline &
\end{tabular}

In this thesis all gene names are denotes in italics and the protein names in roman letters, respectively. 


\section{Introduction}

\subsection{Pancreatic cancer: Incidence and prognosis}

Pancreatic cancer is one of the most aggressive and lethal diseases with a dismal prognosis. The current lifetime risk in the Western countries amounts to $1.49 \%$ (1 in 67) with no marked gender preference (HOWLADER et al. 2013, BECKER et al. 2014). In Germany there are up to 16,000 new cases per year and the average age to be affected is 75 years for women, and 71 for men (RoBERT-KocH INSTITUT 2012). With regard to all malignancies, the incidence of pancreatic ductal adenocarcinoma (PDAC) amounts to $3.5 \%$ and it represents the fourth most common cause of cancer-related deaths, for men ranked behind lung, prostate and colorectal cancer and for women behind lung, breast, and colorectal cancer, respectively (SIEGEL et al. 2013).

No early detection methods are available so far and at the time of diagnosis the disease state is often advanced, because at the early stages most patients have no or no specific symptoms indicating the disease (WoLFGANG et al. 2013). The overall five-year survival is less than $5 \%$ and even patients after surgery, performed in curative intention, show an overall five-year survival which does not exceed 20 - $25 \%$ with a median survival of 17 to 23 months (VInCENT et al. 2011). Patients presenting metastatic disease (50 - $60 \%$ ) have the shortest survival time of three to six months (SHRIKHANDE et al. 2007, ChUE 2009). Among all malignant tumors of the pancreas, PDAC, arising from the exocrine pancreas, account for more than 90 \% (DELPERO et al. 2015). Approximately $65 \%$ of the pancreatic tumors are located in the head, $15 \%$ in the body and the tail and the remaining ones diffusely occur inside the gland (Figure 1, GREENLEE et al. 2000, ARTINYAN et al. 2008).

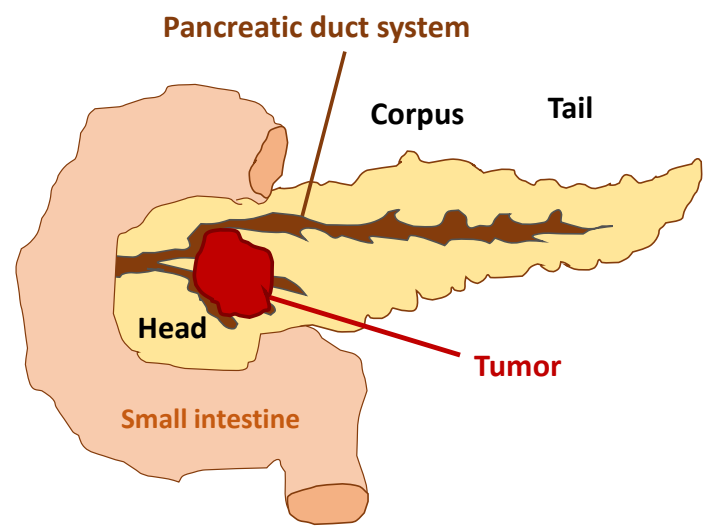

Figure 1: Anatomy of pancreatic ductal adenocarcinoma (PDAC) 


\subsection{Molecular features of pancreatic cancer}

Treatment response to cytostatics is highly variable and a substantial contribution of tumor and host genome variability is presumed. DNA sequencing technologies have shown that pancreatic carcinomas carry on average about 63 acquired somatic mutations, which are predominantly point mutations (JonEs et al. 2008).

Ninety five percent of pancreatic cancers harbor activating mutations in the protooncogene KRAS, which is known to drive pancreatic neoplasia (SMIT et al. 1988, DI MAGLIANO AND LOGSDON 2013, ESER et al. 2014). KRAS mutations correlate with a shortened median survival of 17 vs. 30 months for KRAS wild type (RACHAKONDA et al. 2013). Somatic mutations in SMAD4, which mediated the TGF $\beta$ signaling pathway suppressing epithelial cell growth, have been reported in approximately $50 \%$ of human pancreatic tumors (HAHN et al. 1996, MIYAKI AND KUROKI 2003). Also, the known tumor suppressor gene TP53 belongs to the frequently mutated genes in pancreatic cancer. TP53 is involved in diverse biological effects concerning cell-cycle arrest, DNA replication and repair, apoptosis, angiogenesis inhibition, proliferation and response to cellular stresses. This is due to transcriptional activation of several target genes, e.g. IGF$B P 3$ (negative regulator of cell proliferation), PCNA (involved in DNA replication and nucleotide excision repair in vitro), $B A X$ (linked to regulation of apoptosis) and GADD45 (encodes a protein that binds to PCNA) (CHAN et al. 1999, Hainaut AND Hollstein 2000, TOKINO AND NAKAMURA 2000). Further genes often mutated in PDAC are CDKN2A (CALDAS et al. 1994), APC (HoRII et al. 1992), BRAF and FBXW7 (CALHOUN et al. 2003). Targeted therapies according to the somatic mutation pattern extend treatment options for distinct pancreatic adenocarcinoma subsets.

Some genes like TP53, SMAD4, CDKN2A, and ATM are not only affected by somatic mutations but also carry germline genetic polymorphisms some of them possibly predisposing to PDAC. For another group of genes, germline polymorphisms rather than somatic mutations are reported as relevant in PDAC carcinogenesis (e.g. in BRCA1, BRCA2 or the DNA mismatch-associated genes MLH1 and MSH2) (STOFFEL 2015). Notably, pancreatic cancer cells have inherited the genetic make-up of the host germline variability. Regarding the complex biological reactions upon drug exposure it is thus likely that germline variability contributes substantially to treatment response. 


\subsection{Therapy options}

PDAC is described to have a high tendency for local invasion, distant metastases and limited response to chemotherapeutic agents (MARECHAL et al. 2012).

The only potentially curative approach for PDAC is the complete resection of the tumor. Regrettably, less than $20 \%$ of the patients exhibit a resectable disease at time of diagnosis (BRENNAN et al. 1996). To enhance the chance of curative resection, patients not suitable for surgery or patients with borderline resectable tumors may undergo neoadjuvant treatment (NANDA et al. 2015). Either a combination of chemo- and radiotherapy or a monotherapy of either is commonly used as neoadjuvant treatment (GILLEN et al. 2010). After surgery, adjuvant chemotherapy is commonly used due to the high risk of local tumor recurrence (STALEY et al. 1996, SPERTI et al. 1997). Because most patients suffer from advanced, non resectable disease the optimization of palliative systemic therapy is still ongoing. Monotherapy or combination chemotherapy may enhance the survival time for patients having no chance for cure (VAN LAETHEM et al. 2012).

As standard first-line therapy for PDAC, the nucleoside analogue gemcitabine has been approved for over a decade (VACCARO et al. 2015). With regard to the overall survival (OS) after palliative and adjuvant therapy, the benefit of gemcitabine is very moderate, compared to the former traditionally used chemotherapeutic agent 5-FU (5Fluorouracil) with an OS of 5.7 vs. 4.4 months after palliative, and 23.6 vs. 23 months (5FU plus folinic acid) after adjuvant therapy, respectively. However, gemcitabine improved disease-related symptoms and caused less side effects (BuRRIS et al. 1997, Neoptolemos et al. 2010). The combination of capecitabine (a prodrug of 5-FU) and gemcitabine, used against locally advanced and metastatic pancreatic cancer, had a positive effect on the response rate (19.1\% vs. $12.4 \%)$ as well as on progression-free (Hazard ratio [HR], 0.78; $95 \%$ CI (confidence interval), 0.66 to $0.93 ; p=0.004$ ) and the overall survival ( $\mathrm{HR}, 0.86,95 \% \mathrm{CI}, 0.72$ to $1.02 ; \mathrm{p}=0.08)$, compared to single gemcitabine treatment with tolerable side-effects (CUNNINGHAM et al. 2009). Also nabpaclitaxel (albumin-bound paclitaxel) plus gemcitabine, compared to gemcitabine monotherapy, significantly enhanced the overall (8.5 vs. 6.7 months respectively) and progression-free survival (5.5 vs. 3.7 months, respectively) in patients with metastatic disease (Von HofF et al. 2013). Combinations of gemcitabine with platin compounds in 
most studies did not show an improvement regarding survival time and may just be useful for patients with a good performance status (SAIF AND KIM 2007). A combined treatment of gemcitabine plus the epidermal growth factor receptor (EGFR) tryosine kinase showed an enhanced progression-free (3.8 vs. 2.4 months) and overall survival (7.2 vs. 4.4 months), compared to single gemcitabine administration. Survival time was longer for patients with an EGFR mutation (WANG et al. 2015).

As an alternative treatment to gemcitabine FOLFIRINOX, a combined chemotherapy regimen, including folinic acid (leucovorin, FOL), 5-FU (F), irinotecan (IRIN) and oxaliplatin (OX), approved in 2010, showed a prolonged overall (11 vs. 6.8 months) and progression-free survival (6.4 vs. 3.3 months), but was accompanied by higher toxicity. Therefore, this treatment is an option for patients with metastatic pancreatic cancer showing a good physical condition (CONROY et al. 2011, CONROY et al. 2013). In summary, more aggressive regimens in advanced pancreatic cancer are restricted to patients with a good performance state, otherwise the single-agent gemcitabine is still regarded as gold standard (HEINEMANN et al. 2007).

\subsection{The nucleoside analogue gemcitabine}

Gemcitabine (2',2'-difluorodeoxycytidine, dFdC, marketed as Gemzar ${ }^{\circledR}$ from Eli Lilly and Company) is a nucleoside analogue of deoxycytidine with two additional fluorine atoms in the deoxyribofuranosyl ring (Figure 2).

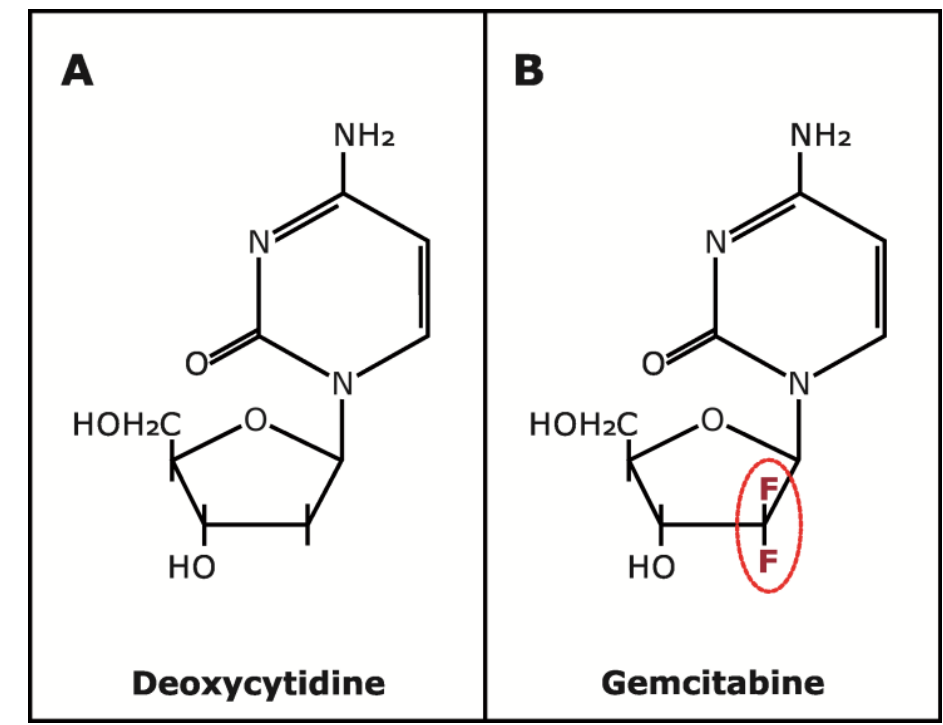

Figure 2: Skeletal formula of desoxycytidine (A) and gemcitabine (B) 


\subsubsection{Clinical indications, administration and toxicity}

Gemcitabine represents a cytostatic drug which is approved for the systemic therapy of advanced (nonresectable Stage II or Stage III) or metastatic (Stage IV) pancreatic cancer since 1995 (Plunkett et al. 1995, ConRoy And Mitry 2011, Elli Lily And Company DRug INFORMATION SHEET GEMZAR 2014, updated version), as single agent or in combination as outlined above (see chapter 1.3). In combination regimens, gemcitabine is also used for non-small-lung and bladder cancer (with cisplatin), ovarian cancer (with carboplatin), and breast cancer (with paclitaxel), respectively (Mini et al. 2006).

The recommended dose of gemcitabine is $1000-1250 \mathrm{mg} / \mathrm{m}^{2}$ administered as a 30minutes infusion once a week for the first seven weeks, followed by one week of rest. After week 8 a weekly dosing on day 1, 8 and 15 of a 28-day cycle is advised (ELLI LILY AND COMPANY DRUG INFORMATION SHEET GEMZAR 2014). Following a standard 30 minute infusion of the recommended gemcitabine dose, plasma concentration of $20-60 \mu \mathrm{M}$ could be achieved at the end of infusion. Though, after intravenous administration, plasma level of gemcitabine decrease rapidly due to rapid deamination to $\mathrm{dFdU}$ (difluorodeoxyuridine) which is mostly occuring before the active drug can enter the tumor cell (ABBRUZZESE et al. 1991, GRUNEWALD et al. 1991). The half-life of gemcitabine varies from 42 to 94 minutes and appears to be affected by gender and age. Gemcitabine $(<10 \%)$ and the inactivated $\mathrm{dFdU}$ (difluorodeoxyuridine) metabolite represent $99 \%$ of the excreted dose measured in the urine of patients, who received a radiolabeled drug infusion (ELLI LILY AND COMPANY DRUG INFORMATION SHEET GEMZAR 2014).

Though, it shows several side-effects, of which myelosuppression, with thrombocytopenia and anemia, represents the dose-limiting toxicity (ABBRUZZESE et al. 1991, ConRoy et al. 2011).

\subsubsection{Route of gemcitabine}

The transport of gemcitabine into the cell is essential for its efficacy. Gemcitabine is highly hydrophilic resulting in a limited intracellular diffusion potential and therefore needs nucleoside transporter (NTs) to enter the cell (PAPROSKI et al. 2013). The equilibrative nucleoside transporter ENT1 (also called SLC29A1) is known as the primary transport protein for gemcitabine and other nucleoside analogues. Also concentrative nucleoside transporter (CNTs), like CNT1 and CNT3 are involved, but to a 
less extent.

As a prodrug, gemcitabine has to be activated inside the cell through phosphorylation by kinases to its derivates $\mathrm{dFdCDP}(2$ ', 2'-difluorodeoxycytidine-diphosphate) and dFdCTP (2', 2'-difluorodeoxycytidine-triphosphate), which are responsible for the cytotoxic effects. The biotransformation of nucleoside analogues to their mononucleotides by phosphorylation is catalyzed by deoxycytidine kinase (DCK) representing the ratelimiting enzyme (FARRELL et al. 2009). Further essential phosphorylation steps of dFdCMP (2', 2'-difluorodeoxycytidine-monophosphate) to di- and triphosphate are mediated by the kinases CMPK1 (cytidine monophosphate kinase) and NDPK (nucleoside diphosphate kinase), respectively (Figure 3) (MINI et al. 2006, KocABAs et al. 2008).

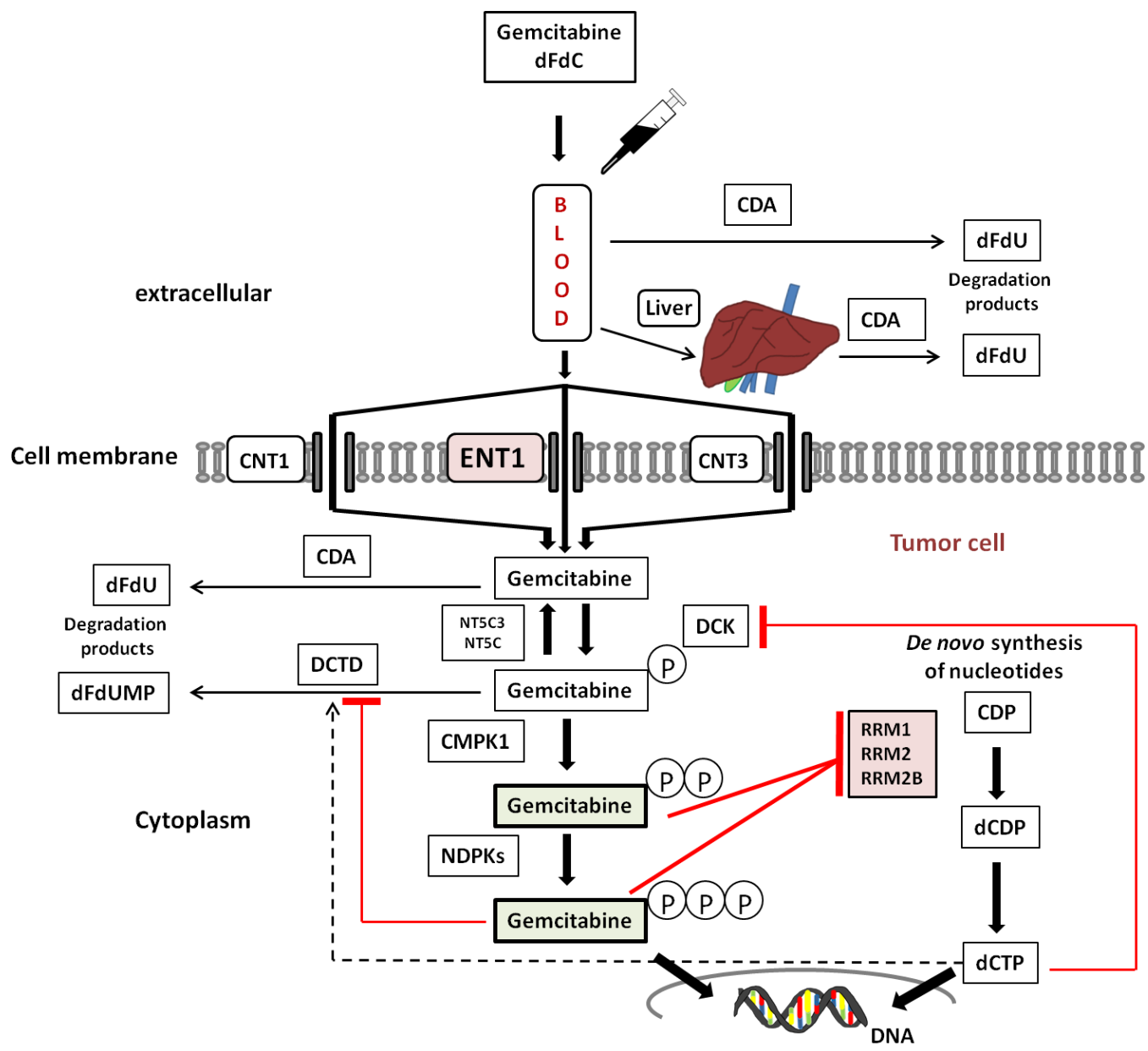

Figure 3: Pathways of gemcitabine (dFdC) transport, metabolism of action and self-potentiation. Black arrows denote uptake and metabolic processes with the involved proteins indicated: Transport proteins ENT1 (equilibrative nucleoside transporter 1), CNT1 (concentrative nucleoside transporter 1) and CNT3 (concentrative nucleoside transporter 3) and the enzymes DCK (deoxycytidine kinase), NT5C3 (cytosolic 5'-nucleotidase 3), NT5C (cytosolic 5'nucleotidase), CMPK1 (cytidine monophosphate kinase 1) and NDPKs (nucleoside diphosphate kinases). The "P" symbols represent phosphates attached to gemcitabine. Competing physiological cytidine metabolites are denoted as CDP (cytidine diphosphate), dCDP (deoxycytidine diphosphate) and dCTP (deoxycytidine triphosphate). The degradation products are dFdU (difluorodeoxyuridine) and dFdUMP (difluorodeoxyuridine-monophosphate). Details are described in the text. Modified according to MinI et al. 2006, WoNG et al. 2009. 
Gemcitabine underlies a self-potentiation mechanism. The metabolite dFdCDP is known to inhibit ribonucleotide reductases (RR) and its regulatory and catalytic subunits (RRM1, RRM2), which are essential for the de novo synthesis of deoxynucleotides. A decreased deoxyribonucleotide pool potentiates the cytotoxic effect of dFdCTP, which competes with physiological dCTPs (deoxycytidine triphosphate) for incorporation into the DNA (MINI et al. 2006). Furthermore, dCTP is a potent feedback inhibitor of DCK, so that low dCTP level cause an increased phosphorylation of gemcitabine (WoNG et al. 2009).

When incorporated into DNA as false nucleotide by DNA polymerase alpha, dFdCTP inhibits further DNA synthesis through masked chain termination, initiated by incorporation of only one additional deoxynucleotide preventing DNA repair mechanisms and fostering cytotoxic effects (HUANG et al. 1991, RUIZ VAN HAPEREN et al. 1993). The described enrichment of dFdCTP as well as the reduction of the dCTP pool lead to an inhibition of the dFdCMP inactivation step mediated by DCTD (deoxycytidylate deaminase), which needs sufficient concentrations of dCTP to be active (HEInEMANn et al. 1992).

Gemcitabine has a short plasma half-life (see chapter 1.4.1) due to its rapid degradation (90\%) to dFdU (2', 2'-difluorodeoxyuridine) catalyzed by cytidine deaminase (CDA), an enzyme which is expressed in the liver and blood and to a less extent inside tumor cells (HeInEmann et al. 1992). Cytosolic 5'-Nucleotidases (5'-NT) are responsible for further gemcitabine inactivation and convert nucleoside monophosphates back to nucleosides, acting as antagonists of DCK (BERGMAN et al. 2002). Another degradation pathway of gemcitabine is the deamination of gemcitabine monophosphate (dFdCMP, 2', 2'difluorodeoxycytidine-monophosphate) to dFdUMP $(2 ', 2$ '-difluorodeoxyuridinemonophosphate) by DCTD (HEINEMANN et al. 1992).

\subsection{Outcome predictors in gemcitabine-treated pancreatic cancer}

\subsubsection{Candidate genes affecting gemcitabine efficacy}

Candidate genes involved in gemcitabine activity are depicted in Figure 3 (section 1.4.2). The determination of a score comprising tumor expression of ENT1, DCK, RRM1 and RRM2 was suggested as a putative biomarker for gemcitabine therapy (NAKANO et al. 2007, FUjITA et al. 2010). 
The relevance of the ENT1 transporter in PDAC has been repeatedly confirmed in several studies as a predictive biomarker for gemcitabine efficacy. Strong ENT1 protein expression detected by immunostaining in the tumor cells was related to longer survival of patients (Spratlin et al. 2004, MAREChAl et al. 2009, GreENHALF et al. 2014). Similar relations were noticed for tumoral ENT1 mRNA expression (GIOVANNETTI et al. 2006).

A significantly prolonged median survival upon gemcitabine treatment was observed in case of low RRM2 mRNA expression (ITOI et al. 2007). On protein level, higher tumoral expression of RRM2 was correlated with a shorter time to disease recurrence and a reduced OS after resection in patients who underwent gemcitabine adjuvant regimen (FISHER et al. 2013). Consistent with the clinical findings, RRM2 overexpression conveys chemoresistance in pancreatic adenocarcinoma and siRNA-mediated knock-down of RRM2 leads to an increased chemosensitivity towards gemcitabine, both in vivo and in vitro. Specifically, the $\mathrm{IC}_{50}$ value of gemcitabine was four times higher upon recombinant RRM2 transfection compared to the empty vector (DUXBURY et al. 2004). In a multi-modal approach with simultaneous overexpression of $D C K$ and uridine monophosphatase (UMP) and gene silencing of RRM2 and TS (thymidylate synthetase) gemcitabine sensitivity of resistant pancreatic cancer cells could be restored (REJIBA et al. 2009). In the gemcitabine resistant pancreatic cancer cell line PancI RRM2 expression gets sharply induced when exposed to gemcitabine via an E2F1-dependent transcriptional activation. CG-5, a glucose transporter inhibitor, was hypothesized to re-establish the sensitivity of gemcitabine-resistant PancI cells by induction of microRNA-520f (LAI et al. 2014).

Regarding RRM1, low RRM1 mRNA expression levels were related to increased gemcitabine sensitivity in pancreatic cancer cell lines and in PDAC (NAKAHIRA et al. 2007). However, in other studies a correlation between RRM1 expression and treatment outcome could not be confirmed (KIM et al. 2011, FISHER et al. 2013). Subsequent studies also could not identify RRM1 as a clear predictive or prognostic parameter in resected PDAC patients exposed to gemcitabine (VALSECCHI et al. 2012).

To ease future clinical use it might be beneficial if variability in gene expression could be referred to genetic markers which can be determined in a more easy and robust fashion compared to tumor-specific expression of mRNA and proteins. For candidate genes of gemcitabine effects, inherited single nucleotide polymorphisms (SNPs) may substantially contribute to treatment outcome. Several SNPs have been associated with the efficacy and toxicity of gemcitabine, e.g. polymorphisms in CDA and DCTD 
(gemcitabine inactivation enzymes), ENT1 or RRM1 (OKAZAKI et al. 2010, FUKUNAGA et al. 2004, UENO et al. 2007, TANAKA et al. 2010).

An in-house conducted retrospective analysis highlighted a SNP in RRM2 associated with OS (Figure 4, ZIMMER 2013). However, this RRM2 SNP was not analyzed functionally so far.

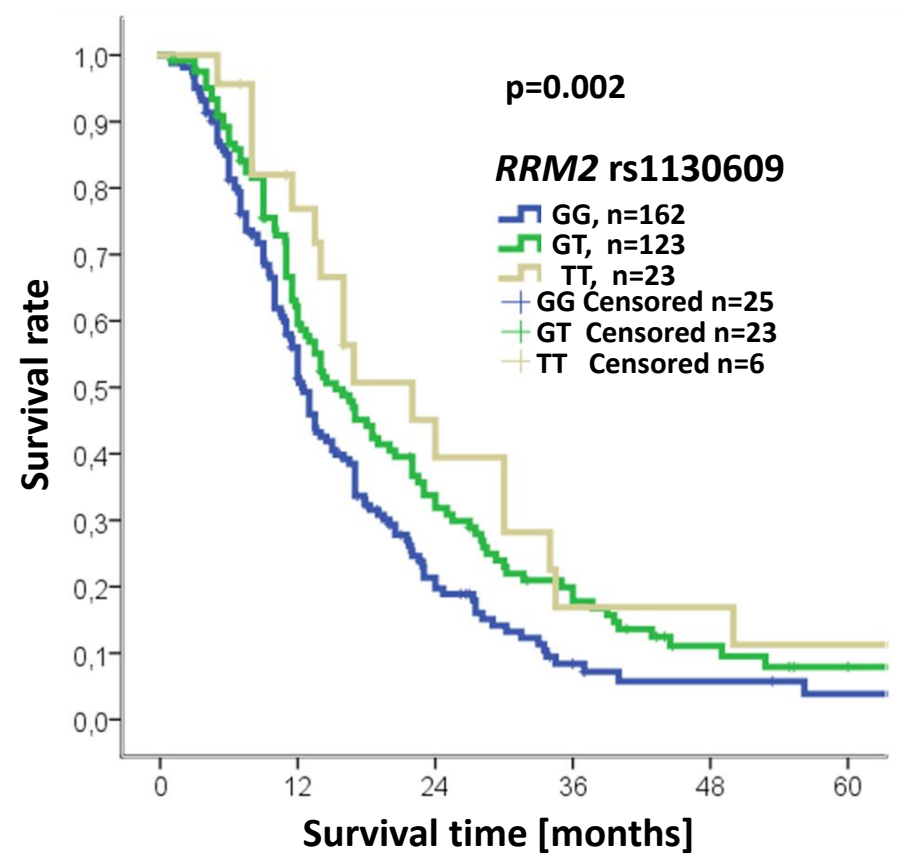

Figure 4: Impact of the inherited RRM2 polymorphism rs1130609 on overall survival. Data is from a set of 308 patients for whom R0 or R1 resections could be achieved. Patients were recruited at three different study sites (Göttingen, Heidelberg, Hamburg) and patient numbers were specified in 12 month intervals. The p-value refers to unadjusted log-rank test (data from ZIMMER 2013).

\subsubsection{Genome-wide association studies (GWAS)}

Genome-wide association studies (GWAS) represent an approach to identify clinically or functionally relevant SNPs in a broad scale (in a so-called hypothesis free approach not restricting the analysis to genes for which specific hypotheses exist). Typically, arrays covering a panel of several hundred thousand SNPs more or less uniformly distributed over the entire genome were applied. More recently, GWAS with complete coverage of genomic varibility have become feasible with emerging of deep sequencing technologies. In 2012, a comprehensive array-based GWAS was undertaken to screen for markers associating with clinical outcome in gemcitabine-treated PDAC. In that study, 351 patients were recruited and $\sim 550,000$ markers were assayed in germline DNA samples isolated of peripheral blood cells. Thereby, the SNP IL17F rs763780 showed the strongest association with OS (INNOCENTI et al. 2012). The variant allele of this SNP was 
hypothesized to mitigate the function of the anti-angiogenic $I L 17 F$, thus possibly promoting tumor growth and hampering therapy responsiveness (ARISAWA et al. 2007, ARISAWA et al. 2008). Other SNPs in or near the genes PRB2, DCP1B, WWOX and BTRC were also associated with overall survival. However, considering multiple testing their role was statistically not significant (INNOCENTI et al. 2012). To assess the clinical relevance of those findings from INNOCENTI et al. an independent validation appeared to be mandatory. In a cooperation between the University Medical Centers in Göttingen, Hamburg, and Heidelberg a statistically significant association of the WWOX SNP, found among the top hits of the mentioned GWAS, could be demonstrated for the first time (Figure 5). However, the role of the SNP IL17F rs763780 could not be confirmed in these german samples. Pilot functional assessment identified members of the specificity protein (SP) family as transcription factors with allele-specific affinity to this WWOX index SNP site. According to those analyses it is unlikely that any other polymorphism as rs11644322 in high linkage disequilibrium (LD) with the latter is causatively functional (ROPPEL 2013). Detailed functional elucidations linking this SNP to WWOX gene expresssion, gemcitabine sensitivity and the clinical finding are not yet performed and might be worthy for potential use as biomarker. Moreover, the pathways in which WWOX acts are still poorly understood.

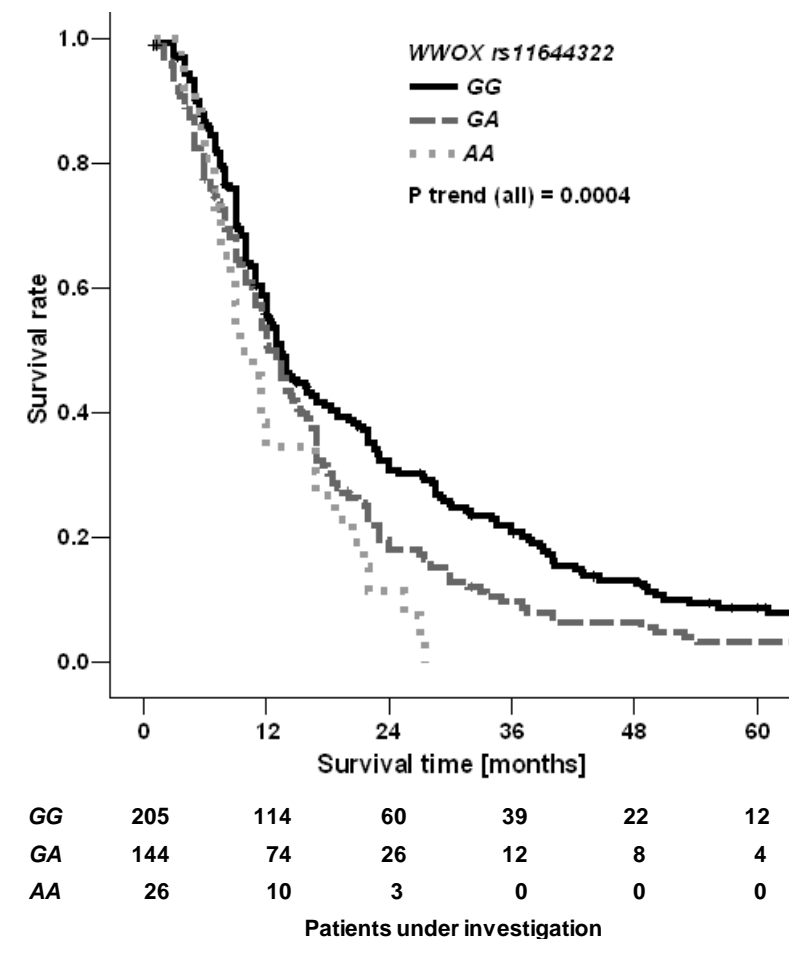

Figure 5: Impact of $W W O X$ rs11644322 on overall survival. Data is from a set of 381 patients for whom R0 or R1 resections could be achieved. Patients were recruited at three different study sites (Göttingen, Heidelberg, Hamburg) and patient numbers were specified in 12 month intervals. The p-value refers to unadjusted log-rank test (data from RoPPEL 2013). 


\subsection{Aims of this thesis}

The aim of my doctoral thesis was the detailed molecular characterization of genetic polymorphisms in $W W O X$ and $R R M 2$, previously identified, to determine gemcitabine response in pancreatic cancer. Knowledge of funtional relationship might contribute to overcome treatment resistance. In the next subchapters, a detailed description of single steps to achieve the aims is provided.

\subsubsection{WWOX}

Based on the clinical association found with the WWOX SNP rs11644322, SNP-specific (items 1-3) and general functions of WWOX (items 4-6) in relation to gemcitabine sensitivity should be addressed:

1. The variant $A$ allele at rs11644322 conferred worse outcome in the clinical setting. It should be delineated whether this variant alters cellular sensitivity to cytostatic drugs in general or specifically to gemcitabine.

2. Is rs11644322 related to gene expression? This genetic polymorphism is located in an extraordinarily huge intron far away from any known coding region. First, the expression levels of the $W W O X$ coding regions upstream and downstream of this index SNP should be quantified in detail. It should be elucidated whether rs11644322 affects global transcriptome in general and specifically the WWOX expression. Furthermore, possible gemcitabine-induced alterations of WWOX expresson should be evaluated in dependence on rs11644322.

3. Since $W W O X$ rs11644322 was identified as a site at which SP proteins bind in an allele-specific fashion, effects of this SNP are presumed to be linked to SP binding. As the expression of SP may be rate-limiting in this issue, the functional consequences of SP1 overexpression in pancreatic cancer cell lines should be explored in conjunction with cytostatic drug exposure.

4. A pro-apoptotic role of $W W O X$ has been suggested. The relationship between $W W O X$ expression level and cytotoxicity of gemcitabine should be analyzed. In addition, potential relationships with known apoptotic genes should be evaluated.

5. The relevance of $W W O X$ in cancer has recently emerged. The role of enhanced or suppressed WWOX expression in pancreatic cancer cell lines should be investigated 
in terms of cell proliferation with a specific focus on interactions with gemcitabine.

6. Knock-down of $W W O X$ might be accompanied by expression alterations affecting cellular proliferation. By means of whole transcriptome analysis consequences of transient and stable RNAi targeting WWOX on gene expression patterns should be delineated.

\subsubsection{RRM2}

A previous study conducted in the institute of Clinical Pharmacology in Göttingen found a SNP pertinent to the RRM2 gene associated with the outcome of patients suffering from PDAC and treated with gemcitabine. An ambiguous relation to RRM2 protein expression in pancreatic cancer tissue has also been reported (ZIMMER 2013). To the best of my knowledge, no functional assessments for this SNP have been conducted so far. The following questions and hypotheses should be elucidated:

1. There are two transcript isoforms of $R R M 2$. The index SNP differs in the relative position to these isoforms. The proportions of the two known transcript isoforms should be illustrated in detail in different cell types.

2. RRM2 counteracts gemcitabine effects and and its up-regulation might be a feature of drug resistance. Upon exposure to gemcitabine the extent of RRM2 induction should be evaluated in comparison with the global transcriptome. Thus differential expression of RRM2 transcript variants upon gemcitabine exposure should be delineated and stratified according to the RRM2 index SNP genotypes.

3. The hypothesis of RRM2 induction upon gemcitabine should be verified in patients during chemotherapy in a prospective fashion.

4. The RRM2 index SNP is located in the so-called Kozak sequence at position -6 relative to the start codon of the major transcript variant. The Kozak sequence has been reported as a major region for transcription factor binding (FITZGERALD et al. 2004). Thus, it should be analyzed whether nuclear protein extracts bind in an allelespecific manner as a possible mechanism for the observed clinical association.

5. The Kozak sequence is known to be essential for translation initiation. Thus, it should be addressed if the mutation causes by the index SNP affects translation efficiency. 
Detailed functional characterizations of the two considered genetic polymorphism in RRM2 and WWOX should provide further evidence for the medical relevance with the perspective to tailor future treatment. 


\section{Materials}

\subsection{Reagents and kits}

\begin{tabular}{|c|c|}
\hline Reagents, kits & Manufacturer \\
\hline$[\alpha-32 \mathrm{P}]-\mathrm{dCTP}$ (for EMSA) & Hartmann Analytic GmbH, Braunschweig \\
\hline $1 \mathrm{~kb}$ standard ladder (for agarose gel) & ABgene, Fermentas, St. Leon-Rot \\
\hline 100 bp standard ladder (for agarose gel) & ABgene, Fermentas, St. Leon-Rot \\
\hline $\begin{array}{l}40 \%(w / v) \text { Acrylamide:Bisacrylamide } \\
\text { (Mix 37.5:1) }\end{array}$ & Biomol, Hamburg \\
\hline 5-FU (Fluorouracil) & $\begin{array}{l}\text { Central Pharmacy, Clinic Hospital } \\
\text { Göttingen }\end{array}$ \\
\hline ABI PRISM ${ }^{\circledR}$ SNaPshot $^{\mathrm{TM}}$ Multiplex Kit & Applies Biosystems, Darmstadt \\
\hline Agar (for bacteriology) & AppliChem, Darmstadt \\
\hline Agarose Ultra Pure (gel electrophoresis) & Invitrogen, Karlsruhe \\
\hline All oligonucleotides (for PCR or EMSA) & $\begin{array}{l}\text { Eurofins MWG synthesis GmbH, } \\
\text { Ebersberg }\end{array}$ \\
\hline Ammoniumpersulfate (APS) & AppliChem, Darmstadt \\
\hline Ampicillin $99 \%$ & AppliChem, Darmstadt \\
\hline AMPure ${ }^{\circledR}$ XP beads & $\begin{array}{l}\text { Agencourt Bioscience Corporation, } \\
\text { Beverly, Massachusetts }\end{array}$ \\
\hline Anti-Protease & Roche, Mannheim \\
\hline Anti-Phosphatase & Roche, Mannheim \\
\hline Aquasafe 500 Plus, Safty Scintillator & Zinsser Analytic, Berkshire, UK \\
\hline Attractene Transfection Reagent & Qiagen, Hilden \\
\hline $\begin{array}{l}\text { BigDye }^{\circledR} \text { v1.1 Sequencing Kit } \\
\text { (Fluorescence based Sanger sequencing) }\end{array}$ & Applied Biosystems, Darmstadt \\
\hline Bovine serum albumin (BSA) & Sigma-Aldrich, Deisenhofen \\
\hline Bromphenolblue Na-Salt (Electrophoresis) & Roth, Karlsruhe \\
\hline CFSE Proliferation Dye & eBioscience, Frankfurt \\
\hline
\end{tabular}


Chloroform $\geq 99.8 \%$

CompactPrep kit (for midi-prep)

CountBright ${ }^{\mathrm{TM}}$ Absolute Counting Beads

Dimethyl sulfoxide (DMSO)

Disodium hydrogen phosphate $\geq 99.9 \%$

DNaseI solution

DNeasy Blood \& Tissue Kit

(DNA extraction)

dNTP Set

Dual-Luciferase ${ }^{\circledR}$ Reporter Assay System

EDTA $0.5 \mathrm{M}$ in water solution

EDTA pure

Ethanol $96 \%$

Ethanol denatured $99 \%$

Ethidiumbromide $1 \%$ in $\mathrm{H}_{2} \mathrm{O}$

EZ1 DNA Blood Card (No. 9015585)

EZ1 DNA Blood Kit

Expand Long Template PCR System

FACS Safe Clean

FACS Flow

FACS Rinse

FAST-AP $(1 \mathrm{U} / \mu \mathrm{l})$

FuGene 6 (Transfection reagent)

Gemcitabine (dFdC)

GeneScanLIZ120 (For SNaPshot ${ }^{\mathrm{TM}}$ )
J.T. Baker, Phillipsburg, USA

Qiagen, Hilden

Invitrogen, Karlsruhe

AppliChem, Darmstadt

Merck, Darmstadt

USB, Staufen

Qiagen, Hilden

ABgene, Hamburg

Promega, Mannheim

Sigma-Aldrich, Deisenhofen

Merck, Darmstadt

Merck, Darmstadt

Chemie-Vertrieb Hannover

Merck, Darmstadt

Qiagen, Hilden

Qiagen, Hilden

Roche Diagnostics, Mannheim

Beckton Dickinson, Franklin Lakes, USA

Beckton Dickinson, Franklin Lakes, USA

Beckton Dickinson, Franklin Lakes, USA

Life Technologies Corporation,

Darmstadt

Roche, Mannheim

Central Pharmacy, University Medical Center, Göttingen

Applied Biosystems, Darmstadt 
Glycerol $85 \%$

GoScript $^{\mathrm{TM}}$ Reverse Transcriptase

Helipur ${ }^{\circledR} \mathrm{H}$ plus N (Desinfection reagent)

Hi-DiTM Formamid (for SNapshot ${ }^{\mathrm{TM}}$ )

HotStarTaq Master Mix Kit (250 units)

Hydrogen chloride

Hygromycin B (50 mg/ml)

Irinotecan

Isoamylalcohol $98 \%$

Isopropanol $\geq 99.9 \%$

Kanamycin $\geq 750 \mathrm{U} / \mathrm{mg}$

Klenow-Fragment (for EMSA)

KOD HotStart DNA Polymerase

Ligate-IT $^{\mathrm{TM}}$ Rapid Ligation Kit

Lipofectamine ${ }^{\mathrm{TM}} 2000$

Lipofectamine ${ }^{\circledR}$ RNAiMAX

(Transfection Reagent)

Luminata $^{\mathrm{TM}}$ Forte Western HRP Substrate

Magic Mark ${ }^{\mathrm{TM}}$ standard

Magnesium chloride $\geq 99 \%$

Magnesium sulfate $\geq 99.5 \%$

Methanol for analysis

Milk powder, blotting grade

Mini Quick Spin Oligo Columns
Central pharmacy, University Medical

Center, Göttingen

Promega, Mannheim

Braun, Melsungen

Applied Biosystems, Darmstadt

Qiagen, Hilden

Merck, Darmstadt

Invitrogen, Karlsruhe

Sigma-Aldrich, Deisenhofen

Schuchardt, Hohenbrunn

Merck, Darmstadt

AppliChem, Darmstadt

Fermentas, St. Leon-Roth

Novagen Merck, Darmstadt

USB, Staufen

Invitrogen, Karlsruhe

Invitrogen, Karlsruhe

MerckMillipore, Darmstadt

Life Technologies Corporation,

Darmstadt

Riedel-De Haën AG, Seelze

Merck, Darmstadt

Merck, Darmstadt

Roth, Karlsruhe

Roche, Mannheim 
Multiplex PCR Kit

Neodisher ${ }^{\circledR}$ A 8 (Cleaning powder)

Nonidet P-40 (NP-40)

NuPage LDS sample buffer (4x)

PAXgene Blood miRNA Kit

PBS

PBS Powder (Dulbeccos 10-fold)

Penicillin/Streptomycin-Solution

Pierce $^{\mathrm{TM}}$ BCA Protein Assay Kit

Plasmid Midi Kit

Poly(deoxyinosinic-deoxycytidylic)

Poly-d-lysine hydrobromide

Polymer POP6 und POP7 for sequencing

Prestained Marker (for Western Blotting)

PrestoBlue ${ }^{\circledR}$ Cell Viability Reagent

QIAquick Gel Extraction Kit

5x HOT FIREPol ${ }^{\circledR}$ EvaGreen ${ }^{\circledR}$ qPCR Mix Plus

QuantiFluor ${ }^{\mathrm{TM}}$ Dye System

Quickszint Flow 302, Liquid Scintillator

Random hexanucleotide primers $d N 6$

RLT Plus Buffer

RNAse $\mathrm{A} \sim 70 \%$

RNAse Inhib P/N 71571 (40 un/ $\mu$ l)

RNase ZAP
Qiagen, Hilden

Chem. Fabrik Dr. Weigert, Mühlenhagen

AppliChem, Darmstadt

Invitrogen, Karlsruhe

Qiagen, Hilden

Invitrogen, Karlsruhe

AppliChem, Darmstadt

Invitrogen, Karlsruhe

Life Technologies Corporation, Darmstadt

Qiagen, Hilden

Sigma-Aldrich, Deisenhofen

Sigma-Aldrich, Deisenhofen

Applied Biosystems, Darmstadt

BioFroxx, Einhausen

Invitrogen, Karlsruhe

Qiagen, Hilden

Solis BioDyne, Estonia

Promega, Mannheim

Zinsser Analytic, Berkshire, United Kingdom

Roche, Mannheim

Qiagen, Hilden

AppliChem, Darmstadt

USB, Staufen

Sigma-Aldrich, Deisenhofen 
RNeasy Plus Mini Kit

Rotiphorese $^{\circledR}$ Gel 30 solution

Sephadex ${ }^{\mathrm{TM}}$ G-50 Superfine

SnapShot ${ }^{\mathrm{TM}}$ Multiplex Kit

Sodium acetate

Sodium chloride

Sodium dodecyl sulfate

Sodium Dodecyl Sulfate (SDS) Solution $10 \%$

Sodium hydroxide pellets pure

Sure Silencing shRNA Plasmid Kit

SYTOX ${ }^{\circledR}$ Blue Dead Cell Stain, for flow cytometry

T4 DNA Ligase

Taq DNA polymerase

TEMED $\geq 99 \%$

(N,N,N',N'- Tetramethylethylenediamine)

TNT ${ }^{\circledR}$ T7 Quick Coupled

Transcription/Translation System

TopTaq Polymerase

Tris $100 \%$

(Tris hydroxymethyl aminomethane)

Tris ultrapure

Triton X-100

Trypan blue solution (0.4\%)

TrypLE $^{\mathrm{TM}}$ Express

Tryptone
Qiagen, Hilden

Roth, Karlsruhe

Amersham Bioscience, Freiburg

Applied Biosystems, Darmstadt

Merck, Darmstadt

Merck, Darmstadt

BioRad, Hercules, USA

AppliChem, Darmstadt

Merck, Darmstadt

Qiagen, Hilden

Life Technologies Corporation, Darmstadt

Fermentas, St. Leon-Roth

Qiagen, Hilden

Sigma-Aldrich, Deisenhofen

Promega, Mannheim

Qiagen, Hilden

Roth, Karlsruhe

AppliChem, Darmstadt

Roth, Karlsruhe

Sigma-Aldrich, Deisenhofen

Gibco/Invitrogen, Karlsruhe

AppliChem, Darmstadt 
Tween20

Vybrant $^{\circledR}$ DyeCycle $^{\mathrm{TM}}$ Ruby stain

X-ray film developer G150

X-ray film fixer G354

X-tremeGENE HP DNA Transfection

Reagent

Xylene cyanol FF (for molecular biology)

Yeast extract
Sigma, Steinheim

Life Technologies Corporation, Darmstadt

AGFA, Leverkusen

AGFA, Leverkusen

Roche, Mannheim

AppliChem, Darmstadt

AppliChem, Darmstadt

\subsection{Used materials}

\begin{tabular}{ll}
\hline Used materials & Manufacturer \\
\hline 5 ml Polysterene Round-Botton Tube & BD Falcon, Durham, USA \\
(FACS Tube) & \\
6-Well plate, Nunclon ${ }^{\text {TM }}$ Delta Surface & Thermo Scientific, Schwerte \\
12-Well plate (for Cell culturing) & Greiner, Frickenhausen \\
24-Well plate (for Cell culturing) & Greiner, Frickenhausen \\
96 Millipore MAHV N45 plate & Millipore, Bedford, USA \\
96-Well PCR-Plate & ABgene, Epsom \\
96-Well Cell Culture Microplate & Greiner, Frickenhausen \\
(PS, F-Bottom, chimey well, black) & \\
Absolute QPCR Seal & Thermo Scientific, Schwerte \\
(Optical Foil for Taqman) & \\
Blotting filter paper & Whatman, Kent, United Kingdom \\
Culture flask $25 \mathrm{~cm}^{2}$ and $75 \mathrm{~cm}^{2}$ & Sarstedt, Nümbrecht \\
Cuvette (UVette ${ }^{\circledR}$ ) 50 - $1000 \mu \mathrm{l}$ & Eppendorf, Hamburg \\
Cuvette 10 x 4 x 45 mm & Sillipore, Schwalbach \\
Dialysis filter VSWP01300 & \\
\hline
\end{tabular}


Electroporation cuvette $2 \mathrm{~mm}$

Flat 12-cap strips

Flat 8-cap strips

FrameStar ${ }^{\circledR} 384$

Freezing container, Nalgene ${ }^{\circledR}$, Mr. Frosty

Gel System PerfectBlue ${ }^{\mathrm{TM}}$

(for electrophoresis)

Gel electrophoresis chamber

(SDS-minigel)

Glass Pasteur pipette $230 \mathrm{~mm}$

Nanodrop cuvette

Neubauer-Cell chamber

Nunclon ${ }^{\mathrm{TM}}$ Multidishes 6 and 12 wells

Parafilm $^{\circledR}$

PAXgene ${ }^{\mathrm{TM}}$ Blood RNA tube $(2.5 \mathrm{ml})$

Petri Dish

Petri Dish for Cell culture, Falcon 353003

Pipette Tip $(10 \mu \mathrm{l}, 100 \mu \mathrm{l}, 1000 \mu \mathrm{l})$

PVDF membrane Hybond-P

Quali-Filterpipette tip sterile

Reactions vessel $0.2 \mathrm{ml}$ (RNase-free)

Reactions vessel (1.5 $\mathrm{ml}$ and $2 \mathrm{ml})$

Sterile pipettes ( $5 \mathrm{ml}, 10 \mathrm{ml}, 25 \mathrm{ml}$ )

Sterile Polypropylen-tube (15 ml)

Sterile Polypropylen-tube $(50 \mathrm{ml})$

Thermo-Fast 384-well plate
PEQLAB Biotechnologie GmbH, Erlangen

ABgene, Epsom, United Kingdom

ABgene, Epsom, United Kingdom

4titude, Wotton, United Kingdom

Sigma-Aldrich, Deisenhofen

PEQLAB Biotechnologie GmbH, Erlangen

Biometra, Göttingen

WU, Mainz

Implen, München

Schütt, Göttingen

Nunc, Wiesbaden

Brand, Wertheim

PreanalytiX GmbH, Hombrechtikon, $\mathrm{CH}$

Sarstedt, Hamburg

Schütt, Göttingen

Sarstedt, Hamburg

Amersham Biosciences, Freiburg

Kisker, Steinfurt

Biozym, Hessisch Oldendorf

Sarstedt, Hamburg

Sarstedt, Hamburg

Greiner, Frickenhausen

Sarstedt, Hamburg

ABgene Epsom, United Kingdom 
Thermo-Fast 96-well plate

Quanti Fluor ${ }^{\mathrm{TM}}$ Dye System
ABgene Epsom, United Kingdom

Promega, Mannheim

\subsection{Equipment}

\begin{tabular}{|c|c|}
\hline Equipment & Manufacturer \\
\hline Accu-jet ${ }^{\circledR}$ & Brand, Wertheim \\
\hline 2100 Bioanalyzer & Agilent Technologies, Santa Clara, USA \\
\hline 3130xl Genetic Analyser & Applied Biosystems, Darmstadt \\
\hline Bacteria Incubator-Incudrive & Schütt, Göttingen \\
\hline Biofuge $15 \mathrm{R}$ & Heraeus, Hanau \\
\hline Biofuge fresco & Heraeus, Hanau \\
\hline Biofuge pico & Heraeus, Hanau \\
\hline BioPhotometer & Eppendorf, Hamburg \\
\hline BioRobot $^{\circledR}$ EZ1 & Qiagen, Hilden \\
\hline Bunsen Burner Phoenix II & Schütt, Göttingen \\
\hline cBot for Cluster generation (RNAseq) & Illumina, San Diego, CA, USA \\
\hline Centrifuge $5810 \mathrm{R}$ & Eppendorf, Hamburg \\
\hline Centrifuge JA-20 Rotor & Beckman, München \\
\hline $\mathrm{CO}_{2}$-Incubator BB 16 Function Line & Heraeus, Hanau \\
\hline $\begin{array}{l}\mathrm{CO}_{2} \text {-Incubator New Brunswick }{ }^{\mathrm{TM}} \text { Galaxy } \\
170 \mathrm{~S}\end{array}$ & Eppendorf, Hamburg \\
\hline ComPhor L Mini Gel-chamber & Biozym, Hessisch Oldendorf \\
\hline Concentrator 5301 & Eppendorf; Hamburg \\
\hline Cryo Storage Tank ARPEGE 140 & German-cryo, Jüchen \\
\hline Electroporator Gene Pulser II & BioRad, Hercules, USA \\
\hline
\end{tabular}


Eppendorf Research and Reference ${ }^{\circledR}$

Pipettes, 0,1 - $10 \mu \mathrm{l}, 10$ - $100 \mu \mathrm{l}$,

$100-1000 \mu \mathrm{l}$

Eppendorf Research ${ }^{\circledR} 8$ channel Pipettes,

$10 \mu \mathrm{l}, 100 \mu \mathrm{l}$

Fine weight machine

Flow cytometer BD LSRII, special order system

Fluor-STM Multilmager

Gel-drying-system (DrygelSr)

Gel electrophoresis power supply,

(Standard Power Pack P 25)

Gel tray, 40-0708-UVT (UV-transmissible)

Gene Pulser capacitance extender II

Gene Pulser controller II

GloMax ${ }^{\circledR}$ Fluorometer

HiSeq2000

Image Quant ${ }^{\mathrm{TM}}$ LAS 4000 Mini

Laboklav for sterile materials

Labor centrifuge 400R

Laminar Flow Clean Air type DFL/REC4

KL2A

Magnetic stirrer

Mastercycler gradient (for 384-well plate), Eppendorf, Hamburg

PCR-Gradient Cycler

Membrane-Vacuum pump

Microscope TELAVAL 31
Eppendorf, Hamburg

Eppendorf, Hamburg

Sartorius, Göttingen

Becton Dickinson, Franklin Lakes, USA

BioRad, Hercules, USA

Hoffer scientific instruments, San

Francisco, USA

Biometra, Göttingen

PEQLAB Biotechnologie GmbH, Erlangen

BioRad, Hercules, USA

BioRad, Hercules, USA

Promega, Mannheim

Illumina, San Diego, CA, USA

GE Healthcare Bio-Sciences AB, Uppsala, Sweden

SHP Steriltechnik AG, Detzel

Schloss/Satuelle

Heraeus, Hanau

Mahl, Trendelburg

Ika, Staufen

Vacuubrand, Wertheim

Zeiss, Jena 
Microwave MWS 2820

MS 2 Mini shaker-Vortexer

Multipette ${ }^{\circledR}$ plus

pH meter, PB-11

Phosphor Imager

PTC-200 Peltier Thermal Gradient Cycler (for 96-well plate)

QiaCube

Qualitron ${ }^{\circledR}$ Microcentrifuges

Scintillation instrument LS1801

Semidry Electroblotter (PerfectBlue ${ }^{\mathrm{TM}}$ )

Shaker for Bacteria K2 260 basic

SpeedVac ${ }^{\circledR}$ Plus SC 110A Concentrator

Standard Power Pack P25

TaqMan 7900HT

Tecan Ultra Plate Reader

(Fluorescence reader)

Thermomixer 5436

Transilluminator TI 2

Vertical-Autoclave KSG 40/60

Vertical-Autoclave: FV for sterile materials

Victor X4 Light Multilabel Reader

Warming cupboard FP
Bauknecht, Schorndorf

IKA, Staufen

Eppendorf, Hamburg

Sartorius, Göttingen

Raytest, Sprockhövel

MJ Research/BioRad, Hercules, USA

Qiagen, Hilden

Fairport, USA

Beckman, München

PEQLAB Biotechnologie GmbH, Erlangen

IKA, Staufen

Schütt, Göttingen

Biometra, Göttingen

Applied Biosystems, Darmstadt

Tecan Deutschland GmbH, Crailsheim

Eppendorf, Hamburg

Biometra, Göttingen

KSG, Olching

Tecnorama, Fernwald

PerkinElmer, Wiesbaden, Germany

Binder, Tuttlingen 


\subsection{Software}

\begin{tabular}{|c|c|}
\hline Software & Manufacturer \\
\hline 3100 Data Collection Software & Applied Biosystems, Darmstadt \\
\hline $\begin{array}{l}\text { Advanced Image Data Analyzer (AIDA) } \\
\text { V.4.15 } 025\end{array}$ & $\begin{array}{l}\text { Raytest Isotopenmeßgeräte } \mathrm{GmbH} \text {, } \\
\text { Sprockhövel }\end{array}$ \\
\hline BASReader (FujiFilm BAS1800-II) & Raytest, Sprockhövel \\
\hline BD-FACSDIVA $^{\text {TM }}$ SOFTWARE & Becton Dickinson, Franklin Lakes, USA \\
\hline Clone Manager Suite v6.0 & Sci-Ed Software, Cary NC, USA \\
\hline CorelDRAW X3 & Corel corporation, Ontario, Canada \\
\hline CurveExpert Professional 2.0 & www.curveexpert.net \\
\hline Cyflogic 1.2.1 & www.cyflogic.com \\
\hline DNA Sequencing Analysis v5.2 & Applied Biosystems, Darmstadt \\
\hline DNASTAR $^{\circledR}$ v11.2 & DNASTAR, Madison WI, USA \\
\hline EndNote X7 & Thomson Reuters, Philadelphia PA, USA \\
\hline Gene mapper v3.7 software ${ }^{\circledR}$ & Applied Biosystems , Darmstadt \\
\hline HaploView $^{\circledR} \mathrm{v} 4.2$ & Broad institute, Cambridge MA, USA \\
\hline $\begin{array}{l}\text { Image Quant }{ }^{\mathrm{TM}} \text { LAS } 4000 \text { mini Control } \\
\text { Software, v1.2 }\end{array}$ & $\begin{array}{l}\text { GE Healthcare Bio-Sciences AB, Uppsala, } \\
\text { Sweden }\end{array}$ \\
\hline MS Office & Microsoft, USA \\
\hline Oligo $^{\circledR}$ v6.58 & $\begin{array}{l}\text { Molecular Biology Insights, Cascade CO, } \\
\text { USA }\end{array}$ \\
\hline Quantity One ${ }^{\circledR}$ S v4.3.1 & BioRad, München \\
\hline SDS v2.1 & Applied Biosystems, Darmstadt \\
\hline SigmaPlot v12.0 & $\begin{array}{l}\text { Systat Software, Technology Drive, San } \\
\text { Jose, CA }\end{array}$ \\
\hline SPSS v12 & SPSS Inc., Chicago, USA \\
\hline
\end{tabular}


Staden Package

XFluor4 Software
Medical research council laboratory of molecular Biology, Cambridge, United Kingdom

Tecan, Crailsheim

\subsection{Databases}

\begin{tabular}{|ll|}
\hline Databases & URL \\
\hline $\begin{array}{l}1000 \text { Genomes, Catalog of Human genetic } \\
\text { Variation }\end{array}$ & http://www.1000genomes.org/ \\
\hline International HapMap Project & http://hapmap.ncbi.nlm.nih.gov/ \\
\hline National Center for Biotechnology Information & $\begin{array}{l}\text { NCBI, Bethesda, USA } \\
\text { http://www.ncbi.nlm.nih.gov/ }\end{array}$ \\
\hline TRANSFAC-Database & $\begin{array}{l}\text { BIOBASE, Göttingen } \\
\text { (http://www.biobase- } \\
\text { international.com/product/explain) }\end{array}$ \\
\hline UCSC Genome Browser & http://genome.ucsc.edu/ \\
\hline
\end{tabular}

\subsection{Enzymes}

\begin{tabular}{|ll|}
\hline Restriction Enzymes & Manufacturer \\
\hline BsaI-HF ${ }^{\circledR}$ & New England Biolabs, Beverly, USA \\
DpnI & New England Biolabs, Beverly, USA \\
ExoI & Fermentas, St. Leon-Roth \\
EcoRI & Fermentas, St. Leon-Roth \\
Fast-AP & Life Technologies Corporation, Darmstadt \\
HindIII & Fermentas, St. Leon-Roth \\
NotI & New England Biolabs, Beverly, USA \\
PstI & Fermentas, St. Leon-Roth \\
PvuII & Fermentas, St. Leon-Roth \\
SacI & Fermentas, St. Leon-Roth \\
SalI & Fermentas, St. Leon-Roth \\
XhoI & Fermentas, St. Leon-Roth \\
\hline
\end{tabular}




\subsection{Strains of bacteria}

\begin{tabular}{|cccc|}
\hline Strain of bacteria & Origin & $\begin{array}{c}\text { Application for } \\
\text { transfection }\end{array}$ & Manufacturer \\
\hline $\begin{array}{c}\text { TOP10 } \\
\text { (One shot TOP10 } \\
\text { Electro-comp. E.coli) }\end{array}$ & Escherichia coli & Electro-competent & Invitrogen, Karlsruhe \\
\hline
\end{tabular}

\subsection{Plasmid vectors}

\begin{tabular}{|lcc|}
\hline Clone-No. & Resistance & Manufacturer \\
\hline pcDNA3.1 & Ampicillin & Invitrogen, Karlsruhe \\
\hline pcDNA5:FRT & Ampicillin & Invitrogen, Karlsruhe \\
\hline $\begin{array}{l}\text { pcDNA5/FRT/TO GFP } \\
\text { (Plasmid 19444) }\end{array}$ & Ampicillin & Addgene, Cambridge, United \\
& & Kingdom \\
\hline $\begin{array}{l}\text { p0TB7:RRM2 } \\
\text { (IRAUp969F0415D) }\end{array}$ & Chloramphenicol & $\begin{array}{c}\text { ImaGenes GmbH, Berlin } \\
\text { (now Source Bioscience, } \\
\text { Nottingham, United Kingdom) }\end{array}$ \\
\hline $\begin{array}{l}\text { p0TB7:SP1 } \\
\text { IRAU97D03 }\end{array}$ & Chloramphenicol & $\begin{array}{c}\text { SourceBioscience, Nottingham, } \\
\text { United Kingdom }\end{array}$ \\
\hline
\end{tabular}

\subsection{Commercial culture media}

\begin{tabular}{|lc|}
\hline Medium & Manufacturer \\
\hline $\begin{array}{l}\text { Dulbecco's Modified Eagle Medium } \\
(\text { DMEM, 1x), 4,5 g/L D-Glucose, L-Glutamine }\end{array}$ \\
\hline $\begin{array}{ll}\text { Roswell Park Memorial Institute (RPMI) 1640 } \\
\text { Medium }{ }^{\text {TM }}+\text { GlutaMax - I }\end{array}$ \\
\hline OPTI-MEM $^{\circledR}$ I Reduced Serum Medium & Gibco/Invitrogen, Karlsruhe \\
\hline
\end{tabular}




\subsection{Cell lines}

\begin{tabular}{|c|c|c|c|}
\hline Cell line & Origin & Characteristics & Manufacturer \\
\hline HEK-293 & Human & $\begin{array}{l}\text { Embryonic kidney cell } \\
\text { line immortalized by } \\
\text { human adenovirus type } 5 \\
\text { DNA }\end{array}$ & DMSZ, Braunschweig \\
\hline AsPC1 & Human & Pancreatic cancer cell line & ATCC, Wesel \\
\hline CFPac & Human & Pancreatic cancer cell line & ATCC, Wesel \\
\hline L3.6 & Human & Pancreatic cancer cell line & ATCC, Wesel \\
\hline MiaPacalI & Human & Pancreatic cancer cell line & ATCC, Wesel \\
\hline PancI & Human & Pancreatic cancer cell line & ATCC, Wesel \\
\hline PaTu8988t & Human & Pancreatic cancer cell line & ATCC, Wesel \\
\hline $\begin{array}{l}\text { Lymphoblastoid cell lines } \\
\text { (LCLs HapMap and } 1000 \\
\text { Genome Project) }\end{array}$ & Human & $\begin{array}{l}\text { Peripheral B lymphocytes } \\
\text { that are immortalized by } \\
\text { Epstein-Barr (EB) virus }\end{array}$ & $\begin{array}{l}\text { Coriell Cell Repositorie, } \\
\text { Camden, New Jersey } \\
\text { USA }\end{array}$ \\
\hline
\end{tabular}




\section{Methods}

\subsection{Patient cohorts}

\subsubsection{Retrospective patient cohort}

According to the inclusion criteria, i.e. histopathologically confirmed PDAC (without ampullary carcinoma) with adjuvant or palliative gemcitabine-containing chemotherapy, 381 Caucasian patients were recruited for a retrospective study performed in our department in collaboration with the relevant clinical centers, for detecting putative clinical marker in gemcitabine-treated pancreatic cancer. The entire cohort includes patients from three german medical center in Göttingen $(n=142)$, Hamburg ( $n=159)$, and Heidelberg $(n=80)$ hospitalized between 2003 and 2010. For genotyping (see section 3.4) isolated DNA of peripheral blood leukocytes (see section 3.2.2) was used and the primary outcome was overall survival. Staging and grading was performed according to current standard classification procedure (published by AJCC (American Joint Commitee on Cancer) and UICC (Union internationale contre le cancer)).

\subsubsection{Prospective patient cohort}

To evaluate gene expression patterns during gemcitabine-based chemotherapy, a pilot cohort comprising 32 patients suffering from PDAC was followed prospectively. At three time points RNA expression was assessed: Prior to the first gemcitabine application, four weeks and ten weeks thereafter. Therefore, $2.5 \mathrm{ml}$ of peripheral blood was immediately filled in PAX tubes containing a RNA-stabilizing reagent, which then was stored at $-20{ }^{\circ} \mathrm{C}$. RNA was isolated using the PAXgene Blood miRNA Kit (Qiagen, Hilden). For reverse transcripton $1 \mu \mathrm{g}$ of total RNA per sample was used (see chapter 3.6.3 for reverse transcription).

\subsection{Standard DNA workflow}

\subsubsection{DNA isolation from eukaryotic cells}

Genomic DNA from eukaryotic cells was isolated with the DNeasy Blood \& Tissue Kit (Qiagen, Hilden), using the QiaCube robot (Qiagen, Hilden) according to the maufacturer's recommendation. Therefor, approximately $5 \times 10^{6}$ cells were harvested 
and dissolved in $100 \mu \mathrm{l}$ of PBS buffer before. The quantification of isolated DNA was performed photometrically (see chapter 3.2.3).

\subsubsection{DNA isolation from peripheral leukocytes}

Genomic DNA from peripheral leukocytes was isolated with the EZ1 DNA Blood Kit (Qiagen, Hilden). For this the BioRobot EZ1 (Qiagen, Hilden) was used and all steps were performed according to the maufacturer's recommendation with an elution volume of $200 \mu \mathrm{l}$.

\subsubsection{Quantification of DNA}

The amount of DNA was determined with a BioPhotometer (Eppendorf, Hamburg), measuring the absorbance at $260 \mathrm{~nm}$. An extinction of 1 at $260 \mathrm{~nm}\left(\mathrm{E}_{260}\right)$ equates to 50 $\mu \mathrm{g}$ DNA per $\mu \mathrm{l}$. The absorbance ratio 260/280 nm characterizes the sample purity. A value near 2 is defined as "high purity" and allows sample usage for further experiments. For DNA quantification $3 \mu$ of the DNA sample was pipetted on a nanodrop cuvette (Implen, München). This quantification method is based on the following Beer-Lambert law (Equation 1):

Equation 1: Beer-Lambert law

\begin{tabular}{|l}
$\qquad \mathbf{A}=\boldsymbol{\varepsilon} * \mathbf{c} * \mathbf{l}$ \\
$A=$ Absorbance \\
$\varepsilon=$ Molar attenuation coefficient $\left[\mathrm{L}^{*} \mathrm{~mol}^{-1}{ }^{*} \mathrm{~cm}^{-1}\right]$ \\
$c=$ Solute concentration $\left[\mathrm{mol}^{*} \mathrm{~L}^{-1}\right]$ \\
$l=$ Path length of the light through the material $[\mathrm{cm}]$
\end{tabular}

\subsubsection{Polymerase chain reaction (PCR)}

The polymerase chain reaction is an in vitro method to amplify DNA. For cloning experiments the KOD Hot Start polymerase was used, which has a proofreading function to make the reaction more efficient. First, double-stranded DNA is denatured to single strands at $95^{\circ} \mathrm{C}$. Next, oligonucleotide primer anneal to the single DNA strand in a selective way. The annealing step takes place at temperatures between 50 and $70{ }^{\circ} \mathrm{C}$. Thereafter, the temperature rises for the elongation step $\left(65-75^{\circ} \mathrm{C}\right)$, where the DNA polymerase synthesizes a copied DNA strand which is complementary to the template DNA, by adding dNTPs in 5' to 3 ' direction. Using the right conditions, the amount of 
DNA is duplicated per cycle what leads to an exponential increase of the DNA region of interest. These steps were repeated 35 times to achieve an adequate amount of DNA. A final elongation step is advised, depending on the length of the DNA fragment. The PCR reactions (see Table 1) were performed in gradient thermal cyclers under conditions listed in Table 2.

Table 1: Standard KOD HotStart PCR reaction

\begin{tabular}{|c|c|}
\hline Reagent & Volume for one sample $[\mu \mathrm{l}]$ \\
\hline 10x buffer & 2.2 \\
\hline dNTPs (2 mM) & 2.2 \\
\hline $\mathrm{MgSO}_{4}(25 \mathrm{mM})$ & 0.9 \\
\hline Q-Solution (optional) & 4.4 \\
\hline Primer forward $(10 \mu \mathrm{M})$ & 0.5 \\
\hline Primer reverse $(10 \mu \mathrm{M})$ & 0.5 \\
\hline DNA $(300 \mu \mathrm{g} / \mathrm{ml})$ & 2 \\
\hline KOD HotStart polymerase $(1.0 \mathrm{U} / \mu \mathrm{l})$ & 0.5 \\
\hline $\mathrm{ddH} 2 \mathrm{O}$ & 8.8 \\
\hline
\end{tabular}

\section{In total}

Table 2: Standard KOD PCR conditions

\begin{tabular}{lcc} 
Phase & Duration & Temperature \\
Initial Denaturation & $3 \mathrm{~min}$ & $95^{\circ} \mathrm{C}$ \\
\hline Denaturation & $30 \mathrm{sec}$ & $95^{\circ} \mathrm{C}$ \\
Annealing & $30 \mathrm{sec}$ & $50-70{ }^{\circ} \mathrm{C}$ \\
Elongation & $1 \mathrm{~min}$ & $72^{\circ} \mathrm{C}$ \\
\hline Terminal Elongation & $10 \mathrm{~min}$ & $72^{\circ} \mathrm{C}$ \\
Cooling down & for ever & $8{ }^{\circ} \mathrm{C}$
\end{tabular}

\subsubsection{Gradient PCR}

To determine the optimal annealing temperature for new primers, a gradient PCR was performed. Therefor five identical PCR reactions were undertaken simultaneously to test different annealing conditions $\left(60-72^{\circ} \mathrm{C}\right)$. For each temperature two reaction mixtures were prepared, one with and one without Q-Solution (included in the Taq 
polymerase or Multiplex PCR Kit from Qiagen, Hilden). Q-Solution is used to enhance the DNA amplification for templates comprising a high GC content. To identify the optimal annealing temperature subsequent to the gradient PCR, samples were run on a 0.8 to $3 \%$ agarose gel, where the amount of the PCR product and the fragment size could be assessed.

\subsubsection{Site-directed mutagenesis}

Site-directed mutagenesis is a method which is used to introduce mutations (one to four bases) into a DNA sequence by mutagenesis primers. In this work the 5 ' single nucleotide polymorphism RRM2 rs1130609 in the full length cDNA clone for construct generation see section 3.5.3) of RRM2 (pcDNA5:RRM2) was mutated at the rs1130609 SNP site from $\mathrm{G}>\mathrm{T}$ with primers listed in Table 3 to obtain the variant allele in addition to the wild type allele.

Table 3: Oligonucleotide primers for the Site-directed mutagenesis (RRM2 rs1130609)

\begin{tabular}{lc}
\hline Name of primer & Sequence $\left(5^{\prime} \rightarrow \mathbf{3}^{\prime}\right)$ \\
\hline Mut_rs1130609for & GTTTAAACTTAAGCTTCGCCTCCACTATGCTCTCC \\
Mut_rs1130609rev & GGAGAGCATAGTGGAGGCGAAGCTTAAGTTTAAAC \\
\hline
\end{tabular}

The mutated base is bolded and underlined

For the performance of the mutagenesis PCR it is important that used plasmids were isolated from bacteria and show bacteria specific methylation patterns. The new products synthesized by this PCR did not have these methylations and thus could not be degraded by Dpn1 endonuclease (methylation dependend restriction enzyme), in contrast to the not mutated original constructs. For site-directed mutagenesis the KOD HotStart polymerase (Novagen Merck, Darmstadt) was used. To identify the optimal annealing temperature for the mutagenesis primers a gradient PCR (see chapter 3.2.5) was conducted, previous to the described mutagenesis PCR (see Table 4 for reaction mixture and Table 5 for PCR conditions).

Following to the DNA amplification, $2 \mu \mathrm{l}$ of the Dpn1 enzyme was added to the PCR product for 1 hour at $37^{\circ} \mathrm{C}$ to get the newly mutated constructs. Then, the PCR product was dialyzed for 30 minutes, transformed into E. coli TOP10 strain by electroporation and plated on agar plates containing ampicillin as selction marker. Based on the grown 
clones on agar plates, plasmid DNA was isolated by mini-preparation (see 3.7.5.1). To verify successful mutagenesis, the open reading frame of RRM2 was sequenced with sequencing primers listed in Table 6.

Table 4: PCR-reaction mixture for the site-directed mutagenesis

\begin{tabular}{lc}
\hline Reagent & Volume $[\boldsymbol{\mu l}]$ \\
\hline 10x buffer & 5 \\
dNTP $(2 \mathrm{mM}$ each) & 5 \\
MgSO $_{4}$ (25 mM) & 2 \\
Q-Solution (optional) & 10 \\
Primer forward (10 nM) & 1.3 \\
Primer reverse (10 nM) & 1.3 \\
KOD HotStart polymerase & 1 \\
Plasmid DNA (50 ng) & 1 \\
\hline
\end{tabular}

$\mathrm{ddH}_{2} \mathrm{O}$

Add to 50

Table 5: PCR consitions used for site-directed mutagenesis

\begin{tabular}{lcc} 
Phase & Duration & Temperature \\
Initial Denaturation & $3 \mathrm{~min}$ & $95^{\circ} \mathrm{C}$ \\
\hline Denaturation & $30 \mathrm{sec}$ & $95^{\circ} \mathrm{C}$ \\
Annealing & $30 \mathrm{sec}$ & $60{ }^{\circ} \mathrm{C}$ \\
Elongation & $3 \mathrm{~min} 30 \mathrm{sec}$ & $72{ }^{\circ} \mathrm{C}$ \\
\hline Cooling down & for ever & $8{ }^{\circ} \mathrm{C}$
\end{tabular}

Table 6: Sequencing primers for the construct pcDNA5-RRM2-eGFP

\begin{tabular}{|c|c|}
\hline Name of primer & Sequence $\left(5^{\prime} \rightarrow 3^{\prime}\right)$ \\
\hline$R R M 2-S e q-F 1$ & CACGGAGCCGAAAACTAAAGC \\
\hline$R R M 2-S e q-F 2$ & TCTGCCTTCTTATACATCTGCCA \\
\hline RRM2-Seq-F3 & ACATTGAGTTTGTGGCAGACAGAC \\
\hline RRM2-Seq-F4 & GCCTACTCTCTTCTCAAAGAAGTTAGTC \\
\hline RRM2-Seq-F5_eGFP & AAGGACGACGGCAACTACAAG \\
\hline RRM2-Seq-F6_eGFP & GCGGATCTTGAAGTTCACCTTG \\
\hline RRM2-Seq-F7_eGFP & AACAGATGGCTGGCAACTAGAAG \\
\hline
\end{tabular}




\subsubsection{Agarose gel electrophoresis}

Agarose gel electrophoresis is used to determine the size and presence of DNA fragments. Nucleic acids are negatively charged and migrate through an agarose matrix by an electric field towards the anode. Because of lower molecular weight, shorter fragments move faster in comparison to longer ones. Dependent on the expected DNA fragment size agarose concentrations between 0.8 and $3 \%$ were used. For the gel preparation the aquired amount of agarose (Agarose Ultrapure, Invitrogen, Karlsruhe) was dissolved in boiling TBE buffer. The solution was cooled down to $\sim 60{ }^{\circ} \mathrm{C}$, then 0.5 $\mu \mathrm{g} / \mathrm{ml}$ of ethidium bromide (EtBr) was added and stirred with a magnetic mixer. Then, the liquid gel was transferred into a gel tray and gel combs were put into the gel tray to form gel pockets. After 30 minutes the solid gel was placed in a Gel System for electrophoresis, covered with TBE buffer (supplemented with $0.5 \mu \mathrm{g} / \mathrm{ml}$ of EtBr, see Table 8). Before loading the gel, the DNA samples were mixed with $5 x$ loading dye (see Table 7) in a sample-dye ratio of 5:1. To identify the DNA fragment sizes, DNA ladders with 100 bp or $1 \mathrm{~kb}$ (ABgene, Fermentas, St. Leon-Rot) were used. The electrophoresis was conducted with 140 V for approximately 30 - 40 minutes in a PerfectBlue Gel System (PEQLAB, Erlangen). To visualize the DNA bands the Fluor-STM Multilmager (BioRad, Hercules, USA) and its corresponding QuantityOne ${ }^{\circledR} S$ version 4.3.1 (BioRad) software were employed.

Table 7: 5x Loading Dye

\begin{tabular}{lc}
\hline Reagent & Concentration \\
\hline Glycerol & $30 \%(\mathrm{v} / \mathrm{v})$ \\
EDTA & $50 \mathrm{mM}$ \\
Bromphenol blue & $0.25 \%(\mathrm{v} / \mathrm{v})$ \\
Xylene cyanol & $0.25 \%(\mathrm{v} / \mathrm{v})$ \\
\hline
\end{tabular}

Table 8: TBE buffer

\begin{tabular}{lc}
\hline Reagent $(\mathbf{p H}=\mathbf{8 . 3}, \mathbf{R T})$ & Concentration $[\mathbf{m M}]$ \\
\hline Tris & 100 \\
Boric acid & 100 \\
EDTA & 3 \\
\hline
\end{tabular}




\subsubsection{DNA purification from agarose gel}

To extract DNA from an agarose gel after electrophoresis, the desired band was cut under UV light, using the transilluminator TI2 (Biometra, Göttingen). The cut slices should not exceed an amount of $400 \mathrm{mg}$ of a $2 \%$ agarose gel. The DNA purification was performed with the QiaCube robot (Qiagen, Hilden), using the QiaQuick Gel Extraction Kit (Qiagen, Hilden) and following the manufacturer's instructions.

\subsubsection{Restriction digestion}

Restriction digestion is used to split double stranded DNA at a specific nucleotide sequence of 4 to 8 bases, which are often palindromic. For this, restriction enzymes, which are endonucleases, are used. The separation of the resultant fragments was performed by agarose gel electrophoresis (see section 3.2.7). This method is used during cloning procedures, either for an analytical or preparative purpose.

\subsubsection{Analytical digestion}

Analytical digestion was used to verify plasmid DNA isolated by mini-preparation (see chapter 3.7.5.1). Independent digestion mixtures with at least two digestion enzymes were prepared. For each enzyme a specific fragmentation pattern should be detected. The number of fragments depends on the number of restriction sites for the enzyme. The analytical digestion mixtures (Table 9) were incubated for 1 hour at $37^{\circ} \mathrm{C}$ before loading them on an agarose gel. For fast digestion enzymes the icubation time was reduced to 15 minutes.

Table 9: Reaction mixture for analytical digestion

\begin{tabular}{lc}
\hline Reagent & Volume $[\mu \mathrm{l}]$ \\
\hline 10x Restriction buffer & 1 \\
BSA (optional) & 0.1 \\
DNA $(\sim 1 \mu \mathrm{g})$ & 1 \\
Enzyme & 1 \\
\hline
\end{tabular}

$\mathrm{ddH}_{2} \mathrm{O}$

Add to 10 


\subsubsection{Preparative digestion}

Preparative digestion was used to generate restriction fragments for cloning, allowing ligation of the digested vector and the digested insert fragment in the next step because of matching DNA ends. The reaction mixture (Table 10) was incubated for two hours or overnight. After this, $1 \mu \mathrm{l}$ of the enzyme was added for one more hour before loading the digestion mixture on an agarose gel. A double digestion is also possible by proceeding in the same way, using the tango universal buffer or a buffer which is compatible with both enzymes. If different buffers are needed, DNA was digested with one enzyme first, followed by agarose gel electrophoresis (see chapter 3.2.7) and agarose gel purification (see chapter 3.2.8). Afterwards, digestion was performed with the second restriction enzyme.

Table 10: Reaction mixture for preparative digestion

\begin{tabular}{lc}
\hline Reagent & Volume $[\boldsymbol{\mu l}]$ \\
\hline 10x Restriction buffer & 5 \\
BSA (optional) & 0.5 \\
DNA & $\max . \mathbf{1 0} \boldsymbol{\mu g}$ \\
Enzyme (dependent on star activity) & 5 \\
\hline $\mathbf{d d H}_{2} \mathbf{O}$ & Add to $\mathbf{5 0}$
\end{tabular}

\subsubsection{Ligation}

The ligation process is used to integrate DNA fragments into a plasmid vector. For that purpose, DNA ends (cut by restriction enzymes) which are complementary to each other and which can be ligated using a DNA ligating enzyme (Ligate-ITTM rapid Ligation Kit, USB Staufen, Germany) are needed. Prior to the ligation performance the DNA was concentrated with a vacuum centrifuge (SpeedVac Plus SC110A) for 5 - 10 minutes. The concentrated DNA, which was attached to the wall of the reaction tube, was dissolved from there by wishing the wall with a drop of the remaining sample. The ligation mixture was prepared as follows (Table 11) with an insert versus vector ratio of 13:2 $(\mathrm{v} / \mathrm{v})$. 
Table 11: Ligation reaction mixture

\begin{tabular}{lc}
\hline Reagent & Volume $[\boldsymbol{\mu l}]$ \\
\hline 5x Ligase buffer & 4 \\
Plasmid vector & 2 \\
Insert (DNA fragment) & 13 \\
Ligase & 1 \\
\hline In total & $\mathbf{2 0}$
\end{tabular}

In total

20

This mixture was incubated for 10 minutes at room temperature, followed by 10 minutes of incubation on ice. To verify that the used vector does not ligate with itself an extra ligation mixture was prepared where the insert was replaced by $\mathrm{ddH}_{2} \mathrm{O}$ as negative control.

\subsubsection{Dialysis}

Prior to the transformation of ligated DNA into bacteria cells (see section 3.7.2) a dialysis step is required to remove salts. Therefor, the whole ligation mixture was pipetted on top of a semipermeable membrane (Dialysis filter, VSWP01300, Millipore, Schwalbach), which was placed with the shiny site up on a petri dish filled with $\mathrm{ddH}_{2} \mathrm{O}$. After 30 minutes the desalted DNA was transferred into a new reaction tube.

\subsection{DNA Sequencing analysis}

The DNA sequencing process was used to ascertain the nucleotides within DNA strands. Primarily, this concept was developed by Sanger and Coulson in 1975 (SANGER AND COULSON 1975). The chain-termination principle uses dideoxy nucleotide triphosphates (ddNTPs) additional to the desoxy-nucleotide triphosphates (dNTPs). The ddNTPs are fluorescently labeled with different dyes. During the chain extension in the sequencing PCR the DNA polymerase either adds a corresponding dNTP or ddNTP. In case of incorporated ddNTPs this leads to the termination of the DNA chain due to the absence of the hydroxyl group $(\mathrm{OH})$ at the 3' carbon. Thus, the Sanger dideoxy sequencing results in the extension of products with a various length, terminated with a ddNTP at the end. Afterwards, using the capillary-gel electrophoresis, the newly synthesized extension products were separated by size at a resolution of one base. The number of DNA fragments which can be sequenced in one run is about 500 base pairs. 
In detail, the sequencing PCR was performed in a 384 well plate (FrameStar ${ }^{\circledR}$, 4titude, Wotton, UK), using the BigDye ${ }^{\circledR}$ terminator v1.1 Sequencing Kit (Applied Biosystems, Darmstadt). The sequencing PCR was conducted as follows (Table 12 and Table 13):

Table 12: Reaction mix for sequencing PCR

\begin{tabular}{lc}
\hline Reagent & Volume $[\boldsymbol{\mu l}]$ per sample \\
\hline DMSO & 0.25 \\
Primer $(10 \mu \mathrm{M})$ & 0.5 \\
BigDye $^{\circledR}$ & 1 \\
ddH $_{2} \mathrm{O}$ & 2.25 \\
DNA from mini preparation $(\sim 300 \mu \mathrm{g} / \mathrm{ml})$ & 1 \\
\hline In total & $\mathbf{5}$
\end{tabular}

Table 13: Sequencing PCR conditions

\begin{tabular}{lcc} 
Phase & Duration & Temperature \\
Initial Denaturation & $2 \mathrm{~min}$ & $94^{\circ} \mathrm{C}$ \\
\hline Denaturation & $15 \mathrm{sec}$ & $96{ }^{\circ} \mathrm{C}$ \\
Annealing & $15 \mathrm{sec}$ & $56.5^{\circ} \mathrm{C}$ \\
Elongation & $4 \mathrm{~min}$ & $60{ }^{\circ} \mathrm{C}$ \\
\hline Terminal Elongation & $7 \mathrm{~min}$ & $72{ }^{\circ} \mathrm{C}$ \\
Cooling down & for ever & $8{ }^{\circ} \mathrm{C}$
\end{tabular}

Before sequencing, the PCR product was purified to eliminate unincorporated ddNTPs. For this, $35 \mathrm{mg}$ of Sephadex G50 superfine (Amersham Bioscience, Freiburg) was distributed per well of a 96-well filter plate (MAHV-N45, Millipore). Each well of the sephadex plate was filled up with $300 \mu$ of $\mathrm{ddH}_{2} \mathrm{O}$ and was incubated for 3 hours at room temperature for swelling. Then, the excess water was removed by centrifugation at $700 \mathrm{rpm}$ for 5 minutes at RT (Centrifuge $5810 \mathrm{R}$, Eppendorf), followed by addition of $150 \mu \mathrm{l}$ of $\mathrm{ddH}_{2} \mathrm{O}$ for another incubation time of half an hour. Again, the excess water was removed by centrifugation, using the same conditions. The prepared sephadex plate was placed on top of a sequencing plate. The sequencing-PCR-mixtures were filled up with $\mathrm{ddH}_{2} \mathrm{O}$ to a total volume of $40 \mu \mathrm{l}$ and were pipetted into the wells of the sephadex plate, which was then centrifuged at $700 \mathrm{rpm}$ for 5 minutes at RT. Finally, the purified samples (collected in the sequencing plate) were sequenced with the 3130xl Genetic Analyser 
(Applied Biosystems, Darmstadt). The data was analyzed with the SequencingAnalysis version 5.2 software ${ }^{\circledR}$ (Applied Biosystems, Darmstadt) first. For the detailed sequence analysis the software Staden Package version 4.0 (Cambridge, UK) or DNASTAR ${ }^{\circledR}$ version 11.2 (Madison WI, USA) and CloneManager (SECentral) were used.

\subsection{Genotyping by Single Base Primer Extension Method (SNaPshot ${ }^{\mathrm{TM}}$ )}

For the determination of single nucleotide polymorphisms (SNPs) in genomic DNA the Single Base Primer Extension method SNaPshot ${ }^{\mathrm{TM}}$ was used, based on multiplex PCR amplification (Multiplex PCR Kit, Qiagen, Hilden) of fragments with the SNP of interest. Primers, sized between 18 and $55 \mathrm{bp}$ were designed. These bind in $5^{\prime} \rightarrow 3^{\prime}$ direction to the multiplex PCR amplification with the 3'-terminus adjacent to the targeted SNP.

For the single nucleotide extension fluorescently labeled dideoxyribonucleotide triphosphates (ddNTPs) are used in a SNaPshot PCR reaction (SNaPshot reaction mixture, ABI PRISM ${ }^{\circledR}$ SNaPshot ${ }^{\mathrm{TM}}$ Multiplex Kit, Applied Biosystems). Due to the missing $(-\mathrm{OH})$ group of ddNTPs at the 3'-terminus further DNA amplification is not possible. This leads to the single nucleotide base extension generated by the fluorescently tagged ddNTPs detected by a special laser detector after fragment separation via capillary electrophoresis. A DNA size standard (GeneScan ${ }^{T M} 120$ LIZ $^{T M}$ Size standard, Applied Biosystems) was used to determine the fragment size. The resulting electropherogram shows differently coloured peaks for each of the four ddNTPs, representing the genotype of the analyzed SNP: Adenine - green, (FS (fluorescent stain) = dR6G), Cytosine - black $\left(\mathrm{FS}=\mathrm{dTAMRA}^{\mathrm{TM}}\right)$, Guanine - blue $(\mathrm{FS}=\mathrm{dR} 110)$ and Thymine - red $\left(\mathrm{FS}=\mathrm{dROX}^{\mathrm{TM}}\right)$.

First, DNA was amplified by Multiplex PCR (Multiplex PCR Kit, see Table 14, Table 15 and Table 16). 
Table 14: Reaction mixture for Multiplex PCR

\begin{tabular}{|c|c|c|}
\hline \multicolumn{2}{|c|}{ Reagent } & Volume $[\mu l]$ per sample \\
\hline \multicolumn{2}{|c|}{ 2x Qiagen Multiplex PCR Master Mix } & 6 \\
\hline \multicolumn{3}{|c|}{ (Comprising Taq Polymerase, dNTP mix and $\mathrm{MgCl}_{2}$ ) } \\
\hline \multicolumn{2}{|c|}{ 10x Primer Mix (see Table 15) } & 1.2 \\
\hline \multicolumn{2}{|c|}{ Q-Solution } & 1.2 \\
\hline \multicolumn{2}{|c|}{ RNAse-free water } & 1.6 \\
\hline \multicolumn{2}{|c|}{ Genomic DNA } & 2 \\
\hline \multicolumn{2}{|l|}{ In total } & 12 \\
\hline Gene & $\begin{array}{l}\text { Forward Primer sequence } \\
\qquad\left(5^{\prime} \rightarrow 3^{\prime}\right)\end{array}$ & $\begin{array}{l}\text { Reverse Primer sequence } \\
\qquad\left(5^{\prime} \rightarrow 3^{\prime}\right)\end{array}$ \\
\hline IL17F & GCACTGGGTAAGGAGTGGCATTTCTAC & TTGGAGAAGGTGCTGGTGACTGTTG \\
\hline BTRC & GGGGCATTTGGGTGTGTGTCAG & GCCCTGCACTAAGGGTCAAACAGGTAC \\
\hline RRM2 & CGGGAGATTTAAAGGCTGCTGGAG & GACACGGAGGGAGAGCATAGTGG \\
\hline PRB2 & CAGCTTCACAGATGGTGGCTGATGAG & CCTGCTCATGATGCCCAGAATCAAG \\
\hline DCP1B & AAGGAAAGCAAATTAATTAGGCTTGTGCTA & GAATGGAGAGTGGGGAGTTATCTTCTAATG \\
\hline WWOX & CTAGGTGGCTTCAGTCAGCAGAACTG & TGCCTTCTGTTCTCATGCAACTTCAC \\
\hline
\end{tabular}

Table 16: Multiplex PCR conditions

\begin{tabular}{lcc} 
Phase & Duration & Temperature \\
Initial Denaturation & $15 \mathrm{~min}$ & $95^{\circ} \mathrm{C}$ \\
\hline Denaturation & $30 \mathrm{sec}$ & $94^{\circ} \mathrm{C}$ \\
Annealing & $1: 30 \mathrm{~min}$ & $64.8^{\circ} \mathrm{C}$ \\
Elongation & $1: 30 \mathrm{~min}$ & $72{ }^{\circ} \mathrm{C}$ \\
\hline Terminal elongation & $10 \mathrm{~min}$ & $72^{\circ} \mathrm{C}$ \\
Cooling down & for ever & $8{ }^{\circ} \mathrm{C}$
\end{tabular}

Afterwards, the PCR product was purified with Fast-AP (Thermosensitive alkaline phosphatase, Life Technologies, Darmstadt, Table 17) and Exonuclease I (ExoI, Fermentas, St. Leon-Roth) to eliminate unincorporated PCR primers and dNTPs. The purification procedure was performed for 3 hours at $37^{\circ} \mathrm{C}$, then the enzymatic reaction was inactivated for 15 minutes at $80^{\circ} \mathrm{C}$. 
Table 17: Reaction mixture for the first purification step

\begin{tabular}{lc}
\hline Reagent & Volume $[\boldsymbol{\mu l}]$ per sample \\
\hline Fast-AP buffer $(10 \mathrm{x})$ & 0.95 \\
Fast-AP $(1 \mathrm{U} / \mu \mathrm{l})$ & 1.695 \\
ExoI $(20 \mathrm{U} / \mu \mathrm{l})$ & 0.35 \\
PCR product & 3 \\
\hline In total & $\mathbf{6}$
\end{tabular}

The SNaPshot PCR (Table 18) was run in a 384-well plate (FrameStar ${ }^{\circledR}$, 4titude, Wotton, UK), under conditions listed in Table 19. The PCR mixture was prepared on ice. Used SNaPshot primers are displayed in Table 20.

Table 18: SNaPshot PCR mixture

\begin{tabular}{lc}
\hline Reagent & Volume $[\boldsymbol{\mu l}]$ per sample \\
\hline SNaPshot ${ }^{\mathrm{TM}}-$ Master Mix & 0.35 \\
Primer Mix $(2-12 \mu \mathrm{M})$ & 0.5 \\
$\mathrm{ddH}_{2} \mathrm{O}$ & 2.15 \\
Purified PCR product & 2 \\
\hline In total & $\mathbf{5}$
\end{tabular}

Table 19: PCR conditions for SNaPshot PCR

\begin{tabular}{lcc} 
Phase & Duration & Temperature \\
Initial Denaturation & $2 \mathrm{~min}$ & $94^{\circ} \mathrm{C}$ \\
\hline Denaturation & $10 \mathrm{sec}$ & $96^{\circ} \mathrm{C}$ \\
Annealing & $5 \mathrm{sec}$ & $50^{\circ} \mathrm{C}$ \\
Elongation & $30 \mathrm{sec}$ & $60^{\circ} \mathrm{C}$ \\
\hline Cooling down & for ever & $8{ }^{\circ} \mathrm{C}$
\end{tabular}


Table 20: SNaPshot Primers

\begin{tabular}{|c|c|}
\hline Gene & Sequence $\left(5^{\prime} \rightarrow 3^{\prime}\right)$ \\
\hline IL17F (rs763780) & GCACCTCTTACTGCACA \\
\hline$B T R C(\operatorname{rs10883617})$ & CTTTGGCCTGAAAAGGTACA \\
\hline RRM2 (rs1130609) & GACACGGAGGGAGAGCATAGTGG \\
\hline PRB2 (rs2900174) & $(\mathrm{CTGA})_{2} \mathrm{CTCCTTACAAGACTCACAAGTGTTCT}$ \\
\hline$D C P 1 B(\operatorname{rs} 11062040)$ & (TGAC) ${ }_{4}$ AATTAATTAGGCTTGTGCTA \\
\hline WWOX (rs11644322) & $(\text { GACT })_{6}$ GATGTGATTACAGTGAATTAGGGTGG \\
\hline
\end{tabular}

A second purification step was conducted (Table 21) for 30 minutes at $37^{\circ} \mathrm{C}$ to remove unincorporated fluorescently labeled ddNTPs which would affect the data analysis, followed by an incubation time of 15 minutes at $80{ }^{\circ} \mathrm{C}$ for enzyme deactivation.

Table 21: Reaction mixture for the second purification step

\begin{tabular}{lc}
\hline Reagent & Volume $[\boldsymbol{\mu l}]$ per sample \\
\hline Fast-AP $(1 \mathrm{U} / \mu \mathrm{l})$ & 0.5 \\
Fast-AP buffer $(10 \mathrm{x})$ & 0.5 \\
SNaPshot PCR product & 5 \\
\hline In total & $\mathbf{6}$
\end{tabular}

Next, $1 \mu \mathrm{l}$ of the purified product was added to a 96-well sequencing plate, containing 10 $\mu \mathrm{l}$ of the sequencing mixture (Table 22), which was then incubated for 5 minutes at $95{ }^{\circ} \mathrm{C}$ and was placed on ice directly afterwards. Finally, the samples were analyzed with the 3130xl Genetic Analyser (Applied Biosystems, Darmstadt) and data analysis was performed by using the Gene mapper v3.7 software ${ }^{\circledR}$ (Applied Biosystems, Darmstadt).

Table 22: Sequencing mixture for SNaPshot ${ }^{\mathrm{TM}}$

\begin{tabular}{|c|c|}
\hline Reagent & Volume $[\mu \mathrm{l}]$ per sample \\
\hline Formamid & 10 \\
\hline (Hi-DiTM Formamid, Applied Biosystems) & \\
\hline GeneScan $^{T M} 120$ LIZ $^{T M}$ (Size standard) & 0.05 \\
\hline Purified sample & 1 \\
\hline
\end{tabular}




\subsection{Generation of DNA constructs}

\subsubsection{Cloning of WWOX cDNA}

For overexpression of WWOX in pancreatic cancer cell lines a genetic construct was generated, based on the pcDNA3 vector (Invitrogen, Karlsruhe). First, WWOX cDNA was engineered from total RNA of the LCL sample with the number 238. Using the GoScript ${ }^{T M}$ Reverse Transcription system (Promega, Mannheim) with $(\mathrm{T})_{20} \mathrm{VN}$ (Eurofins MWG, Ebersberg) as anchored primer, total mRNA was reversely transcribed. Afterwards, a specific PCR-based amplification of WWOX cDNA (using KOD-Polymerase and QSolution, see section 3.2.4, annealing temperature $63.4^{\circ} \mathrm{C}$ ), containing the exons $1-9$, was carried out with the following primer pair (Table 23):

Table 23: Primers for $W W O X$ cDNA amplification

\begin{tabular}{ll}
\hline Name of primer & Sequence $\left(5^{\prime} \rightarrow 3^{\prime}\right)$ \\
\hline WWOXcomp_EcoRI-forward & CTGACTEAATTCCCAGGTGCCTCCACAGTCA \\
WWOXcomp_XhoI-reverse & CTGACTETCGAGCATCCGCTCTGAGCTCCACTTAG \\
\hline
\end{tabular}

Restriction sites are underlined and italic.

A restriction site for $E c o$ RI was added to the forward, and for $X h o I$ to the reverse primer. After WWOX amplification, both, the pcDNA3 plasmid DNA and the generated WWOX cDNA were cut with the named restriction enzymes in double digestion fashion (see chapter 3.2.9.2), followed by gel electrophoresis (see chapter 3.2.7) and agarose gel purification (see chapter 3.2.8). Next, the WWOX fragment was inserted between the restriction sites of EcoRI and XhoI of the pcDNA3 vector (see 3.2.10 and 3.2.11 and Figure 6), which then was transformed into E. coli (see chapter 3.2.11 and 3.7.2). 

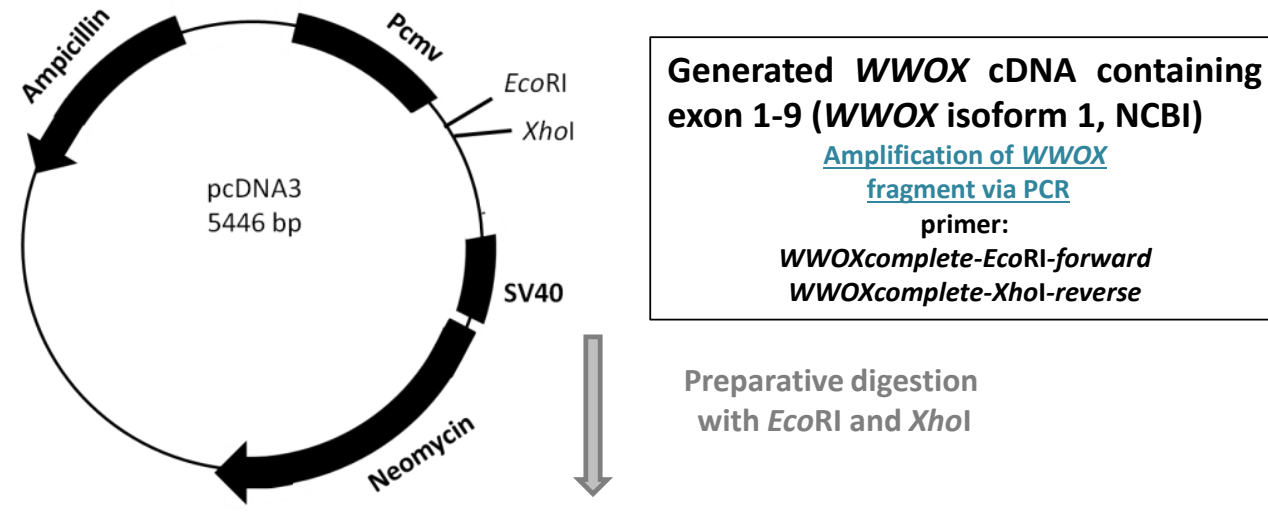

Preparative digestion

with EcoRI and Xhol

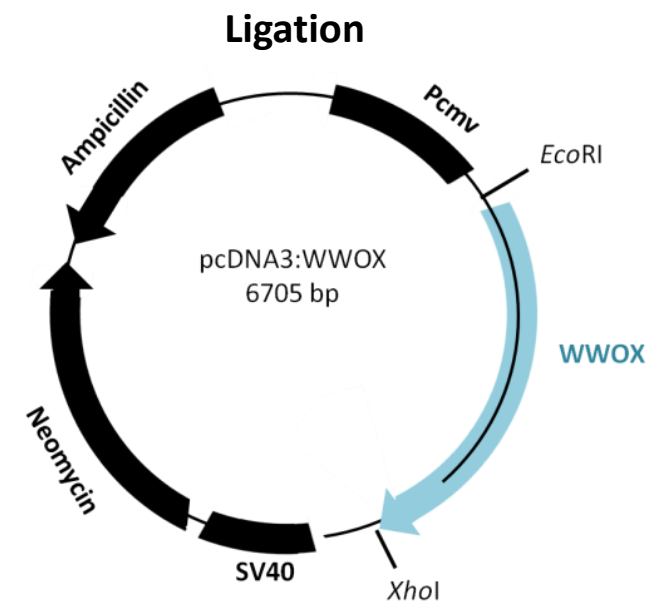

Figure 6: Cloning procedure: Generation of a pcDNA3:WWOX construct

Finally, the mini- and midi-preparation (see sections 3.7.5.1 and 3.7.5.2) of single clone cultures were performed to obtain purified plasmid DNA. To verify cloning of the whole WWOX coding region into the pcDNA3 vector Sanger-based direct sequencing (see 3.3) was conducted with the sequencing primers listed below (Table 24).

Table 24: Sequencing primers to verify the pcDNA3-WWOX construct

\begin{tabular}{|c|c|}
\hline Name of primer & Sequence $\left(5^{\prime} \rightarrow 3^{\prime}\right)$ \\
\hline WWOX-Seq-F1 & CTCTGGCTAACTAGAGAACCCACTGCTTAC \\
\hline WWOX-Seq-F2 & CCAACCACCCGGCAAAGATA \\
\hline WWOX-Seq-F3 & AATGCTGCACGCTACGGAG \\
\hline WWOX-Seq-F4 & ATGTACTCCAACATTCATCGCAG \\
\hline WWOX-Seq-F5 & GTCTCTTCGCTCTGAGCTTCT \\
\hline WWOX-Seq-F6 & CGAAACCGCCAAGTCT \\
\hline WWOX-Seq-F7 & AGAGTCCCATCGATTTACAG \\
\hline WWOX-Seq-F8 & ATGGCTGGCAACTAGAAG \\
\hline
\end{tabular}


This construct served as reference for absolute quantification of the expression ratios between WWOX mRNA of exon 4-6 (core region) and of exon 8-9 (last exon), obtained from LCLs.

\subsubsection{Cloning of SP1 into the pCDNA3 vector}

To analyse the effect of the transcription factor SP1 (specifity protein 1) on pancreatic cancer cells, a SP1 construct was generated. Therefore, a p0TB7:SP1 construct was purchased from SourceBioscience (IRAU97D03, Nottingham, UK). The aim was to introduce SP1 into the pcDNA3 vector. For that reason, the p0TB7:SP1 and pcDNA3 plasmids were digested with EcoRI and XhoI in a double digestion fashion (3.2.9.2). Afterwards gel electrophoresis (see section 3.2.7) and gel purification (3.2.8) were performed, followed by the insertion of the SP1 fragment into the pcDNA3 vector (see sections 3.2.10 and 3.2.11, Figure 7).

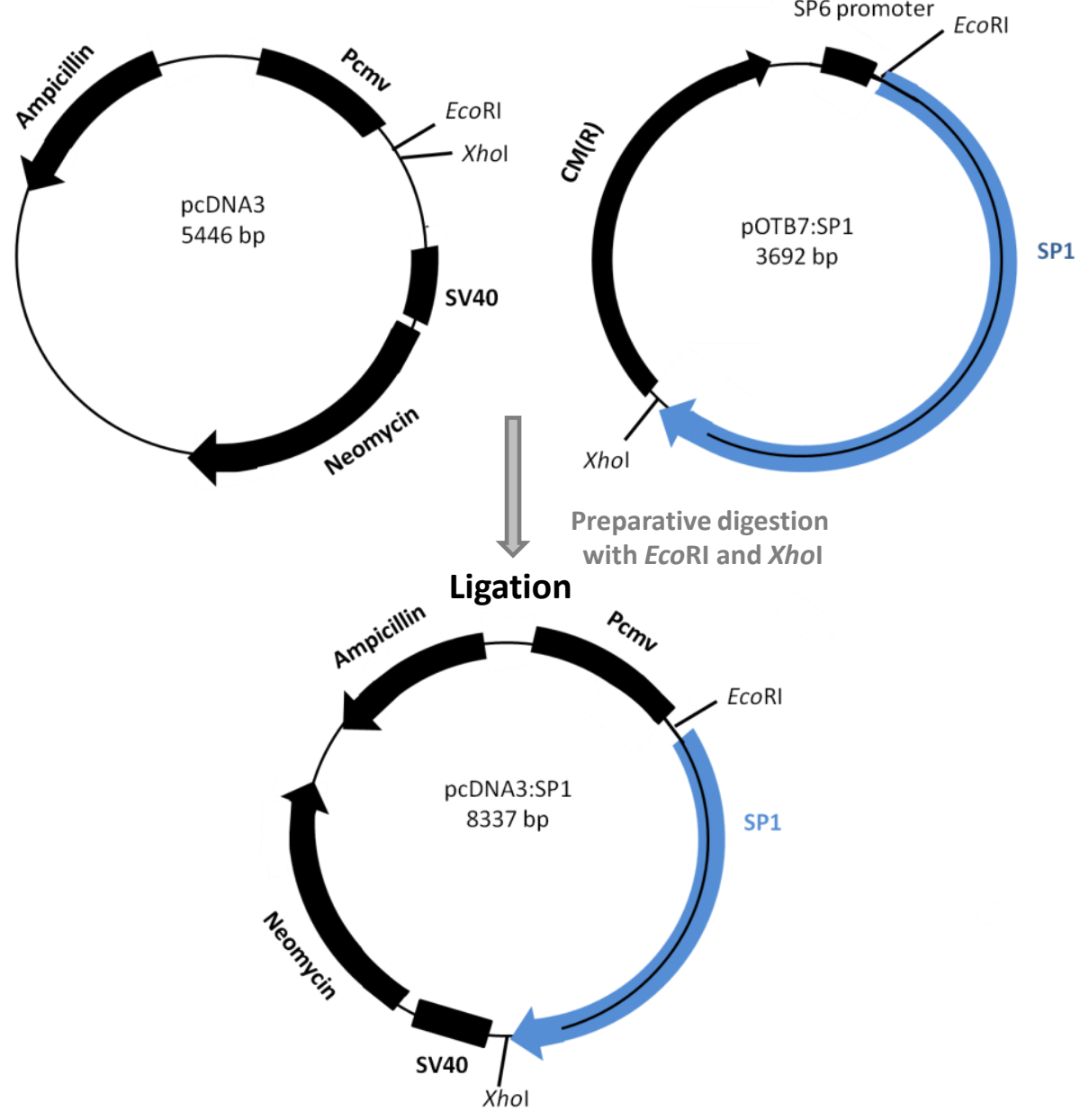

Figure 7: Cloning procedure: Generation of a pcDNA3:SP1 construct 
Finally, the newly generated construct was transformed into E. coli (see chapter 3.7.2) and mini- and midi-preparation were performed using single clone cultures (3.7.5.1, 3.7.5.2). Complete and error-free cloning of the entire SP1 coding region was controlled by DNA sequencing analysis (see 3.3) with the next listed primers (Table 25).

Table 25: Sequencing primers for the construct pcDNA3:SP1

\begin{tabular}{ll}
\hline Name of primer & Sequence $\left(\mathbf{5}^{\prime} \rightarrow \mathbf{3}\right)$ \\
\hline $\boldsymbol{S P 1}$-Seq-F1 & CTCTGGCTAACTAGAGAACCCACTGCTTAC \\
$\boldsymbol{S P 1}$-Seq-F2 & GTTTGGCATAGCAGCAATGATGTTG \\
$\boldsymbol{S P 1}$-Seq-F3 & TTGATGGGCAACAGCTGCAGT \\
$\boldsymbol{S P 1}$-Seq-F4 & CATTGGGGCTAAGGTGATTGTTTG \\
$\boldsymbol{S P 1}$-Seq-F5 & TGGACAGGTCAGTTGGCAGACTCTAC \\
$\boldsymbol{S P 1}$-Seq-F6 & GGTGAGAGGTCTTGCCATACACTTTC \\
$\boldsymbol{S P 1}$-Seq-F7 & CCTGCCCCTACTGTAAAGACAGTGAAG \\
$\boldsymbol{S P 1}$-Seq-F8 & GGCCTCCATGGCTACCATATTG \\
$\boldsymbol{S P 1}$-Seq-F9 & GGACAGTGGGGCAGGTTCAG \\
$\boldsymbol{S P 1}$-Seq-F10 & GAATCCATCATGGAAGAGCTGAGAA \\
$\boldsymbol{S P 1}$-Seq-F11 & CCATGAGCGACCAAGATCA \\
$\boldsymbol{S P 1 - S e q - F 1 2}$ & GGGTGTGAGAGTGGTGTTG \\
$\boldsymbol{S P 1}$-Seq-F13 & CTGGTGGTGATGGAATACATGA \\
$\boldsymbol{S P 1 - S e q - F 1 4}$ & GCACCCTGTGAAAGTTGTGT \\
\hline
\end{tabular}

\subsubsection{Cloning of eGFP-tagged RRM2 into the pcDNA5 vector}

For cloning of the RRM2 (Ribonucleotide reductase subunit M2) coding region into the pcDNA5 vector, the full length cDNA clone p0TB7:RRM2 (Clone3528619, IRAUp969F0415D) was purchased from SourceBioscience (Nottingham, UK). The RRM2 fragment was amplified out of the primary p0TB7:RRM2 vector by using following primers, comprising restriction sites for HindIII and NotI (Table 26), under conditions described in section 3.2.4 (with Q-Solution, annealing temperature $63.4^{\circ} \mathrm{C}$ ). 
Table 26: Primers to amplify RRM2 out of the pOTB7:RRM2 construct

\begin{tabular}{ll}
\hline Name of primer & Sequence $\left(\mathbf{5}^{\prime} \rightarrow \mathbf{3}\right.$ ') \\
\hline RRM2-HindIII-forward & CTGACT $\underline{A A G C T T C G C C G C C A C T A T G C T C T C ~}$ \\
RRM2-NotI-reverse & CTGACTGCGGCCGCGAAGTCAGCATCCAAGGTAAAAGAATTCTC \\
\hline
\end{tabular}

Restriction sites are underlined and italic.

After gel electrophoresis (see 3.2.7) and the agarose gel clean up process (3.2.8), preparative digestion (see 3.2.9.2) of the resulting RRM2 fragment and of the pcDNA5 vector were conducted, first with HindIII, thereafter with NotI. Again, gel electrophoresis and the agarose gel purification were carried out, before integrating the RRM2 DNA fragment between the restriction sites of the mentioned enymes of the pcDNA5 vector (see 3.2.10, 3.2.11, Figure 8).

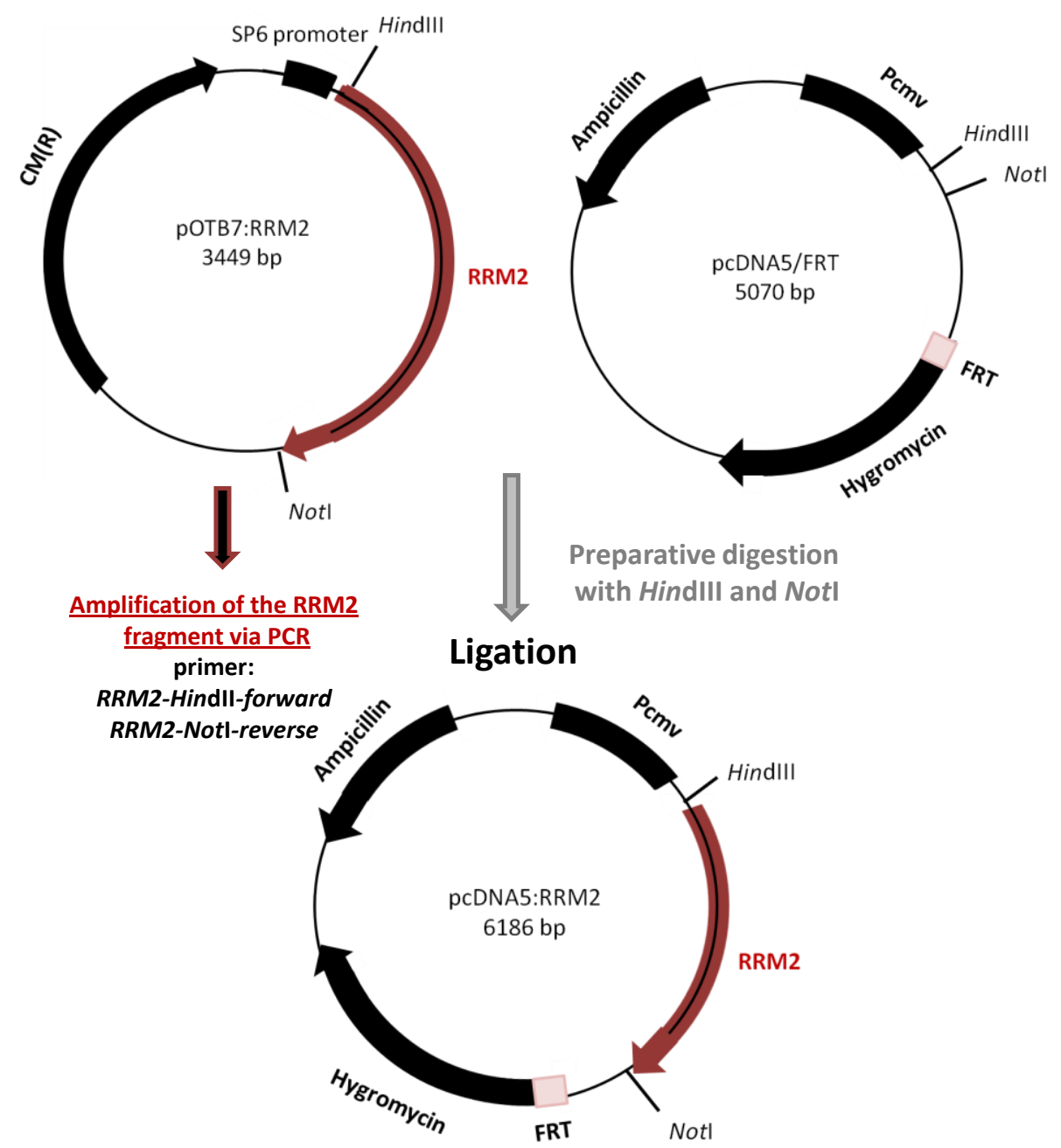

Figure 8: Cloning procedure: Generation of a pcDNA5:RRM2 construct 
For RRM2 detection on translational level (see 3.8.4) RRM2 was tagged with an eGFP (enhanced green fluorescent protein, see Figure 9). Therefore, a pcDNA5/FRT/TO GFP construct was bought from Addgene (Plasmid 19444, Cambridge, UK). Similar to the RRM2 amplification procedure before, specific primers with artificial inserted restriction sites (Table 27) were ordered to amplify the eGFP out of the purchased construct (PCR as described in 3.2.4, with Q-Solution, annealing temperature $63.4{ }^{\circ} \mathrm{C}$ ).

Table 27: Primers to amplify eGFP out of the pcDNA5/FRT/TO GFP construct

\begin{tabular}{ll}
\hline Name of primer & Sequence $\left(5^{\prime} \rightarrow \mathbf{3}^{\prime}\right)$ \\
\hline eGFP-NotI-forward & CTGACT $\underline{G C G G C C G C T A T G G T G A G C A A G G G C G A G G A G C}$ \\
eGFP-XhoI-reverse & CTGACTCTCGAGTTACTTGTACAGCTCGTCCATGCCGAGAGT \\
\hline
\end{tabular}

Restriction sites are underlined and italic.

After gel electrophoresis and agarose gel purification, preparative digestion of the eGFP fragment and of the pcDNA5-RRM2 construct was conducted, first with Not then with XhoI. Then, eGFP was ligated into the pcDNA5-RRM2 construct (see Figure 9), which then was transformed into E. coli TOP10. Single clones were cultivated (see 3.7.4) and the mini-preparation (see 3.7.5.1) was undertaken. Finally, a mutation at the position of a 5' single nucleotide polymorphism (SNP) rs1130609 of RRM2 (located in the Kozak sequence) from $G>T$ was inserted by mutagenesis PCR with specific mutagenesis primers (see section 3.2.6, annealing temperature $65.2{ }^{\circ} \mathrm{C}$ with Q-Solution) to have an additional construct carrying the variant allele for further analysis. 

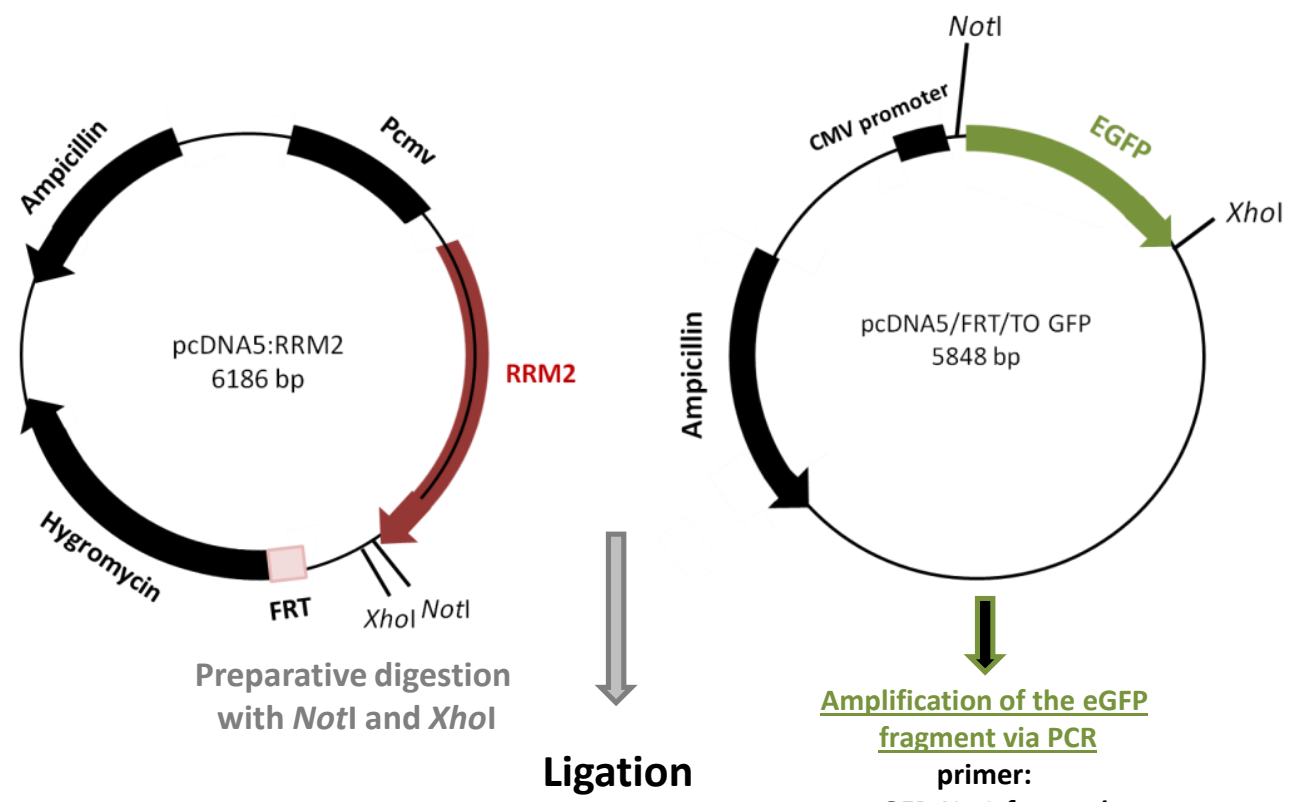

Ligation eGFP-Notl-forward

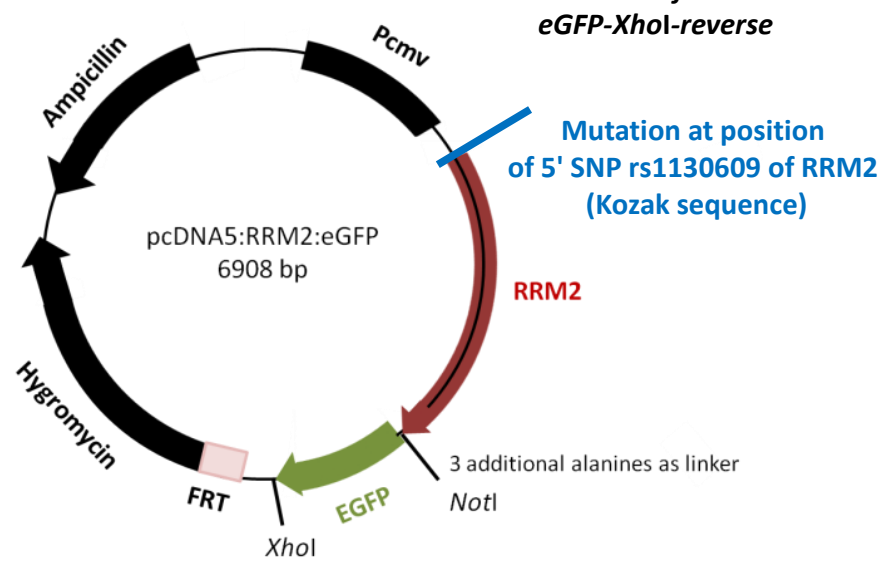

Figure 9: Cloning procedure: Generation of a pcDNA5:RRM2:eGFP construct

\subsection{RNA workflow}

When working with RNA, the existence of a ribonuclease-free environment should be ensured. For that reason, RNA work was performed under a fume hood, using materials, which were protected with an anti-RNase spray (RNaseZap, Sigma-Aldrich, Deisenhofen). Moreover, RNase-free filter tips were used.

\subsubsection{RNA isolation}

For RNA isolation $1 \times 10^{6}$ cells were harvested and transferred into a $50 \mathrm{ml}$ falcon tube. The cell suspension was centrifuged at $500 \mathrm{~g}$ for 5 minutes at RT. The supernatant was removed and a washing step with 3 - $4 \mathrm{ml}$ of PBS buffer was performed. Afterwards, the centrifugation step was repeated and the supernatant was discarded completely. Then, 
the pellet was dissolved in $350 \mu \mathrm{l}$ of RLT Plus buffer (Qiagen, Hilden). The solution was pipetted into a $2 \mathrm{ml}$ reaction tube for the further RNA isolation process in the QiaCube robot (Qiagen, Hilden), using the RNeasy Plus Mini Kit (protocol with miRNA, Qiagen, Hilden) according to the manufacturer's instructions. After this procedure, the samples were put on ice directly and the RNA concentration was measured photometrically (see 3.6.2). Finally, the samples were stored at $-80^{\circ} \mathrm{C}$.

\subsubsection{Quantification of RNA}

RNA quantification was performed photometrically, analog to DNA quantification (see section 3.2.3). For RNA an extinction of 1 at $260 \mathrm{~nm}\left(E_{260}\right)$ equates to $40 \mu \mathrm{g}$ RNA per $\mu \mathrm{l}$.

\subsubsection{Reverse Transcription}

For the analysis of gene expression (performed by quantitative RT-PCR, see section 3.6.4) isolated RNA had to be converted into cDNA (copy or complementary DNA) by reverse transcription (RT), performed by the Super Script II reverse transcriptase (Invitrogen, Karlsruhe). This polymerase uses dN6 random hexamer oligonucleotide primers (six randomly combined nucleotides, Roche, Mannheim) to generate cDNA. In comparison to the usual eukaryotic DNA the newly synthesized cDNA had no introns, due to the fact that the mRNA template is already spliced. For primer annealing $1 \mu \mathrm{g}$ of RNA was incubated with $2 \mu \mathrm{l}$ of the dN6-primers diluted in $\mathrm{ddH}_{2} \mathrm{O}$ in a total volume of $18.5 \mu \mathrm{l}$ for 5 minutes at $70^{\circ} \mathrm{C}$. Then, the samples were put on ice directly and were cooled down for 10 minutes. During that time the reverse transcription master mix was pipetted as shown in Table 28, from which $11.5 \mu \mathrm{l}$ were added to each RNA-primermixture. The reverse transcription was run under $42{ }^{\circ} \mathrm{C}$ for 1 hour, followed by an inactivation step at $70{ }^{\circ} \mathrm{C}$ for 15 minutes. 


\begin{tabular}{lc}
\hline Reagent & Volume $[\boldsymbol{\mu l}]$ per sample \\
\hline 5x Superscript RT buffer & 6 \\
DTT $(0.1 \mathrm{M})$ & 3.5 \\
dNTPs $(10 \mathrm{mM})$ & 1.5 \\
RNase Inhibitor P/N $(40 \mathrm{U} / \mu \mathrm{l})$ & 0.5 \\
Super Script & 0.25 \\
\hline In total & $(200 \mathrm{U} / \mu \mathrm{l})$ \\
\end{tabular}

Finally, the cDNA was diluted with $0.1 \mathrm{mM}$ TE-buffer to a concentration of $2 \mathrm{ng} / \mu \mathrm{l}$, except for cDNA pools (used for qRT-PCR standard curve), which were adjusted to 10 $\mathrm{ng} / \mu \mathrm{l}$.

\subsubsection{Quantitative real-time PCR (qRT-PCR)}

The quantitative real-time PCR is a technique to assess gene expression, which combines the amplification and quantitative detection of cDNA transcripts. The used cDNA was synthesized from total RNA during reverse transcription (see section 3.6.3). For quantification of the amounts of DNA products at each cycle the fluorescent DNA intercalating dye eva green (excitation $500 \mathrm{~nm}$, emission $530 \mathrm{~nm}$ ), included in the $5 x$ HOT FIREPol ${ }^{\circledR}$ EvaGreen ${ }^{\circledR} q$ PCR Mix Plus (Solis BioDyne, Estonia), was used. The measured fluorescent signal is proportional to the amount of amplified cDNA. A low cycle number implies a higher gene expression, because less cycles are needed to reach a specific threshold (Cycle threshold (Ct)) of DNA amount. The Ct value represents the number of cycles needed for the fluorescent signal to cross a threshold, which exceeds the background level. Additional to the gene of interest, at least three housekeeping genes (36b4, HPRT1 and UBC, for primer sequences see Table 31 below) were measured to normalize the expression results. For this normalization process the $\Delta \Delta \mathrm{Ct}$ method was used. All samples, which were pipetted in duplicate, were averaged first. Then, the values of the intern control (housekeeping genes) were subtracted from the samples $(\Delta \mathrm{Ct})$. And finally, the normalized control samples (treated with PBS) were subtracted from the normalized samples $(\Delta \Delta \mathrm{C} \mathrm{t})$. To have the fold-change of expression, relative to the basal expression, the following equation (Equation 2) was used: 
Equation 2: Formula to calculate relative gene expression

Relative expression $=2-[C t-C t$ housekeeping gene $)-(C t$ control $-C t$ housekeeping control $)]$ $=2 \cdot[\Delta \Delta C t]$

The qRT-PCR mixture was prepared (see Table 29) in a 348 well-plate (Thermo Fast Plate 384 PCR, ABgene), which was covered with an optical clear film. Furthermore, on every qRT-PCR plate a standard curve with six concentrations of a cDNA pool (pooled from cDNA of the measured cell lines, 1:5 dilutions) was pipetted to evaluate the amplification. For the performance of the quantitative RT-PCR under conditions shown in Table 30, the TaqMan 7900HT (Applied Biosystems) machine was used. Data analysis was performed with the SDS 1.2 software (Applied Biosystems).

Table 29: qRT-PCR master mix

\begin{tabular}{lc}
\hline Reagent & Volume $[\boldsymbol{\mu l}]$ per sample \\
\hline qRT-PCR master mix & 2 \\
Primer $(1: 10)$ & 0.2 \\
$\mathrm{ddH}_{2} \mathrm{O}$ & 4.8 \\
cDNA & 3 \\
\hline In total & $\mathbf{1 0}$
\end{tabular}

Table 30: qRT-PCR conditions

Phase

Initial Denaturation

\section{Duration}

$15 \mathrm{~min}$

Denaturation

Annealing

Elongation

Dissociation Step

15 sec

$20 \mathrm{sec}$

$40 \mathrm{sec}$

$15 \mathrm{sec}$

$15 \mathrm{sec}$

$15 \mathrm{sec}$

\section{Temperature}

$95^{\circ} \mathrm{C}$

$95^{\circ} \mathrm{C}$
$60{ }^{\circ} \mathrm{C}$
$72^{\circ} \mathrm{C}$
$95^{\circ} \mathrm{C}$
$60^{\circ} \mathrm{C}$
$95^{\circ} \mathrm{C}$


Table 31: Primers for qRT-PCR

\begin{tabular}{|c|c|c|}
\hline Gene & $\begin{array}{l}\text { Forward Primer sequence } \\
\qquad\left(5^{\prime} \rightarrow 3^{\prime}\right)\end{array}$ & $\begin{array}{l}\text { Reverse Primer sequence } \\
\qquad\left(5^{\prime} \rightarrow 3^{\prime}\right)\end{array}$ \\
\hline \multicolumn{3}{|l|}{ Reference genes } \\
\hline $36 b 4$ & GCAGATCCGCATGTCCCTT & TGTTTTCCAGGTGCCCTCG \\
\hline$B 2 M G$ & CCAGCAGAGAATGGAAAGTC & CATGTCTCGATCCCACTTAAC \\
\hline GAPDH & CССТTCATTGACCTCAACTACAT & ACGATACCAAAGTTGTCATGGAT \\
\hline HPRT1 & TGACACTGGCAAAACAATGCA & GGTCCTTTTCACCAGCAAGCT \\
\hline$U B C$ & CGGTGAACGCCGATGATTAT & ATCTGCATTGTCAAGTGACGA \\
\hline \multicolumn{3}{|c|}{$R R M 2$ related primer } \\
\hline$R R M 2$ & CACGGAGCCGAAAACTAAAGC & TCTGCCTTCTTATACATCTGCCA \\
\hline$R R M 2 v 1$ & GGAGATTTAAAGGCTGCTGGAGT & CACGGAGGGAGAGCATAGTG \\
\hline \multicolumn{3}{|c|}{ WWOX related primer } \\
\hline WWOX exon 4-6 & CCAACCACCCGGCAAAGATA & AATGCTGCACGCTACGGAG \\
\hline WWOX exon 8-9 & ATGTACTCCAACATTCATCGCAG & GTCTCTTCGCTCTGAGCTTCT \\
\hline \multicolumn{3}{|l|}{ Other primer } \\
\hline BCL2 & ACATCGCCCTGTGGATGACT & GGGCCGTACAGTTCCACAAA \\
\hline$G A D D 45 A$ & GCTCAGCAAAGCCCTGAGT & GTTATCGGGGTCGACGTTGA \\
\hline TP53 & AGCTTTGAGGTGCGTGTTTG & TTGGGCAGTGCTCGCTTAG \\
\hline$S P 1$ & CAGGCCTCCAGACCATTAAC & CAAGCTGAGCTCCATGATCAC \\
\hline RNA5-8SP2 & ACTGGGCTTCTGTGTGTCGATG & TGCAATTGCGTTCGAAGTGTC \\
\hline
\end{tabular}

\subsubsection{RNA sequencing (RNAseq)}

The RNA sequencing method (whole expressome analysis) is based on next generation sequencing and was used to investigate RNA transcripts vicinal to the WWOX index SNP (rs11644322). This procedure was performed by the Transcriptome and Genome Analysis Laboratory (TAL) of the Göttingen University Medical Center, headed by Dr. rer. nat. Gabriela Salinas-Riester. The analyzed samples were two pooled RNA probes from LCLs, whereof one sample was obtained from five cell lines carrying the wild type allele (Cell identifiers at the Coriell institute: HG00096, HG00109, HG00120, HG00244, and HG00258) and the other sample from five cell lines carrying the variant allele (Cell identifiers: HG00100, HG00108, HG00122, HG00245, and HG00265), respectively. Besides, RNA of the pancreatic cancer cell lines AsPC1 and MiaPaca-II, which were SP1overexpressed and exposed to PBS or $30 \mathrm{nM}$ of gemcitabine, were examined. 
Furthermore, RNA (from three different clones) of the pancreatic cancer cell line PaTu8988t, stably transfected with shRNA plasmids for WWOX knock-down reason, was analysed, compared to control samples transfected with a negative control shRNA plasmid.

For RNA sequencing the Illumina TruSeq technology was used, comprising the following workflow steps: Sample preparation, Cluster generation, Sequencing chemistry, and data analysis. All working steps were performed according to the TruSeq ${ }^{\circledR}$ Stranded Total RNA Sample LS (Low Sample) Preparation Guide (Illumina, San Diego, CA, USA).

The typical RNAseq workflow implies the generation of cDNA fragments, which are flanked by multiple indexing adapters with constant sequences (Figure 10). This pool of cDNA fragments is called DNA library and is needed for sequencing with the HiSeq ${ }^{\circledR}$ 2000 sequencer (Illumina, San Diego, CA, USA) where millions of short sequence reads are generated, corresponding to individual cDNA pieces.

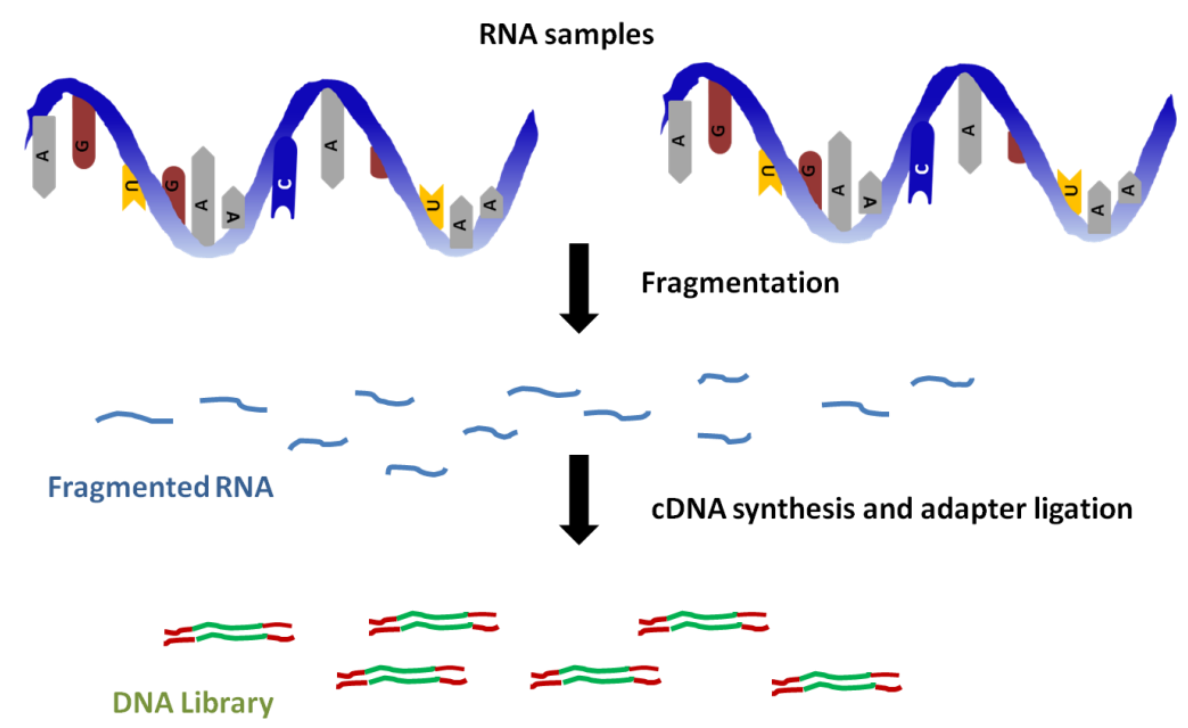

Figure 10: Workflow of RNA sequencing

The first step of sample preparation was the depletion of ribosomal RNA from total RNA. Afterwards, the remaining RNA was purified, fragmented and primed (with random hexamers) for cDNA synthesis. This cleaved RNA fragments were reversely transcribed to first strand cDNA by using reverse transcriptase and random primers, followed by second strand cDNA synthesis, where RNA templates were removed and a substitution strand was synthesized, incorporating dUTP instead of dTTP to generate dsDNA. To obtain blunt-ended cDNA, the dscDNA was separated from the second strand reaction 
mixture by usage of AMPure XP beads (Agencourt Bioscience Corporation, Beverly, Massachusetts). Next, the 3' ends had to be adenylated. This means that a single adenine nucleotide was added to the 3' end of the generated blunt fragments to prevent ligation with each other during the following adapter (specific constant sequence) ligation. The adapter sequence contains a corresponding, complementary overhang of a single thymine nucleotide allowing its ligation to the cDNA fragment. The adapter ligation process to the end of the cDNA fragments is needed for the further hybridization step onto a flow cell, used for simultaneous analysis. Afterwards, DNA fragments carrying adapter molecules at both ends were selectively enriched by PCR with a primer cocktail, that can anneal to the adapter ends. For providing an optimal cluster density of every flow cell, the DNA library templates were quantified, using the QuantiFluor ${ }^{T M}$ Dye System (Promega, Mannheim) containing a fluorescent DNA-binding dye, which was measured via Glomax ${ }^{\circledR}$ Fluorometer (Promega, Mannheim). Besides, the sample quality (size and purity) was determined with the Bioanalyzer 2100. This analyzer provides an automated capillary gel electrophoresis system (Agilent, Santa Clara, USA), using a DNA specific chip (Chip DNA 1000), allowing DNA fragment separation by size. Prior to sequencing, the cluster generation was performed using a cBOT instrument (Illumina, San Diego, CA, USA), where the library samples were bound to a flow cell by hybridization to oligonucleotides that are complementary to the adapter sequence and that are immobilized on the flow cell surface. Following steps are involved in this process: Immobilization, 3' extension, bridge amplification, linearization and hybridization.

In detail, the templates are copied by hybridized primers by 3 ' extension using a DNA polymerase. Only the copied immobilized template remains on the flow cell and was amplified via bridge amplification, where the template makes a loop to hybridize to a nearby oligonucleotide. The new template was duplicated by polymerase, forming a dsDNA bridge, which was denaturated afterwards to form single DNA strands. These strands loop over to adjacent oligonucleotides again and the procedure goes on as described, so that millions of individual, clonal cluster are created. Finally, each dsDNA bridge cluster was denaturated and the reverse strand was eliminated by specific base cleavage, so that the forward DNA strand is present. The 3' end of this forward strand and flow-cell bound oligonucleotides were blocked, preventing interference with the sequencing reaction. Then, the sequencing primer was hybridized to the complementary sequence on the illumina adapter on unbound ends of templates in the clusters, 
whereafter the flow cell contained $>200$ million clusters with $\sim 1000$ molecules per cluster and was ready to be sequenced (read lenght $50 \mathrm{bp}$ ).

\subsection{Working with bacteria}

To work with bacteria in an aseptic way, all working steps were peformed close to a Bunsen burner flame.

\subsubsection{Bacteria growth and storage conditions}

The Escherichia coli bacteria strain One Shot ${ }^{\circledR}$ TOP10 Electrocomp ${ }^{T M}$ E. coli (Invitrogen, Karlsruhe) was used, which was grown in Luria-Bertani (LB) medium. The LB medium was prepared as follows (Table 32):

Table 32: LB medium

\begin{tabular}{lc}
\hline Reagent & Amount [g] \\
\hline Tryptone & 10 \\
Yeast extract & 5 \\
$\mathrm{NaCl}$ & 5 \\
\hline
\end{tabular}

$\mathrm{ddH}_{2} \mathrm{O}$

Add to $1000 \mathrm{ml}$

This solution was autoclaved and stored at $4{ }^{\circ} \mathrm{C}$. For the preparation of solid LB agar plates, $14 \mathrm{~g}$ of Agar (AppliChem, Darmstadt) was added additionally prior to the autoclaving step. Afterwards, the solution was cooled down to $\sim 50{ }^{\circ} \mathrm{C}$ and the required

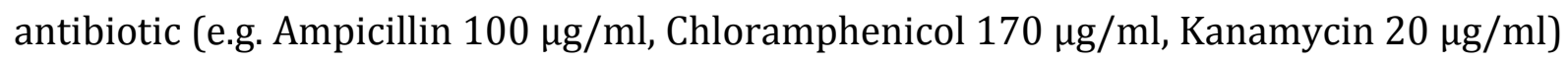
was added. Then, the prepared solution was poured into $92 \mathrm{~mm}$ petri dishes under the fume hood, which were placed there till they became dry. To store generated bacterial cultures for a long time, these were mixed at a ratio of $1: 1$ with a $50 \%$ glycerol solution in a $2 \mathrm{ml}$ reaction tube, and were frozen at $-80{ }^{\circ} \mathrm{C}$ directly after.

\subsubsection{Transformation by electroporation}

This method is used to insert plasmids into bacteria cells. Bacteria can increase the amount of plasmids, so that a high amount can be harvested by mini- or midipreparation (see 3.7.5.1, 3.7.5.2). An electric shock ( 2500 volt $/ \mathrm{cm}$ ) increases the permeability of the cell membrane, allowing plasmid DNA to get inside the cell. The 
electroporation mixture contained $30 \mu \mathrm{l}$ of $\mathrm{ddH}_{2} \mathrm{O}$ and $10 \mu \mathrm{l}$ of the electrocompetent $E$. coli, which was transferred into a pre-cooled $2 \mathrm{~mm}$ electroporation cuvette. Then, $1 \mu \mathrm{l}$ of dialyzed plasmid DNA (see 3.2.11) was added. For the electroporation process the Gene Pulser II (Biorad, Herkules USA) with the conditions of $2.5 \mathrm{kV}, 25 \mu \mathrm{F}$ and $200 \Omega$ for five milliseconds was used. Directly afterwards, $800 \mu \mathrm{l}$ of LB medium (at $37^{\circ} \mathrm{C}$ ) was added to the cuvette, which was then incubated for 1 hour at $37^{\circ} \mathrm{C}$. Finally, 50 and $200 \mu \mathrm{l}$ of this solution were struck on agar plates containing the required antibiotic as selection marker, allowing growth only for successfully transformed bacteria.

\subsubsection{Cultivation of bacteria on agar plates}

To get single clones after the transformation process or to prepare a backup plate of a liquid bacteria solution prepared for mini-preparation, bacteria were cultivated on agar plates with the required antibiotic. The bacteria solution was distributed on agar plates with a pre-flamed arcuate Pasteur pipette. Then, the plates were incubated at $37^{\circ} \mathrm{C}$ in the incubator Incudrive (Schütt, Göttingen) with the upside down overnight. These plates could be kept at $4{ }^{\circ} \mathrm{C}$ for approximately one month, if sealed with Parafilm ${ }^{\circledR}$ (Brand, Wertheim).

\subsubsection{Cultivation of bacteria in solution}

To generate a bacteria suspension for the mini preparation (see 3.7.5.1), in which the amount of a single bacteria clone can be highly increased overnight, $5 \mathrm{ml}$ of LB medium were supplemented with the needed antibiotic (selection marker) in a $15 \mathrm{ml}$ tube. Then, a picked clone from the agar plate was resuspended in this mixture, followed by a shaking period at $37^{\circ} \mathrm{C}$ on the K2 260 basic shaker for bacteria (Ika, Staufen) at $250 \mathrm{rpm}$ overnight. The tubes (lid not closed completely) were placed on a stand in an angular way to provide a larger surface for oxygen exchange. For the midi-preparation (see 3.7.5.2) $30 \mathrm{ml}$ of LB medium (supplemented with the appropriate antibiotic) was filled in an autoclaved $500 \mathrm{ml}$ glass bottle. Then, $30-80 \mu \mathrm{l}$ of a pre-shaken $5 \mathrm{ml}$ bacteria solution (as described before) was added to the bottle, which then was shaken at $37{ }^{\circ} \mathrm{C}$ overnight with the lid not attached in a tight way. 


\subsubsection{DNA isolation from bacteria}

Plasmid DNA was isolated in two different ways. For the first analysis of new bacteria clones or as starting material for subcloning the mini-preparation method was performed. For later transfection experiments into mammalian cells a larger amount of plasmid DNA (300 - $3000 \mathrm{ng} / \mu \mathrm{l}$ ) with high purity is needed, which can be isolated by plasmid midi-preparation extraction.

\subsubsection{Isolation of Plasmid DNA by chloroform extraction (Plasmid mini-preparation)}

For this procedure, single clones, which were grown on agar plates, were picked and mixed with $5 \mathrm{ml} \mathrm{LB}$-media supplemented with the required antibiotic. This mixture was shaken for 12 - 16 hours at $37^{\circ} \mathrm{C}$. For having an inoculum for further experiments, $5 \mu \mathrm{l}$ of this solution were plated on an agar plate with the required antibiotic. The $5 \mathrm{ml}$ bacteria solution was centrifuged for 10 minutes at $4000 \mathrm{rpm}$ (Centrifuge $5810 \mathrm{R}$; Eppendorf) at room temperature. The supernatant was discarded, then the pellet was resuspended in $250 \mu \mathrm{l}$ of resuspension buffer (see Table 33) and transferred into a 1.5 $\mathrm{ml}$ reaction tube. Thereafter, the cells were lysed with $250 \mu \mathrm{l}$ of Alkaline lysis buffer (Table 34) and shaken well. For the neutralization process, $350 \mu \mathrm{l}$ of Neutralization buffer (Table 35) was added and the sample was inverted 6 to 8 times. The precipitation of proteins was seen as white smear. Then, the sample was centrifuged at $13000 \mathrm{rpm}$ for 10 minutes (Biofuge pico, Heraeus) at $4{ }^{\circ} \mathrm{C}$. The clear supernatant, containing the plasmid DNA, was pipetted into a new $1.5 \mathrm{ml}$ reaction tube and was mixed with $500 \mu \mathrm{l}$ of a chloroform-isoamylalcohol (24:1) solution. The solution was inverted and shaken well, so that no phase boundary could be seen before the next centrifugation step at 13000 rpm for 5 minutes at RT. The upper phase was transferred in a new $1.5 \mathrm{ml}$ reaction tube and $650 \mu \mathrm{l}$ of pre-cooled isopropanol $\left(-20^{\circ} \mathrm{C}\right)$ was added, followed by 15 minutes of centrifugation at $13000 \mathrm{rpm}$ at $4{ }^{\circ} \mathrm{C}$. Thereafter, the supernatant was discarded and the sample was washed with $800 \mu \mathrm{l}$ of $70 \%$ ethanol $\left(-20^{\circ} \mathrm{C}\right)$. Again, a centrifugation step was conducted at $13000 \mathrm{rpm}$ for 4 minutes at $4{ }^{\circ} \mathrm{C}$ and the supernatant was removed, followed by a repeated washing and centrifugation step. Next, supernatant removal was performed, even discarding the last drop, and the opened reaction tube was put on a heating block at $37^{\circ} \mathrm{C}$ till the pellet appeared transparent and dry. Then, $50 \mu \mathrm{l}$ of TE 
buffer (Table 36) was added and the sample was put on a heating block $\left(37^{\circ} \mathrm{C}\right)$ for further 30 minutes, shaking. At the end, DNA was quantified photometrically (see 3.2.3).

Table 33: Resuspension buffer

\begin{tabular}{lc}
\hline Reagent $\left(\mathbf{p H}=\mathbf{8}\right.$, at $^{\mathbf{}}{ }^{\mathbf{C}} \mathbf{)}$ & Concentration \\
\hline Tris-HCl & $50 \mathrm{mM}$ \\
EDTA & $10 \mathrm{mM}$ \\
RNAse A (added after autoclaving process) & $100 \mu \mathrm{g} / \mathrm{ml}$
\end{tabular}

Table 34: Alkaline Lysis buffer

\begin{tabular}{lc}
\hline Reagent $(\mathbf{p H}=\mathbf{8}$, at $\mathbf{R T})$ & Concentration \\
\hline $\mathrm{NaOH}$ & $200 \mathrm{mM}$ \\
$\mathrm{SDS}$ & $1 \%(\mathrm{w} / \mathrm{v})$
\end{tabular}

Table 35: Neutralization buffer

\begin{tabular}{lc}
\hline Reagent $(\mathbf{p H}=\mathbf{5 . 5}$, at $\mathbf{R T})$ & Concentration \\
\hline Potassium acetate & $3 \mathrm{M}$ \\
Table 36: TE buffer & \\
\hline Reagent & Concentration \\
\hline Tris & $10 \mathrm{mM}$ \\
EDTA & $0.1 \mathrm{mM}$
\end{tabular}




\subsubsection{Isolation of plasmid DNA by solid extraction}

\section{(Plasmid midi-preparation)}

The Plasmd midi-preparation was performed via the Plasmid Plus Midi Kit (Qiagen, Hilden) according to the manufacturer's instructions. This DNA, with a high purity, was used for later transfection experiments in mammalian cells.

\subsection{Protein analysis}

\subsubsection{Preparation of cell lysates for Western Blots}

To isolate proteins for Western Blot analysis, pancreatic cancer cells, cultivated in a 6well plate, were trypsinized with $500 \mu \mathrm{l}$ of trypsin per well for $2-3$ minutes at $37^{\circ} \mathrm{C}$. Afterwards, the cell suspension was transferred in a $15 \mathrm{ml}$ falcon tube already containing the doubled amount of DMEM medium (15\% FCS, $1 \%$ PS) for trypsin deactivation and was centrifuged for 5 minutes at $500 \mathrm{~g}$. The supernatant was removed and the cell pellet was washed with $3 \mathrm{ml}$ of PBS. The centrifugation step was performed again, then 50 - $100 \mu$ l of RIPA buffer (supplemented with protease and phosphatase inhibitors, Roche, Mannheim) was added. Afterwards, three repetitions of freeze-thaw cycles in liquid nitrogen and on a heating block at $37^{\circ} \mathrm{C}$, respectively were performed to ensure cell disruption, followed by centrifugation at $13000 \mathrm{rpm}$ for 10 minutes at $4{ }^{\circ} \mathrm{C}$. Finally, the supernatant was transferred into a new reaction tube and was stored at minus $20^{\circ} \mathrm{C}$.

Table 37: RIPA buffer

\begin{tabular}{lc}
\hline Reagent & Concentration [mM] or percentage \\
\hline Tris-HCl & 50 \\
$\mathrm{NaCl}$ & 150 \\
EDTA & 1 \\
NP-40 & $1 \%(\mathrm{v} / \mathrm{v})$ \\
Na-deoxycholate & $0.25 \%(\mathrm{v} / \mathrm{v})$ \\
SDS & $0.1 \%$ \\
\hline
\end{tabular}




\subsubsection{Determination of protein content via Bicinchoninic acid assay}

For quantitation of total protein, the Pierce ${ }^{T M}$ BCA Protein Assay Kit (Life Technologies, Darmstadt) was used. This method is a combination of the reduction of $\mathrm{Cu}^{+2}$ (cupric ion) to $\mathrm{Cu}^{+1}$ (cuprous ion) by protein in an alkaline environment (called biuret reaction) and a highly sensitive and selective colorimetric detection of the cuprous cation $\left(\mathrm{Cu}^{+1}\right)$ by usage of a special reagent comprising bicinchoninic acid. The chelation of two BCA (bicinchoninic acid) molecules with one $\mathrm{Cu}^{1+}$ ion forms a purple, water-soluble reaction product. This complex shows a strong absorbance at $562 \mathrm{~nm}$, which is almost linear with increasing protein concentrations over a working range of $20-2000 \mu \mathrm{g} / \mathrm{ml}$. This assay was performed as follows: First, a BCA working reagent solution was prepared (50 parts of Bicinchoninic acid solution, 1 part of $4 \%$ cupric sulfate solution). Then, $25 \mu$ of a standard solution (standard bovine serum albumin (BSA), range of $0-1500 \mu \mathrm{g} / \mathrm{ml}$ ) or of the sample, as well as $200 \mu \mathrm{l}$ of the BCA working reagent solution was pipetted in each well of a 96-well plate, which was shaken for 30 seconds. Afterwards the plate was incubated for 30 minutes at $37^{\circ} \mathrm{C}$ and the absorbance was measured with a Victor X4 Light Multilabel Reader (PerkinElmer, Wiesbaden) at $562 \mathrm{~nm}$.

\subsubsection{Western Blot}

The Western Blot technique is used for the identification of specific proteins out of a protein mixture, which was extracted from cells. This mixture was applied to gel electrophoresis for protein separation by size. Afterwards, the resulting protein bands were transferred to a membrane, where the proteins were accessible for specific antibody binding for detection. In this thesis siRNA targeted gene knock-down of the WWOX tumor supressor gene was conducted (see chapter 3.10.1) in the two pancreatic cancer cell lines PaTu8988t and L3.6. To evaluate this knock-down, Western Blotting was performed with transfected and control samples.

\subsubsection{SDS-polyacrylamide gel electrophoresis (SDS-PAGE)}

Using SDS-PAGE, proteins can be separated corresponding to their size. For that reason, samples were mixed and denaturated at $95^{\circ} \mathrm{C}$ for 5 minutes in a $4 \mathrm{x}$ Bromphenol Blue loading buffer (NuPage LDS Sample Buffer, 3 parts of loading buffer, 1 part of lysate), containing SDS (amphipathic surfactant), which charges the proteins proportionally to 
their mass. This ensures that the separation step during electrophoresis was solely dependent on the molecular weight. Following to denaturation, samples were put on ice for 5 minutes.

The polyacrylamide gel consists of two parts, a separating and a stacking gel. First, the separating gel was prepared as follows (Table 38):

Table 38: $10 \%$ Separating Gel, mixture for two mini gels

\begin{tabular}{|c|c|}
\hline Reagent & Added Volume \\
\hline $\mathrm{ddH}_{2} \mathrm{O}$ & $7.9 \mathrm{ml}$ \\
\hline $\begin{array}{l}30 \% \text { AB (Acrylamide/Bis-acrylamide) } \\
\text { (Rotiphorese }^{\circledR} \text { ) }\end{array}$ & $6.7 \mathrm{ml}$ \\
\hline Tris (1.5 M, pH = 8.8, separating gel buffer) & $5 \mathrm{ml}$ \\
\hline $10 \%$ SDS Solution & $200 \mu \mathrm{l}$ \\
\hline $10 \%$ APS Solution & $200 \mu \mathrm{l}$ \\
\hline TEMED & $20 \mu \mathrm{l}$ \\
\hline In total & $20 \mathrm{ml}$ \\
\hline
\end{tabular}

The gel was poured into a gel electrophoresis chamber (Biometra, Göttingen) until 1.5 $\mathrm{cm}$ of the chamber top. The rest of the gel chamber was filled up with water. Then, the gel was incubated at RT for 30 minutes till the gel was polymerized. During that time the stacking gel was prepared as follows (Table 39):

Table 39: 5 \% Stacking Gel

\begin{tabular}{lc}
\hline Reagent & Added Volume \\
\hline $\mathrm{ddH}_{2} \mathrm{O}$ & $3.4 \mathrm{ml}$ \\
$30 \% \mathrm{AB}$ (Acrylamide/Bis-acrylamide) & $0.83 \mathrm{ml}$ \\
$\left(\right.$ Rotiphorese $\left.^{\circledR}\right)$ & \\
Tris (1M, pH = 6.8, stacking gel buffer) & $0.63 \mathrm{ml}$ \\
$10 \%$ SDS Solution & $50 \mu \mathrm{l}$ \\
$10 \%$ APS Solution & $50 \mu \mathrm{l}$ \\
TEMED & $5 \mu \mathrm{l}$ \\
\hline In total & $\mathbf{5 ~} \mathbf{~ l}$
\end{tabular}


The water on top of the separating gel was removed and the prepared stacking gel was poured instead, which was incubated for 30 - 40 minutes at RT to polymerize.

\subsubsection{Gel electrophoresis}

The gel was placed into an electrophoresis chamber, which was filled with 1x SDS running buffer (dilution of 10x buffer, see Table 40). Then, 1x SDS buffer was put on top of the gel, to cover the wells of the gel.

Table 40: SDS Running Buffer (10x)

\begin{tabular}{lc}
\hline Reagent $(\mathbf{p H}=\mathbf{8 . 3})$ & Concentration $[\mathbf{m M}]$ or percentage \\
\hline Tris & 250 \\
Glycin & 1920 \\
SDS & $1 \%$ \\
\hline
\end{tabular}

$\mathrm{ddH}_{2} \mathrm{O}$

Ad $1000 \mathrm{ml}$

The wells of the gel were flushed with a syringe shortly before loading. Thereafter, an amount of $20 \mu \mathrm{g}$ of each denaturated sample was loaded on the gel, which was run for 3 - 4 hours at $20 \mathrm{~mA}$. Two different molecular weight marker were used, $1 \mu \mathrm{l}$ of the MagicMark $^{T M}$ XP Western Protein Standard (LifeTechnologies), which is visible upon detection and $2 \mu \mathrm{l}$ of a Prestained Marker (10 - $180 \mathrm{kDa}$, biofroxx), which is visible on the gel and the PVDF membrane.

\subsubsection{Blotting}

To transfer the gel on a blotting membrane (PVDF, polyvinylidene difluoride), the semidry transfer method was used. The gel and the blotting membrane were arranged like a sandwich between filter papers. First, the blotting membrane was activated with methanol (100\%) for 10 seconds, washed with water for 3 minutes and then incubated in 1x transfer buffer (dilution of 10x buffer, see Table 41) for 15 minutes. The transfer buffer is used to facilitate the binding of proteins to the blot. The gel was detached from the gel chamber plates, the stacking gel was cut and then the separating gel was incubated for 15 minutes in transfer buffer as well. 
Table 41: Western Blot Transfer Buffer (10x)

\begin{tabular}{lc}
\hline Reagent & Concentration [mM] \\
\hline Tris & 48 \\
Glycin & 39 \\
$10 \%$ SDS solution & $0.037 \%$ \\
Methanol & $20 \%$ \\
\hline
\end{tabular}

\section{Diluted in $\mathrm{ddH}_{2} \mathrm{O}$}

Six thick Whatman filter papers (for one gel) were also soaked in transfer buffer for 5 to 10 minutes. Then, the gel sandwich arrangement was performed on a Semi-DryElectroblotter (peqlab). First, three soaked filter papers were put on the Electroblotter, then the blotting membrane followed by the gel, was added. Air bubbles under the gel were erased by adding some transfer buffer on top of the gel. The bubbles were pushed by hand to the border of the gel. Three further filter papers (soaked in transfer buffer) were placed on top of the gel. Afterwards, the sandwich-complex was compressed with a little roll. The blotting process was performed at $100 \mathrm{~mA}$ (for one gel) for 1 hour at RT. Following to this, the blotting membrane was cut near the desired kDa number of the protein of interest (WWOX, $46 \mathrm{kDa}$ ) and of the control protein (Actin, $42 \mathrm{kDa}$ ), which can be estimated from the Prestained marker. The cut membrane pieces were washed with TBS-T (0.1\% Tween20, see Table 42 and Table 43 ) for 5 minutes at RT.

Table 42: Tris buffered saline (TBS) Buffer

\begin{tabular}{lc}
\hline Reagent $(\mathbf{p H}=\mathbf{7 . 5})$ & Concentration $[\mathbf{m M}]$ \\
\hline $\mathrm{NaCl}$ & 150 \\
Tris & 50
\end{tabular}

Table 43: TBS-Tween

\begin{tabular}{lc}
\hline Reagent & Concentration \\
\hline Tween20, dissolved in TBS buffer & $0.1 \%$
\end{tabular}




\subsubsection{Blocking}

To avoid unspecific binding of the antibody to the membrane, the membrane pieces with the transferred protein bands were blocked by adding $5 \%$ milk dissolved in TBS-T (0.1\% Tween20, see Table 44$)$ for 1 hour at RT.

Table 44: Blocking Buffer for the Western Blot membrane

\begin{tabular}{lcc}
\hline Reagent & Final concentration & $\mathbf{1 0 0 ~} \mathbf{~ m l}$ \\
\hline Non-fat blotting grade milk & $5 \%$ & $5 \mathrm{~g}$ \\
powder, dissolved in $0.1 \%$ & & \\
TBS-Tween & & \\
\hline
\end{tabular}

\subsubsection{Incubation with antibodies}

After the blocking procedure, 4 - $5 \mathrm{ml}$ of the primary antibody (see Table 45), diluted for actin in $5 \%$ milk-TBST (1:4000) and for WWOX in $5 \%$ BSA-TBST (1:200), were added to the blot overnight at $4{ }^{\circ} \mathrm{C}$.

Table 45: First Antibody Information

\begin{tabular}{c|c|ccccc}
\hline Membrane & Antibody & Host & Company & $\begin{array}{c}\text { Protein } \\
\text { size }\end{array}$ & Dilution & Buffer \\
\hline A & WWoX & goat & Santa Cruz & 46 & $1: 200$ & $5 \%$ \\
& $\begin{array}{c}\text { (N-19): } \\
\text { sc-20528 }\end{array}$ & & & & & $\begin{array}{r}\text { BSA- } \\
\text { TBST }\end{array}$ \\
\hline B & Actin & rabbit & Acris & 42 & $1: 4000$ & $5 \%$ \\
(For normalization) & & & & & & $\begin{array}{c}\text { milk- } \\
\text { TBST }\end{array}$ \\
\hline
\end{tabular}

On the next day, the membranes were washed three times for 5 minutes with TBST (0.1\% Tween 20$)$ and the second antibody (Table 46), diluted in $5 \%$ milk-TBST, was added ( 2 - 3ml) for 2 hours shaking at RT. Afterwards, the blot was washed three times with TBST (0.1\% Tween20) again. 
Table 46: Second Antibody Information

\begin{tabular}{c|c|cccc}
\hline Membrane & Antibody & Host & Company & Dilution & Buffer \\
\hline A & $\begin{array}{c}\text { Anti-goat IgG } \\
\text { HRP } \\
\text { (Horseradish } \\
\text { peroxidase) }\end{array}$ & rabbit & Acris & $1: 30000$ & $5 \%$ milk- \\
TBST & & & \\
\hline B & $\begin{array}{c}\text { Anti-rabbit IgG } \\
\text { HRP } \\
\text { (For normalization) }\end{array}$ & goat & Acris & $1: 30000$ & $5 \%$ milk- \\
& peroxidase) & & & & TBST \\
\hline
\end{tabular}

\subsubsection{Detection with HRP substrate}

The HRP (Horseradish peroxidase), contained in the second antibody, can be detected by an enhanced chemiluminescent solution (ECL, Luminata ${ }^{T M}$ Forte Western HRP Substrate, MerckMillipore, Darmstadt). The membranes were covered with the ECL solution and were placed in a Luminescent Image Analyzer (Image Quant ${ }^{T M}$ LAS 4000 Mini). The chemiluminescent signals were determined with the corresponding Image Quant LAS 4000 Mini Control software v1.2.

\subsubsection{In vitro translation via TNT Assay}

Using the in vitro TNT ${ }^{\circledR}$ Coupled Transcription/Translation System (Promega, Mannheim) allows analysis of protein expression without using cells. The delivered master mix contains all essential components like RNA polymerase, nucleotides, salts, ribonucleotide inhibitor and reticilocyte-solution to generate complex proteins, based on plasmid DNA. Used plasmid DNA requires a T7 promoter located upstream of the expressed gene. For information about the used pcDNA5:RRM2:eGFP construct see section 3.5.3.

The reaction mixture was pipetted on ice as described in Table 47, followed by an incubation time of 90 minutes at $30^{\circ} \mathrm{C}$. Thereafter, the reaction was stopped on ice and was diluted (1:2) with $\mathrm{ddH}_{2} 0$. These mixtures $(100 \mu \mathrm{l})$ were transferred into a black 96well plate with a transparent bottom (Greiner, Frickenhausen) for fluorescence measurement (of eGFP) with the Tecan reader (excitation $485 \mathrm{~nm}$, emission $535 \mathrm{~nm}$ ). 


\begin{tabular}{|c|c|}
\hline Reagent & Added volume $[\mu \mathrm{l}]$ \\
\hline TNT $^{\circledR}$ T7 Quick Master Mix & 40 \\
\hline Methionin [1mM] & 2 \\
\hline Plasmid-DNA $[0.5 \mu \mathrm{g} / \mu \mathrm{l}]$ & 2 \\
\hline T7 TNT ${ }^{\circledR}$ PCR Enhancer & 1 \\
\hline
\end{tabular}

$\mathrm{ddH}_{2} \mathrm{O}$

Add to 50

\subsection{Mammalian cell culturing}

All cell culture work was performed under the sterile bench. The used cell lines were cultured in an incubator at $37{ }^{\circ} \mathrm{C}$ under $5 \% \mathrm{CO}_{2}$ and $95 \%$ humidity. To avoid microbial contamination and to check the growth status, all cells were controlled via microscope (Microscope TELAVAL 31, Zeiss, Jena) regularly. The culture media was pre-warmed at $37{ }^{\circ} \mathrm{C}$ before use and was supplemented with $1 \%$ Penicillin-Streptomycin (PS) to prevent bacterial contamination. Besides, fetal calf serum (FCS) was added, which contains proteins that are necessary for cell growth. The subculturing of cells was performed twice a week in a cell specific split ratio, which was dependent on the proliferation rate and the specific conditions needed for the experiments. The general cell number for suspension cells should be between $3 \times 10^{5}-8 \times 10^{5}$ cells per milliliter of media. Adherent cells should not exceed a confluence of $80 \%$. For detaching adherent cells from the culture flask bottom, these were washed with PBS buffer (see Table 48) and were trypsinized with $5 \mathrm{ml}$ of trypsin (TrypLE ${ }^{\mathrm{TM}}$ Express, Gibco/Invitrogen) for a 75 $\mathrm{cm}^{2}$ flask and $3 \mathrm{ml}$ of trypsin for a $25 \mathrm{~cm}^{2}$ flask, followed by an incubation time of approximately 3 minutes at $37^{\circ} \mathrm{C}$. For the deactivation of trypsin, the doubled volume of culture media (supplemented with FCS) was added. Afterwards, the cells were transferred to a $50 \mathrm{ml}$ falcon tube and centrifuged at $500 \mathrm{~g}$ for 5 minutes at room temperature. The supernatant was removed and the pellet was resuspended in culture media. Then, cell counting was conducted (see section 3.9.3) and the required volume was seeded on plates and/or transferred into a new cell culture flask for subculturing. 


\begin{tabular}{lc}
\hline Reagent $(\mathbf{p H}=\mathbf{7 . 4})$ & Concentration [mM] \\
\hline $\mathrm{NaCl}$ & 128.5 \\
$\mathrm{KCl}$ & 2.8 \\
$\mathrm{Na}_{2} \mathrm{HPO}_{4}$ & 8.1 \\
$\mathrm{KH}_{2} \mathrm{PO}_{4}$ & 1.5 \\
\hline
\end{tabular}

\subsubsection{Freezing cultured cells}

For long-time preservation of cells for later studies, cell lines were stored in liquid nitrogen. It is advised to cryopreserve cells with a low passage number and when a confluence of $80 \%$ is reached. The cells were harvested and transferred into a $50 \mathrm{ml}$ falcon tube, followed by centrifugation at $500 \mathrm{~g}$ for 5 minutes at RT. The supernatant was removed and the pellet was resuspended in $7.5 \mathrm{ml}$ of a pre-cooled freezing solution, consisting of $90 \%$ pure FCS and $10 \%$ of sterile DMSO (Dimethylsulfoxide, AppliChem, Darmstadt). DMSO is used as antifreezing agent, which prohibits the generation of ice crystals, which can lead to cell death. Further steps were performed on ice. Afterwards, the cells $(1.5 \mathrm{ml})$ were pipetted in $1.8 \mathrm{ml}$ Cryo tubes (Nunc, Thermo Scientific, Denmark) and were stored in a pre-cooled Mr. Frosty freezing box (Sigma-Aldrich, Deisenhofen) at $-80{ }^{\circ} \mathrm{C}$ overnight, allowing cells to cool down with a speed of $1{ }^{\circ} \mathrm{C} / \mathrm{min}$. The next day, the frozen cells were transferred into a liquid nitrogen storage container at around $-170{ }^{\circ} \mathrm{C}$.

\subsubsection{Defreezing cultured cells}

Cryopreserved cell lines that were stored in liquid nitrogen were thawed quickly and transferred into a $50 \mathrm{ml}$ falcon tube for centrifugation ( 5 minutes, $500 \mathrm{~g}$, RT), which already contained $20 \mathrm{ml}$ of cell culture media (1\% PS). It is important to relieve the cells from the toxic DMSO. Afterwards, the supernatant was removed, the pellet was resuspended in $10 \mathrm{ml}$ of media (1\% PS, 10 - 15 \% FCS (depending on the cell line)) and the cell suspension was pipetted into a $25 \mathrm{~cm}^{2}$ Tissue Culture Flask. After a cultivation time of 1 - 2 days at $37^{\circ} \mathrm{C}$ and $5 \% \mathrm{CO}_{2}$, cells were transferred to a $75 \mathrm{~cm}^{2}$ flask $(20 \mathrm{ml})$ for increased growth. 


\subsubsection{Counting cells with the Neubauer-Cell Chamber}

The number of cells in a cell suspension was determined via Neubauer-Cell Chamber. To distinguish between living and dead cells, the cell suspension was mixed with the vital stain Trypan Blue (Sigma-Aldrich, Deisenhofen) in a ratio of 1:1. Afterwards, $15 \mu \mathrm{l}$ of the staining solution were pipetted on the counting chamber, which was covered with a cover slip. Living cells do not absorbe Trypan Blue, while dead cells do. Via microscopy the living cells appear in a more bright colour, in comparison to the blue background media and the dead cells. All living cells in each of four squares were counted. The cell concentration per ml was calculated as follows (see Equation 3):

Equation 3: Calculation of cell concentration per milliliter

Cell concentration $/ \mathrm{ml}=\underline{\text { Sum of all living cells in all four squares } * 2 * 1000}$

$4 * 0.1 \mu \mathrm{l} /$ square

Cell concentration $/ \mathrm{ml}=$ Sum of all living cells in all four squares * 5000

The average of all four squares is calculated at first. The dilution factor of the cell suspension, which was 2 , has to be considered. The area of each square is $1 \mathrm{~mm}^{2}$ and the chamber hight is $0.1 \mathrm{~mm}$. This results in a volume of $0.1 \mu \mathrm{l} / \mathrm{square}$. To sustain the concentration of cells per milliliter, a factor of 1000 has to be included into the equation.

\subsubsection{Lymphoblastoid cell lines}

The lymphoblastoid cell lines (LCLs), which are donated by Britain Caucasian, are non adherent cells, which were obtained from the NIGMS Human Genetic Cell Repository at the Coriell Institute for Medical Research. These were established by Epstein-Barr Virus transformation of peripheral blood mononuclear cells using phytohemagglutinin as a mitogen. All cell lines are free of bacterial, fungal or mycoplasma contamination. Cultivation of these cells was carried out in $75 \mathrm{~cm}^{2}$ Tissue Culture Flasks. The used media was RPMI media (2 mM L-glutamine, $15 \%$ FCS, $1 \%$ PS). The passaging of cells was performed twice a week at a ratio of 1:7. For experiments only cells with a passage number $<10$ were used. All LCLs from Coriell Cell Repositories, I used as an ethnically homogenous sample set, are listed in Table 49. 
Table 49: ID numbers of lymphoblastoid cell lines from Coriell Cell Repositories (http://ccr.coriell.org).

\begin{tabular}{|l|l|l|l|l|l|l|l|l|}
\hline HG00096 & HG00097 & HG00099 & HG00100 & HG00101 & HG00102 & HG00103 & HG00104 & HG00106 \\
\hline HG00108 & HG00109 & HG00110 & HG00111 & HG00112 & HG00113 & HG00114 & HG00116 & HG00117 \\
\hline HG00118 & HG00119 & HG00120 & HG00121 & HG00122 & HG00123 & HG00124 & HG00125 & HG00126 \\
\hline HG00127 & HG00128 & HG00129 & HG00130 & HG00131 & HG00133 & HG00134 & HG00135 & HG00136 \\
\hline HG00137 & HG00138 & HG00139 & HG00140 & HG00141 & HG00142 & HG00143 & HG00146 & HG00148 \\
\hline HG00149 & HG00150 & HG00151 & HG00152 & HG00154 & HG00155 & HG00156 & HG00158 & HG00159 \\
\hline HG00160 & HG00231 & HG00232 & HG00233 & HG00234 & HG00235 & HG00236 & HG00237 & HG00238 \\
\hline HG00239 & HG00240 & HG00242 & HG00243 & HG00244 & HG00245 & HG00246 & HG00247 & HG00249 \\
\hline HG00250 & HG00251 & HG00252 & HG00253 & HG00254 & HG00255 & HG00256 & HG00257 & HG00258 \\
\hline HG00259 & HG00260 & HG00261 & HG00262 & HG00263 & HG00264 & HG00265 & HG01334 &
\end{tabular}

\subsubsection{Pancreatic cancer cell lines}

Pancreatic cancer cell lines I used for experiments during my PhD program were MiaPaca-II, AsPC1, CFPac, L3.6, PaTu8988t and PancI. These cell lines were purchased from the ATCC company (Wesel, www.atcc.org). The cultivation of these cells was performed according to their recommendation (http://www.lgcstandards-atcc.org). The split ratio was 1:8.

\subsubsection{HEK-293 cells}

HEK-239 cells are human embryonic kidney cells which grow in an adherent manner and were cultivated in DMEM media supplemented with $10 \%$ FCS and $1 \%$ PS. The passaging was performed at a ratio of 1:10.

\subsubsection{PaTu8988t cells stably transfected with shRNA plasmids against WWOX}

The pancreatic cancer cell line PaTu8988t was stably transfected with SureSilencing shRNA plasmids (linearized pGeneClip ${ }^{\mathrm{TM}}$ Hygromycin Vector with specific sequences targeting WWOX, Qiagen, Hilden, see 3.10.2). The used culture media was DMEM supplemented with $10 \%$ FCS, $1 \%$ PS and $100 \mu \mathrm{g} / \mathrm{ml}$ Hygromycin B. The passaging was performed at a ratio of 1:8. 


\subsection{Transfection of mammalian cells}

The transfection process allows the injection of plasmid DNA into cells for overexpression or knock-down reason of genes. In this work the liposome transfection method was used, where a positively charged lipid reagent surrounds the negatively charged plasmid DNA and forms an aggregate, which can permeate the cell membrane. Inside the nucleus the inserted DNA is then released and can be expressed. Two different transfection ways were conducted. Performing a transient transfection implies that the DNA is not inserted into the nuclear genome, and therefore is just temporarily expressed. Stably transfected cells exhibit persistence of the inserted gene in the genome of the cell and their daughter cells. For transient overexpression of genes, the $X$ tremeGene HP DNA Transfection Reagent (Roche, Mannheim) was used. Transient transfection of siRNA (small interfering RNA) used for gene silencing was performed by usage of RNAiMAX Transfection reagent (Invitrogen, Karlsruhe). For the stable gene knock-down via shRNA (short-hairpin RNA) the Attractene Transfection reagent (Qiagen, Hilden) was employed.

\subsubsection{Transient WWOX knock-down by siRNA}

The pancreatic cancer cell lines L3.6 and PaTu8988t were used to assess the consequences of targeted WWOX knock-down by transient siRNA (20 - 25 bp long, doublestranded) transfection. SiRNA can affect the expression of genes, with a complementary nucleotide sequence, by cracking the mRNA after transcription, so that translation is impaired. The transfection was carried out on six-well plates, three wells per condition, in a fast-forward fashion. First, the cells were freshly seeded at a density of 250,000 cells/2 ml in DMEM medium (10\% FCS) without Penicillin-Streptomycin. The transfection mixture, containing 30 pmol of a predesigned panel of four siRNAs to target WWOX (Dharmacon/GE Healthcare Cat-№ M-003961-03-0005, Lafayette, CO, USA), OptimMem ${ }^{\circledR}$ medium and the transfection reagent RNAiMAX (both from Invitrogen, Karlsruhe) was prepared as listed in Table 50 and incubated for 20 minutes at RT. Thereafter, $500 \mu \mathrm{l}$ of the mixture was added in a dropwise manner per well. A scrambled panel of siRNAs (ON-TARGETplus Non-targeting siRNA \#1, Dharmacon Cat№ D-001810-01) was transfected the same way serving as negative control. After transfection, the cells were cultured for $24 \mathrm{~h}$ at $37^{\circ} \mathrm{C}$ before being treated with gemcitabine or 5-FU (see chapter 3.10.4). 
Table 50: siRNA transfection mixture

\begin{tabular}{lc}
\hline Reagent & Volume $[\boldsymbol{\mu l}]$ per well \\
\hline OptiMem ${ }^{\circledR}$ & 500 \\
SiRNA & $1.5(20 \mu \mathrm{M}$ stock $)$ \\
Lipofectamine ${ }^{\circledR}$ RNAiMAX & 5 \\
\hline
\end{tabular}

\subsubsection{Stable WWOX knock-down by shRNA}

Another technique for WWOX gene knock-down is plasmid-based RNA interference, where plasmids carrying a shRNA (short-hairpin RNA, artificial RNA that exhibts a tight hairpin turn) are stably transfected into cells. For this purpose, I used the SureSilencing shRNA Plasmid Kit from Qiagen (Hilden), containing four gene-specific shRNA plasmids and one negative control plasmid (21 bp long). The Kit used the pGeneClip ${ }^{\mathrm{TM}}$ vector (4989 bp, obtained from Promega Corporation, Madison, WI, see Figure 11, for sequence see appendix), which expresses a shRNA under control of the U1 promoter and the hygromycin resistance gene. The selection of stably transfected cells is allowed due to the hygromycin resistance.

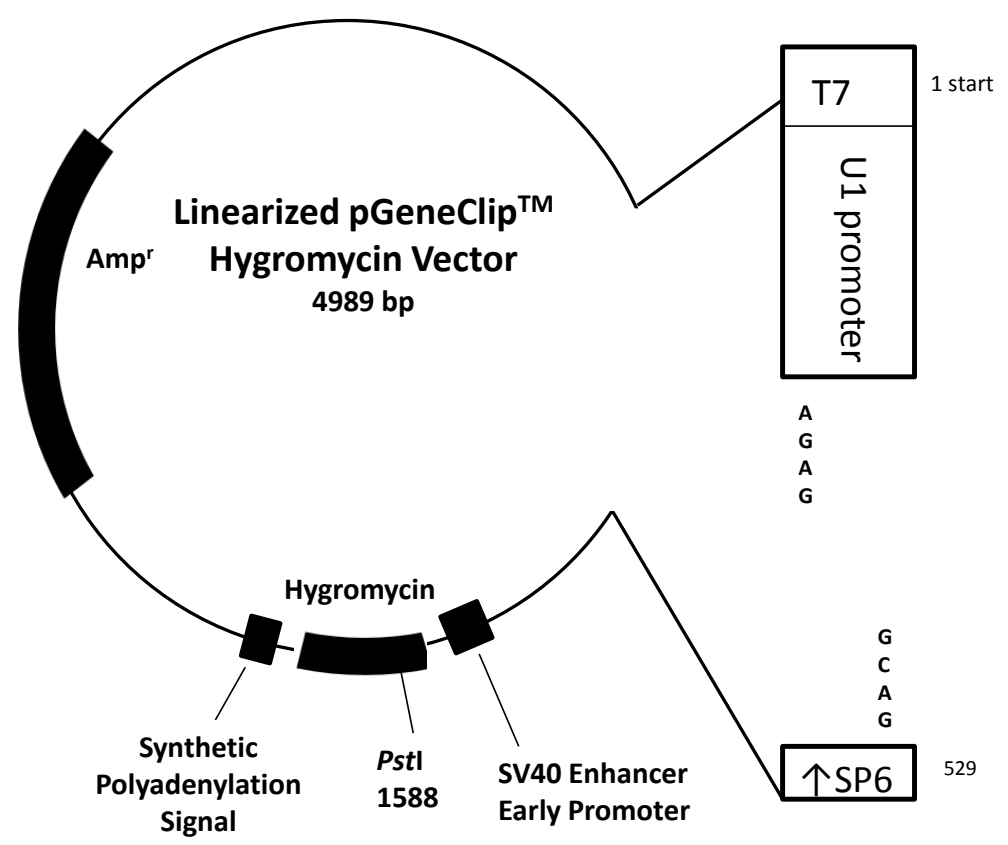

Figure 11: Scheme of the pGeneClipTM Hygomycin Vector. Modified according to SureSilencing ShRNA Plasmid Handbook, Qiagen)

The specific shRNA sequences (see Table 51) are inserted between position 438 and 439 of the plasmid sequence. 


\begin{tabular}{ll}
\hline Clone ID & Insert Sequence \\
\hline $\mathbf{1}$ & AGTGCATCCTGGAAATATGAT \\
$\mathbf{2}$ & GAGACCACCTTTCAAGTGAAT \\
$\mathbf{3}$ & CAGCACCACTGCCATGGAAAT \\
$\mathbf{4}$ & GTGAAGCAGTGTCACGCATTT \\
Negative control & GGAATCTCATTCAATGCATAC \\
\hline
\end{tabular}

First, the delivered shRNA plasmids were transformed into E. coli via electroporation (see section 3.7.2), then the bacteria solution was distributed on agar plates containing ampicillin as selection marker. The next day, clones were picked and single clone culturing was performed, followed by the isolation of plasmid DNA via mini-preparation (see section 3.7.5.1). For qualitiy control, a successful Pst restriction enzyme digestion was conducted. Thereafter, midi-preparation (see section 3.7.5.2) was performed.

Next, the appropriate hygromycin B concentration (for selection process) had to be identified by testing of seven different concentrations $(0,100,200,400,600,800$ and $1000 \mu \mathrm{g} / \mathrm{ml}$ ). For this, PaTu8988t cells were plated at a density of 5000 cells/ml (24well plate), cultured at $37{ }^{\circ} \mathrm{C}$ at $5 \% \mathrm{CO}_{2}$ till a confluence of $<10 \%$ was reached, before being exposed to hygromycin $\mathrm{B}$. When the "0" concentration point reached confluence, the medium containing hygromycin B was changed every two days till confluence was seen. Then, cell viability analysis of these cells (in quadruplicates), referred to a drugfree condition, was conducted via PrestoBlue ${ }^{\circledR}$ staining and fluorescence measurement with the Tecan reader (see 3.10.4). For an increased likelihood of integration and a shorter time to get stable transfectants, the plasmid was linearized with the enzyme BsaI-HF (see 3.2.9.2).

Then, the shRNA plasmids were transfected into the cells. For this purpose, $59.5 \mu \mathrm{l}$ of OptiMem ${ }^{\circledR}$ medium were dispensed into a 24 -well plate. Afterwards, $0.4 \mu \mathrm{g}$ of the shRNA plasmids was added per well and mixed by gently rocking the plate for several times, before adding $3 \mu \mathrm{l}$ of the Attractene Transfection Reagent (Qiagen, Hilden) per well. Again, the plate was shaken for some time. Then, the plate was incubated for 15 minutes at RT to allow the formation of the transfection complex. During that time, cells were prepared by washing twice with PBS, trypsinization with $150 \mu \mathrm{l}$ of trypsin and cell harvesting by centrifugation at $500 \mathrm{~g}$ for 5 minutes in a falcon already containing $300 \mu \mathrm{l}$ 
of DMEM medium. Afterwards, the pellet was washed once with medium by resuspension and recentrifugation. Then, the pellet was resuspended in fresh growth medium (10 \% FCS, $1 \%$ PS). After cell counting, 125,000 cells/500 $\mu$ l were added to the well containing the Attractene-plasmid-complexes, when 15 minutes of transfection complex formation were over. Moreover, untransfected cells were seeded on the same plate to have another control. Again, the plate was mixes gently by rocking back and forth and was incubated at $37^{\circ} \mathrm{C}$ for 48 hours.

Thereafter, cells were harvested as described before and 2500 cells/500 $\mu$ l $(<10 \%$ confluence) were seeded again on a 24 -well plate, 4 wells per condition in DMEM medium without hygromycin B. Cell growing without hygromycin B was carried out for 5 hours, before the effective hygromycin B concentration was added again. The hygromycin medium was renewed every 2 - 3 days for a time range of 7 days. Afterwards no hygromycin was added anymore till cell growing was seen. Then, hygromycin B was supplemented again, but in a reduced concentration of $100 \mu \mathrm{g} / \mathrm{ml}$. The grown single clones were picked with a $10 \mu$ pipette tip by pipetting $5 \mu$ l of DMEM medium 5 - 6 times on the place of clone growing. The pipetted volume was transferred into a 12-well plate, filled with $500 \mu \mathrm{l}$ of DMEM medium (supplemented with $100 \mu \mathrm{g} / \mathrm{ml}$ of hygromycin B). Again, cell cultivation was performed, till clones were seen and transferred to a new 24-well plate. When $50 \%$ of confluence was reached, cells were trypsinized and pipetted first into a $25 \mathrm{~cm}^{2}$ cell culture flask with $5 \mathrm{ml}$ of DMEM medium, containing $100 \mu \mathrm{g} / \mathrm{ml}$ of hygromycin $\mathrm{B}$, followed by a later transfer into a 75 $\mathrm{cm}^{2}$ culture flask comprising hygromycin medium as well.

Finally, gemcitabine sensitivity (10 - $1000 \mathrm{nM})$ was tested for this stably shRNAtransfected cells, according to the Viability Assay described in section 3.10.4.

\subsubsection{Transient overexpression of genes}

Pancreatic cancer and HEK-293 cells were plated at a density of $2 \times 10^{5}-4 \times 10^{5}$ cells $/ 2 \mathrm{ml}$ (depending on the cell line and the purpose) on a six-well plate (three wells per condition) and were cultured at $37{ }^{\circ} \mathrm{C}$ and $5 \% \mathrm{CO}_{2}$ till a confluence of $80 \%$ was reached. In this work following plasmids were transfected into cells: pcDNA3-SP1 and pcDNA3-WWOX.

The transient transfection was performed as follows: First, $200 \mu \mathrm{l}$ of DMEM medium 
(without FCS and PS) were mixed with $3.6 \mu \mathrm{g}$ of plasmid DNA. Then $10.8 \mu \mathrm{l}$ (Ratio 1:3, $\mu \mathrm{g}$ DNA : $\mu$ l transfection reagent) of the $X$-tremeGene Transfection Reagent was added and mixed carefully. This mixture was incubated for 15 minutes at RT. During that time the culture medium of the wells was renewed (without PS). Finally, $200 \mu \mathrm{l}$ of the transfection mixture was added in a dropwise manner and the plate was shaken slightly and incubated for four hours at $37{ }^{\circ} \mathrm{C}$ and $5 \% \mathrm{CO}_{2}$. Next, the readout of the transfection procedure was performed. Cells, overexpressed with pcDNA3-WWOX were exposed to gemcitabine as follows: After the mentioned four hours, cells were harvested and transferred into a $50 \mathrm{ml}$ falcon tube, which already contained $12 \mathrm{ml}$ of DMEM medium, followed by centrifugation at $500 \mathrm{~g}$ for 5 minutes. Then, supernatant removal was conducted and the pellet was resuspended in $700 \mu \mathrm{l}$ of media. After cell counting, cells (3000 cells $/ 100 \mu \mathrm{l}$ ) were seeded on a black 96-well plate with a transparent bottom (Greiner, Frickenhausen) and were cultured for 24 hours $\left(37^{\circ} \mathrm{C}, 5 \% \mathrm{CO}_{2}\right)$, before being treated with gemcitabine in quadruplicates. After further 72 hours, cell viability was analyzed via PrestoBlue ${ }^{\circledR}$ staining (see section 3.10.4).

In case of SP1-transfection, four hours after transfection, transfected wells were pooled in the doubled amount of cell culture medium, centrifuged (500 g, 5 minutes) and resuspended in $12.5 \mathrm{ml}$ of medium. Afterwards, $1 \mathrm{ml}$ of this suspension was plated per well of a 12-well plate. Then, 48 hours after transfection, cells were treated with gemcitabine, 5-FU or irinotecan in duplicates. After further 24 hours, RNA samples were collected (3.6.1), which were used for future expression analysis (see Methods sections 3.6.3 and 3.6.4.)

\subsubsection{Viability Assay of cytostatic-treated cells}

To assess gemcitabine and 5-FU sensitivity of cells with RNAi-mediated WWOX knockdown (see 3.10.1, 3.10.2) or WWOX overexpression (see 3.10.3) cell viability testing was performed. Therefore, cells were trypsinized 24 hours after transfection and were seeded at a density of 3,000 cells $/ 100 \mu \mathrm{l}$ on a black 96 -well plate with a transparent bottom (Greiner, Frickenhausen). Afterwards, gemcitabine or 5-FU was applied on the 96-well plate at ten concentrations (for each cell line concentration ranges tested in concentration tests before, but identical distances on a $\log _{10}$-scale, for gemcitabine from 10 to $1000 \mathrm{nM}$ for PaTu8988t and from 4 to $400 \mathrm{nM}$ for L3.6; for 5-FU 250 - $50000 \mathrm{nM}$ for both cell lines) and referred to a drug-free condition, each in quadruplicates. Upon a 
further incubation time of $72 \mathrm{~h}$ at $37{ }^{\circ} \mathrm{C}$ and $5 \% \mathrm{CO}_{2}$ the resazurin-based PrestoBlue ${ }^{\circledR}$ Cell Viability reagent (Invitrogen, Karlsruhe) was added and fluorescence signals (excitation $485 \mathrm{~nm}$, emission $612 \mathrm{~nm}$ ) were recorded after 4 hours. Viable cells are able to reduce the blue resazurin to the red-fluorescent resorufin. The measured fluorescent signal is proportional to the number of metabolically active cells, allowing quantification. The read out was conducted with the Tecan Ultra Plate reader (Tecan, Crailshaim, excitation $485 \mathrm{~nm}$, emission $612 \mathrm{~nm}$ ).

In addition, transfected cells were incubated for further $48 \mathrm{~h}$ on a 6 -well plate (referred to the time point when cells were removed from the six-well plate $24 \mathrm{~h}$ after transfection) to evaluate WWOX knock-down on protein level (3.8.3).

\subsection{Sensitivity of lymphoblastoid cells toward gemcitabine}

Using a genome-wide approach, comprising 89 fully sequenced lymphoblastoid cell lines (LCLs, see section 3.9.4), individual cell line's sensitivity toward gemcitabine was assessed. Dose-effect curves for gemcitabine treatment were established and $\mathrm{EC}_{50}$ (half maximal effective concentration) values were calculated and correlated in relation to the cell vitality. The inhibition of cell proliferation was used as toxicity readout, which was ascertained by Carboxyfluorescein succinimidyl ester (CFSE, eBioscience, Frankfurt) staining, measured by flow cytometry. Gemcitabine was used at concentrations of $0,1.9$, $3.8,6.4,10.8,18.1,30.4$, and $76.0 \mathrm{nM}$. This chosen concentration range was based on a test phase, performed by a former student in our lab, Dr. rer. nat. Sebastian Roppel, who executed this experiment for a another set of 111 LCLs.

First of all, the cell lines were cultured in $75 \mathrm{~cm}^{2}$ culture flasks in a volume of $50 \mathrm{ml}$ RPMI medium (supplemented with $15 \%$ of FCS, $1 \%$ PS, flask stored in a vertical way) to get a sufficient number of cells for the experiment (for cell counting see section 3.11.1). Per week, around 8 - 14 cell lines were analyzed in parallel. The cell concentration was kept between $3 \times 10^{6}$ and $6 \times 10^{6}$ cells per milliliter, to allow logarithmic growth. Besides, $30 \%$ of the cell lines were measured twice, to exclude unreliable results. Prior to the gemcitabine treatment, the cells were stained with CFSE (see section 3.11.2), which dilutes with each cell division allowing to assess the effect of gemcitabine on the inhibition of cell proliferation. After the CFSE staining procedure cells were incubated at $37{ }^{\circ} \mathrm{C}$ and $5 \% \mathrm{CO}_{2}$ for $24 \mathrm{~h}$, prior to plating of 100,000 cells $/ \mathrm{ml}$ per well, in duplicate for 
each concentration, on a 24-well plate and the exposure to gemcitabine at the concentrations mentioned above. The treated cells were incubated for $72 \mathrm{~h}$ at $37^{\circ} \mathrm{C}$ and $5 \% \mathrm{CO}_{2}$, before the analysis via flow cytometry (see 3.11.3, 3.11.4) with excitation at $485 \mathrm{~nm}$ and emission at $517 \mathrm{~nm}$ was performed. PBS treated LCL control samples (in duplicate) were incubated for 48 hours, before being measured by flow cytometry. These control samples were needed to calculate the proliferation index by comparing these results of the control samples with those control samples measured after 72 hours. In addition, LCLs were seeded on 6 well plates, treated with PBS (Control) and the gemcitabine concentrations $3.8 \mathrm{nM}$ and $30.4 \mathrm{nM}$ (three wells per condition, $3 \mathrm{ml}$ per well) for DNA and RNA collection. After 24 hours three wells were pooled for each concentration, and the suspension was divided up into two 5 ml FACS tubes (BD Falcon), which were processed as described in chapter 3.2.1 and 3.6.1 dealing with DNA and RNA isolation, respectively.

The whole procedure was divided up into several parts as described before, which were conducted as follows:

\subsubsection{Counting cells via flow cytometer}

For counting cells, $150 \mu \mathrm{l}$ of the well resuspended cell suspension (out of the $50 \mathrm{ml}$ in the flask) were pipetted into $5 \mathrm{ml}$ Falcon tubes. Afterwards, a special staining solution containing Sytox Blue and Vybrant ${ }^{\circledR}$ DyeCycle ${ }^{T M}$ Ruby stain (both Life Technologies Corporation, Darmstadt) was prepared, which stains living and dead cells. Both dyes incorporate into the DNA of cells and can be detected via measurement of fluorescence. The Vybrant Ruby stains dead and living cells, whereas Sytox Blue merely represents a dead cell stain. This cell dyeing allows the differentiation of living cells from dead cells and cell debris by flow cytometry. To provide a consistent cell counting system, the number of cells per sample was determined by addition of CountBright ${ }^{T M}$ Absolute Counting Beads (Invitrogen, Karlsruhe). The ratio of bead events (adjusted to 2500 beads) was compared to the ratio of cell events (adjusted to 100,000 events), which leads to the absolute number of cells per sample. The staining mixture per sample was composed as follows (Table 52): 
Table 52: Mixture for vitality staining

\begin{tabular}{lc}
\hline Reagent & Volume per sample [ $\boldsymbol{\mu l}]$ \\
\hline RPMI medium $(15 \%$ FCS, 1 \% PS) & 150 \\
Sytox Blue stain & $0.3(1: 1000)$ \\
Vybrant Ruby stain & $0.15(1: 2000)$ \\
Counting Beads & 10 \\
\hline
\end{tabular}

Then, $160 \mu \mathrm{l}$ of the vitality staining solution was added to $150 \mu \mathrm{l}$ of cell suspension and was mixed well, followed by 15 minutes of incubation at $37^{\circ} \mathrm{C}$. Afterwards, cell counting was conducted with the Flow Cytometer BD LSRII (Becton Dickinson). The cell number determination by counting beads was performed according to manufacturer's instruction and the cell concentration was calculated with the following Equation 4:

Equation 4: Calculation of the cell concentration in a cell suspension containing counting beads.

Counted cells $x$ total number of beads in the solution $x$ dilution factor

Counted beads $x$ total volume of sample (cell suspension and volume of beads)

\subsubsection{CFSE staining of LCLs for proliferation analysis}

To assess the inhibition of cell proliferation, induced by gemcitabine, LCLs were loaded with CFSE (Carboxyfluorescein succinimidyl ester) stain. After cell division of these cells, the progeny contains half of the number of CFSE-tagged molecules. Therefore each cell division can be determined by measuring the corresponding decrease in cell fluorescence via flow cytometry. The diacetylated non-fluorescent CFDA, SE form (Carboxyfluorescein diacetate succinimidyl ester) can easily cross intact cell membranes. Esterases, which are present inside the cell, cleave the acetates. The deacetylated form is fluorescent and covalently binds to intracellular amines, so that fluorescent CFSE stays within the cell.

Prior to CFSE staining, the cells were counted (see chapter 3.11.1) and adjusted to the appropriate volume for $15 \times 10^{6}$ LCLs. The cell suspension was centrifuged at $250 \mathrm{~g}$ for 7 minutes at RT. Afterwards, the supernatant was discarded and the pellet was resuspended in $500 \mu \mathrm{l}$ of PBS. Then, $500 \mu \mathrm{l}$ of the staining solution, consisting of $40 \mu \mathrm{M}$ 
CFSE in PBS (550 $\mu$ l PBS mixed with $2.2 \mu \mathrm{l}$ of CFSE), was added and vortexed gently at $1400 \mathrm{rpm}$ for 5 seconds, before this cell suspension was transferred directly to $37^{\circ} \mathrm{C}$ for 2 minutes and 30 seconds. Immediately afterwards, the staining process was stopped with $10 \mathrm{ml}$ of ice-cold cell culture medium (RPMI medium supplemented with $15 \%$ FCS, $1 \%$ PS) in complete darkness for 5 min on ice. Again centrifugation and supernatant removal was performed under the same conditions as before, followed by resuspension of the pellet in $25 \mathrm{ml}$ of warm cell culture medium. Thereafter, the cell suspension was transferred into a new cell culture flask, which was incubated at $37{ }^{\circ} \mathrm{C}$ and $5 \% \mathrm{CO}_{2}$ for $24 \mathrm{~h}$.

\subsubsection{Flow cytometry preparation}

After an incubation time of 72 hours, cells were harvested by mixing the well, pipetting in circles. Then, a defined suspension volume (see Table 53) was transferred into $5 \mathrm{ml}$ FACS tubes. Due to different cell growth behaviour upon different gemcitabine concentrations and the need for similar cell numbers for the following staining procedure, an adjustment of the cell number was performed by pipetting different volumes.

Table 53: Volume of gemcitabine treated samples measured by flow cytometry

\begin{tabular}{c|c}
\hline Concentration of gemcitabine $[\mathbf{n M}]$ & Volume of cell suspension $[\boldsymbol{\mu l}]$ \\
\hline Control & 200 \\
1.9 & 200 \\
3.8 & 200 \\
6.4 & 300 \\
10.8 & 300 \\
18.1 & 400 \\
30.4 & 600 \\
76.0 & 800 \\
\end{tabular}


After cell washing with PBS, centrifugation at $250 \mathrm{~g}$ for 5 minutes and supernatant removal, $200 \mu \mathrm{l}$ of the staining solution for vitality analysis (see Table 52 in chapter 3.11.1) was added. These solutions were mixed at $1400 \mathrm{rpm}$ for 10 seconds and were incubated for 15 minutes at $37^{\circ} \mathrm{C}, 5 \% \mathrm{CO}_{2}$ before being measured with the flow cytometer. The data was analyzed by usage of the Cyflogic 1.2.1 free software (www.cyflogic.com).

\subsubsection{Flow cytometry and its measurement conditions}

Flow cytometry allows the multiparametric analysis of individual cells in a cell suspension, passing a laser with high speed. Depending on the shape, structure and/or staining different effects can be seen, giving information about cellular characteristics. In this work the method was used to assess the impact of gemcitabine on vitality and proliferation of LCLs. To eliminate cell debris seen as small particles the particle size was analysed first in the FCS (forward scatter channel), which is dependent on the volume of the cell, and the SSC (sideward scatter channel), which is related to the granularity of particles. For vitality testing, the fluorescent DNA intercalating dye Sytox Blue (excitation $440 \mathrm{~nm}$, emission $480 \mathrm{~nm}$ ), assessed in the Pacific Blue (based on 6,8difluoro-7 hydroxycoumarin fluorophore) channel, and the Vybrant Ruby dye (excitation $638 \mathrm{~nm}$, emission $686 \mathrm{~nm}$ ), assessed in the APC (Allophycocyanin, a photosynthetic pigment found in blue-green algea) channel, were used. To determine the proliferation rate under gemcitabine treatment, CFSE staining (excitation $492 \mathrm{~nm}$, emission $517 \mathrm{~nm}$, see chapter 3.11.2) was performed, which was detected in the FITC (fluorescein isothiocyanate) channel. For each channel different voltages were used, 170 volts for the FCS channel, 210 volts for the SSC channel, 685 volts for the APC channel, 215 volts for the FITC channel and 220 volts for the APC channel.

\subsubsection{Data Analysis}

Data analysis was performed by usage of the Cyflogic 1.2.1 free software for academic use (www.cyflogic.com). To differentiate between living and dead cells, Dot-Plots were drawn, with the APC channel on the x-scale, and the Pacific Blue channel on the y-scale (see Figure 12 - Figure 14). This allows gating of living cells, so that their percentage compared to dead cells could be calculated. Besides, the geometric mean of the FITC channel detection for living cells was determined, which stands for the CFSE dye used 
for proliferation analysis. These described values were needed for the statistical assessment of cellular sensitivity upon gemcitabine treatment and the calculation of $\mathrm{EC}_{50}$ values $\left(\mathrm{EC}_{50 \mathrm{Vit}}, \mathrm{EC}_{50 \text { Prolif). Two different }} \mathrm{EC}_{50}\right.$ values were computed: One for the impact of gemcitabine on cell vitality $\left(\mathrm{EC}_{50 \mathrm{Vit}}\right)$ by using the four-parametric MMF model (Multiple Multiplicative Factor Model), and one for the impact of gemcitabine on proliferation inhibition ( $\mathrm{EC}_{50 \mathrm{P} \text { rolif) }}$ using the three-parametric Gompertz model. The choice of an adequate model was performed with the Curve Expert Professional software (www.curveexpert.net), which encompasses 80 models. The criteria for the chosen model was a $\mathrm{r}^{2}$ value $\geq 0.95$ for each cell line. For the determination of $\mathrm{EC}_{50}$ values for all cell lines, the Solver algorithm in EXCEL was used. Below, exemplary data generated via flow cytometer is presented, showing the detected living cell population under PBS and gemcitabine exposure (two concentrations).

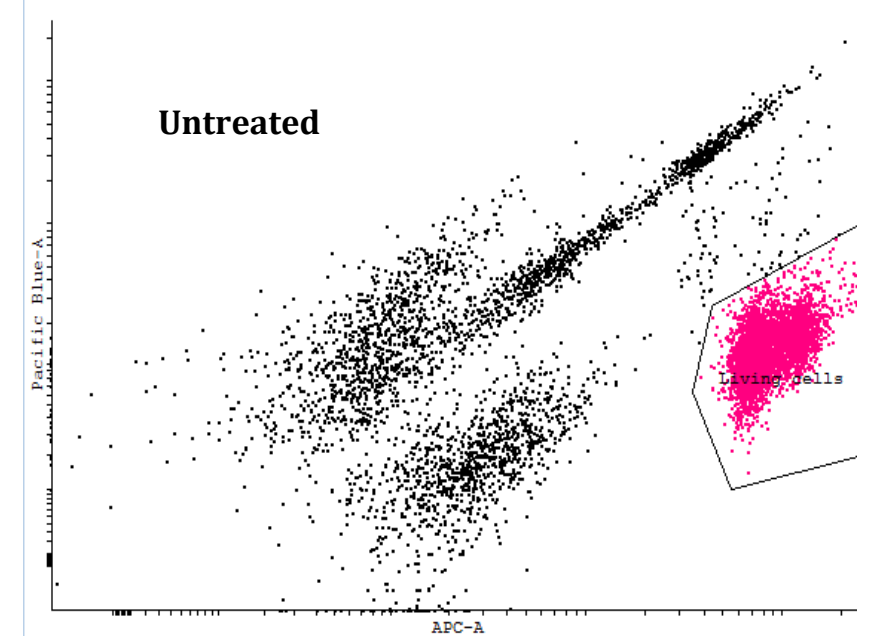

Figure 12: Flow cytometry data of untreated LCL number 240: The determination of living cells (red coloured gate) was performed via Vybrant Ruby and Sytox Blue staining.

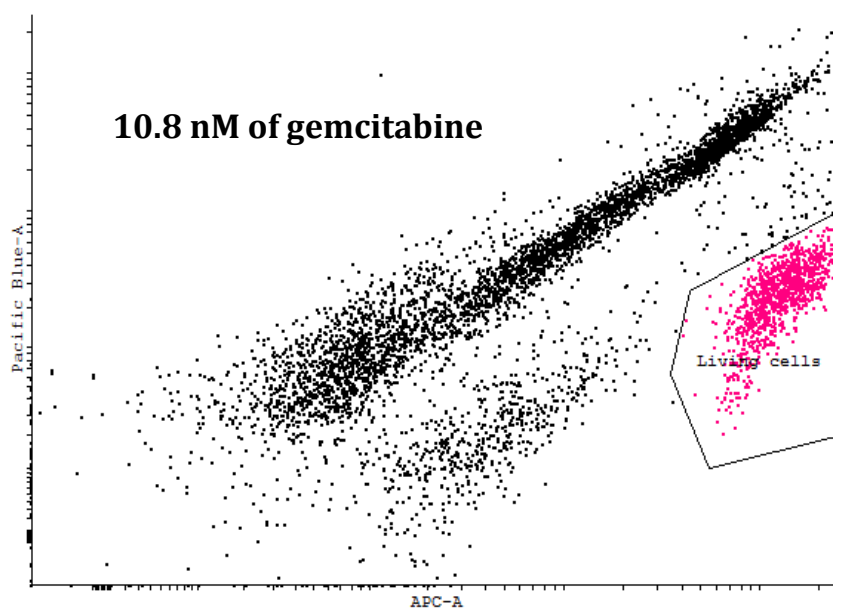

Figure 13: Flow cytometry data of LCL number 240, treated with $10.8 \mathrm{nM}$ of gemcitabine for $72 \mathrm{~h}$ : The determination of living cells (red coloured gate) was performed via Vybrant Ruby and Sytox Blue staining. 


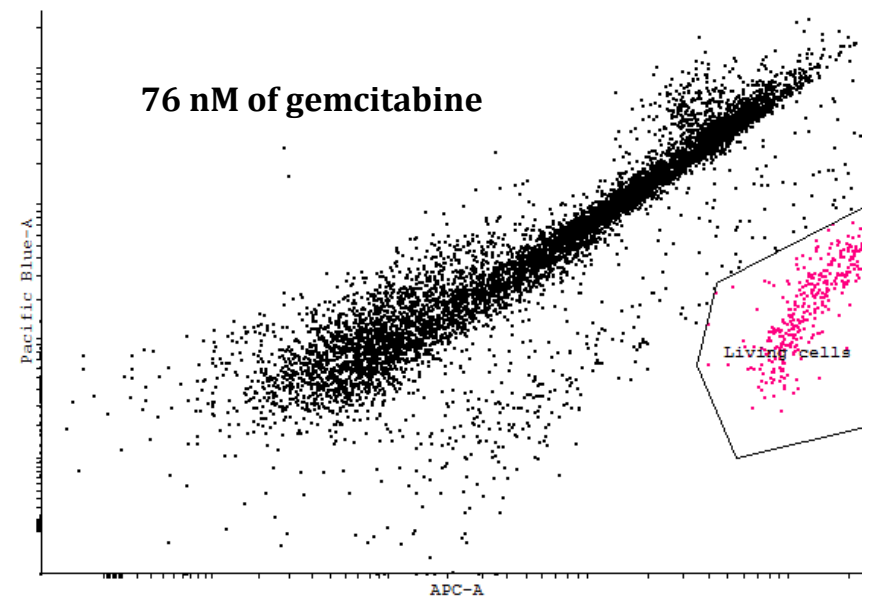

Figure 14: Flow cytometry data of LCL number 240, treated with $76 \mathrm{nM}$ of gemcitabine for $72 \mathrm{~h}$ : The determination of living cells (red coloured gate) was performed via Vybrant Ruby and Sytox Blue staining.

\subsection{Electrophoretic Mobility Shift Assay}

The Electrophoretic Mobility Shift Assay (EMSA) is used for detecting sequence-specific binding of DNA to proteins (e.g. of transcription factors) from nuclear extracts of cells. For detecting the protein binding to the probe, the probe, which is a complementary oligonucleotide probe with a GATC-nucleotide overhang on the 5' terminus, was radioactively labeled with $\alpha-32 \mathrm{P}-\mathrm{dCTP}$.

\subsubsection{Isolation of Nuclear Protein Extracts}

For the isolation of nuclear protein extracts from the pancreatic cancer cell lines CFPac, PancI, PaTu8988t and MiaPaca-II the protocol from the CelLytic ${ }^{T M}$ NuCLEAR ${ }^{T M}$ Extraction Kit (Sigma, Deisenhofen, Germany) was modified. First, cells were lysed by osmotic pressure so that the cytosolic components move out of the cells. The cytosolic components were separated from membranes and the nuclei by centrifugation steps. To prevent nuclear proteins from leaving the nucleus, sodium-ortho-vanadate (AppliChem, Darmstadt, Germany), an inhibitor of nuclear transporters, was added. At the end, the membrane was destroyed chemically and mechanically so that membrane fragments could be separated from the nuclear proteins by centrifugation. The detailed procedure, which was conducted on ice for the whole time, is described below.

A cell number of at least $1 \times 10^{7}$ was required for the isolation of nuclear protein extract. The cells were harvested and transferred into cooled $50 \mathrm{ml}$ tubes. The tubes were centrifuged at $500 \mathrm{~g}$ for 10 minutes at $4{ }^{\circ} \mathrm{C}$. Then, the supernatant was discarded and the 
pellet was washed with $10 \mathrm{ml}$ of ice-cold PBS containing sodium-ortho-vanadate to a final concentration of $1 \mathrm{mM}$. The tube was centrifuged at $500 \mathrm{~g}$ for 10 minutes at $4{ }^{\circ} \mathrm{C}$. Again the supernatant was removed and the cells were resuspended with $1.5 \mathrm{ml}$ of icecold PBS (containing sodium-ortho-vanadate to a final concentration of $1 \mathrm{mM}$ ) and pipetted into a $2 \mathrm{ml}$ reaction tube. The reaction tube was centrifuged at $3000 \mathrm{rpm}$ for 10 minutes at $4{ }^{\circ} \mathrm{C}$. Supernatant removal was performed and the pellet was slowly resuspended in a five-fold packing volume of a buffer based on HEPES/KOH (pH 7.9 at $4{ }^{\circ} \mathrm{C}$, Nuclear Extraction Buffer A, see Table 54), which was supplemented with DTT, PMSF and sodium-ortho-vanadate shortly before use (should not exceed a volume more than $500 \mu \mathrm{l}$ ). The formation of foam should be avoided. The mixture was incubated on ice for 15 minutes. The damage of cells was controlled with the microscope via cell staining with Trypan blue. Afterwards, the cells were destroyed mechanically in an oblong glass envelope by usage of a pestle. The mixture was compressed 30 times. Then $10 \mu \mathrm{l}$ of a $10 \%$ NP-40-solution (nonyl-phenoxypolyethoxylethanol, Sigma) was added per $100 \mu \mathrm{l}$ of lysed sample and vortexed vigorously for 10 seconds. Thereafter, the sample was centrifuged at $10000 \mathrm{~g}$ for 30 seconds. The supernatant contains the cytoplasmic fraction which was discarded. The pellet was absorbed in 2/3 of packing volume $(\sim 70 \mu \mathrm{l})$ of a $20 \mathrm{mM}$ HEPES/KOH buffer (pH 7.9 at $4{ }^{\circ} \mathrm{C}$, Nuclear Extraction Buffer B, see Table 55), which was supplemented with DTT, PMSF and sodium-orthovanadate shortly before use. The reaction tube was shaken, fixed on a plate vortexer, at $1800 \mathrm{rpm}$ for 30 minutes at $4{ }^{\circ} \mathrm{C}$ in the cooling room. Finally, the mixture was centrifuged at $17,000 \mathrm{~g}$ for 5 minutes at $4{ }^{\circ} \mathrm{C}$ and the supernatant containing the nuclear proteins was transferred into a new reaction tube, which was stored at $-80^{\circ} \mathrm{C}$. 
Table 54: Ingredients of Nuclear Extraction Buffer A

\begin{tabular}{lcc}
\hline Reagent $\left(\mathbf{p H}=\mathbf{7 . 9}\right.$, at $\left.^{\circ}{ }^{\circ} \mathbf{C}\right)$ & $\begin{array}{c}\text { Concentration of stock } \\
\text { solution [M] }\end{array}$ & Concentration [mM] \\
\hline Hepes/KOH & 0.5 & 10 \\
$\mathrm{MgCl}_{2}$ & 1 & 1.5 \\
$\mathrm{KCl}$ & 1 & 10 \\
\hline DTT (added shortly before use) & 0.1 & 0.5 \\
PMSF (added shortly before use) & & 1 ml of saturated solution \\
Sodium-ortho vanadate & 0.2 & 1 \\
(added shortly before use) & & Ad 100 $\mathbf{~ m l}$
\end{tabular}

Table 55: Ingredients of Nuclear Extraction Buffer B

\begin{tabular}{|c|c|c|}
\hline Reagent $\left(\mathrm{pH}=7.9\right.$, at $\left.4^{\circ} \mathrm{C}\right)$ & $\begin{array}{c}\text { Concentration of stock } \\
\text { solution [M] }\end{array}$ & Concentration [mM] \\
\hline Hepes/KOH & 0.5 & 20 \\
\hline Glycerin $85 \%$ & & $25 \%$ \\
\hline $\mathrm{NaCl}$ & 5 & 420 \\
\hline $\mathrm{MgCl} 2$ & 1 & 1.5 \\
\hline EDTA & 0.5 & 0.2 \\
\hline NP-40 (= modification) & & $1 \%$ final concentration \\
\hline Na-DOC (= modification) & & $0.5 \%$ final concentration \\
\hline $\begin{array}{l}\text { DTT } \\
\text { (added shortly before use) }\end{array}$ & 0.1 & 0.5 \\
\hline $\begin{array}{l}\text { PMSF } \\
\text { (added shortly before use) }\end{array}$ & & $1 \mathrm{ml}$ of saturated solution \\
\hline $\begin{array}{l}\text { Sodium-ortho vanadate } \\
\text { (added shortly before use) }\end{array}$ & 0.2 & 1 \\
\hline
\end{tabular}




\subsubsection{Labeling of probes}

Before probe labeling with radioactive $\alpha$-32 P-dCTP, they had to be annealed. The two complementary strands (complementary besides the GATC-nucleotide overhang) were mixed as follows in a $1.5 \mathrm{ml}$ reaction tube (Table 56 ).

Table 56: Mixture for oligo-nucleotide annealing

\begin{tabular}{lc}
\hline Reagent & Added volume $[\boldsymbol{\mu l}]$ \\
\hline Oligo_forward $(100 \mu \mathrm{M})$ & 1 \\
Oligo_reverse $(100 \mu \mathrm{M})$ & 1 \\
$\mathrm{NaCl}(0.5 \mathrm{M})$ & 1 \\
\hline $\mathbf{d d H}_{2} \mathbf{O}$ & Ad $\mathbf{5 0} \boldsymbol{\mu l}$
\end{tabular}

This mixture was incubated in one liter of heated water $\left(\sim 95^{\circ} \mathrm{C}\right)$, which was stirred gently with a magnet stirrer with $100 \mathrm{rpm}$ till the water reached room temperature and the oligonucleotides were annealed. Thereafter, the 5' overhang was filled via Klenowenzyme. During this step, in addition to non-radioactive dATP, dGTP and dTTPnucleotides, alpha-32P-labeled dCTP was incorporated. The labeling process was performed in the radioactive labour where all safety rules and procedures were followed.

Before entering the radioactive area, the double-stranded oligonucleotides were mixed with dNTPs (A, G, T), a 10x Klenow-buffer and $\mathrm{ddH}_{2} \mathrm{O}$ on ice (see Table 57). Afterwards, the Klenow-enzyme and $\alpha$-32P-dCTP were added in the radioactive room and the samples were incubated for 1 hour at $37^{\circ} \mathrm{C}$. 
Table 57: Mixture for probe-labeling with alpha-32P-dCTP

\begin{tabular}{lc}
\hline Reagent & Added volume $[\boldsymbol{\mu l}]$ \\
\hline Double-stranded oligonucleotides & 1 \\
$(2 \mathrm{pmol} / \mu \mathrm{l})$ & 1 \\
$\mathrm{dNTPs}(\mathrm{A}, \mathrm{G}, \mathrm{T}$ each $1 \mathrm{mM})$ & 2 \\
$10 \mathrm{x}$ Klenow-buffer & 12 \\
$\mathrm{ddH}_{2} \mathrm{O}$ & $2 \mu \mathrm{l}$ (added in the radioactive area) \\
\hline$\alpha-32 \mathrm{P}-\mathrm{dCTP}(10 \mu \mathrm{Ci} / \mu \mathrm{l})$ & $2 \mu \mathrm{l}$ (added in the radioactive area) \\
Klenow-enzyme $(1 \mathrm{U} / \mu \mathrm{l})$ & $\mathbf{2 0} \boldsymbol{\mu l}$
\end{tabular}

To separate the labeled oligonucleotides from the not incorporated radioactive and nonradioactive dNTPs, mini Quick Spin Oligo Colums (Roche) were used. The sephadex matrix of the columns was homogenized by shaking and vortexing. Thereafter, the lid and the bottom of the column were opened and the column was transferred into a $1.5 \mathrm{ml}$ reaction tube for centrifugation at $3200 \mathrm{~g}$ for 2 minutes at room temperature (Biofuge $15 \mathrm{R}$, Heraeus). Then, the column was placed into a new $1.5 \mathrm{ml}$ reaction tube and the radioactive probe (which was centrifuged before to avoid contamination) was pipetted into the middle of the column and centrifuged again for 4 minutes. The flow-through contained the purified $\alpha$-32P-dCTP labeled probe. To quantify the radioactivity, $4 \mathrm{ml}$ of safety scintillator (Aquasafe 500 Plus, Zinsser Analytic) was mixed with $1 \mu$ l of the probe. This mixture was measured with the scintillation counter LS1801. The radioactivity was detected as counts per minute (cpm). For the EMSA experiment 30,000 cpm of the probe were needed to perform the binding reaction. The following table (Table 58) shows the primers, which I radioactively labeled and used for the EMSA experiment.

Table 58: Olionucleotides for the EMSA experiment (RRM2)

\begin{tabular}{|c|c|}
\hline Name of primer & Sequence $\left(5^{\prime} \rightarrow 3^{\prime}\right)$ \\
\hline RRM2_v1_1130609-G (WT) & GATCCTCTGCTTCGCTGCGCCGCCACTATGCTCTCССTC \\
\hline RRM2_v1_1130609-C (WT) & GATCGAGGGAGAGCATAGTGGGGGGCAGCGAAGCAGAG \\
\hline RRM2_v1_1130609-T (Var) & GATCCTCTGCTTCGCTGCGCCTCCACTATGCTCTCССTC \\
\hline RRM2_v1_1130609-A (Var) & GATCGAGGGAGAGCATAGTGGAGGGGCAGCGAAGCAGAG \\
\hline
\end{tabular}




\subsubsection{The binding reaction}

An amount of $20 \mu \mathrm{g}$ of the nuclear extract was mixed and incubated with a $4 \mathrm{x}$ binding buffer (see Table 59), poly dI-dC (poly deoxyinosinic-deoxycytidylic, unspecific competitor to avoid unspecific protein binding) and $\mathrm{ddH}_{2} \mathrm{O}$ for 10 minutes on ice (see Table 60). Afterwards, the respective radioactive probe $(30,000 \mathrm{cpm})$ was added to the binding reaction mixture (performed in the radioactive area).

Table 59: 4x Binding buffer

\begin{tabular}{lc}
\hline Reagent $\left(\mathbf{p H}=\mathbf{7 . 9}\right.$ at $\left.^{\circ}{ }^{\circ} \mathbf{C}\right)$ & Concentration $[\mathbf{m M}]$ \\
\hline Hepes (pH 7.8) & 80 \\
EDTA (pH 8) & 4 \\
DTT & 2 \\
Glycerin & $40 \%$ \\
KCl & 560 \\
\hline
\end{tabular}

Table 60: Mixture for the binding reaction

\begin{tabular}{lc}
\hline Reagent & Added volume $[\mu \mathrm{l}]$ or amount $[\mu \mathrm{g}]$ \\
\hline $4 \mathrm{x}$ binding buffer & 5 \\
Nuclear protein extract & 20 \\
Poly dI-dC $(1 \mu \mathrm{g} / \mu \mathrm{l})$ & 2 \\
\hline
\end{tabular}

$\mathrm{ddH}_{2} \mathrm{O}$

Ad $18 \mu \mathrm{l}$

After an incubation time of 15 minutes, $4 \mu \mathrm{l}$ of a $6 \mathrm{x}$ loading dye (see Table 61 ) was added and the samples were loaded on a $5 \%$ native non-denaturating polyacrylamide gel (see $3.12 .4)$.

Table 61: 6x loading dye

\begin{tabular}{lc}
\hline Reagent $\left(-\mathbf{2 0}^{\circ} \mathbf{C}\right)$ & Concentration [\%] \\
\hline Glycerol $87 \%$ & $30(\mathrm{v} / \mathrm{v})$ \\
Bromphenol blue & $0.25(\mathrm{w} / \mathrm{v})$ \\
Xylene Cyanol FF & $0.25(\mathrm{w} / \mathrm{v})$ \\
\hline
\end{tabular}




\subsubsection{Non-Denaturating Polyacrylamide Gel Electrophoresis}

The polyacrylamide gel was equilibrated in $0.5 \%$ TBE-buffer (dilution of $5 \mathrm{x}$ buffer, see Table 63) for 1 hour with $180 \mathrm{~V}$ before usage. After sample loading, the gel was run for 1.5 hours with the same voltage. The polyacrylamide gel was prepared as follows (Table 62):

Table 62: 5 \% Polyacrylamide Gel

\begin{tabular}{lc}
\hline Reagent & Added Volume [ml] \\
\hline $40 \%(\mathrm{w} / \mathrm{v}$ ) Acrylamide/Mix 27:5:1 & 4.4 \\
$5 \mathrm{x}$ TBE & 3.5 \\
$\mathrm{ddH}{ }_{2} \mathrm{O}$ & 27 \\
\hline APS $10 \%(\mathrm{w} / \mathrm{v})$ & 0.350 (added in the end $\rightarrow$ gel forming process) \\
TEMED & 0.035 (added in the end $\rightarrow$ gel forming process) \\
\hline
\end{tabular}

Table 63: 5x TBE buffer

\begin{tabular}{lc}
\hline Reagent $(\mathbf{p H}=\mathbf{8})$ & Concentration [mM] \\
\hline Tris & 450 \\
Boric acid & 450 \\
EDTA & 10 \\
\hline
\end{tabular}

After electrophoresis, the gel was laid on two Whatman paper (Schleicher und Schüll, Dassel) and was covered with a wrapping film. The drying process was performed on a vacuum-gel-drying-system at $80^{\circ} \mathrm{C}$ for one hour. For visualizing the bands the gel was placed in a cassette, covered with a Fujifilm BAS1500 plate overnight. The radioactive signals were detected in a PhosphorImager (Raytest, Sprockhövel) by using the software BASreader and AIDA (Version 4.15.025, Raytest, Sprockhövel). In addition, the gel was put in a cassette with an x-rayfilm (Hyperfilm MP $(18 \times 24 \mathrm{~cm})$, GE Healthcare) for 7 - 10 days at $-80^{\circ} \mathrm{C}$. To develop the x-rayfilm the x-ray-developer G150 und fixer G354 (AGFA, Leverkusen) were used in the darkroom. The signals were quantified by using the FluorSTM Multilmager (BioRad, Hercules, CA, USA). 


\subsubsection{Cold Competition Experiment}

To assess the specificity of a protein binding, cold competition experiments were conducted. Therefor, non-radioactive labeled samples were added with an excess (5- till 100 -fold) to the mixture for the binding reaction (see chapter 3.12 .3 , Table 60 ), after the binding reaction was incubated for 10 minutes. Thereafter, this mixture was again incubated for 10 minutes before adding the radioactive probe in the radioactive area. Specific binding is indicated by loss of factor binding to the radioactively labeled probe.

The cold competition procedure was performed for investigation of binding specificity between the different alleles of the RRM2 SNP rs1130609 located in the 5 ' region.

\subsection{Statistical analysis}

$\mathrm{EC}_{50}$ values for individual LCL proliferation inhibition by gemcitabine were calculated by a three-parameter Gompertz model based on dose-response effects for eight gemcitabine concentrations $(0,1.9,3.8,6.4,10.8,18.1,30.4$, and $76.0 \mathrm{nM})$. Suitability of this model fit was proven by $r^{2}$ values $>0.95$ for 88 LCLs and $r^{2}=0.93$ for one LCL.

Descriptive statistics include data characterization by their distribution and visualization. Error bars and dot plots were used for parametric, box plots for nonparametric presentation of cumulative data. Single data point correlations were visualized by scatter plots.

All analytical testing was carried out two-sided. By default, threshold for statistical significance was set at $\mathrm{p}<0.05$ not accounting for multiplicity testing. Correction for multiple testing did not apply for the functional effects of the single investigated SNPs, for which clear hypotheses were deduced from clinical association data. However, in case of mechanistic studies apart from defined SNP effects the numbers of statistical tests according to the investigated parameters should be considered when interpreting the reported p-values. Applicability of parametric tests was assessed by compatibility of data with normal distribution (if $\mathrm{p}>0.05$ according to Shapiro-Wilk test). In some cases, this assumption could be matched by data log-transformation (e.g. $\mathrm{EC}_{50}$ values for gemcitabine in LCLs). If no compatibility with normal distribution could be achieved non-parametric testing was applied.

Regarding the presented correlation data, in each case normal distributions of the 
respective two parameters could be assumed. Thus, correlation coefficients according to Pearson are reported. Differences between paired samples (e.g. RNA expression before and during chemotherapy) were assessed using the Wilcoxon signed rank test. Treatment effects between two groups in pancreatic cancer cell lines were evaluated by t-test without assuming equal variances. Genotype effects on functional parameters were assessed by Mann-Whitney U testing for two groups, and by Jonckheere-terpstra test for three group comparisons. Statistical testing was performed using SPSS, version 12.0 (IBM, IL, USA). 


\section{Results}

An earlier analysis of our research group identified genetic single nucleotide polymorphisms in the $W W O X$ and RRM2 genes by genotyping germline DNA samples isolated from peripheral blood cells (RoPPEL 2013, ZIMMER 2013). These SNPs were associated with the overall survival of patients treated with gemcitabine. Below, firstly all experimental data concerning the $W W O X$ polymorphism are presented, followed by the data concerning the RRM2 polymorphisms.

\subsection{The SNP rs11644322 association with the overall survival suggesting relevance of WWOX in pancreatic cancer and gemcitabine treatment}

The variant $A$ allele at the $W W O X$ SNP rs11644322 (G > A) site was found associated with a worse clinical outcome in patients treated with gemcitabine for PDAC (ROPPEL 2013). Therefore, I set out for detailed functional assessment of this SNP in my thesis. That included a presumed specific functional role of the WWOX rs11644322 SNP site, but also experiments aiming at elucidation of the role of WWOX in gemcitabine therapy in general.

\subsubsection{Modulation of gemcitabine sensitivity by WWOX rs11644322}

The hypothesis was tested whether the WWOX index SNP affects cellular sensitivity to cytostatic drugs. Therefore, dose-response effects were examined in a panel of 89 LCLs employing different concentrations of gemcitabine $(0,1.9,3.8,6.4,10.8,18.1,30.4$, and $76.0 \mathrm{nM}$ ). For each cell line, $\mathrm{EC}_{50}$ values were calculated as described in the Methods section (see section 3.11.5). Gemcitabine sensitivity was found to be modulated by rs11644322. The $A$ allele was associated with increased resistance toward gemcitabine ( $p=0.002$, see Figure 15). This finding is accordant to the clinical observation in which carriers of this $A$ allele experienced shortened overall survival (see section 1.5.2, Figure 5). 


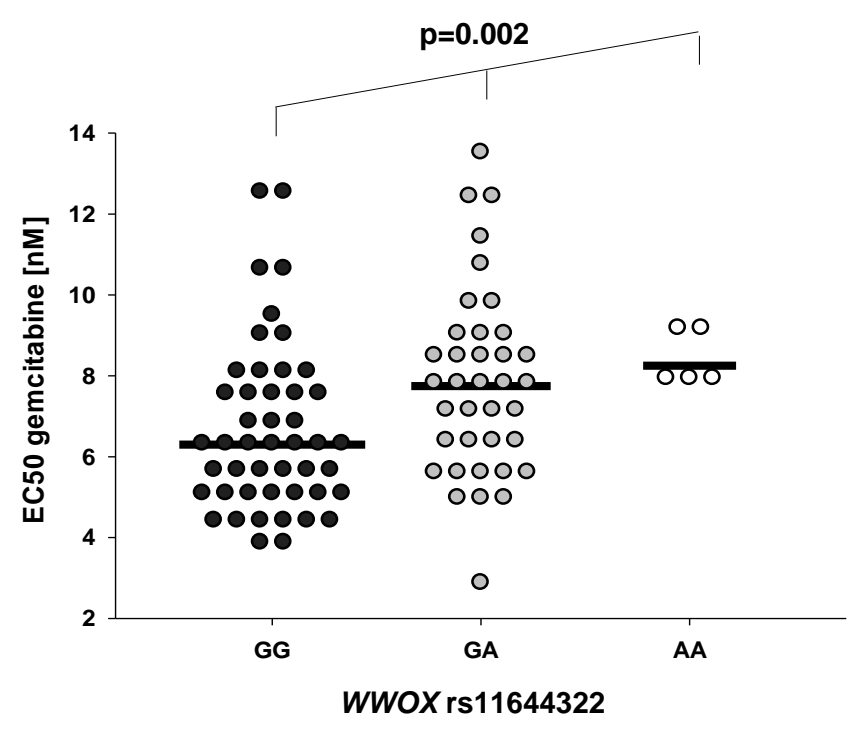

Figure 15: Impact of WWOX rs11644322 on cellular gemcitabine sensitivity of lymphoblastoid cell lines. $\mathrm{EC}_{50}$ values representing cellular sensitivity towards gemcitabine in relation to the three genotype configurations at rs11644322. Out of 89 LCLs, 47 harbored GG genotype, $37 \mathrm{GA}$, and $5 \mathrm{AA}$. $\mathrm{EC}_{50}$ data were calculated by a three-parameter Gompertz model for proliferation inhibition determined by flow cytometry-recorded CFSE staining based on dose-response effects of gemcitabine concentrations at $0,1.9,3.8,6.4,10.8,18.1$, 30.4 , and $76.0 \mathrm{nM}$. Statistical differences were assessed by the non-parametric Jonckheere-Terpstra trend test with given p-value referring to two-sided testing. This figure was generated with Sigma Plot, version 12 .

\subsubsection{WWOX expression in relation to the rs11644322 SNP site}

\subsubsection{Location of the rs11644322 SNP site}

The SNP WWOX rs11644322 with a minor allele frequency (MAF) of $26.1 \%$ is located in the immense intron 8 (776656 bp long) separating exon 8 and 9 (see Figure 16 for full length transcript). GeneBank entries (http://www.ncbi.nlm.nih.gov/gene/) suggest several alternative transcripts of WWOX terminating within intron 8.

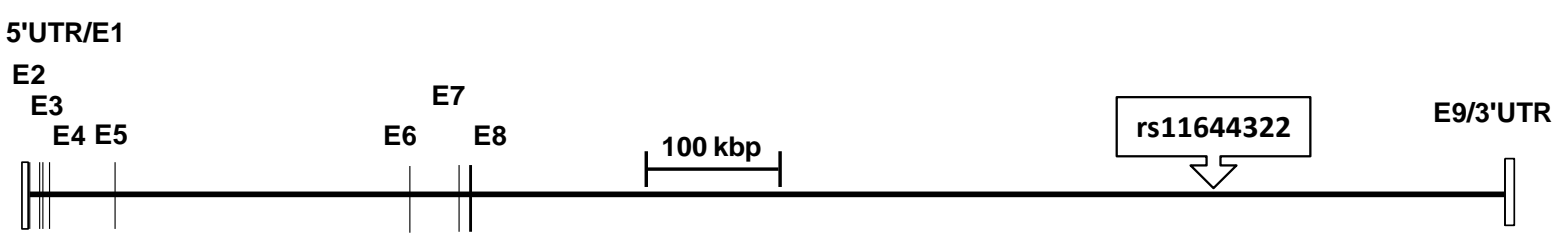

Figure 16: Genetic architecture at the WWOX locus. Information was taken from NCBI GeneBank (see assembly GRCh38.p2). The coding region contains 9 exons, the first and the last one flanked by the $5^{\prime}$ and the 3 '-untranslated region (UTR), respectively. The vertical lines represent the exons. The location of the index SNP rs11644322 in intron 8 is marked. Proportionality of sizes and distances are retained. The vertical lines denoted with E1 - E9 represent the protein coding exons.

\subsubsection{WWOX expression of exons flanking the index SNP}

As illustrated in Figure 16, rs11644322 is flanked by the exons 8 and 9 of WWOX. Transcription of this region was compared with that of exon 4-6, considered as core WWOX region. For absolute quantification of the expression ratios between these two WWOX coding regions a cDNA comprising entire WWOX, was cloned as reference (see 
3.5.1). Expression analysis (see 3.6.4) in 88 LCLs (for one cell line reverse transcription failed) identified a mean transcription rate of $67 \%$ for exon 8-9 compared to the core coding region (see Figure 17, bar plot), indicating the presence of the last exon in the majority of WWOX transcripts. In addition, a substantial intra-cell line correlation between the expression of these two WWOX regions was verified, which even increased upon gemcitabine exposure (Figure 17).

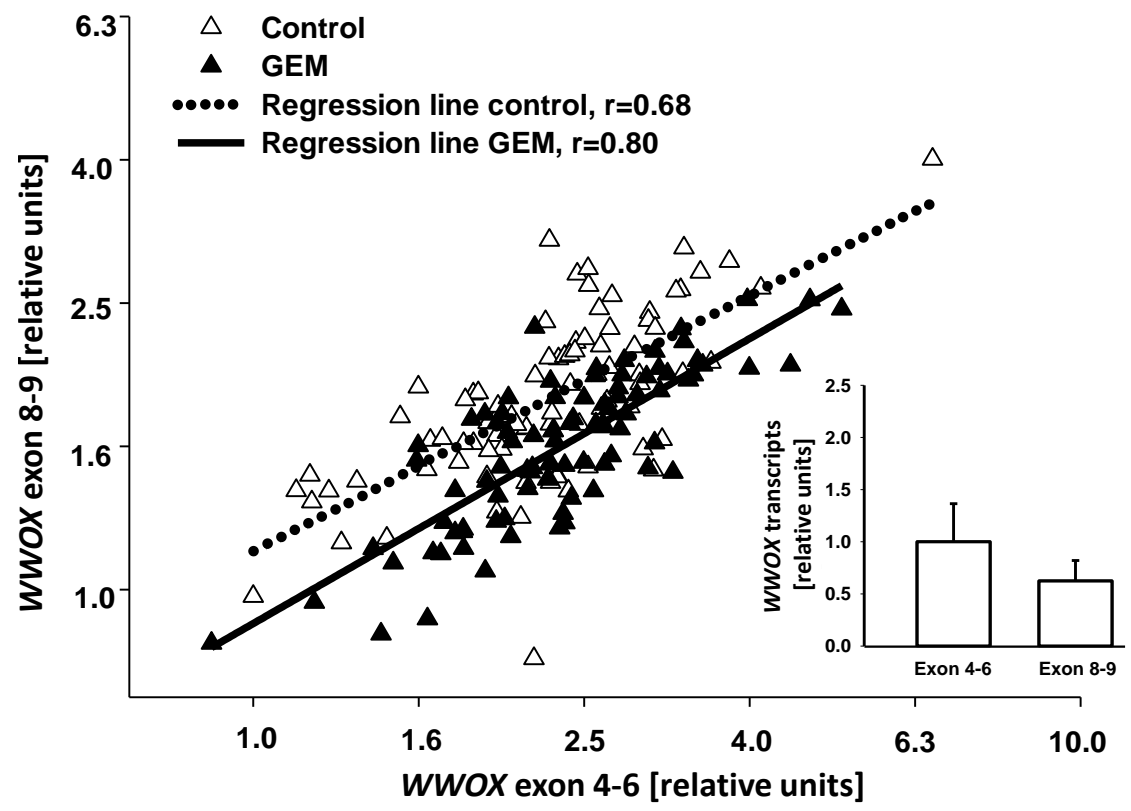

Figure 17: Expression of the last exon in relation to that of the core $\boldsymbol{W} W O X$ coding region. The mRNA expression of the terminal exon 9 (captured by an exon 8/exon 9-spanning primer pair) was compared with the major part of the coding region (represented by an exon 4/exon 5/exon 6-spanning primer pair). The graphs summarize the data obtained with 88 lymphoblastoid cell lines (for one cell line reverse transcription failed) treated either with PBS only (baseline) or with $30 \mathrm{nM}$ of gemcitabine at $37^{\circ} \mathrm{C}$ for $24 \mathrm{~h}$. The scatter plot illustrates expression correlation between regions 4-6 and 8-9. Both axes are displayed in $\log _{10}$-scale, by which normal distributions of the data could be assumed. The respective regression lines with the Pearson correlation coefficient $r$ are indicated. All expression data were referred to the cell line with the lowest transcript numbers for exon 4-6 under basal conditions (set to "1"). To account for inter-sample heterogeneity, expression data were normalized to a weighted mean of five reference genes (B2MG, GAPDH, HPRT1, UBC, 36b4). The lower right insert illustrates the quantitative transcript numbers of the last WWOX exon in relation to the core coding region of which the mean over the entire LCL cohort was set to "1" (error symbols denote one SD). This figure was generated with Sigma Plot version 12. 


\subsubsection{Impact of rs11644322 SNP on WWOX regional transcription}

It should be delineated whether the WWOX SNP rs11644322 affects transcription of exon 4-6 and 8-9. Presence of the $A A$ genotype at the index SNP site was accompanied by lower transcription of both WWOX regions, with and w/o gemcitabine (Figure 18). However, no significant change in $W W O X$ gene expression could be detected between $G G$ and $G A$ genotypes in the present experimental setting with short-term incubation time of $24 \mathrm{~h}$.

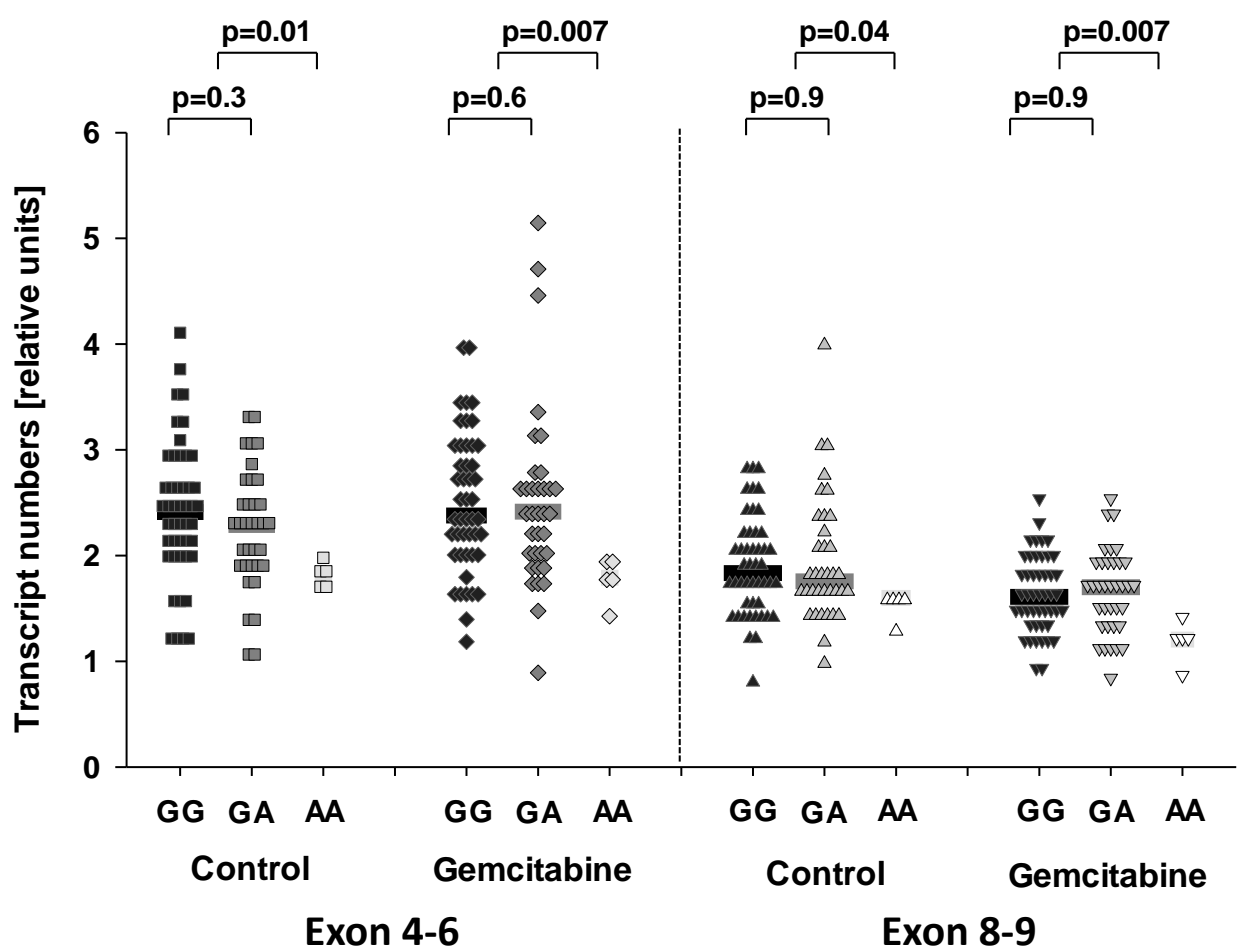

Figure 18: Impact of rs11644322 SNP on WWOX regional transcription (exon 4-6/8-9). The left side of the image refers to the central coding region (exon 4-6), the right to that of exon 8-9, each for baseline conditions and upon $30 \mathrm{nM}$ gemcitabine incubation for $24 \mathrm{~h}$ at $37^{\circ} \mathrm{C}$. The median value for each group is highlighted by a horizontal grey-shaded line. Statistical differences between two groups were assessed by the non-parametric Mann-Whitney $\mathrm{U}$ test. The lower line of p-values refers to testing between $G G$ and $G A$ genotype, the upper one between combined $G G$ and $G A$ versus $A A$ configuration. This figure was generated with Sigma Plot version 12.

\subsubsection{Whole transcriptome analysis around the WWOX index SNP}

As located far distant from exon 8 and 9, it was suggested that the rs11644322 site might be involved in regulation of non-coding RNA expression. To discover non-coding RNAs vicinal to the index SNP, whole transcriptome analysis (RNAseq, see 3.6.5) was undertaken. For two pooled RNA probes from LCLs, carrying the $G G$ vs. $A A$ genotype at rs11644322, there was no coverage around the index SNP site (see Figure 19). 
This observation demonstrates that there are no transcripts encoded in the genetic vicinity of rs11644322.

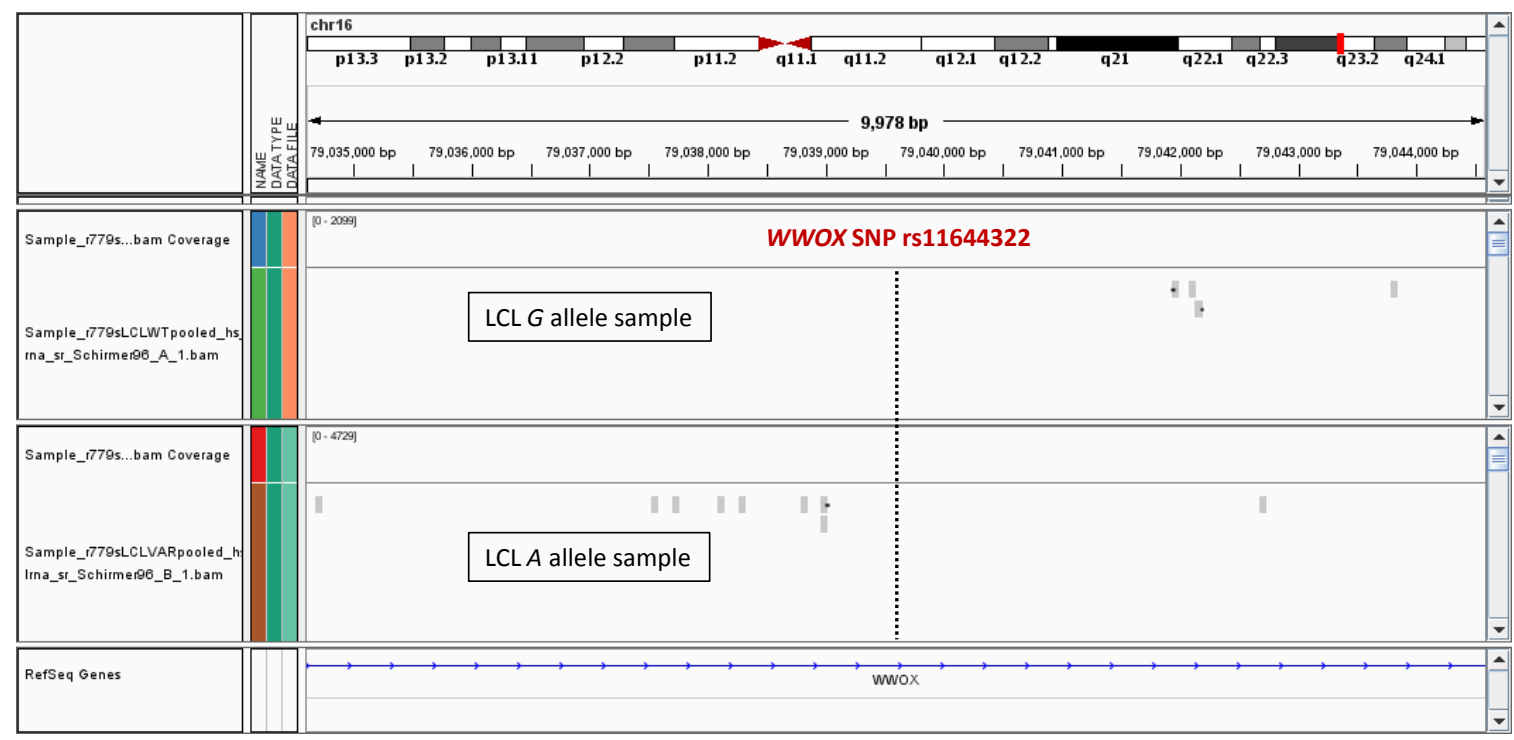

Figure 19: Whole transcriptome analysis around rs11644322. Data were analyzed by RNA sequencing of two pooled LCL samples containing the homozygous $G$ (upper panel) or the $A$ (lower panel) allele at rs11644322 with each pool consisting of RNA of five LCLs (cell identifiers at the Coriell institute for G allele: HG00096, HG00109, HG00120, HG00244, and HG00258; for A allele: HG00100, HG00108, HG00122, HG00245, and HG00265). Genomic sequences $\pm 5000 \mathrm{bp}$ around the index SNP (marked with a dashed line) are shown.

Likewise, in the pancreatic cancer cell lines PaTu8988t, MiaPaca-II, and AsPC1 no reads or only reads at very low amounts, not distinguishable from technical noise ( $<0.5$ reads/kilobase of transcript/per million mapped reads), could be observed within a range of $\pm 1 \mathrm{Mbp}$ referred to the index SNP rs11644322.

\subsubsection{Global transcriptome stratified for rs11644322}

Five pooled LCLs each with $G G$ or $A A$ genotype at rs11644322, not exposed to gemcitabine, were subjected to global transcriptome analysis. Out of all identified and annotated transcripts only six showed differential expression of more than 2-fold (see Table 64). Compared with $G G$, transcription in cells with $A A$ genotype was lower for TIMP2 and SEMA3C and higher for RNA5-8SP2, IGHA1, AL161626.1, and RNA5-8SP6. The most pronounced ratio was observed for RNA5-8SP2 (ribosomal pseudogene). For this transcript, which is located on chromosome 16 like WWOX, correlation with $\mathrm{EC}_{50}$ values for gemcitabine and with WWOX expression was evaluated in the entire set of 89 LCLs. However, expression of RNA5-8SP6 was neither related to $\mathrm{EC}_{50}$ for gemcitabine nor to WWOX expression (core region and last exon). 
Table 64: Expression profile in LCL samples in dependence of $W W O X$ rs11644322. Five non-treated LCLs each with homozygous wild-type (Coriell ID HG00096, HG00109, HG00120, HG00244, and HG00258) and homozygous variant allele (HG00100, HG00108, HG00122, HG00245, and HG00265) configuration at rs11644322 were pooled. This table lists all transcripts differing by a log2-fold change of at least 2.0 between these two groups. Data were obtained by sequencing of total RNA. Transcript data refer to RPKM values. RPKM-normalized transcripts for $A A$ at rs11644322 were divided by those for $G G$ genotype.

\begin{tabular}{lccc}
\hline Transcript notation & Rs11644322_GG [RPKM] & Rs11644322_AA [RPKM] & Ratio $A \boldsymbol{A} / \boldsymbol{G G}$ \\
\hline TIMP2 & 1.50 & 0.18 & 0.12 \\
SEMA3C & 1.50 & 0.25 & 0.16 \\
RNA5-8SP2 & 15.0 & 1653 & 110 \\
IGHA1 & 28.14 & 503 & 17.9 \\
AL161626.1 & 1757 & 10429 & 5.94 \\
RNA5-8SP6 & 373 & 28728 & 77.1 \\
\hline
\end{tabular}

\subsubsection{Consequences of SP1 overexpression for cytostatic drug sensitivity}

Previously, weaker SP1 binding for the minor $A$ allele at the WWOX rs11644322 site was identified and hypothesized to be linked to poor cytostatic response (RoPPEL 2013). Based on this finding, I investigated the functional consequences of SP1 overexpression on cytostatic drug sensitivity in the pancreatic cancer cell lines AsPC1, MiaPaca-II and Pancl. First, time kinetics analysis in the model cell line HEK-293 were conducted to establish proper transfection conditions. Following 48 hours upon transfection (see Methods SP1 transfection, chapter 3.10.3), high amounts of SP1 transcripts were detected (Figure 20). Thus, this time point was selected for starting drug exposure lasting for additional $24 \mathrm{~h}$.

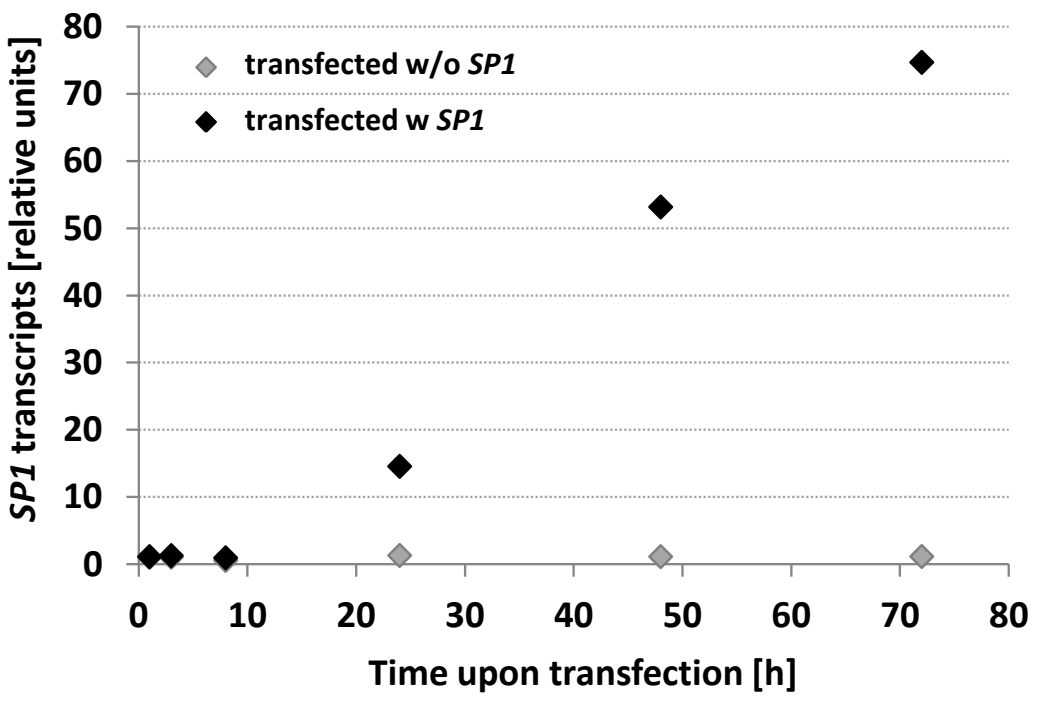

Figure 20: Time kinetics of SP1 overexpression. Here, easily tranfectable HEK-293 cells were used. SP1 gene expression was assayed $1,3,8$, 24,48 and 72 hours upon transfection of pcDNA3 vector with and without SP1 coding sequence. These data were normalized to a weighted mean of three reference genes (36b4, $U B C, H P R T 1$ ) and referred to the first time point $(1 \mathrm{~h})$ upon vector transfection without $S P 1$. 
SP1 transfection resulted in different effects on WWOX transcription in various pancreatic cancer cell lines (see Figure 21). Expression of WWOX exon 4-6 appeared to be reduced by about $40 \%$ and $20 \%$ in AsPC1 and PancI, respectively, and induced by $70 \%$ in MiaPaca-II. However, none of these observations based on three independent experimental series reached statistical significance. Concerning WWOX 8-9 transcripts, which were about $30 \%$ in regard to WWOX exon 4-6 in AsPC1, $85 \%$ in MiaPaca-II and absent in PancI without SP1 overexpression, were not altered substantially upon SP1 transfection.
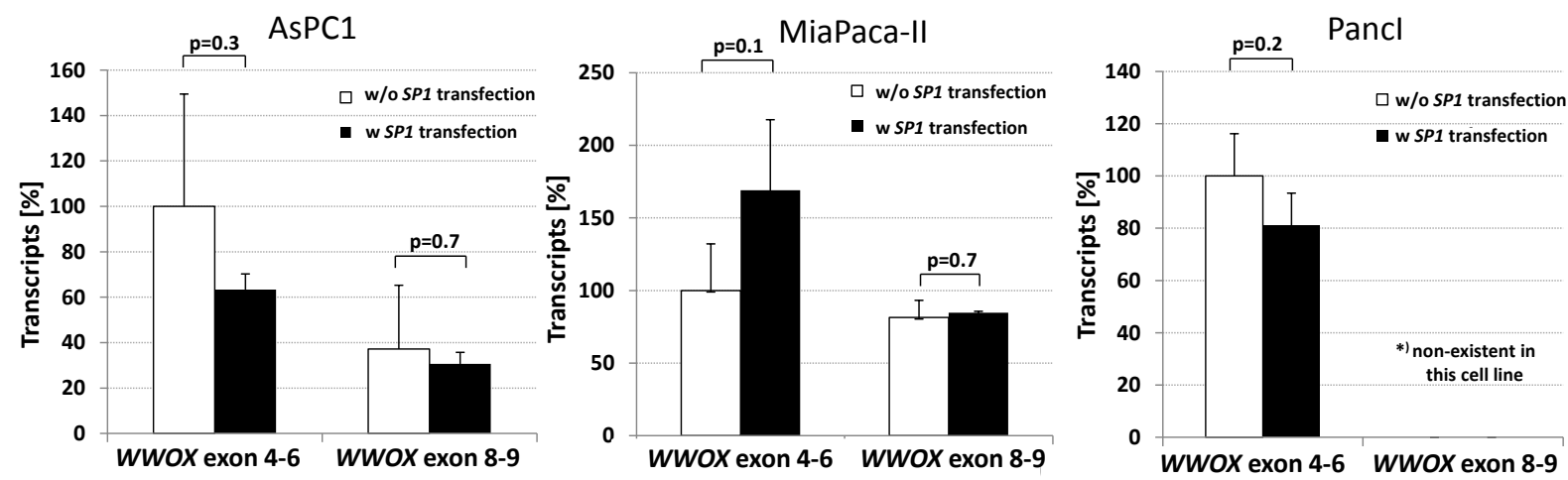

Figure 21: Impact of $S P 1$ overexpression on $W W O X$ transcription. In each of the three investigated cell lines (AsPC1, left panel), MiaPaca-II (center), and PancI (right) expression of WWOX exon 4-6 and 8-9 region was quantified upon transfection of pcDNA3 vector with and w/o $S P 1$ and subsequent incubation at $37^{\circ} \mathrm{C}$ for $72 \mathrm{~h}$. $W W O X$ expression data were normalized to a weighted mean of three reference genes $(36 b 4, U B C, H P R T 1)$ and then referred to exon 4-6 expression w/o SP1 transfection. Bars represent mean values of three independent experiments and the errors the respective standard deviations. Statistical differences between two groups were assessed by t-test without assuming equal variances.

In AsPC1 and MiaPaca-II cells, which exhibited detectable amounts of WWOX exon 8-9 transcripts, cytostatic drug effects on expression of the two interrogated WWOX regions elicited mostly similar (Figure 22, panel A and B). In PancI, in which transcription of the exon 8-9 region was below the detection level, conditions with and w/o SP1 overexpression were compared for expression of the exon 4-6 region (Figure 22, panel C). In this cell line WWOX expression was not much affected by the tested cytostatics (besides a moderate increase induced by the lower gemcitabine concentration). In contrast, irinotecan exhibited a strong $W W O X$ suppression in SP1-overexpressing AsPC1 and MiaPaca-II cells, regardless of the considered WWOX region. Respective assessment in AsPC1 without SP1 transfection revealed similar effects for irinotecan albeit to a lesser extent. Intriguingly, gemcitabine elicited cell line-specific effects with differential affections of the WWOX region considered. In AsPC1, expression of the WWOX core region was substantially suppressed by gemcitabine whereas that of the last exon 
remained virtually unaltered in relation to a drug-free control. In contrary, respective analysis in MiaPaca-II revealed a slight induction of both investigated WWOX regions. 5FU, however, did not modify WWOX transcription neither in AsPC1 nor MiaPaca-II. 

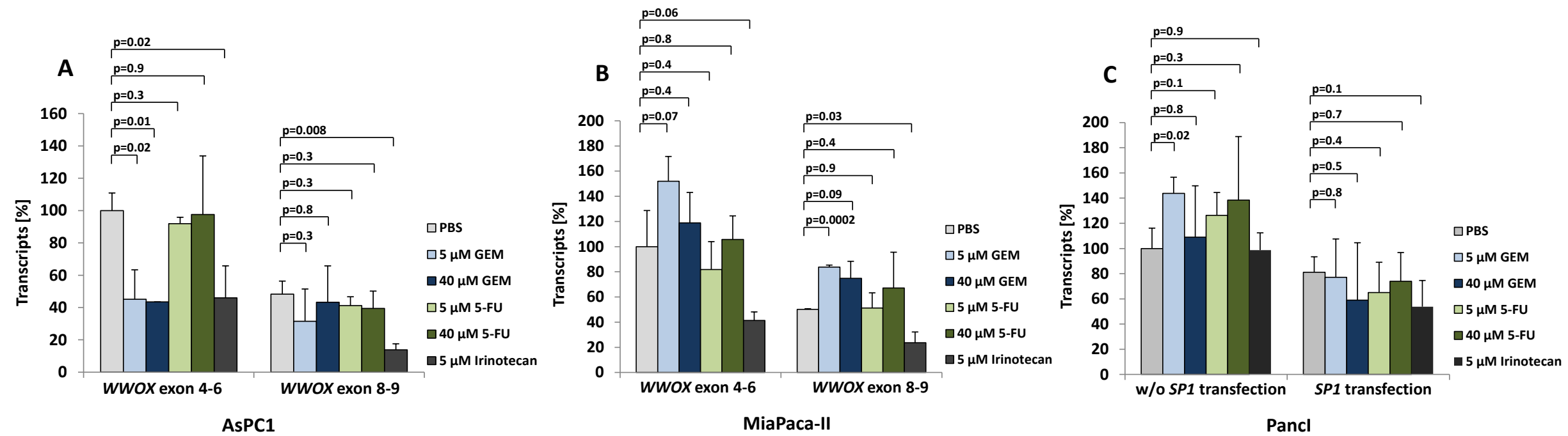

Figure 22: Modulation of WWOX transcription by cytostatics upon SP1 overexpression. Experimental design was accordingly to Figure 21 with additional cytostatic treatments at the indicated drug concentrations $48 \mathrm{~h}$ following $S P 1$ transfection (i.e. drugs were present in the last $24 \mathrm{~h}$ period of the entire $72 \mathrm{~h}$ incubation at $37^{\circ} \mathrm{C}$ since $S P 1$ transfection). Drug effects were each referred to treatment with PBS and statistically assessed by t-test without assuming equal variances. Note that for AsPC1 (panel A) and MiaPaca-II (panel B), data for both transcript regions upon SP1 overexpression are displayed (data referred to WWOX 4-6 expression upon PBS treatment). In case of PancI (panel C), in which WWOX exon 8-9 expression was not detectable, drug effects on WWOX exon 4-6 are illustrated w/o and with SP1 transfection (data referred to pcDNA3 transfect w/o SP1 and PBS treatment). With regard to reported p-values, the number of statistical tests according to the investigated parameters might be considered for interpretation. 


\subsubsection{WWOX in the context of apoptosis-related genes}

After successful testing of normal distribution ( $p>0.05$ according to Shapiro-Wilk test for deviation from normal) bivariate correlation analysis of WWOX exon 4-6 transcripts with the $\mathrm{EC}_{50}$ values of gemcitabine were conducted in LCLs. A weak correlation was identified under basal conditions and appeared intensified after an incubation time of 72 $\mathrm{h}$ with $30 \mathrm{nM}$ of gemcitabine $(\mathrm{r}=0.34, \mathrm{p}=0.001$, see Figure 23). For WWOX exon 8-9 correlation tendencies were the same, but less pronounced $(r=0.14, p=0.2$ at baseline level, $r=0.30, p=0.005$ at $30 \mathrm{nM}$ of gemcitabine).
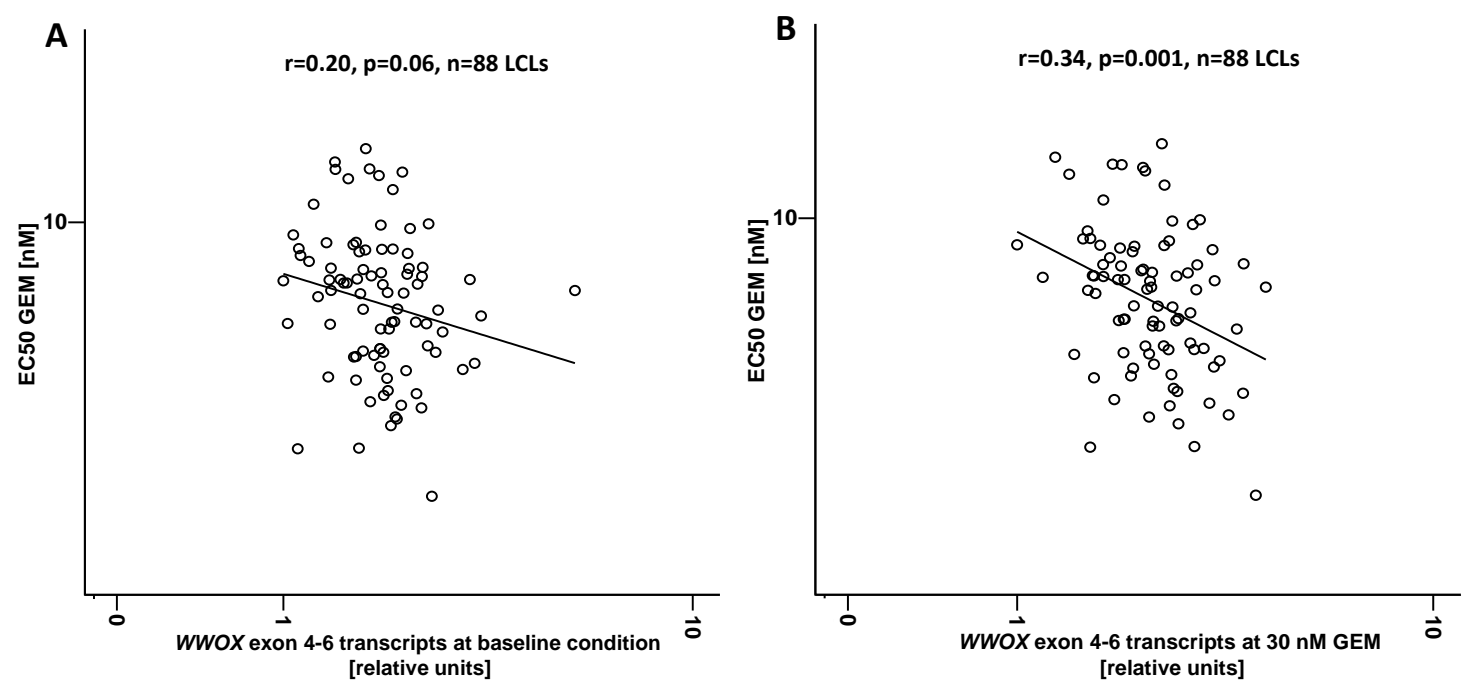

Figure 23: Correlation of WWOX exon 4-6 transcripts with $\mathbf{E C}_{50}$ values of gemcitabine. Data were based on 88 LCLs. For cell line number 247 the RNA content upon isolation was low and thus genes at low expression level like $W W O X$ could not be determined. Panel A refers to baseline conditions, panel B illustrates the correlation at $30 \mathrm{nM}$ of gemcitabine. Transcript numbers were normalized to the weighted mean of 36b4, B2MG, GAPDH, HPRT1 and UBC. Pvalues are according to the Pearson correlation coefficient $\mathrm{r}$. $\mathrm{EC}_{50}$ values and expression data are denoted in a $\log _{10}$ scale. A linear regression line is delineated.

Due to the observed link between WWOX expression and cellular gemcitabine sensitivity an interaction with apoptosis-related genes was supposed. Therefore, expression between $W W O X$ and three genes, related to apoptosis, was correlated in LCLs (see Table 65). One of those genes, BCL2 (B-cell lymophoma 2), is known to inhibit apoptosis (JACOBSON et al. 1993), the second, TP53 (Tumor protein p53), promotes apoptosis (Fridman AND Lowe 2003), and the third, GADD45A (Growth Arrest And DNA-DamageInducible, alpha), fosters cell cycle arrest upon genotoxic stress and may be a crucial component in orchestrating DNA damage repair (SCHAFER et al. 2010, BARRETO et al. 2007). 
Table 65: Expression correlation of WWOX with BCL2, GADD45A, and TP53. Correlation coefficients and p-values according to Pearson are listed for WWOX exon 4-6 and WWOX exon 8-9 each for baseline condition and at $30 \mathrm{nM}$ gemcitabine.

\begin{tabular}{lcccc}
\hline Gene & \multicolumn{2}{c}{ WWOX exon 4-6 } & \multicolumn{2}{c}{ WWOX exon 8-9 } \\
& Baseline & at 30 nM GEM & Baseline & at 30 nM GEM \\
\hline BCL2 & $\mathrm{r}=0.07, \mathrm{p}=0.5$ & $\mathrm{r}=0.15, \mathrm{p}=0.2$ & $\mathrm{r}=0.09, \mathrm{p}=0.4$ & $\mathrm{r}=0.16, \mathrm{p}=0.1$ \\
GADD45A & $\mathrm{r}=0.08, \mathrm{p}=0.5$ & $\mathrm{r}=0.36, \mathrm{p}=0.001$ & $\mathrm{r}=0.16, \mathrm{p}=0.2$ & $\mathrm{r}=0.41, \mathrm{p}=6 \times 10^{-5}$ \\
TP53 & $\mathrm{r}=0.20, \mathrm{p}=0.06$ & $\mathrm{r}=0.32, \mathrm{p}=0.002$ & $\mathrm{r}=0.36, \mathrm{p}=0.001$ & $\mathrm{r}=0.16, \mathrm{p}=0.1$ \\
\hline
\end{tabular}

Regarding the BCL2 gene, no correlation was detected, neither with the WWOX core region nor with the last exon. Interestingly, GADD45A was substantially correlated with WWOX exon 4-6 and to an even stronger extent with WWOX exon 8-9 region upon exposure to gemcitabine, but not at baseline condition. Moreover, GADD45A transcription upon gemcitabine elicited highly correlated with $\mathrm{EC}_{50}$ of gemcitabine, but again no relationship was observed for baseline GADD45A expression (see Figure 24). In contrast, a different correlation pattern between the two WWOX transcript regions and TP53 was noticed: Upon gemcitabine exposure, the correlation with the WWOX core region increased and that with the last exon decreased.
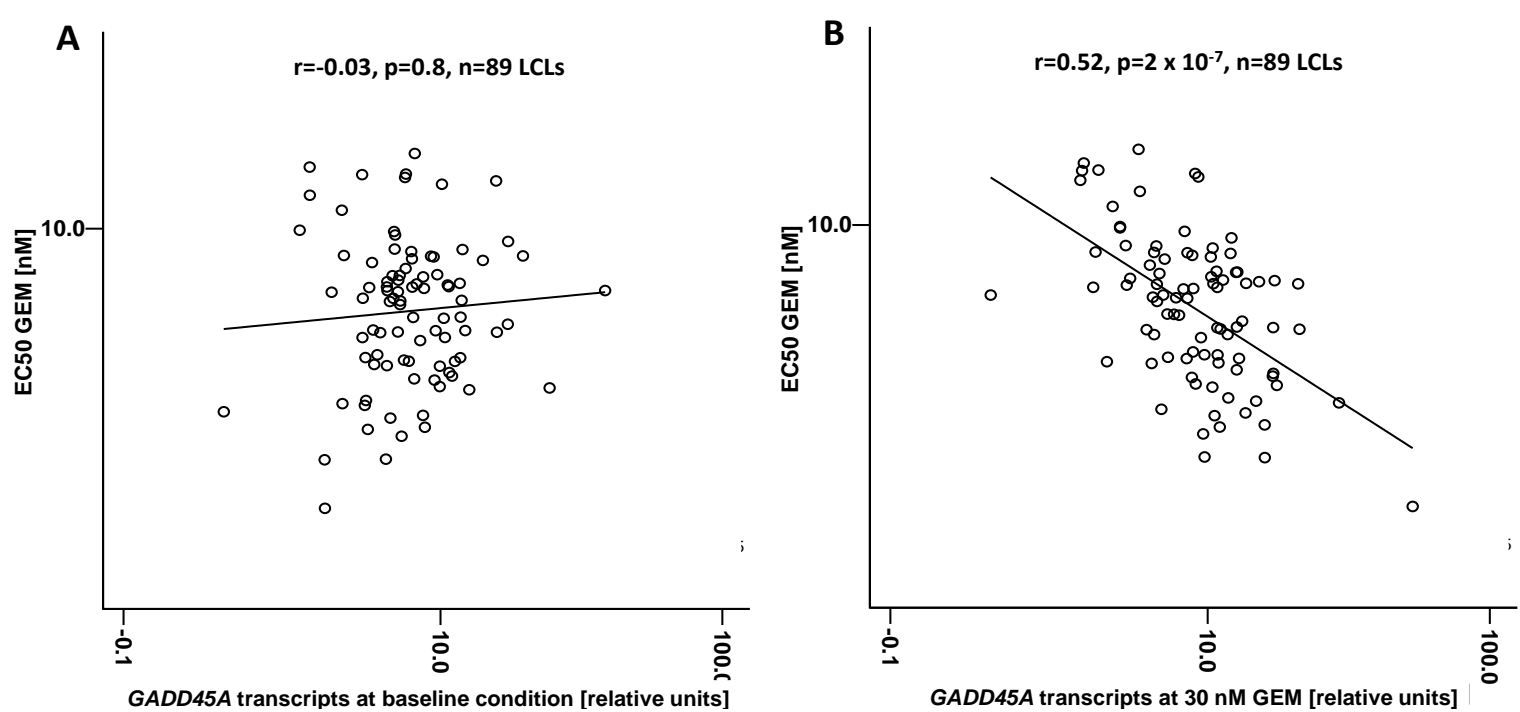

Figure 24: Correlation of GADD45A transcripts with EC $_{50}$ values of gemcitabine. Data was based on 89 LCLs. Panel A refers to baseline conditions, panel B shows the correlation at $30 \mathrm{~nm}$ of gemcitabine. Transcript numbers were normalized to the weighted mean of 36b4, B2MG, GAPDH, HPRT1 and UBC. P-values are according to the Pearson correlation coefficient $r$. EC 50 values and expression data are denoted in a $\log _{10}$-scale. A linear regression line is delineated. 


\subsubsection{WWOX and cytotoxicity of gemcitabine}

As the SNP rs11644322 was identified as related to cellular gemcitabine sensitivity in LCLs (chapter 4.1.1) and to WWOX expression (see chapter 4.1.2.3) it was hypothesized that WWOX enhances cytotoxicity of gemcitabine. Therefore, the correlation between WWOX expression level and cytotoxicity of gemcitabine was examined.

WWOX transcript numbers were negatively correlated with the $\mathrm{EC}_{50}$ value of gemcitabine in LCLs (see Figure 25). A negative correlation implies that higher WWOX expression is accompanied by lower $\mathrm{EC}_{50}$ values for gemcitabine resulting in increased sensitivity. Expression changes of WWOX upon gemcitabine exposure further strengthened this correlation with $\mathrm{EC}_{50}$.
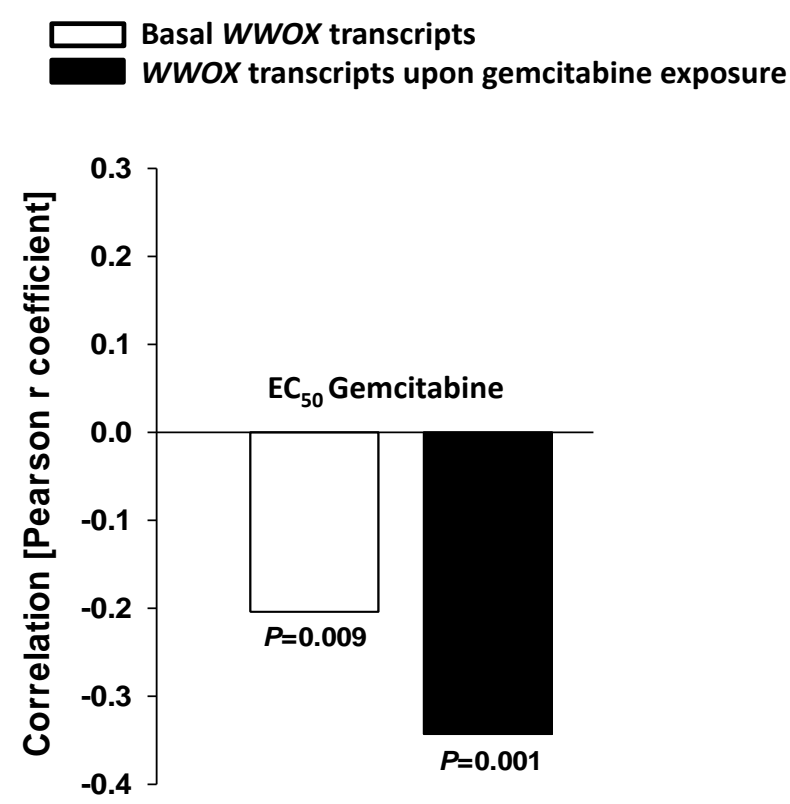

Figure 25: Correlation of WWOX transcripts with EC $_{50}$ values of gemcitabine. Data are based on the same 88 LCLs as in Figure 17 (section 4.1.2.2). (For cell line number 247 the RNA content upon isolation was low and thus genes at low expression level like WWOX could not be determined.) Shown correlations refer to WWOX transcripts of the E4-6 region and were very similar for E8-9. Transcript numbers were normalized to the weighted mean of 36b4, B2MG, GAPDH, HPRT1, and UBC. P-values are according to the Pearson correlation coefficient $r$ which is displayed on the y-axis. Note that a negative correlation means higher WWOX expression and is accompanied by lower $\mathrm{EC}_{50}$ values, i.e. increased sensitivity toward cytotoxic effects. Gemcitabine was administered at $30 \mathrm{nM}$ for $24 \mathrm{~h}$ at $37^{\circ} \mathrm{C}$ prior to RNA harvesting. These drug concentrations were chosen about 5 -fold higher than mean $\mathrm{EC}_{50}$ observed upon $72 \mathrm{~h}$ drug exposure (see Figure 15, section 4.1.1). This figure was generated with Sigma Plot version 12.

\subsubsection{Drug sensitivity upon knock-down or overexpression of WWOX}

\subsubsection{WWOX knock-down via siRNA}

SiRNA-mediated WWOX knock-down (see chapter 3.10.1) in the two pancreatic cancer cell lines PaTu8988t and L3.6 was performed to figure out whether WWOX directly affects gemcitabine sensitivity. A successful knock-down of WWOX protein expression was demonstrated for both cell lines, as shown by Western blotting (see 3.8.3 and Figure 26). 
A

PaTu8988t

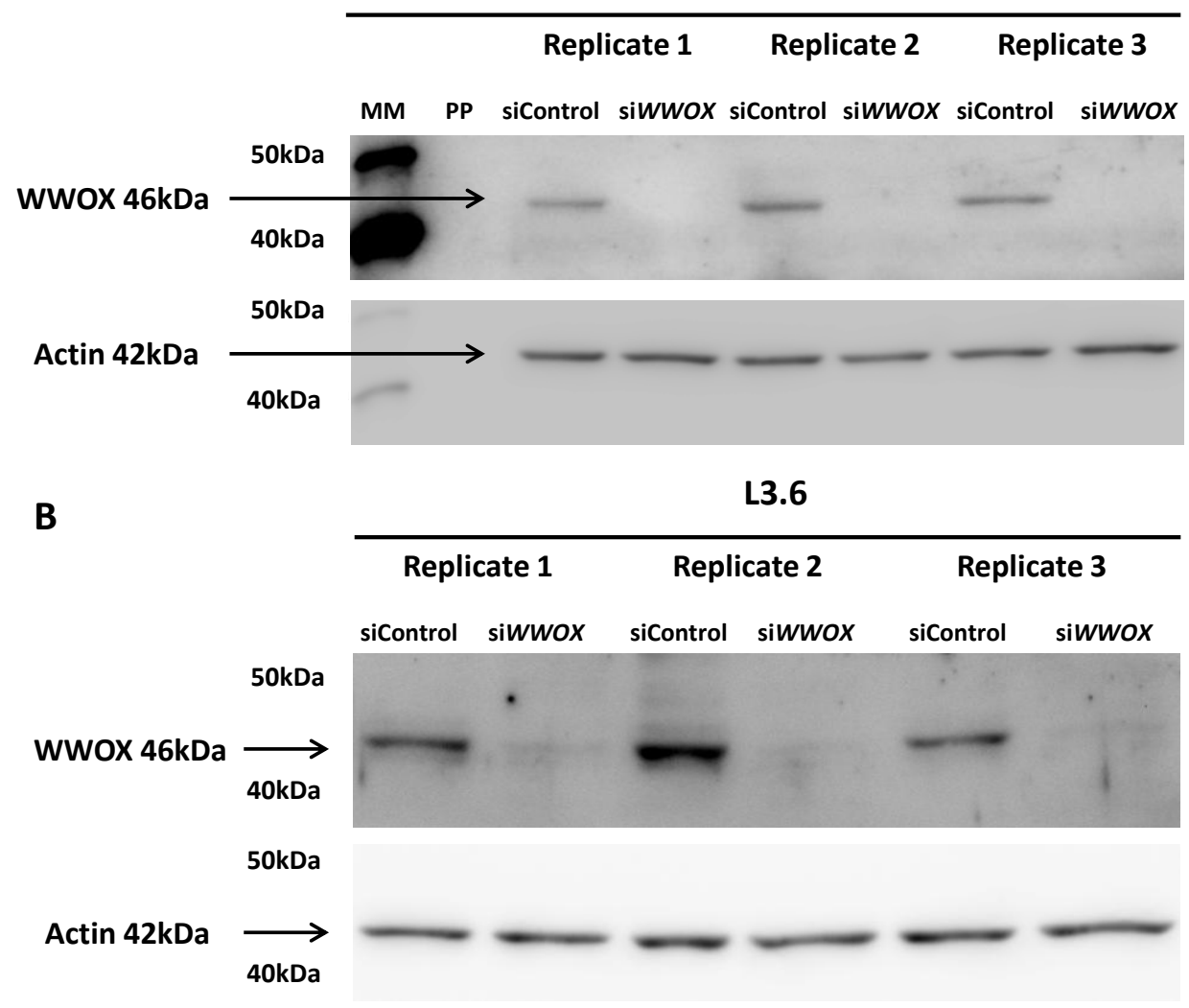

Figure 26: Western Blotting for siRNA knock-down in adenoductal pancreatic cancer cell lines PaTu8988t (A) and L3.6 (B). Actin was used as reference. "MM" = MagicMark ${ }^{\mathrm{TM}} \mathrm{XP}$, "PP" = pre-stained protein marker (see methods "Western Blot"). The images show samples from three independent experiments. Note that for L3.6 the marker bands were hidden from imaging to get visible bands for WWOX, which is weakly expressed in this cell line.

For both cell lines, a distinct decrease in basal proliferation was observed after WWOX siRNA transfection compared to control siRNA (see Figure 27).

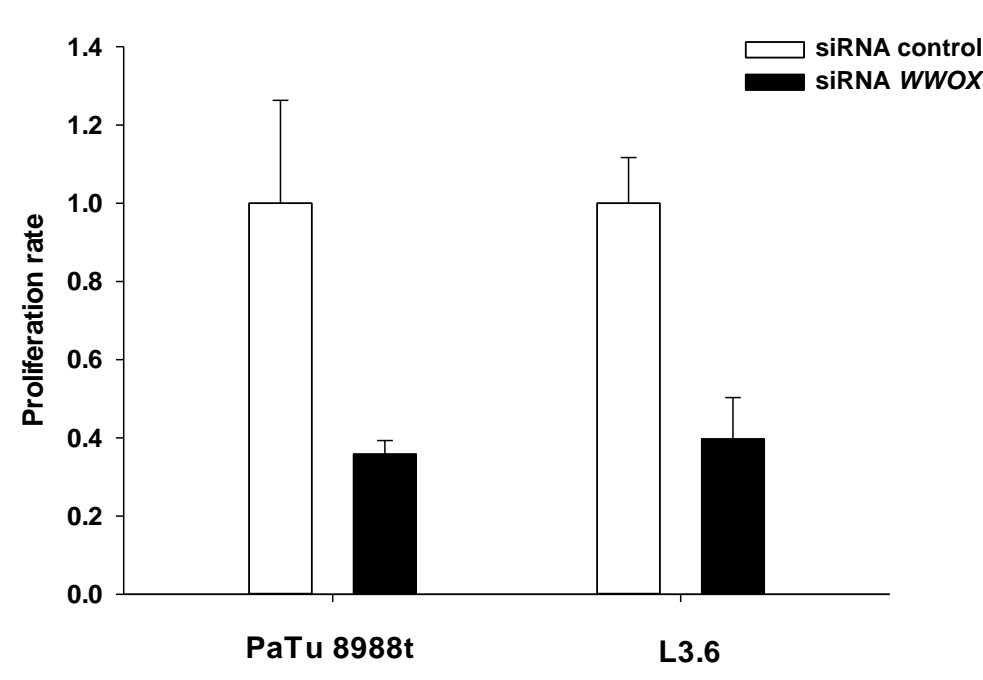

Figure 27: WWOX knock-down by siRNA. Effects of WWOX knock-down on basal proliferation rates of the two adenoductal pancreatic cancer cell lines PaTu8988t and L3.6. Cells were transfected either with a panel of four siRNAs intended to target WWOX or with a scrambled panel of unspecific siRNAs as control. Total incubation time upon siRNA transfection was $96 \mathrm{~h}$ before PrestoBlue ${ }^{\circledR}$ was added and recorded (recorded in methods part 3.10.4). Bars represent means of three independent experiments with the errorbars indicating one standard deviation. This figure was generated with Sigma Plot version 12. 
The impact of WWOX knock-down on 5-FU response was moderate in the two investigated cell lines. In gemcitabine treated L3.6 cells, WWOX depletion moderately decreased the gemcitabine sensitivity, whereas in PaTu8988t cells an intensified resistance was recorded under knock-down conditions (see Figure 28). These findings hypothesize that the impact of WWOX expression on gemcitabine sensitivity differs among different pancreatic cancer cell lines.
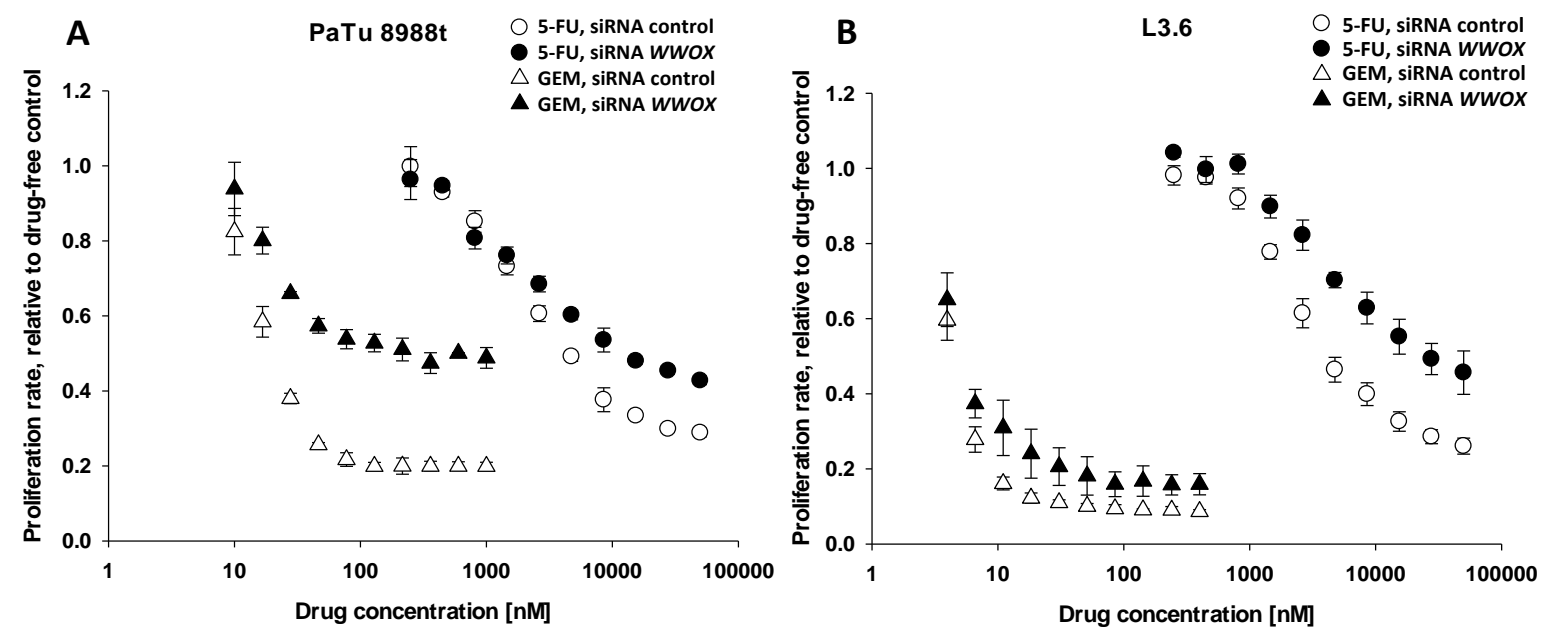

Figure 28: Consequences of WWOX knock-down on cytostatic drug sensitivity. Panel A displays data for the PaTu8988t and panel B for the L3.6 cell line. Drug concentrations are denoted in a $\log _{10}$-scale. Data for gemcitabine are shown as triangles (open ones for control siRNA, filled ones for siRNA against WWOX), for 5-FU analogously as circles. For each transfection condition and each drug, the proliferation rate for a drug-free control was set to 1.0 to which the indicated drug concentrations were each referred to. Data represent means of three independent experimental series with one standard deviation, indicated as error symbols. Within each series, each single condition was assayed in quadruplicates of which median values were taken for analysis. This figure was generated with Sigma Plot version 12 . 


\subsubsection{WWOX knock-down via shRNA}

The consequences of stable WWOX knock-down were addressed in PaTu8988t cells (see section 3.10.2). Three stably transfected clones showed more than $50 \%$ suppression of WWOX expression (see Figure 29).

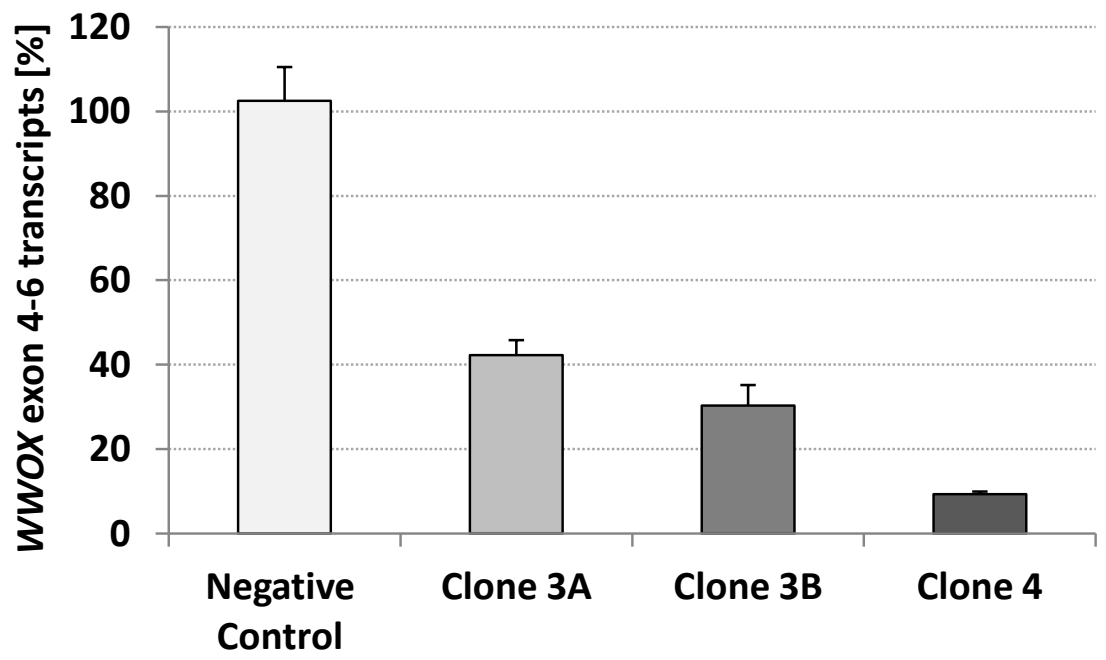

Figure 29: WWOX exon 4-6 expression upon suppression by shRNA. PaTu8988t cells were transfected with different shRNA plasmids targeting WWOX or an unspecific shRNA negative control. Clone 3A and 3B represent two subclones of a common shRNA transfection. Clone 4 was derived from a different shRNA against WWOX. Four different subclones of one negative control transfection were established. Expression data were normalized to the weighted mean of three reference genes $(36 b 4, U B C, H P R T 1)$ and were then referred to the unspecific shRNA negative control. Bars indicate mean values of three independent measurements and errors the respective standard deviation.

The knock-down of WWOX protein expression was affirmed by Western Blot performance (see Figure 30 and section 3.8.3). A more efficient knock-down was identified for Clone 4, which also featured the strongest knock-down on WWOX exon 4-6 expression level (see Figure 29).

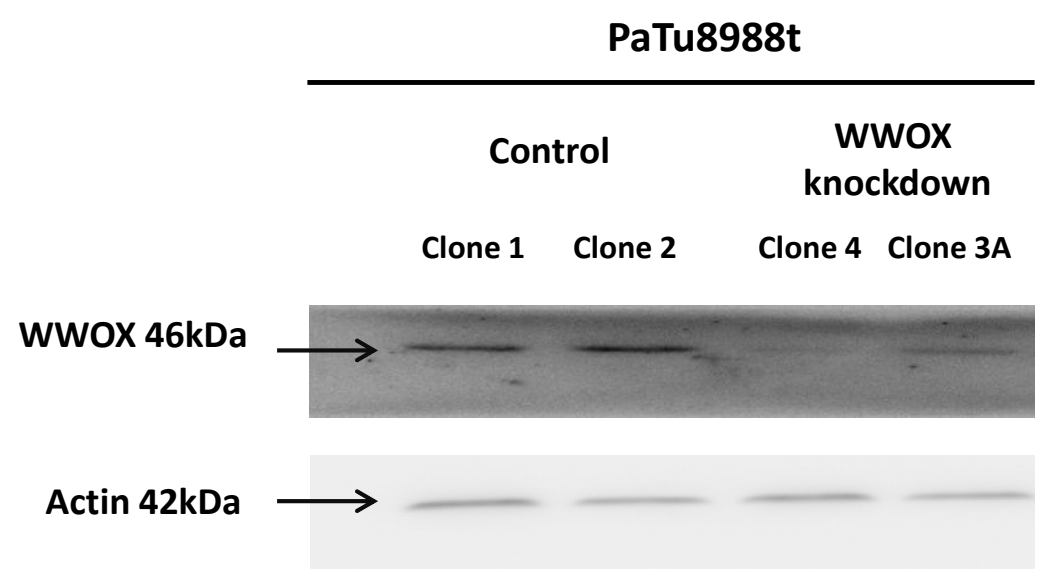

Figure 30: Western Blotting to demonstrate WWOX knock-down by shRNA. Actin was used as reference. Two clones each for shRNA negative control and shRNA WWOX-targeting transfection are displayed. The numbering of WWOX knock-down clones refers to Figure 29. 
WWOX knock-down by shRNA (clone 4 in Figure 29 and Figure 30) surprisingly did not alter gemcitabine sensitivity (see Figure 31, panel A). However, additional siRNAtransfection of this shRNA-transfected clone resulted in profound resistance to gemcitabine (see Figure 31, panel B) in a similar extent as observed for siRNA-only knock-down of WWOX in PaTu8988t cells (compare with Figure 28, panel A in section 4.1.6.1).
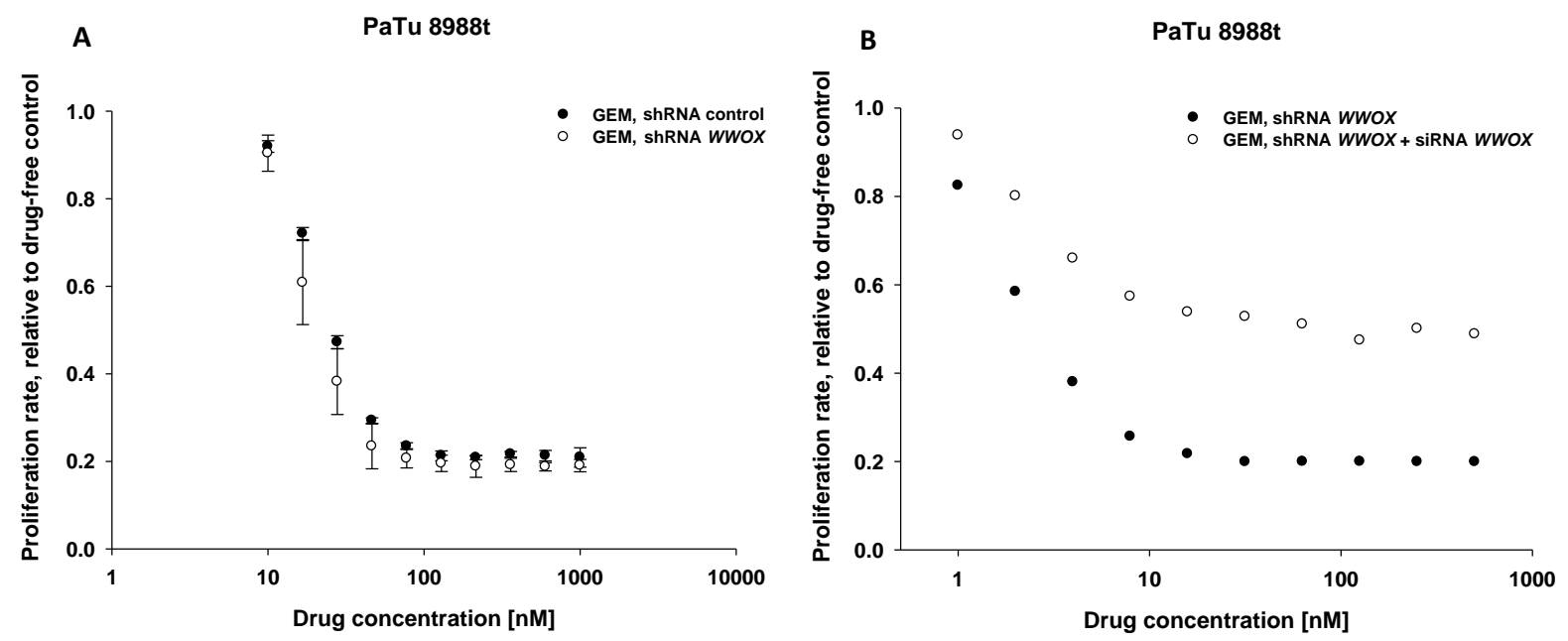

Figure 31: Gemcitabine sensitivity upon WWOX knock-down by shRNA and in combination with siRNA. Drugresponse effects in PaTu8988t cells following shRNA-mediated WWOX knock-down (panel A) or with additional siRNA, targeting WWOX (panel B) are shown. Gemcitabine concentrations are denoted in a $\log _{10}-\mathrm{scale}(10-1000 \mathrm{nM}$ for panel A, 1 - $500 \mathrm{nM}$ for panel B). For each transfection condition, the proliferation rate for a drug-free control was set to 1.0, to which the indicated drug concentrations were each referred to. Data in panel A represents means of two independent experimental series with one standard deviation. Data in panel B refers to one experimental series. Within each series, each single condition was assayed in quadruplicates, of which median values were taken for analysis. This figure was generated with Sigma Plot version 12.

\subsubsection{Transient overexpression of WWOX}

Following the finding that siRNA knock-down of WWOX resulted in dramatically increased resistance toward gemcitabine in PaTu8988t (4.1.6.1), it was hypothesized that vice versa WWOX overexpression might increase sensitivity to this drug in this cell line. However, there is obviously a surplus of $W W O X$ expression in PaTu8988t as shRNAmediated reduction by $90 \%$ (see Figure 29, Figure 30) did not substantially affect gemcitabine sensitivity (Figure 31, panel A) unlike virtually complete WWOX suppression by siRNA (Figure 28, panel A, Figure 31, panel B). Hence, assessing overexpression of WWOX in PaTu8988t did not appear reasonable. Thus, MiaPaca-II cells featuring a 6.6-fold less basal WWOX expression (according to whole transcriptome analysis, referred to RPKM) were chosen for this investigation. Overexpression of WWOX (see methods section 3.10.3) was repeated three times (Figure 32). In a linear 
regression model, assessing gemcitabine concentration and WWOX transfect as independent variables, the latter did not affect cell viability $(p=0.4)$.

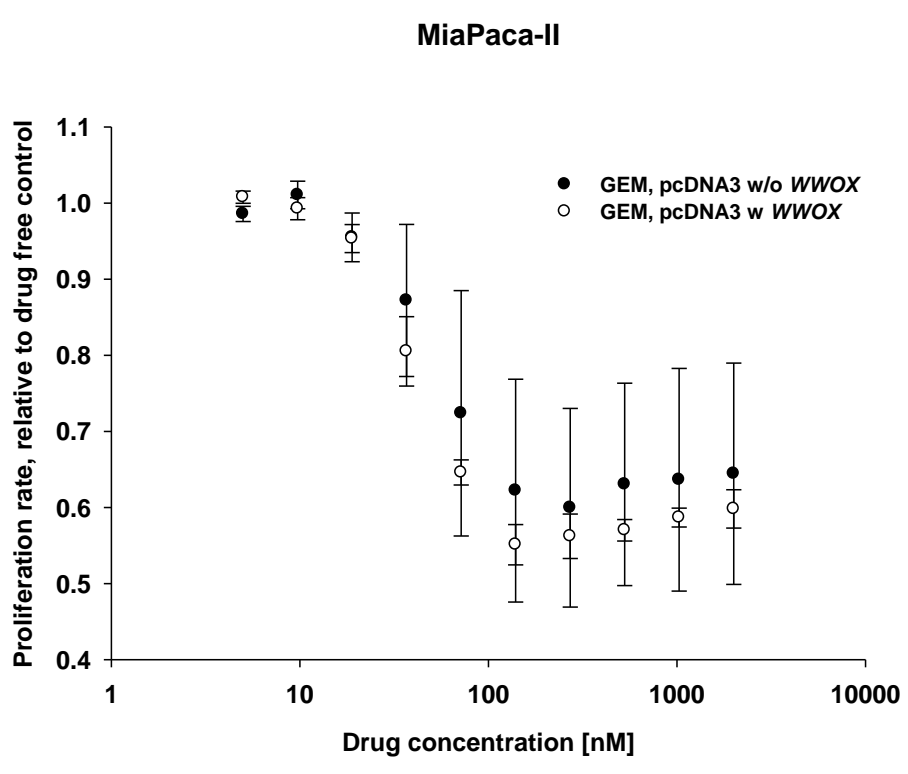

Figure 32: Gemcitabine sensitivity upon WWOX overexpression. Drug-response effects in MiaPaca-II cells following transient transfection w/o WWOX (pcDNA3 vector) and with WWOX (pcDNA3-WWOX) are displayed. Drug concentrations are denoted in a $\log _{10^{-}}$ scale. For each transfection condition, the proliferation rate for a drug-free control was set to 1.0 to which the indicated drug concentrations were each referred to. Shown data represent means of three independent experimental series with one standard deviation. Within each series, each single condition was assayed in quadruplicates, of which median values were taken for analysis. This figure was generated with Sigma Plot version 12. 


\subsubsection{WWOX expression in relation to whole transcriptome}

Whole transcriptome analysis was conducted in PaTu8988t cells stably transfected with shRNA against WWOX versus transfection with unspecific shRNA. Three clones each were analyzed. None of the transcripts was altered $\geq 2$-fold by shRNA (see Figure 33). Targeted WWOX by shRNA was the gene showing strongest downregulation in terms of mean suppression ( $42 \%, \mathrm{p}=0.008$ ). Fifteen further genes were suppressed by 30 to $41 \%(0.0001 \leq \mathrm{p} \leq 0.09)$. Statistically pronounced induction was identified for $R A B 12$ $\left(\mathrm{p}=6.7 \times 10^{-8}\right), \operatorname{MED} 24\left(\mathrm{p}=8 \times 10^{-7}\right), \operatorname{ANKRD13C}\left(8.3 \times 10^{-5}\right)$ and DDI2 $\left(\mathrm{p}=2.7 \times 10^{-4}\right)$. However, in each case the effect size in transcription increase was very moderate (between 58 and $72 \%$ ).
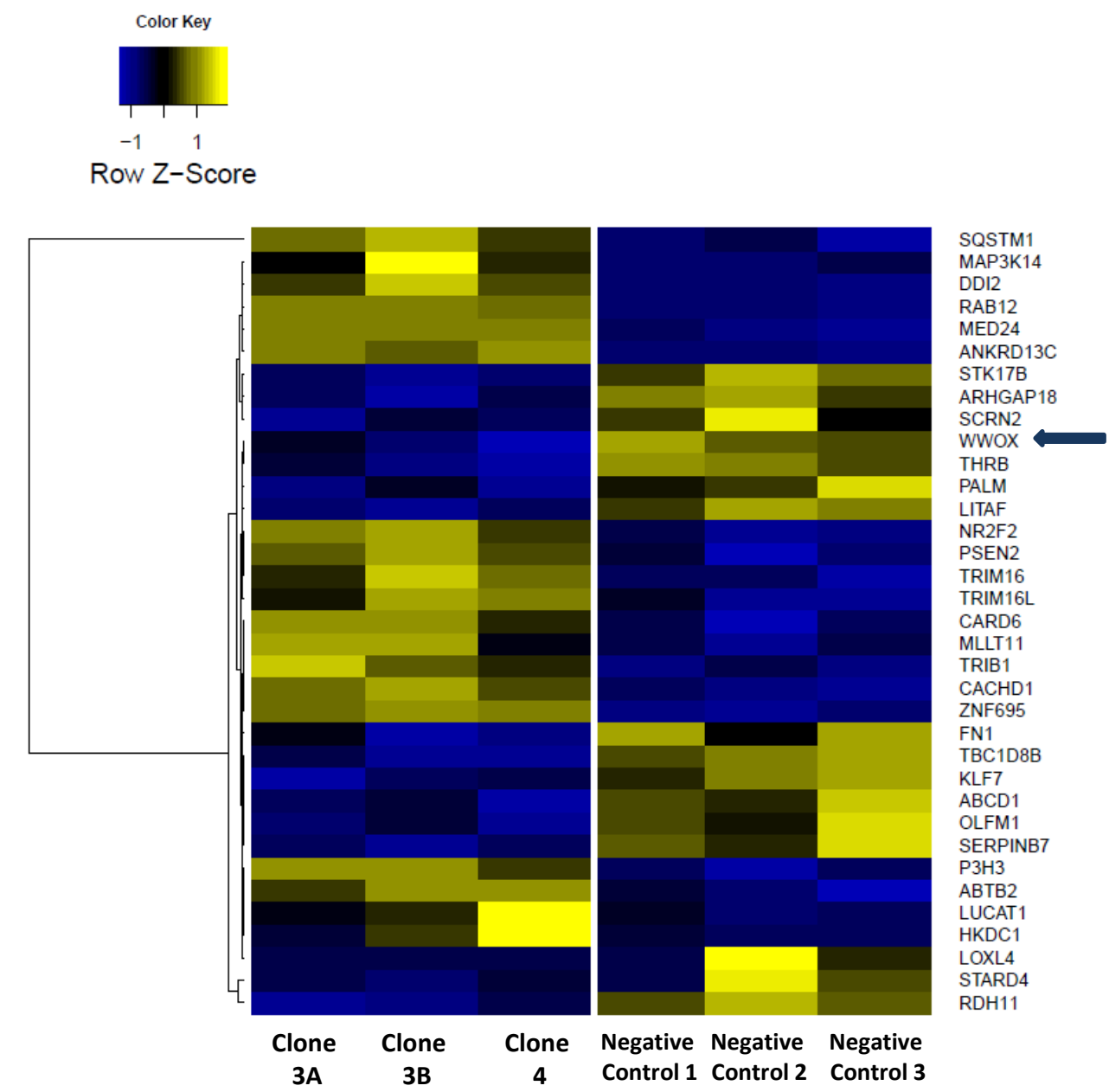

Figure 33: Differential gene expression upon WWOX knock-down by shRNA. The shown heatmap displays hierarchy clustering according to inter-clone correlation. Data were analyzed by RNA sequencing. Each row represents one gene. PaTu8988t cell clones with three each for specific shRNA against WWOX (left side) and for unspecific shRNA (controls, right) were assessed. Transcripts with a log2-fold change of at least 0.5 are displayed. Genes up-regulated upon shRNA-guided WWOX knock-down appear yellow, down-regulated ones in blue. Normalization was performed with regard to the total amount of sequence fragments per sample. WWOX is marked by a blue arrow. 


\subsection{Kozak region SNP in RRM2}

The RRM2 index SNP rs1130609 (base exchange G > T, frequency of the $T$ allele $22.2 \%$ ) was identified in an in-house retrospective analysis associated with the overall survival of patients suffering from PDAC and treated with gemcitabine-containing regimens. The variant $T$ allele conferred a significant better overall survival as outlined in the introduction (see Figure 4 in chapter 1.5.1, ZIMMER 2013). The following chapters describe the functional analyses that I conducted regarding RRM2.

\subsubsection{RRM2 expression}

\subsubsection{RRM2 expression in relation to whole transcriptome upon gemcitabine}

Total transcriptome of AsPC1 and MiaPaca-II cell lines was assayed for treatment with and without gemcitabine. In both cell lines, gemcitabine treatment for $24 \mathrm{~h}$ at $37^{\circ} \mathrm{C}$ resulted in an increase of RRM2 (major transcript isoform) by 1.9- and 2.8-fold for AsPC1 and MiaPaca-II, respectively. When considering the mean induction observed in these two cell lines, there was no other protein-coding transcript found with a higher basal transcription rate over the entire transcriptome to be induced stronger by gemcitabine than RRM2. There were only seven transcripts (all of them non-coding) which feature a stronger induction by gemcitabine at a higher basal expression level (see Table 66). Of all coding transcripts with a basal mean RPKM value of $\geq 1.0$ in AsPC1 and MiaPaca-II only 54 out of 5853 showed an equal or stronger induction by gemcitabine than RRM2. These data highlight the role of $R R M 2$ in cellular response toward gemcitabine. It should be announced that these whole transcriptome data refer all to cell lines transfected with a SP1-overexpressing plasmid. Comparison to vector transfection without SP1 by qRT-PCR demonstrated no statistically significant alteration ( $p>0.2$ by paired Wilcoxon signed rank test). 
Table 66: RRM2 induction by gemcitabine in relation to entire transcriptome. Expression data (basal and fold induction by gemcitabine) were averaged for AsPC1 and MiaPaca-II. Basal expression data are presented as normalized RPKM. The entire list of 57,396 transcripts was first filtered for known transcripts leaving 57,181. Second, all items with an RPKM value of zero were sorted out remaining 19,932 transcripts. These latter were sorted according to basal expression status. Then, all entries with an equal or higher expression level than RRM2 were further sorted in relation to fold induction by gemcitabine of which the top eight are listed.

\begin{tabular}{lccc}
\hline Transcript notation & RNA type & $\begin{array}{c}\text { Basal expression } \\
\text { [RPKM] }\end{array}$ & $\begin{array}{c}\text { Fold induction by } \\
\text { gemcitabine }\end{array}$ \\
\hline RNA5-8SP6 & rRNA $^{1}$ & 240.3 & 13.9 \\
RNU5F-1 & snRNA $^{2}$ & 130.7 & 6.3 \\
MT-RNR1 & Mt-rRNA & 45.3 & 4.2 \\
SNORA80B & snoRNA & 3.7 \\
RNU5A-8P & snRNA & 106.7 & 3.3 \\
MT-RNR2 & Mt_rRNA & 37.6 & 2.9 \\
SNORA34 & snoRNA & 255.9 & 2.6 \\
RRM2 & Protein coding & 57.7 & 2.3 \\
\hline
\end{tabular}

${ }_{1}^{1}$ rRNA = ribosomal $\quad$ RNA, ${ }^{2}$ snRNA = small nuclear $\quad$ RNA, ${ }^{3}$ Mt-rRNA = mitochondrial ribosomal RNA, ${ }^{4}$ SnoRNA = small nucleolar RNA

\subsubsection{RRM2 transcript variant expression}

The location of this SNP differs in relation to the two known transcript variants of RRM2. Regarding variant 1 (V1), this SNP site represents an amino acid exchange from alanine to serine at position 59, in relation to variant 2 (V2, major transcript) the SNP resides inside the Kozak sequence 6 bp prior to the methionine translation start site (see Figure $34)$.

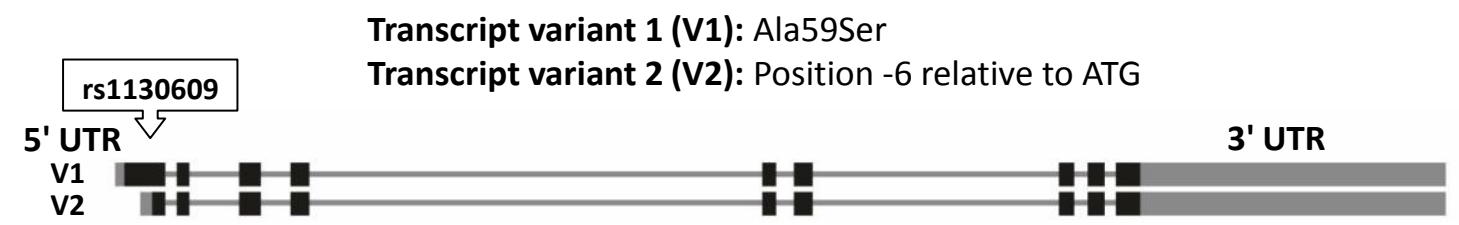

Figure 34: Relation of the index SNP (rs1130609) to the two RRM2 transcript variants, according to NCBI GenBank. The corresponding GenBank entries are denoted as NM_001165931.1 and NP_001159403.1 for V1 mRNA and protein and as NM_001034.3 and NP_001025.1 for V2 mRNA and protein, respectively. The coding region contains 9 exons, the first one flanked by the 5 ' and the last by the $3^{\prime}$-untranslated region (UTR). The black rectangles respresent the exons. The location of the index SNP rs1130609 is marked. Relationships of sizes and distances are retained.

In order to determine the quantitative relations of V1 and V2 transcript numbers, quantitative RT-PCR (see section 3.6.4) was conducted. As the sequence of V2 is a complete substring of V1, specific primers for V2 cannot be designed. Thus, two primer pairs specifically covering V1 or both transcripts (V1+V2) were employed. 
Gene expression analysis was conducted in the pancreatic cancer cell lines AsPC1, PancI and MiaPaca-II as well as in 89 LCLs (see Figure 35). In pancreatic cancer cell lines, the fraction of V1 was $3.5 \%$ of total RRM2 transcription, whereas in LCLs V1 represented only $1 \%$.

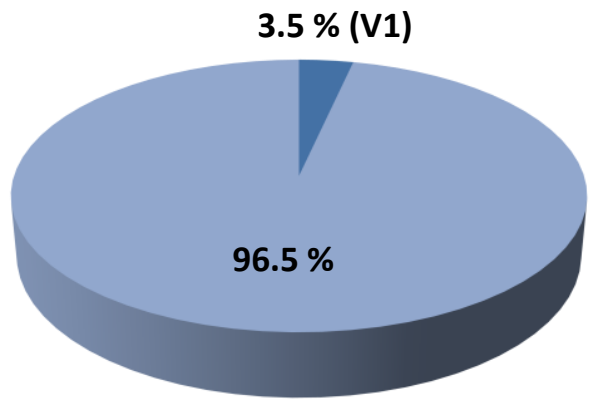

Pancreatic cancer cell lines

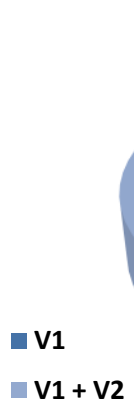

$\square \mathbf{V} 1+\mathrm{V} 2$

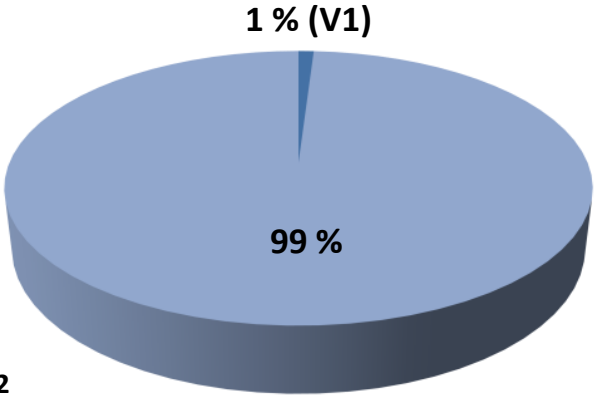

Lymphoblastoid cell lines (LCLs)

Figure 35: Quantitative proportions of $R$ RM2 transcript variant expression. The fraction of $R R M 2$ transcript variant $1(\mathrm{~V} 1)$ in relation to total $R R M 2(\mathrm{~V} 1+\mathrm{V} 2)$ is displayed for the average of three pancreatic cancer cell lines AsPC1, PancI and MiaPaca-II (left) and for 89 LCLs (right). Data were obtained by qRT-PCR.

\subsubsection{RRM2 variant expression upon gemcitabine}

In LCLs, gemcitabine treatment (30 $\mathrm{nM}$ ) resulted in a significant induction of total RRM2 $\left(\mathrm{p}=8 \times 10^{-6}\right)$ and a reduction of $\mathrm{V} 1\left(\mathrm{p}=2 \times 10^{-12}\right)$ (see Figure 36$)$. Thus, the ratio of $R R M 2 v 1 / R R M 2$ total decreased (see Figure 37, panel A).
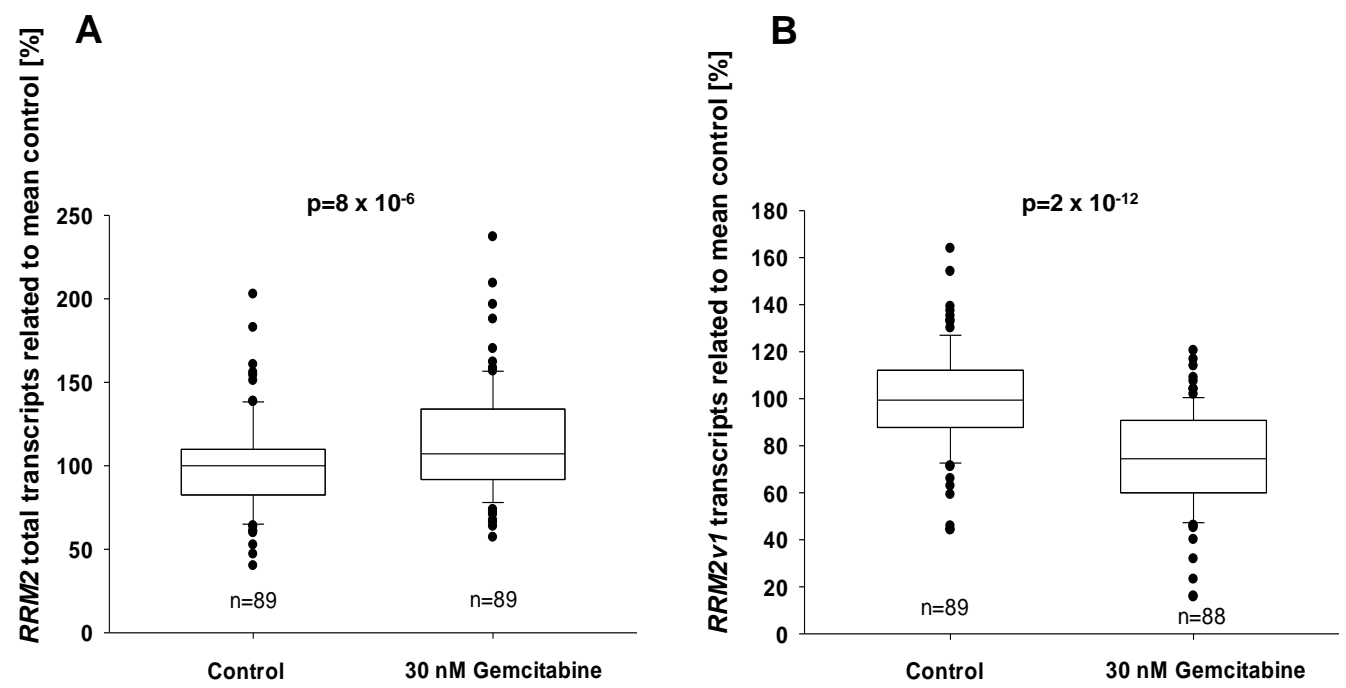

Figure 36: Gemcitabine effects on RRM2 transcript variant expression in LCLs. Panel A features the RRM2 total and panel B the RRM2v1 transcript expression in 89 LCLs exposed to either PBS (control) or $30 \mathrm{nM}$ of gemcitabine. Expression data obtained by qRT-PCR analysis were normalized to the weighted mean of $3664, B 2 M G, G A P D H, H P R T 1$ and $U B C$ serving as reference genes. The normalized data were then referred to the median of the PBS treatment, each for RRM2 and RRM2v1. The p-values indicating statistical differences between PBS and gemcitabine treatment were calculated by paired Wilcoxon signed rank test. 
Concordant to this ratio decrease in LCLs, a reduced ratio could be recorded for the pancreatic cancer cell lines AsPC1 $(p=0.001)$, PancI $(p=0.006)$ and MiaPaca-II ( $p=0.07$, see Figure 37 , panel B) exposed to $40 \mu \mathrm{M}$ of gemcitabine.
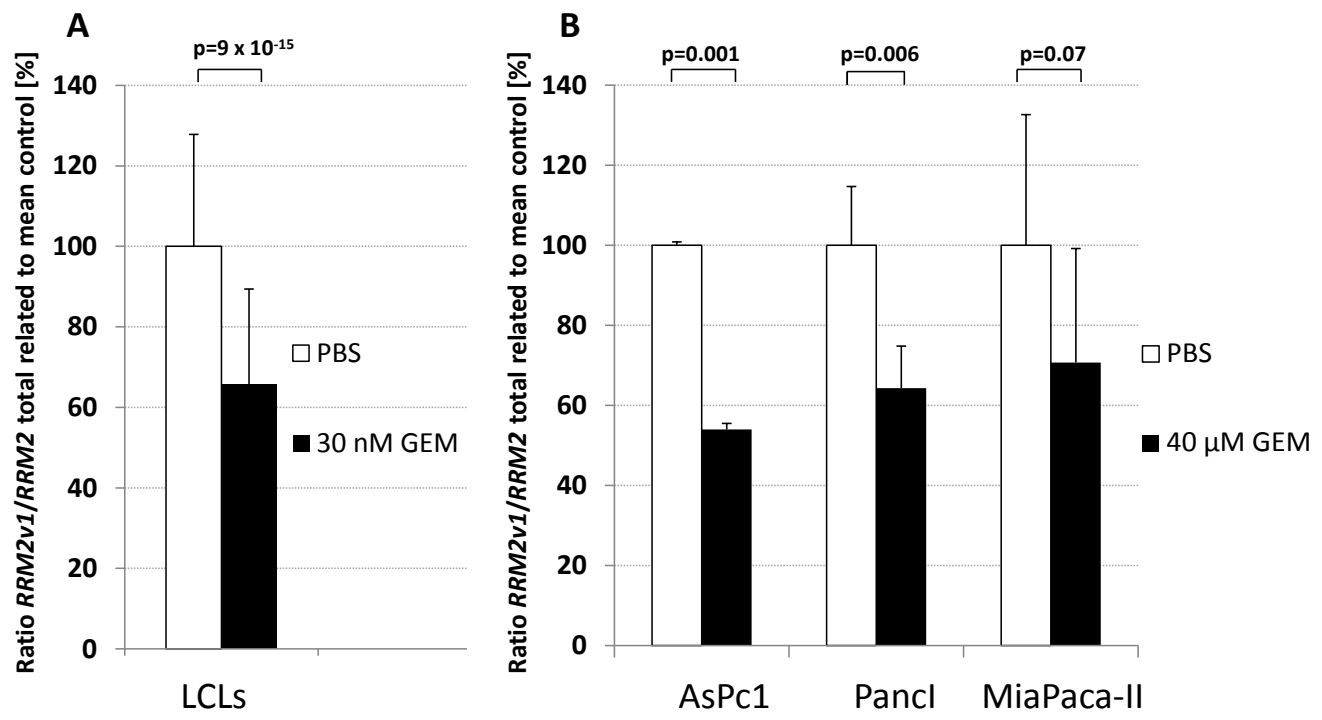

Figure 37: Consequences of gemcitabine on RRM2 transcript variant expression ratio. Panel A displays summarized data of 89 LCLs, panel B the three denoted pancreatic cancer cell lines each representing three independent measurements. LCLs were exposed either to PBS (control) or to $30 \mathrm{nM}$ of gemcitabine, pancreatic cancer cell lines to PBS or $40 \mu \mathrm{M}$ of gemcitabine due to substantially differing sensitivity of these cell types. RRM2v1/RRM2 ratios were calculated and then referred to the mean of PBS for each cell type. The bars represent mean values with the errors indicating standard deviation. Statistical differences were assessed by paired Wilcoxon signed rank test with the respective p-values indicated.

The differential effects of gemcitabine on $R R M 2$ transcript variant expression in cell lines raised the hypothesis whether analogous patterns might be present in patients as well. A marked induction of total RRM2 within one month upon chemotherapy start $(\mathrm{p}=0.001$, $\mathrm{n}=28$ ) was observed and appeared sustained up to ten weeks in relation to treatment start, whereas RRM2v1 expression did not change (see Figure 38). This data indicate that the rise in $R R M 2$ was due to the major transcript isoform $R R M 2$. 
A

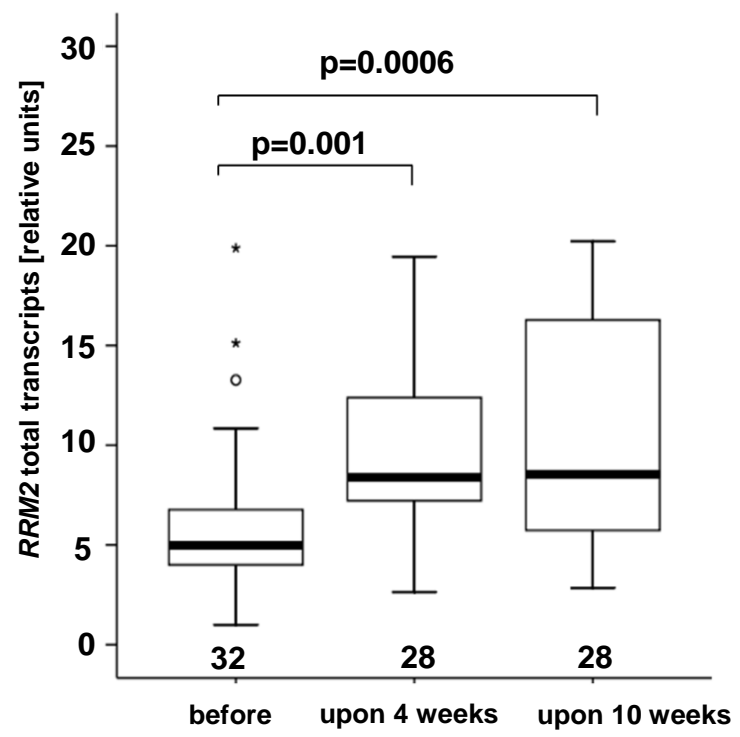

B

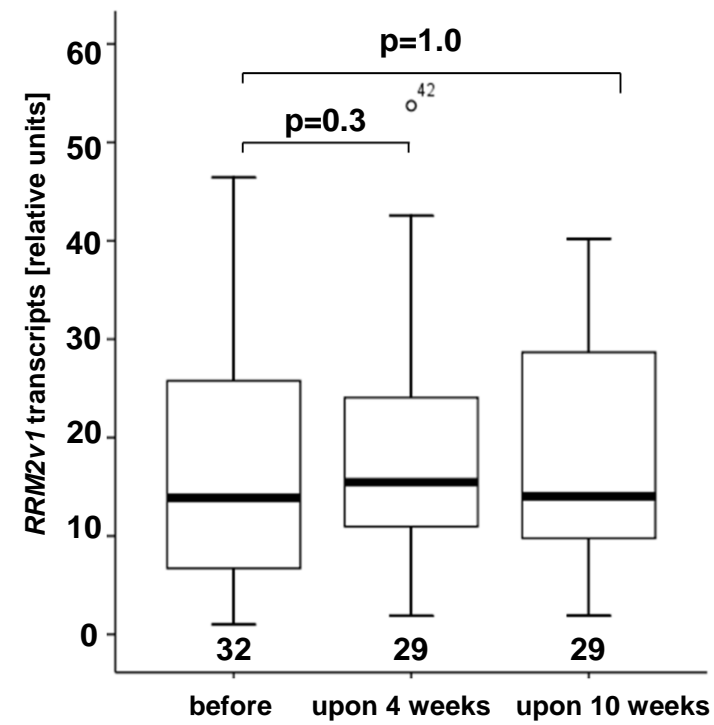

\section{Sampling in relation to chemotherapy start}

Figure 38: RRM2 transcript variant expression in patients' blood during chemotherapy. RRM2 total (A) and $R R M 2 v 1$ (B) transcript expression in blood before and during chemotherapy (upon 4 and 10 weeks) is shown. The data were ascertained by qRT-PCR and normalized to HPRT1. Statistical differences between each of the two sampling time points upon gemcitabine start and the reference determined prior to therapy were assessed by paired Wilcoxon signed rank test.

\subsubsection{Impact of RRM2 index SNP on RRM2 transcript variant expression}

The basal gene expression of RRM2 in 89 LCLs was not altered by rs1130609, neither for total RRM2 ( $\mathrm{p}=0.9)$ nor for RRM2v1 ( $\mathrm{p}=0.2)$ (see Figure 39). Also upon gemcitabine treatment, no statistically significant SNP effect could be observed with regard to total $R R M 2$ expression ( $\mathrm{p}=0.2$, compared to control). However, RRM2v1 suppression by gemcitabine was weaker in case of the $T$ variant allele ( $\mathrm{p}_{\text {trend }}=0.008$ for number of $T$ alleles compared to $G$ allele). This $T$ allele was associated with better clinical outcome. Due to limited sample number, assessment of RRM2 expression in dependence on rs1130609 was not feasible for pancreatic cancer cell lines and for patients during gemcitabine treatment. 
A

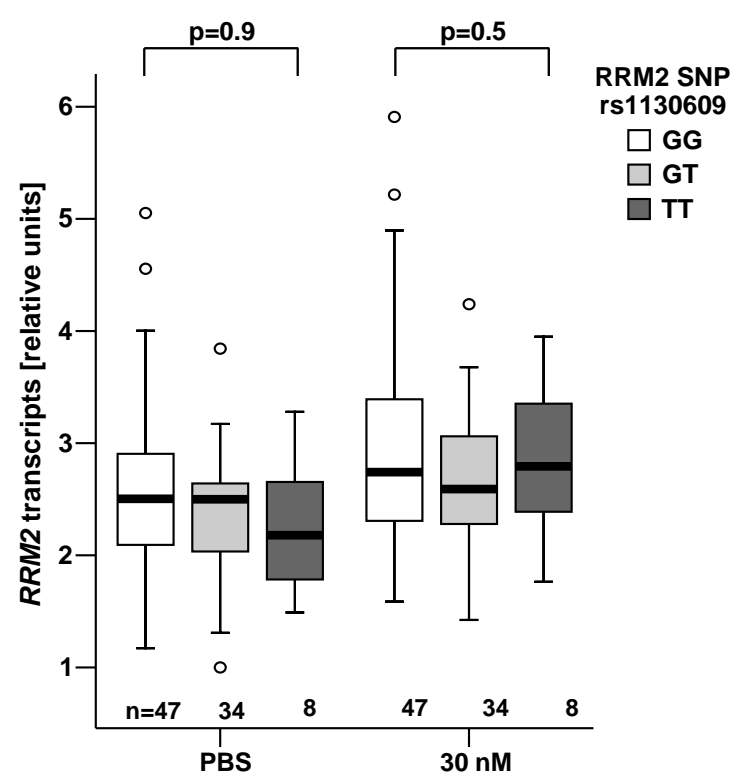

B

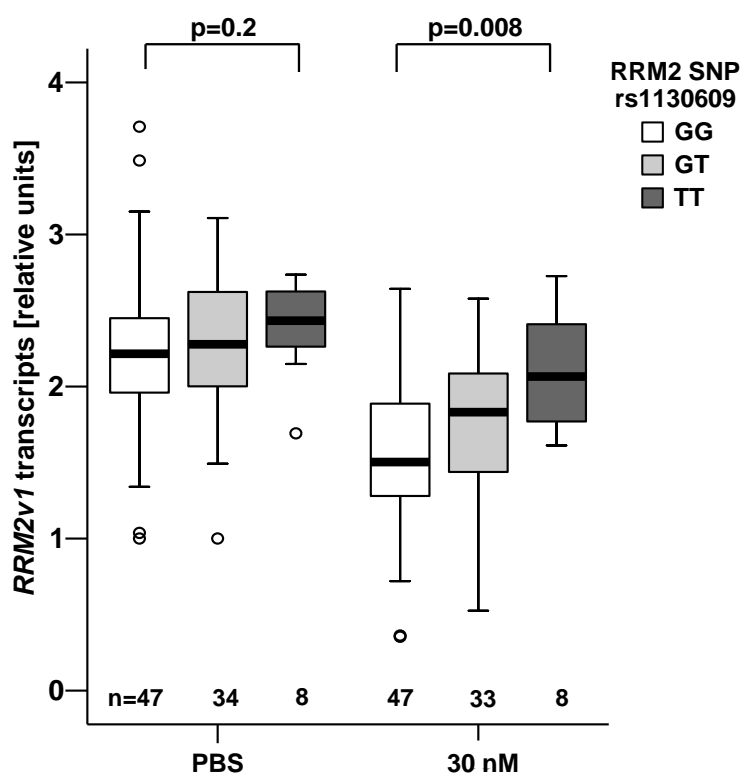

Figure 39: RRM2 transcript variant expression in dependence on $R R M 2$ rs1130609. $R R M 2$ total (A) and $R R M 2 v 1$ (B) transcript expression data in 89 lymphoblastoid cell lines treated with PBS (left half of either panel) and upon gemcitabine exposure ( $30 \mathrm{nM}$, right half). Allelic effects were evaluated by Jonckheere-Terpstra trend test. Expression data are identical to those described in Figure 36, in which gemcitabine treatment effects are displayed independent of rs1130609.

\subsubsection{Nuclear protein binding at RRM2 rs1130609}

With respect to the RRM2 transcript variant 2, rs1130609 is located in the Kozak sequence, which is known as a transcription factor binding region (FITZGERALD et al. 2004). To investigate nuclear protein binding at rs1130609 electrophoretic mobility shift assays (EMSA, see section 3.12) were conducted using nuclear cell extracts of HEK293 cells, LCLs and pancreatic cancer cell lines.

For nuclear extracts of LCLs, allele-specific protein binding was observed, with stronger binding for the wild type $G$ allele (see Figure 40, panel A). To assess allele specificity cold competition experiments were undertaken. The radioactive labeled probe containing the $G$ allele was competed with excesses (5-, 10- and 20-fold) of non-labeled probes with the $G$ and the $T$ allele. These competition experiments using nuclear cell extracts of LCLs indicated stronger affinity for the $G$ allele (Figure 40, panel B). In a linear regression analysis based on three independent competition experiments higher affinity to the $G$ versus the $T$ allele was observed at a p-value of 0.05 adjusted for the three levels of probe excess. 


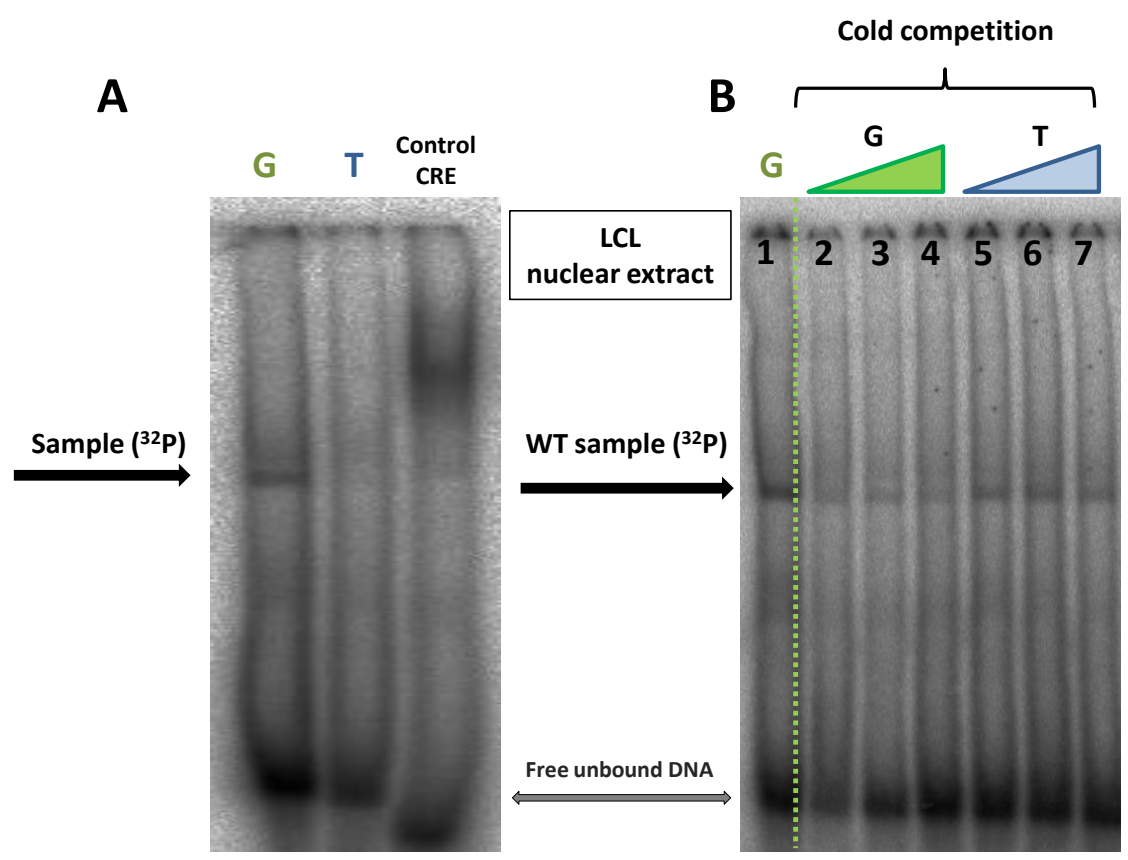

Figure 40: (A) Electrophoretic Mobility Shift Assay (EMSA) for RRM2 rs1130609 with LCL nuclear cell extract, (B) cold competition experiments for ${ }^{32} \mathrm{P}$ labeled rs113609 wild type probe. The radioactive labeled wild type probe was competed with non-labeled wild type probe with increased concentrations (line 2 - 4 show 5-, 10- and 20fold molar excess of the radioactive labeled probe) and competed with non-labeled variant probe (line 5 - 7, same concentrations), respectively. The unspecific probe CRE (cAMP response element) is shown as positive control in panel A. The band, indicating nuclear protein binding is marked with a black arrow.

Using nuclear extracts from HEK-293 cells, stronger binding and higher affinity to the $G$ allele at rs1130609 has been confirmed (see Figure 41).

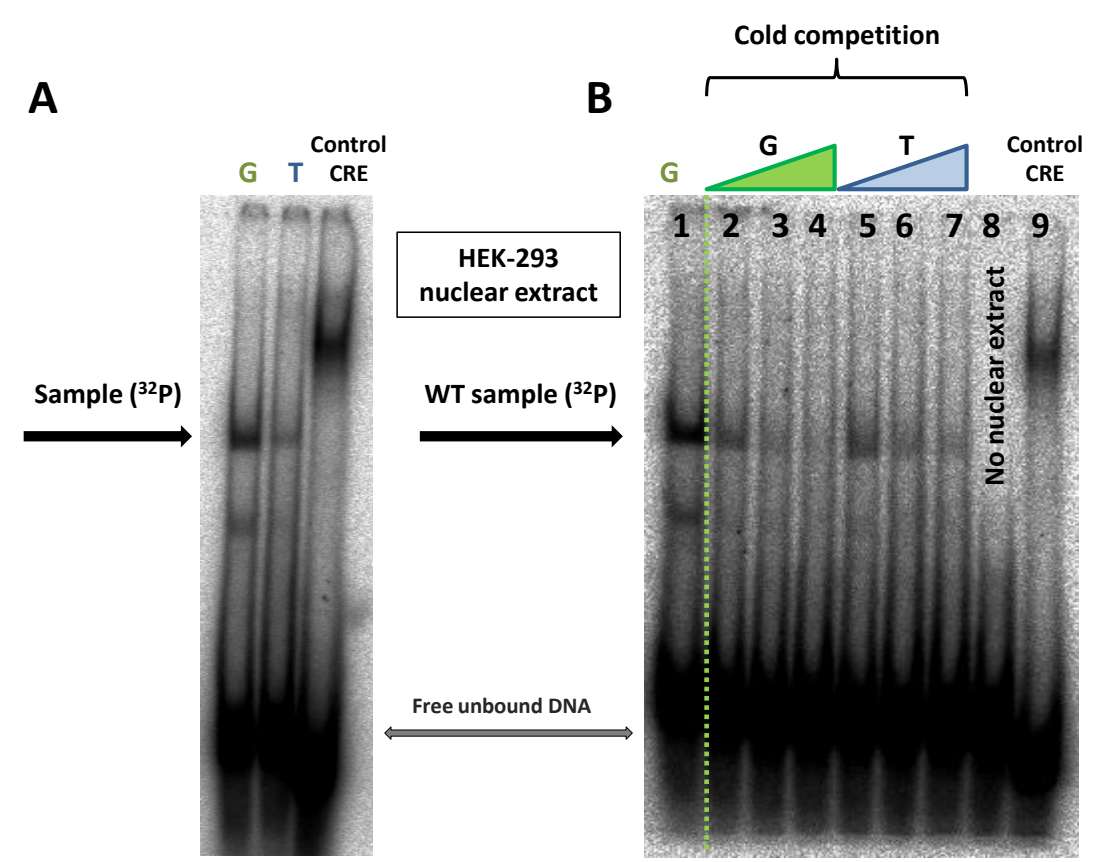

Figure 41: (A) Electrophoretic Mobility Shift Assay (EMSA) for RRM2 rs1130609 with HEK-293 nuclear cell extract, (B) cold competition experiments for ${ }^{32} \mathrm{P}$ labeled rs113609 wild type probe. The radioactive labeled wild type probe was competed with non-labeled wild type probe with increased concentrations (line 2 - 4, 5-, 10- and 20 -fold molar excess of the radioactive labeled probe) and competed with non-labeled variant probe (line $5-7$, same concentrations), respectively. Line 8 illustrates the negative control, without nuclear extract. The unspecific probe CRE (cAMP response element) is shown as positive control in line 9. The band, indicating nuclear protein binding is marked with a black arrow. 
Consistently, when extracts of pancreatic cancer cell lines were employed, radio-labelled probes with the $G$ allele exhibited stronger protein binding than those with the $T$ allele (band 1 corresponding to the interaction noticed for LCLs and HEK, see Figure 42). In contrast, an additional and larger DNA-protein complex appeared more pronounced in case of the $T$ allele (band 2 in Figure 42). Though this issue was seen for all four tested pancreatic cancer cell lines, it was more distinct in PaTu8988t and PancI.

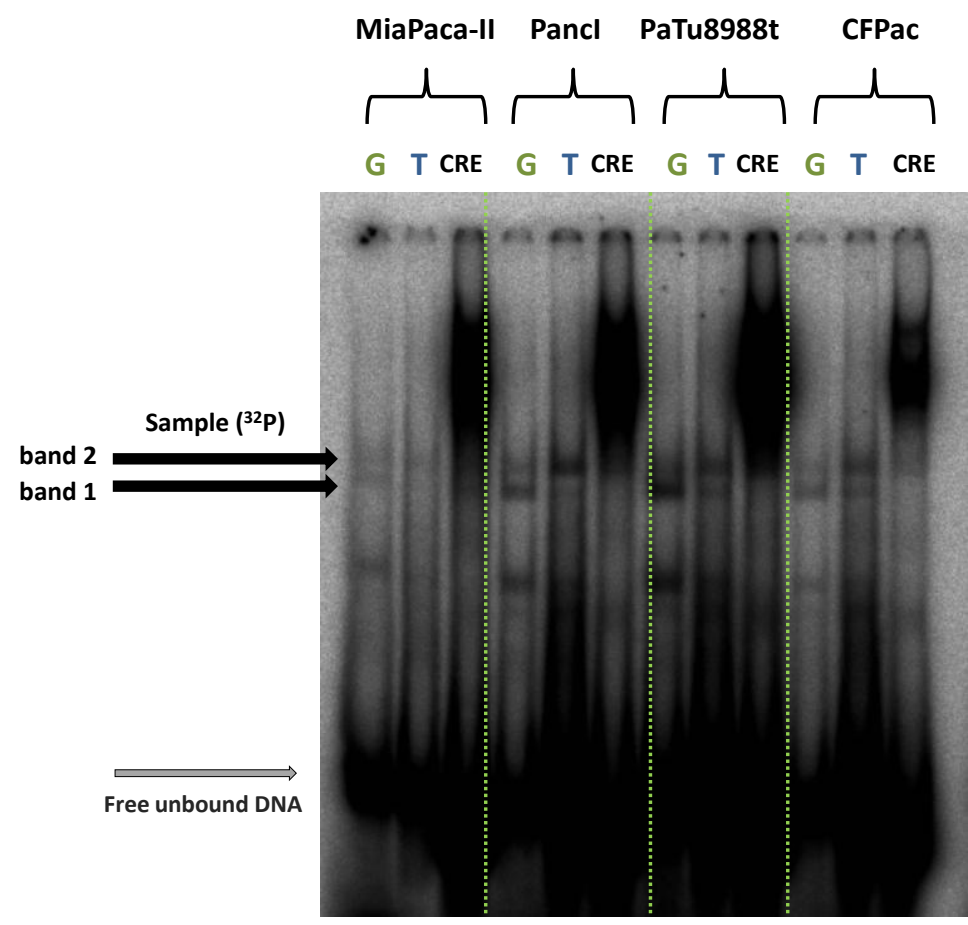

Figure 42: Electrophoretic Mobility Shift Assay (EMSA) for RRM2 rs1130609 with nuclear extracts of the pancreatic cancer cell lines MiaPaca-II, PancI, PaTu8988t and CFPac. The unspecific probe CRE (cAMP response element) is shown as positive control for each extract. The band, indicating nuclear protein binding (supposed to be the same compared to Figure 40 and Figure 41 in LCL and HEK-293 nuclear extracts) is denoted as band 1 and an additional and larger DNA-protein complex appeared, more pronounced in case of the $T$ allele denoted as band 2 .

In summary, these data suggest a protein which interacts more strongly with the $G$ allele, which was associated with worse clinical outcome (see section 1.5.1, Figure 4).

\subsubsection{Effects on translation}

To investigate the impact of RRM2 rs1130609 on protein synthesis, GFP-tagged RRM2 constructs (see 3.5.3) were analysed with an in vitro $\mathrm{TNT}^{\circledR}$ Quick Transcription/Translation system (see 3.8.4). Preliminary data via fluorescent quantification of the GFP signal suggest a $37 \%$ lower signal in presence of the variant $T$ allele, compared to the wild type $G$ allele at rs1130609. 


\section{Discussion}

In a genome-wide and a candidate gene approach the two genes WWOX and RRM2 elicited as particularly promising biomarkers in gemcitabine-treated PDAC. The major findings of my thesis with regard to these two genes are discussed in the following sections.

\subsection{WWOX}

Based on the clinical finding that WWOX rs11644322 is associated with patients' OS, I could get several lines of evidence for the functional role of WWOX in general and of the index SNP in particular with respect to cellular gemcitabine sensitivity. The WWOX gene located at chromosome region 16q23.3 - q24.1 encodes for a $46 \mathrm{kDa}$-sized protein described as a "fragile tumor suppressor" (SCHROCK AND HUEBNER 2015).

\subsubsection{WWOX rs11644322 affects cytotoxicity of gemcitabine but not 5-FU}

Testing of gemcitabine sensitivity in LCLs revealed increased resistance in presence of the $A$ allele at rs 11644322 (see section 4.1.1, Figure 15) accordant to the clinical finding of worse OS for patients treated with gemcitabine harboring this allele (see section 1.5.2, Figure 5). In contrary, in a comparative study, using 5-FU in the same set of LCLs, cytotoxicity was not altered by rs11644322 (data provided by Mr. Ruben Pflüger, personal communication, $\mathrm{p}=0.4$ ).

Concerning this observation, assessment of this SNP for treatment other than gemcitabine was not possible in absence of respective patient cohorts. Thus, it is debatable if the observed SNP effect is linked to cytostatic exposure in general or specifically to gemcitabine. At present, there are no data in literature comparing OS in PDAC for different cytostatics in dependence on germline genetic variability. However, with regard to hematological toxicity, a SNP in the gemcitabine deactivating CDA was reported as associated in patients treated with gemcitabine but not with 5-FU (FARRELL et al. 2012).

Differential intrinsic resistance between pancreatic cancer cell lines was observed upon exposure toward gemcitabine or 5-FU (SHI et al. 2002). In general, pancreatic cancer cell lines appeared to be much more sensitive toward gemcitabine than 5-FU. This was also 
seen in the cells I used (see Figure 28). Similar relations in sensitivity difference were found in LCLs (Figure 15). In this regard, LCLs appear as a suitable model to evaluate drug-specific cytotoxicity in dependence on genetic variability. Unlike pancreatic cancer cell lines, much higher numbers of genetically diverse LCLs are available to be tested for the impact of genetic polymorphisms. LCLs were used in previous studies as well to test for cytotoxicity of gemcitabine and cytosine arabinoside (Li et al. 2008). Whereas LCLs with their high sensitivity toward gemcitabine appear suitable to evaluate an impact of genetic polymorphisms, I am aware of the limitations of these cell lines with regard to pancreatic cancer. Nonetheless, common features in cellular drug response could be assumed for different cell types. Different expression levels of genes might modify sensitivity to a specific drug. A drug might be particularly efficient in a sub-group of patients with specific expression levels of genes related to handling of this drug or representing a molecular target for it. In this manner, expression levels of such candidate genes for a specific drug have been investigated in relation to clinical outcome. For instance, low expression of 5-FU-degrading DPD (dihydropyrimidine dehydrogenase) and high expression of the major molecular target TS could be favourable when this drug is applied (SHImoda et al. 2015). Otherwise, genes related to gemcitabine transport and metabolism might interfere with this drug's response (IWAмото et al. 2015). Besides such candidate genes, for which an interaction with a specific drug is evident, there are probably numerous other genes of which a substantial contribution is present but not yet identified. A possible "new" gene in this regard might be WWOX.

\subsubsection{WWOX expression affected by rs11644322}

Regardless whether the core region or the last exon were considered and regardless whether LCL samples were subjected to gemcitabine or not, in all conditions homozygous $A A$ allele of rs11644322 was accompanied by reduced WWOX expression levels (Figure 18). No relevant differences in WWOX transcript amounts could be detected between $A G$ and $G G$ genotypes in this cellular model. As the expression of the two investigated WWOX regions is highly correlated (Figure 17), similar association with a genetic polymorphism is obvious. This correlation appeared even intensified upon gemcitabine exposure suggesting a link between induced genotoxic stress and transcription of the entire $W W O X$ gene. Regarding mean transcription rate in the entire 
investigated LCL panel, that of exon 8-9 amounts to $67 \%$ in relation to the core coding region (see Figure 17, inserted bar plot).

\subsubsection{Consequences of overexpression of SP1 binding to rs11644322}

Allele-specific binding at rs11644322 was demonstrated previously for SP transcription factor family members (ROPPEL 2013). Weaker SP1 protein binding for the minor $A$ allele at the WWOX rs11644322 site was hypothesized to be related to less WWOX expression. Thus, I analyzed WWOX expression in relation to rs11644322.

In the panreatic cancer cell lines AsPC1, MiaPaca-II and PancI, I analyzed specifically the consequences of SP1 overexpression on WWOX transcription. Though statistical significance was not reached by three independent experimental repetitions, cell linespecific effects could be assumed (Figure 21) with expression induction of the WWOX core region only in MiaPaca-II. Genotyping at rs11644322 was carried out for these three cell lines. It turned out that PancI is derived from a host with $G G$ allelic configuration at rs11644322. AsPC1 seems to stem from an initially heterozyous GA carrier with later loss of the $A$ allele during carcinogenesis. In contrast, MiaPaca-II clearly showed heterozygosity. Since these are just observations on single cell lines, conclusions derived thereof are limited. Nonetheless, one might speculate about any relationship between this genotypic configuration and the observed differential responsiveness to SP1 overexpression in terms of WWOX transcription. Often, transcription factors are regulated on the activity level by phosphorylation (WHITMARSH AND DAVIS 2000) implying that expression level mostly is not limiting. However, in case of a poor interaction between a transcription factor and its DNA binding motif, it is conceivable that the full capacity of transcriptional activation is not reached under usual expression levels. Overexpression leads to an increased pool of activatable molecules, which might enhance binding according to the law of mass action in case of a less favourable binding motif. This hypothesis might argue for the idea that binding at rs11644322 is the reason for the differential effects observed upon SP1 overexpression. However, several other binding sites for SP transcription factor family members in the WWOX genomic region are conceivable, which were not addressed in my thesis. Nevertheless, if the hypothesis is assumed that rs11644322 is a relevant SP binding site, which regulates WWOX expression, one might ask about the spatial relationships since this SNP is located far downstream in an extraordinarily huge intron. 
In cell lines with overexpressed SP1, surprisingly, different effects of cytostatic drugs on WWOX gene expression were observed (Figure 22): Substantial suppression, moderate induction and no alteration of the WWOX core region transcription by gemcitabine in AsPC1, MiaPaca-II, and PancI cells, respectively, whereas virtually no alterations by 5FU. The second interesting observation at this point was the absence of WWOX core region suppression by irinotecan in PancI cells. In this cell line, which was identified to be gemcitabine resistant in terms of cytostatic activity (REJIBA et al. 2009), transcripts of WWOX exon 8-9 were not detected. The lack of exon 8-9 transcripts might be involved in cytostatic resistance (e.g. towards gemcitabine or irinotecan) indicating the need of the entire WWOX gene transcription for efficacy of these drugs. It is conceivable that the index polymorphism rs11644322 is involved in expression of the last exon (see Figure 18). The co-association of this SNP with $W W O X$ core region expression is plausible due to the high correlation of transcripts of the two investigated WWOX regions (displayed in Figure 17). From the data in that figure the primary effect of this SNP on WWOX regional expression cannot unambiguously be ascertained. In the subsequent chapters hypothesis taking into account, also spatial relationships are discussed.

\subsubsection{Rs11644322 located in extraordinarily huge intron: Looping hypothesis}

The last WWOX intron, which spans over $730 \mathrm{~kb}$, is one of the longest introns in humans. The longest known intron is $1.1 \mathrm{Mb}$ (intron 5 in KCNIP4, http://kirschner.med.harvard.edu/files/bionumbers/Human genome and human gene statistics.pdf). Large introns render the possibility of intra-molecular looping within the DNA. The involvement of genome's three-dimensional topography in transcriptional processes has become increasingly accepted within the last years (LI et al. 2012, SCHOENFELDER et al. 2010). Folded chromatin loops can bring gene regions into close proximity to cognate promoters or distant regulatory elements leading to gene activation (e.g. for the $C D 68$ gene spanning over a $2.5 \mathrm{~kb}$ distance (O'REILLY AND GREAVES 2007, MERCER et al. 2013) or the insulin gene looping over a range of $1.4 \mathrm{~kb}$ (BABU et al. 2008)). Further long-range enhancer-promoter communications are reported, e.g. for the sonic hedgehog (Shh) limb bud-specific enhancer, which interacts with its target promoter one megabase apart (AMANO et al. 2009). Another study found the SNP rs6983267 associated with higher risk of colorectal cancer to be located in a "gene desert" at the human chromosome 8q24. The rs6983267 containing region acts as an 
enhancer in reporter gene assays and interacts with the promoter in the $M Y C$ oncogene, residing $330 \mathrm{~kb}$ apart (TUUPANEN et al. 2009, POMERANTZ et al. 2009, SCHOENFELDER et al. 2010). Remote interaction over a distance of $200 \mathrm{~kb}$ between the 3'-UTR region and the promoter region of BCL2 was identified to be regulated via SATB1 (AT-rich sequence binding protein 1)-mediated chromatin looping (GoNG et al. 2011). Also similar noncancer related enhancing effects were observed with intronic SNPs (e.g. rs3857080 in intron 3 in the NR3C2 gene which was associated with increased potassium excretion (DALILA et al. 2015)).

As in the close vicinity of WWOX rs11644322, no transcripts were discovered (Figure 19), the region containing rs11644322 might act as enhancer with an upstream promoter region in a three-dimensional manner as well. SP transcription factor family members might affect such a mechanism. A similar looping mechanism has been reported for SP1 in relation to the human heme oxygenase-1 gene in renal cells, where SP1 siRNA and a SP1 binding site inhibitor led to loss of looping formation between the intronic enhancer and the $6 \mathrm{~kb}$ distant HO-1 promoter, identified via chromosome conformation capture assay (DESHANE et al. 2010).

This looping hypothesis is further supported by the data obtained upon exposure to the topoisomerase inhibitor irinotecan. As topoisomerases are required for proper DNAunwinding it could be assumed that these enzymes are also involved in remote interactions between DNA elements. Thereby, it appears plausible that irinotecan suppressed expression of WWOX in those cell lines (AsPC1, MiaPaca-II) with relevant expression of exons 8 and 9 flanking the index SNP, but not in PancI, in which last exon transcription was below the detection level (Figure 22). This effect observed in AsPC1 and MiaPaca-II was enhanced when cells were transfected with SP1 suggesting crucial involvement of an SP1-binding site like rs11644322.

Binding of the human transcription factor SP1 to 10-bp G+C-rich elements ("GC boxes") residing at -100 and $+1700 \mathrm{bp}$ relative to the RNA start site was studied. A synergism of the distantly located site with the promoter-proximal site was seen resulting in strongly activated transcription in vivo. This synergism is regarded as direct consequence of interactions between remote and local SP1, whereof the remote SP1 was translocated to the promoter via DNA looping (MASTRANGELO et al. 1991).

The previously identified allele-specific binding of the transcription factor specificity 
protein SP1 or SP3 at the rs11644322 (ROPPEL 2013) might represent such an enhancer element with mitigated function in case of the $A$ allele.

\subsubsection{Model linking functional and clinical findings for rs11644322}

A model linking the above-mentioned functional data in conjunction with the clinical findings is presented (Figure 43). The presence of the $G$ allele at the index SNP site results in stronger SP1 binding, which might lead to a stronger looping formation to the promoter region, resulting in induced WWOX transcription. This hypothesis would match to the finding of higher WWOX expression in LCLs (core region and last exon), lower $\mathrm{EC}_{50}$ values of gemcitabine (as WWOX enhances cytotoxicity of gemcitabine) resulting in better OS of patients. Gemcitabine treatment seems to be an important element in this cascade, but the mechanisms behind are still unknown.

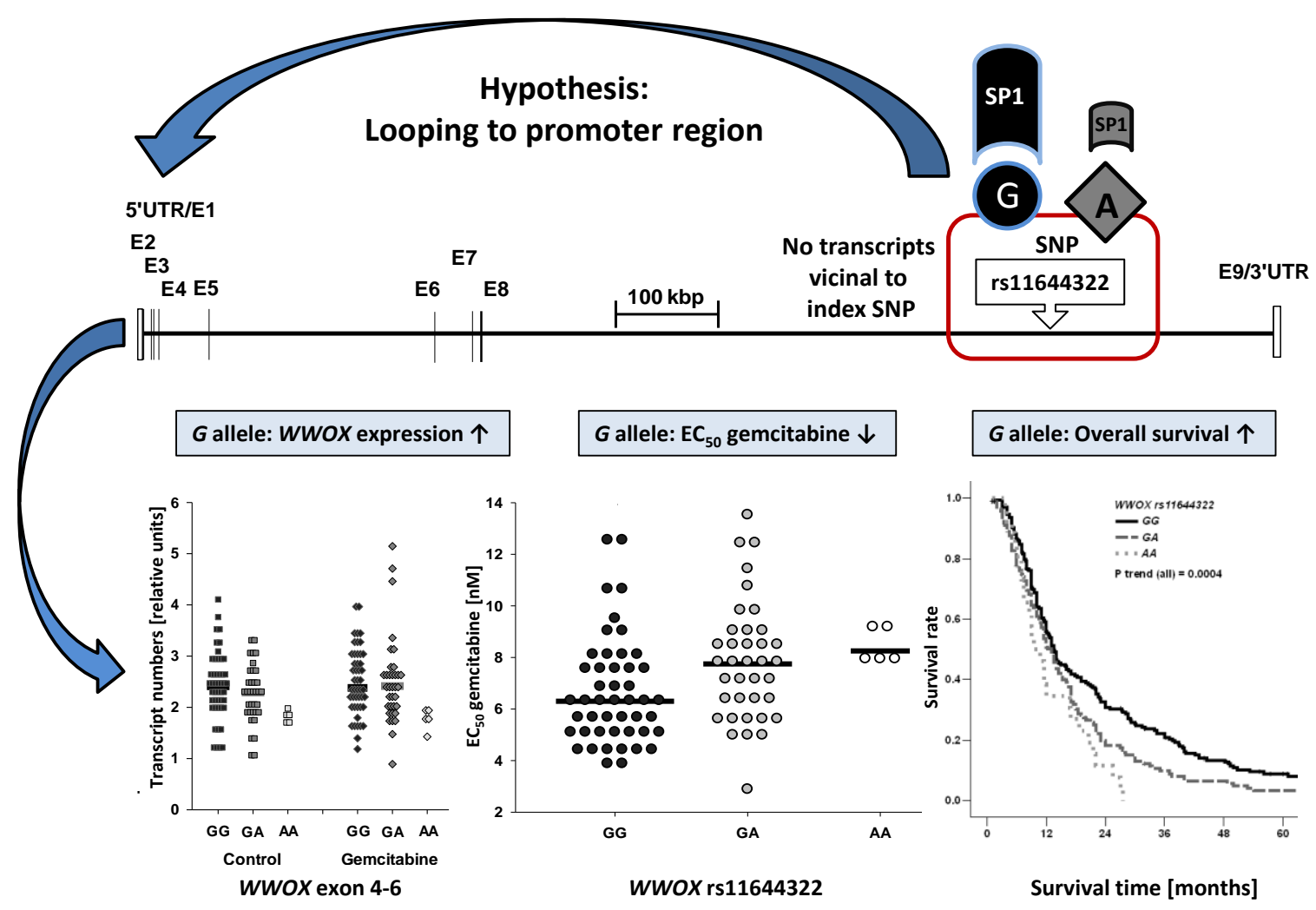

Figure 43: Hypothesis linking functional and clinical findings for rs11644322. Schematic illustration how differential SP1 binding at the rs11644322 site might affect WWOX expression via looping resulting in altered cellular sensitivity towards gemcitabine affecting clinical outcome (Kaplan-Meier curve, survival data according to RoPPEL 2013). Specifically, presence of the $G$ allele at rs11644322 accompanied by stronger SP1 binding and thus by enhanced WWOX expression might sensitize cells to the cytotoxic effects of gemcitabine, which in turn might reason the longer survival of patients carrying this allele. 


\subsubsection{WWOX knock-down slows cell proliferation and hampers gemcitabine cytotoxicity}

The finding of substantially decreased basal proliferation in PaTu8988t and L3.6 cells induced by siRNA-mediated WWOX knock-down (see Figure 27) is in line with decreased gemcitabine sensitivity in case of WWOX abrogation. However, as proliferation was reduced in a similar extent, the effects of WWOX knock-down differed substantially between these two cell lines. This raises the hypothesis about cell line specific interactions between gemcitabine and WWOX, possibly due to the respective genetic make-up. On the contrary, responsiveness of 5-FU was moderately and similarly affected in both cell lines (see Figure 28), what again suggests specific actions for gemcitabine. Consistently, the sensitivity of LCLs toward gemcitabine but not 5-FU (5-FU data in LCLs from Ruben Pflüger, personal communication) was affected by the WWOX SNP rs11644322 as outlined above (Figure 15).

Surprisingly, stable WWOX knock-down via shRNA transfection in PaTu8988t cells could not verify this effect observed for siRNA. First, the above-mentioned dramatic suppression of basal cell proliferation by siRNA-mediated WWOX knock-down (w/o any cytostatic drug applied) could not be detected upon shRNA transfection targeting WWOX. Second, gemcitabine sensitivity was not affected upon WWOX suppression by shRNA (Figure 31, panel A). However, when additional siRNA against WWOX was transfected, gemcitabine resistance was markedly increased in a similar manner (Figure 31, panel B) as seen before for the knock-down by siRNA only (Figure 28, left panel). These data indicate that shRNA-guided WWOX suppression by about $90 \%$ is not sufficient, neither to slow down cell proliferation nor to alter substantially the cytotoxic effects of gemcitabine. In other words, there seems to be a surplus of WWOX expression in regard to the analyzed phenotypes. A relative low number of WWOX molecules might be sufficient to drive cell proliferation as well as gemcitabine-mediated cytotoxic reactions.

Contemporary literature addressing interactions between gemcitabine and WWOX is still scarce. However, some current reports indicate a relationship of WWOX in regard to the regulation of epithelial to mesenchymal transition (EMT). EMT is characterized by downregulation of E-cadherin expression leading to disruption of cell-cell junctions and distribution of cells from the primary tumor (THIERY et al. 2009). Thus, EMT and/or 
backward (MET, reattachment of floating cells) are supposed to be crucial processes in tumor metastasis. EMT and an associated cancer stem cell phenotype are regarded as a major cause for therapy resistance in pancreatic cancer, e.g. shown for gemcitabine resistance in a panel of pancreatic cancer cell lines (MEIDHOF et al. 2015, ARUMUGAM et al. 2009, WANG et al. 2014). In endometrial cancer, WWOX was found to be related to the expression of markers for EMT/cell motility (PLUCIENNIK et al. 2015). In ovarian cancer stem cells, WWOX was identified to invert the EMT process resulting in reduced tumor invasion (YAN AND SUN 2014). This reversion to a MET phenotype may imply reinforced E-cadherin expression promoted by intracellular WWOX (BENDINELLI et al. 2015).

Both, decreased basal proliferation rate and enhanced resistance toward gemcitabine might represent a feature of induced EMT caused by lower WWOX expression in presence of the variant allele at rs11644322 (possibly due to weaker SP1 binding, see chapter 5.1.3). An increased EMT phenotype constitutes a plausible explanation for worse clinical outcome in case of an allele connected with low WWOX expression (see Figure 44).

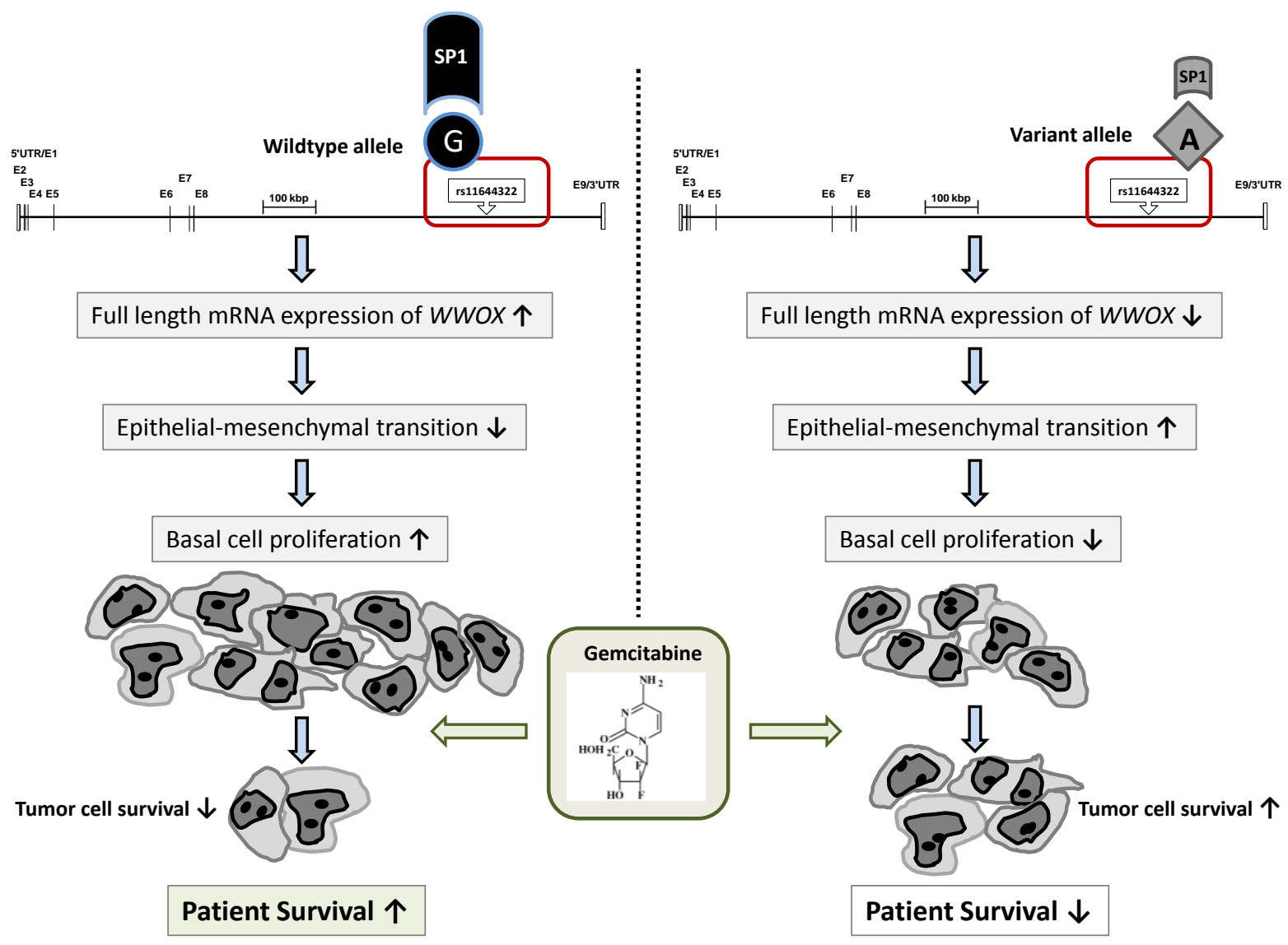

Figure 44: EMT as a putative mechanism for the effects of WWOX rs11644322. The chart shows hypothesized consequences for the rs11644322 wild type (left side) and variant allele (right). 


\subsubsection{WWOX in the context of genomic stability and carcinogenesis}

In view of the fact that genomic instability is a feature of human cancers, it is noteworthy that WWOX spans the second most common fragile site in the human genome, termed FRA16D (BEDNAREK et al. 2000, RIED et al. 2000, BEDNAREK et al. 2001). Instability at the FRA16D site was associated with poor prognosis in human cancers. Mechanistically, this was linked to induction of aberrant WWOX expression with, in most cases, a lack of Cterminal sequences needed for $W W O X$ acting as an oxidoreductase. As cancer cells are known to possess altered metabolism (Warburg effect), it was hypothesized that aberrant WWOX contributes to changes in metabolism in cancer (RICHARDS et al. 2015).

Moreover, WWOX is described to play a direct role in DNA damage response (DDR), a crucial antagonist of genomic instability. In case of WWOX deficiency, reduced activation of the ataxia telangiectasia-mutated (ATM) checkpoint kinase and hampered DNA repair was reported, what might explain the loss of WWOX during cancerogenesis (ABU-ODEH et al. 2014).

The WWOX SNP rs11644322 is more than $300 \mathrm{~kb}$ apart from the downstream end of the FRA16D region. Thus, an interaction is unlikely. Moreover, no genetic marker in high LD with rs11644322 was identified to touch the FRA16D region.

\subsubsection{WWOX in the context of apoptosis induction and DNA damage repair}

WWOX mRNA expression and cellular gemcitabine sensitivity in LCLs were identified to be correlated (see Figure 23). As WWOX is known to be involved in stress and apoptotic responses (CHANG et al. 2003), a connection between transcripts of WWOX and those of apoptosis-related genes was presumed. In vitro studies identified an interaction of the WWOX protein with various binding partners to regulate proliferation, cellular apoptosis and/or cell maturation (SCHROCK AND HUEBNER 2015).

Overexpression of WWOX fosters apoptosis and inhibits proliferation of cancer cells (HU et al. 2012, CHIANG et al. 2013). In addition, WWOX was found to block the Wnt/betacatenin pathway (BouTEILLE et al. 2009). Mechanistically, this effect is exerted through inhibition of transcriptional activity of a beta-catenin coactivator by WWOX (EL-HAGE et al. 2015). Suppression of WWOX was reported to promote Wnt/beta-catenin transcription (HUA et al. 2015). Recently, gemcitabine effected stronger in terms of 
proliferation inhibition and apoptosis induction when Wnt/beta-catenin signalling was disrupted (Jung et al. 2015). Vice versa, activation of this pathway was shown to enhance resistance toward gemcitabine in pancreatic cancer cell lines (NAGANo et al. 2013). Based on these cited reports and the data I gained it can be hypothesized that WWOX mitigates Wnt/beta-catenin signalling thereby enhancing gemcitabine efficacy. Alternatives for WWOX actions in the context of gemcitabine sensitivity are also conceivable.

WWOX was shown to interact with p53 and its homologue p73 by WW-containing domains thus enhancing stress response-induced cell death when translocated into the nucleus (ABu-Odeh et al. 2014, Aqeilan et al. 2004, ChAng et al. 2003). Furthermore, WWOX is able to enhance cytotoxic signalling (e.g. induced by tumor necrosis factor) by downregulating BCL2, but upregulating p53 thereby acting as a pro-apoptotic mitochondrial protein (CHANG et al. 2001). GADD45A constitutes an important component linking p53 downstream to DNA base excision repair (SMITH et al. 2000, JUNG et al. 2013). Intriguing, distinctions were observed for correlation of WWOX exonspecific transcripts and mRNA expression of BCL2, GADD45A, and TP53 (Table 65).

WWOX protein phosphorylation at tyrosine-33 was reported necessary for p53mediated cell death in a fibroblast cell line (CHANG et al. 2005). Protein interaction between p53 and WWOX was strengthened when MDM2, a nuclear localized E3 ubiquitin ligase, antagonizing p53, was blocked. Interestingly, in glioblastoma cell lines with mutant but not with wild type p53, ectopic WWOX overexpression induced apoptosis, by a mechanism independent of the intrinsic apoptotic pathway (CHIANG et al. 2012). This observation suggests alternative routes of WWOX-induced apoptosis when p53 is not functional. Eventually, WWOX restores chemosensitivity toward gemcitabine, which was shown to be lost in pancreatic adenocarcinoma with mutant p53 (FIORINI et al. 2015). With an alteration frequency of $40-75 \%$ p53 is one of the most mutated genes in PDAC (Li et al. 2004). PDAC metastasis was reported to be driven by mutant p53 (Morton et al. 2010, WeIsSMUEller et al. 2014). Perhaps, WWOX is involved in these processes. In LCLs, mRNA transcripts (TP53) coding for p53 protein did not correlate with gemcitabine sensitivity. However, there was a positive correlation between transcripts of TP53 and the WWOX core region particularly upon gemcitabine exposure. In contrast, the relationship with the last WWOX exon transcripts was stronger under basal conditions. Thus, one might speculate whether WWOX-p53 interactions are modulated by regional WWOX transcription. Possibly, genotoxic stress induced by 
gemcitabine triggers cellular signals inducing parallel transcriptional induction of TP53 and the $W W O X$ core region. Expression of the last exon, however, might rely on distinct mechanisms. As a limitation, it should be noted that data I obtained at this point only refer to transcription and do not address protein levels.

In the above-mentioned panel of 89 LCLs, GADD45A was correlated with WWOX expression when exposed to gemcitabine, but not at baseline conditions (Table 65). Furthermore, GADD45A transcript numbers at gemcitabine exposure, but again not at baseline, exhibited a strongly inverse correlation with $\mathrm{EC}_{50}$ for gemcitabine in LCLs (Figure 24). This relationship was not impacted by variations in LCL proliferation in a relevant manner. These data argue for stress-induced responses involving GADD45A upon a variety of genotoxic stimuli (FoRNACE et al. 1992).

GADD45A is involved in a variety of biological processes like cell cycle, senescence, apoptosis and nucleotide excision repair and its disruption results in genomic instabilty (Hollander AND FoRNACE 2002). In hematopoietic stem cells, apoptosis was damped in absence of GADD45A (CHEN et al. 2014). Enhanced levels of GADD45A mRNA and protein were reported for splenic lymphocytes from mice exposed to ionizing radiation or other agents inducing DNA damage and growth arrest (HollandER et al. 2001). Thus, the correlation between GADD45A expression and sensitivity toward gemcitabine observed in LCLs appears plausible.

Among the GADD45 family members, GADD45A is the only one responsive to p53 (Hollander et al. 1993). By that, GADD45A interacts with apoptosis-related genes and is involved in DNA repair (HILDESHEIM AND FORNACE 2002). Pro-apoptotic effects of GADD45A are often mediated by p38 and JNK (c-Jun N-terminal kinase), which in turn represent upstream activators of GADD45A constituting a positive feedback loop (reviewed in SALVADOR et al. 2013). GADD45A was established as a component connecting p53-dependent cell cycle checkpoint and DNA repair by interacting with the proliferating cell nuclear antigen ( Вмітн et al. 1994). It counteracts mitosis by inhibiting specifically the Cdc2-cyclin B1 kinase complex (ZHAN et al. 1999). Beyond that, the acidic GADD45A was identified to bind to chromatin structures around damaged DNA sites thus making them more accessible for DNA repair machinery components like topoisomerases (CARRIER et al. 1999).

Whereas gemcitabine induces GADD45A transcription (in median by 3 -fold in LCLs), this 
drug was identified to specifically inhibit GADD45A-mediated DNA demethylation (SCHAFER et al. 2010). For GADD45A mutant mice, genomic instability and tumorgenesis was observed representing common features of human cancers, which were linked to changes in DNA methylation patterns (BARRETo et al. 2007, BIRD 2002, HollANDER AND FORNACE 2002). Reduced GADD45A expression was hypothesized to induce hypermethylation and thus inactivate tumor suppressor genes as MLH1 (mutL homolog1) (BARRETO et al. 2007). At this point, the net effect of gemcitabine on GADD45A functions (increased transcription versus mitigated demethylation activity) remains to be elucidated.

Direct or indirect interactions between GADD45A and WWOX are likely, however, so far not addressed in literature. Exact mechanisms for the proposed interactions between WWOX and GADD45A remain to be elucidated. Transcriptional regulation of GADD45A by WWOX, at least, is unlikely as I could not detect any alterations in GADD45A expression upon siRNA-mediated WWOX knock-down. An interaction with the Wnt/beta-catenin pathway, as outlined above for WWOX, is conceivable as GADD45A favors distribution of beta-catenin to the cell membrane and its cytoplasmic and nuclear degradation (Ji et al. 2007).

\section{$5.2 \quad$ RRM2}

RRM2 is part of physiological nucleotide synthesis and counteracts cytotoxic effects of gemcitabine on DNA synthesis. In the subsequent chapters, findings obtained during my thesis for RRM2 in general, and the SNP rs1130609 in particular are discussed in relation to the contemporary literature.

\subsubsection{RRM2 expression increases upon gemcitabine}

With regard to entire transcriptome analysis in AsPC1 and MiaPaca-II cells, RRM2 expression increased upon gemcitabine exposure (Table 66). Intriguingly, this RRM2 induction was highlighted as it was stronger than that of any other protein-coding transcript in this setting. Consistent with this finding, expression of the RRM2 major isoform, which accounts for the vast majority of transcripts, was enhanced upon gemcitabine in LCLs (Figure 36, panel A) and in patients within one month after gemcitabine-based chemotherapy start (Figure 38, panel A). 
Overexpression of RRM2 is described as a hallmark of gemcitabine resistance in pancreatic cancer cell lines (WANG et al. 2015, NAKANO et al. 2007). This induction of $R R M 2$ by gemcitabine was reported to be mediated via $E 2 F 1$ transcriptional activation. $R R M 2$ upregulation is regarded as part of DNA damage response leading to enhanced cellular DNA repair. According to this, targeting gemcitabine-dependent RRM2 expression is hypothesized as promising strategy to overcome gemcitabine resistance (LAI et al. 2014).

In patients suffering from PDAC, pre-therapeutic tumoral RRM2 mRNA expression was reported as a prediction marker for sensitivity to gemcitabine-based adjuvant chemotherapy. Lower RRM2 expression was accompanied by a better patient survival (FujiTA et al. 2010, ITоI et al. 2007). In this manner, the observed induction of RRM2 during chemotherapy courses with gemcitabine might add the peripheral blood stream as a system to monitor occurrence of secondary resistance toward this drug. Alternatively, as gemcitabine di- and triphosphate metabolites counteract RRM2 activity, it is also possible that transcriptional induction of RRM2 may reflect stronger gemcitabine activation and efficacy. Thus, interpretation of these observed expression changes should be done with caution since survival data of the respective patients have not been analyzed yet.

\subsubsection{RRM2 variant expression is differentially affected by gemcitabine}

Two human RRM2 transcript isoforms are known (Figure 34). The RRM2 transcript isoform with the shorter 5 '-tail represents the vast majority of $R R M 2$ transcripts. This implies that the data discussed in chapter 5.2.1 virtually reflect this isoform. The second variant, which features an extended 5'-region, exhibited markedly different response to gemcitabine. This resulted in a shift of the isoform ratio favoring the major one upon gemcitabine exposure in LCLs (Figure 36, Figure 37 panel A), pancreatic cancer cell lines (Figure 37, panel B) as well as in patients blood during chemotherapy (Figure 38). This finding suggests alternative promoters or interacting enhancer elements to drive versatile gene expression (AYOUBI AND VAN DE VEN 1996). To the best of my knowledge, no transcript isoform-specific investigations have been undertaken so far in literature. 


\subsubsection{Index SNP affects $R R M 2$ transcript variant-specific expression}

No statistically significant impact of $R R M 2$ index SNP on transcription of the RRM2 major isoform could be identified (Figure 39, panel A). However, an increased expression of the extended 5'-region variant was observed with increasing numbers of the $T$ variant allele at the index SNP rs1130609. This association appeared intensified upon gemcitabine exposure (Figure 39, panel B).

The SNP rs1130609 is located in the Kozak sequence regarding the major transcript isoform and at codon 59 with respect to the isoform with 5 '-extension. As only the latter was affected by this SNP a classical modulation of promoter activity is not assumed. Alternative hypotheses include an enhancer element for transcription of the extended isoform modulated by this SNP or an indirect consequence of a primary impact of this SNP on major transcript isoform expression (see below, section 5.2.4).

Isoform-specific gene transcription mediated by polymorphisms was also reported for the progesterone receptor $(P R)$ gene associated with endometrial cancer risk (DE VIVo et al. 2002).

\subsubsection{Allele-specific binding at the index SNP site}

Using nuclear extracts from different cell lines, allele-specific protein binding was observed at rs1130609 with stronger binding in presence of the $G$ allele (see Figure 40 and Figure 41). This allele was the one associated with poor clinical prognosis. This SNP is located in the Kozak sequence, 6 bp prior to the translation start site, which was described as a typical binding site for transcription factors as SP1, NF-Y, ETS and NRF-1 (FITZGerald et al. 2004). The identity of the binding protein could not be identified. At least, SP1 was excluded. However, it is unlikely that allele-specific transcription factor binding constitutes a relevant mechanism in this issue since no impact on the expression of the respective (major) isoform could be noticed (Figure 39, panel A). That raises the assumption that translation to protein rather than gene transcription might be impacted by this SNP modifying the Kozak sequence. 


\subsubsection{Unifying model how the RRM2 SNP might act}

Presumed mechanisms linking the RRM2 rs1130609 SNP effect to RRM2 transcript expression and RRM2 protein translation are illustrated in an unifying model (see Figure 45): Di-and tri-phosphorylated gemcitabine metabolites inhibit the physiological function of RRM2 by competing with ADP, CDP, GDP, and UDP. Thus decreased levels of dADP, dCDP, dGDP, and dUDP stimulate RRM2 transcription, most probably that of the major variant. In presence of the $G$ wild type allele, translational mechanisms are supposed to work proper leading to unimpaired RRM2 protein synthesis. In this case, there is no need for enhanced transcription of the alternative 5 '-extended isoform V1. Vice verca in presence of the $T$ variant allele, the translational machinery is assumed to act less efficient, what impairs protein translation. As a consequence, expression of isoform V1 is stimulated.

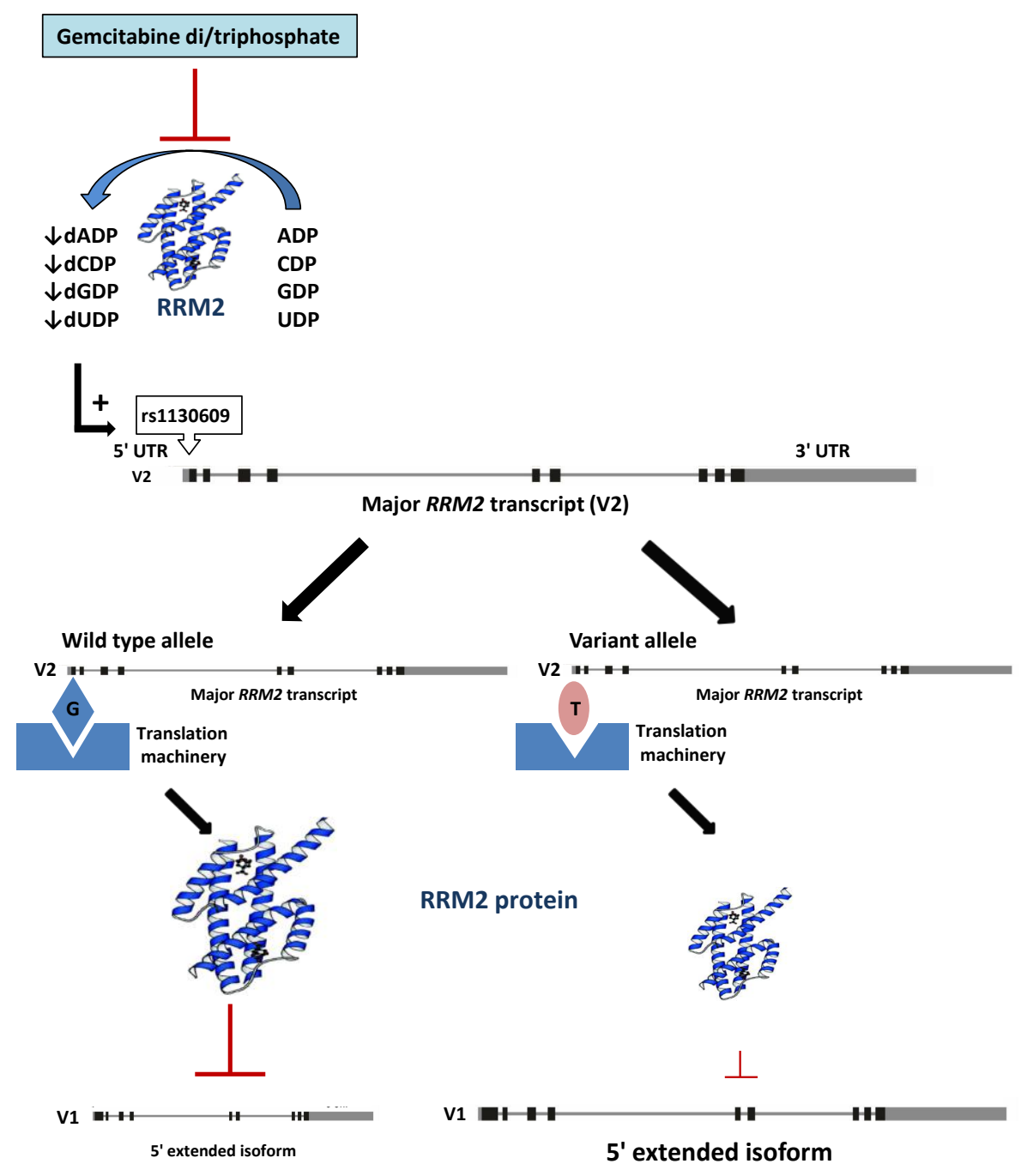

Figure 45: Hypothesized impact of RRM2 rs1130609 on RRM2 transcript expression and protein translation. The major transcript isoform is denoted as V2, the 5'-extended one as V1. 


\subsection{Limitations}

Regarding to the results of my thesis some limitations have to be considered. Sensitivity testing toward gemcitabine was performed in a set of LCLs instead in pancreatic cancer cell lines. The reason for this was the limited number of genetically divers pancreatic cancer cell lines. A clear link of SP1 overexpression with the WWOX index SNP is debatable since there are several other sites containing the consensus sequence for SP1 binding. Genome-wide consequences on transcriptome were assessed upon shRNA against WWOX, what subsequently turned out to be insufficient. Instead, transcriptome analysis upon siRNA-mediated WWOX knock-down should have been performed.

Though full integrity of the generated $R R M 2$ vector constructs was proven, translational effects of the two RRM2 index SNP alleles, as assessed by an in vitro Transcription/Translation system, were not clearly distinguishable. In view of an overall low signal intensity the difference of $37 \%$ between the two alleles is debatable. Further elaboration is required to decipher if there is any allelic distinction in translation efficacy. Regarding the prospective patient cohort, clinical outcome data were lacking and thus the medical relevance of the observed RRM2 induction is not clear. 


\subsection{Outlook}

Based on the results of my thesis, further investigations are necessary to establish WWOX in general and the rs11644322 SNP in particular as biomarker in gemcitabinetreated pancreatic cancer. In clinical regard, prospective and randomized trials should address this SNP. In functional regard, deeper mechanistic understanding how WWOX interferes with cytotoxic effects provoked by gemcitabine might contribute to improve treatment efficacy. A hypothesized model for the putative role of WWOX (modulated by the SNP rs11644322) in dependence on the p53 mutation status is proposed in Figure 46: The principal assumption is that WWOX might substitute, at least in part, for p53 function, which becomes particularly relevant if the latter is inactivated by mutation what frequently occurs in cancer. In presence of the $G$ allele at rs11644322 (see Figure 46, panel A) higher WWOX expression may foster cytotoxicity of gemcitabine by inhibiting both wnt/ $\beta$-catenin signaling and EMT. In contrast, in case of the $A$ allele (Figure 46, panel B) this disinhibiting effect of WWOX is assumed to be mitigated resulting in less gemcitabine cytotoxicity. These presumed interactions and analyses of components involved in the genotoxic response like the p53-inducible GADD45A should be elucidated in detail. Moreover, following this suggested model the effect of WWOX might be particularly relevant in case of inactivated p53, what appears promising to study in PDAC tissues with respect to clinical outcome.

A

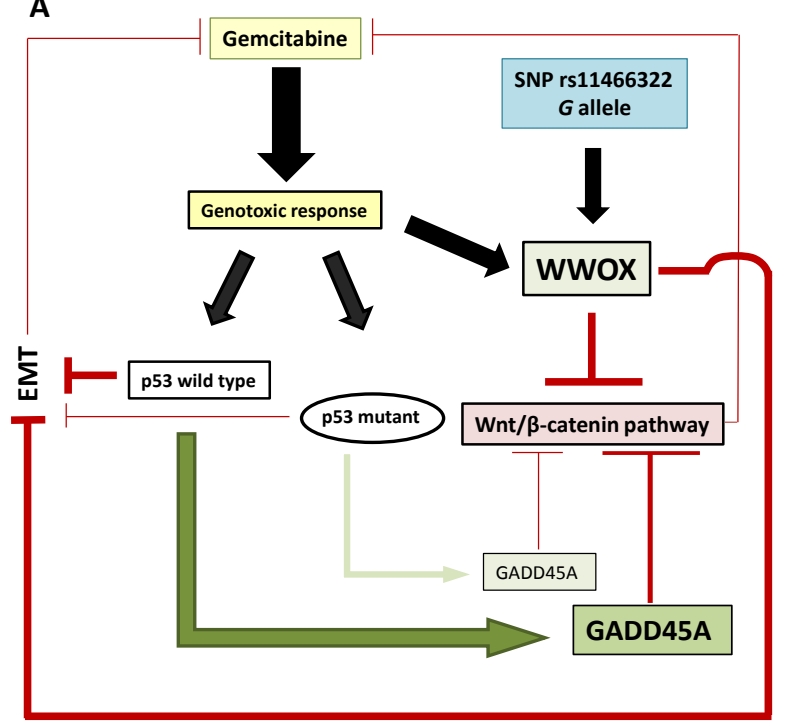

B

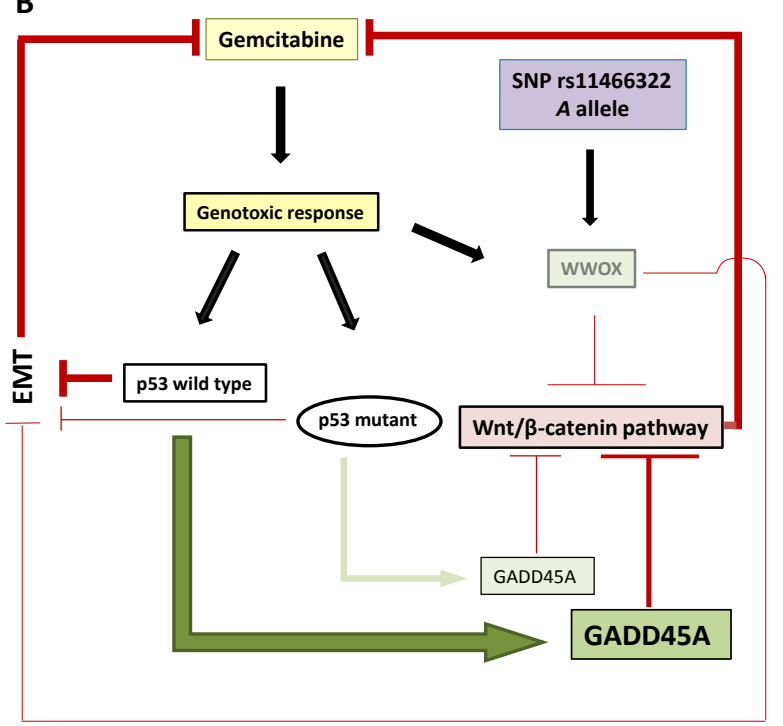

Figure 46: Hypothesized interactions of WWOX with p53, EMT and the Wnt/ $\beta$-catenin pathway. Panel A demonstrates the model in case of the wild type $G$ allele at the WWOX SNP rs11644322, panel B in case of the variant $A$ allele, respectively. See text for details. 


\section{Conclusion}

Regarding WWOX, by several lines of evidence I could delineate specific functional relations with gemcitabine supporting the clinical association. The data I gained may assist to circumvent failure of gemcitabine-based chemotherapy in PDAC. Though several mechanisms have been studied in this thesis and elicited striking results. The full interactions of WWOX in general and of the index SNP in particular with the DNA damage repair and the apoptotic machinery remains to be clarified. In view of the recently strongly increasing number of literature reports, highlighting the role of WWOX in the context of carcinogenesis, functional data addressing drug-specific interactions valuably expand the mechanistic understanding of this factor.

With respect to RRM2, a mechanism of action for a Kozak sequence polymorphism is proposed. Pending an unequivocal functional read-out for assessing an allele-specific impact on translation the data I obtained could contribute to the understanding of RRM2 in relation to gemcitabine resistance. Future strategies to overcome such resistance may consider this $R R M 2$ SNP. The clinical relevance of $R R M 2$ transcriptional induction during chemotherapy along with a possible modulation by this SNP remains to be further elaborated. 


\section{References}

Abbruzzese, J. L., Grunewald, R., Weeks, E. A., Gravel, D., Adams, T., et al. (1991). "A phase I clinical, plasma, and cellular pharmacology study of gemcitabine." J Clin Oncol 9(3): 491-498.

ABU-Odeh, M., BAR-MAG, T., HUANG, H., KIM, T., SALAH, Z., et al. (2014). "Characterizing WW domain interactions of tumor suppressor WWOX reveals its association with multiprotein networks." J Biol Chem 289(13): 8865-8880.

Abu-Odeh, M., Salah, Z., Herbel, C., Hofmann, T. G. and Ageilan, R. I. (2014). "WWOX, the common fragile site FRA16D gene product, regulates ATM activation and the DNA damage response." Proc Natl Acad Sci U S A 111(44): E4716-4725.

Amano, T., SAgal, T., TANABe, H., Mizushina, Y., NAKAZAWA, H., et al. (2009). "Chromosomal dynamics at the Shh locus: limb bud-specific differential regulation of competence and active transcription." Dev Cell 16(1): 47-57.

Aqeilan, R. I., Pekarsky, Y., Herrero, J. J., Palamarchuk, A., Letofsky, J., et al. (2004). "Functional association between Wwox tumor suppressor protein and p73, a p53 homolog." Proc Natl Acad Sci U SA 101(13): 4401-4406.

Arisawa, T., TAhara, T., Shibata, T., Nagasaka, M., Nakamura, M., et al. (2008). "The influence of polymorphisms of interleukin-17A and interleukin-17F genes on the susceptibility to ulcerative colitis." J Clin Immunol 28(1): 44-49.

Arisawa, T., Tahara, T., Shibata, T., Nagasaka, M., Nakamura, M., et al. (2007). "Genetic polymorphisms of molecules associated with inflammation and immune response in Japanese subjects with functional dyspepsia." Int J Mol Med 20(5): 717-723.

Artinyan, A., Soriano, P. A., Prendergast, C., Low, T., Ellenhorn, J. D., et al. (2008). "The anatomic location of pancreatic cancer is a prognostic factor for survival." HPB (Oxford) 10(5): 371-376.

Arumugam, T., Ramachandran, V., Fournier, K. F., Wang, H., Marquis, L., et al. (2009). "Epithelial to mesenchymal transition contributes to drug resistance in pancreatic cancer." Cancer Res 69(14): 5820-5828.

AYOUBI, T. A. AND VAN DE VEN, W. J. (1996). "Regulation of gene expression by alternative promoters." FASEB J 10(4): 453-460.

Babu, D. A., Chakrabarti, S. K., Garmey, J. C. and Mirmira, R. G. (2008). "Pdx1 and BetA2/NeuroD1 participate in a transcriptional complex that mediates short-range DNA looping at the insulin gene." $\mathrm{J}$ Biol Chem 283(13): 8164-8172. 
BarReto, G., Schafer, A., MARHold, J., StACH, D., SWAminathan, S. K., et al. (2007). "Gadd45a promotes epigenetic gene activation by repair-mediated DNA demethylation." Nature 445(7128): 671-675.

BeCKeR, A. E., Hernandez, Y. G., Frucht, H. ANd LUCAS, A. L. (2014). "Pancreatic ductal adenocarcinoma: risk factors, screening, and early detection." World J Gastroenterol 20(32): 11182-11198.

Bednarek, A. K., KeCK-Waggoner, C. L., Daniel, R. L., Laflin, K. J., Bergsagel, P. L., et al. (2001). "WWOX, the FRA16D gene, behaves as a suppressor of tumor growth." Cancer Res 61(22): 8068-8073.

BednAREK, A. K., LAfLIN, K. J., DANIEL, R. L., LiAo, Q., HaWkins, K. A., et al. (2000). "WWOX, a novel WW domain-containing protein mapping to human chromosome 16q23.3-24.1, a region frequently affected in breast cancer." Cancer Res 60(8): 2140-2145.

Bendinelli, P., Maroni, P., Matteuccl, E. And Desiderio, M. A. (2015). "HGF and TGFbeta1 differently influenced Wwox regulatory function on Twist program for mesenchymal-epithelial transition in bone metastatic versus parental breast carcinoma cells." Mol Cancer 14: 112.

Bergman, A. M., Pinedo, H. M. And Peters, G. J. (2002). "Determinants of resistance to 2',2'difluorodeoxycytidine (gemcitabine)." Drug Resist Updat 5(1): 19-33.

BIRD, A. (2002). "DNA methylation patterns and epigenetic memory." Genes Dev 16(1): 6-21.

Bouteille, N., Driouch, K., Hage, P. E., Sin, S., Formstecher, E., et al. (2009). "Inhibition of the Wnt/beta-catenin pathway by the WWOX tumor suppressor protein." Oncogene 28(28): 2569-2580.

BRENNAN, M. F., MocCIA, R. D. AND KLIMSTRA, D. (1996). "Management of adenocarcinoma of the body and tail of the pancreas." Ann Surg 223(5): 506-511; discussion 511-502.

Burris, H. A., 3Rd, Moore, M. J., Andersen, J., Green, M. R., Rothenberg, M. L., et al. (1997). "Improvements in survival and clinical benefit with gemcitabine as first-line therapy for patients with advanced pancreas cancer: a randomized trial." J Clin Oncol 15(6): 2403-2413.

Caldas, C., Hahn, S. A., DA Costa, L. T., Redston, M. S., Schutte, M., et al. (1994). "Frequent somatic mutations and homozygous deletions of the p16 (MTS1) gene in pancreatic adenocarcinoma." Nat Genet 8(1): 27-32.

CalHoun, E. S., Jones, J. B., AshfaQ, R., Adsay, V., BAKER, S. J., et al. (2003). "BRAF and FBXW7 (CDC4, FBW7, AGO, SEL10) mutations in distinct subsets of pancreatic cancer: potential therapeutic targets." Am J Pathol 163(4): 1255-1260.

Carrier, F., Georgel, P. T., Pourquier, P., Blake, M., Kontny, H. U., et al. (1999). "Gadd45, a p53responsive stress protein, modifies DNA accessibility on damaged chromatin." Mol Cell Biol 19(3): 1673-1685. 
Chan, T. A., Hermeking, H., Lengauer, C., Kinzler, K. W. and Vogelstein, B. (1999). "14-3-3Sigma is required to prevent mitotic catastrophe after DNA damage." Nature 401(6753): 616-620.

Chang, N. S., Doherty, J., Ensign, A., Lewis, J., Heath, J., et al. (2003). "Molecular mechanisms underlying WOX1 activation during apoptotic and stress responses." Biochem Pharmacol 66(8): 13471354.

ChANG, N. S., DOHERTY, J., ENSIGN, A., SCHULTZ, L., HSU, L. J., et al. (2005). "WOX1 is essential for tumor necrosis factor-, UV light-, staurosporine-, and p53-mediated cell death, and its tyrosine 33phosphorylated form binds and stabilizes serine 46-phosphorylated p53." J Biol Chem 280(52): 43100-43108.

Chang, N. S., Pratt, N., Heath, J., Schultz, L., SleVE, D., et al. (2001). "Hyaluronidase induction of a WW domain-containing oxidoreductase that enhances tumor necrosis factor cytotoxicity." J Biol Chem 276(5): 3361-3370.

CHEN, Y., MA, X., ZHANG, M., WANG, X., WANG, C., et al. (2014). "Gadd45a regulates hematopoietic stem cell stress responses in mice." Blood 123(6): 851-862.

Chiang, M. F., Chou, P. Y., Wang, W. J., Sze, C. I. ANd Chang, N. S. (2013). "Tumor Suppressor WWOX and p53 Alterations and Drug Resistance in Glioblastomas." Front Oncol 3: 43.

CHIANG, M. F., YEH, S. T., LIAO, H. F., CHANG, N. S. AND CHEN, Y. J. (2012). "Overexpression of WW domaincontaining oxidoreductase WOX1 preferentially induces apoptosis in human glioblastoma cells harboring mutant p53." Biomed Pharmacother 66(6): 433-438.

CHUE, B. M. (2009). "Five-year survival of metastatic pancreatic carcinoma: a study of courage and hope." Gastrointest Cancer Res 3(5): 208-211.

Conroy, T., Desseigne, F., YChou, M., Bouche, O., Guimbaud, R., et al. (2011). "FOLFIRINOX versus gemcitabine for metastatic pancreatic cancer." N Engl J Med 364(19): 1817-1825.

Conroy, T., Gavoille, C., SAmalin, E., YChou, M. And DucreuX, M. (2013). "The role of the FOlfiRINOX regimen for advanced pancreatic cancer." Curr Oncol Rep 15(2): 182-189.

ConRoY, T. AND MITRY, E. (2011). "[Chemotherapy of metastatic pancreatic adenocarcinoma: challenges and encouraging results]." Bull Cancer 98(12): 1439-1446.

Cunningham, D., ChaU, I., Stocken, D. D., VAlle, J. W., SMITH, D., et al. (2009). "Phase III randomized comparison of gemcitabine versus gemcitabine plus capecitabine in patients with advanced pancreatic cancer." J Clin Oncol 27(33): 5513-5518. 
Dalila, N., Brockmoller, J., TZVetkov, M. V., SChiRmer, M., HAUbrock, M., et al. (2015). "Impact of mineralocorticoid receptor polymorphisms on urinary electrolyte excretion with and without diuretic drugs." Pharmacogenomics 16(2): 115-127.

De Vivo, I., Huggins, G. S., Hankinson, S. E., Lescault, P. J., Boezen, M., et al. (2002). "A functional polymorphism in the promoter of the progesterone receptor gene associated with endometrial cancer risk." Proc Natl Acad Sci U S A 99(19): 12263-12268.

DelPERO, J. R., TURRINI, O. AND RAOUL, J. L. (2015). "[Management of localized, locally advanced and metastatic pancreatic adenocarcinoma]." Rev Prat 65(3): 382-389.

Deshane, J., KIM, J., BolisetTy, S., Hock, T. D., Hill-KAPTURCZAK, N., et al. (2010). "Sp1 regulates chromatin looping between an intronic enhancer and distal promoter of the human heme oxygenase-1 gene in renal cells." J Biol Chem 285(22): 16476-16486.

DI MAgLIANO, M. P. AND LOGSDON, C. D. (2013). "Roles for KRAS in pancreatic tumor development and progression." Gastroenterology 144(6): 1220-1229.

DuXBURY, M. S., ITO, H., ZINNER, M. J., AsHLEY, S. W. AND WHANG, E. E. (2004). "RNA interference targeting the $\mathrm{M} 2$ subunit of ribonucleotide reductase enhances pancreatic adenocarcinoma chemosensitivity to gemcitabine." Oncogene 23(8): 1539-1548.

El-Hage, P., Petitalot, A., Monsoro-Burq, A. H., Maczkowiak, F., Driouch, K., et al. (2015). "The TumorSuppressor WWOX and HDAC3 Inhibit the Transcriptional Activity of the beta-Catenin Coactivator BCL9-2 in Breast Cancer Cells." Mol Cancer Res 13(5): 902-912.

ELLI LILY AND COMPANY DRUG INFORMATION SHEET GEMZAR (2014) Drug information Gemzar. available from: www.gemzar.com

ESER, S., SCHNIEKE, A., SCHNEIDER, G. AND SAUR, D. (2014). "Oncogenic KRAS signalling in pancreatic cancer." Br J Cancer 111(5): 817-822.

Farrell, J. J., Bae, K., Wong, J., GuhA, C., Dicker, A. P., et al. (2012). "Cytidine deaminase singlenucleotide polymorphism is predictive of toxicity from gemcitabine in patients with pancreatic cancer: RTOG 9704." Pharmacogenomics J 12(5): 395-403.

farrell, J. J., Elsaleh, H., Garcia, M., Lal, R., Ammar, A., et al. (2009). "Human equilibrative nucleoside transporter 1 levels predict response to gemcitabine in patients with pancreatic cancer." Gastroenterology 136(1): 187-195.

FIORINI, C., Cordani, M., PAdRoni, C., Blandino, G., Di Agostino, S., et al. (2015). "Mutant p53 stimulates chemoresistance of pancreatic adenocarcinoma cells to gemcitabine." Biochim Biophys Acta 1853(1): $89-100$. 
FisheR, S. B., PATEL, S. H., BAgCl, P., KoOBY, D. A., El-RAYeS, B. F., et al. (2013). "An analysis of human equilibrative nucleoside transporter-1, ribonucleoside reductase subunit $M 1$, ribonucleoside reductase subunit $\mathrm{M} 2$, and excision repair cross-complementing gene-1 expression in patients with resected pancreas adenocarcinoma: implications for adjuvant treatment." Cancer 119(2): 445-453.

FitzGerald, P. C., Shlyakhtenko, A., MiR, A. A. And VInson, C. (2004). "Clustering of DNA sequences in human promoters." Genome Res 14(8): 1562-1574.

Fornace, A. J., JR., JACKMAn, J., Hollander, M. C., Hoffman-LiebermanN, B. And LIebermann, D. A. (1992). "Genotoxic-stress-response genes and growth-arrest genes. gadd, $\mathrm{MyD}$, and other genes induced by treatments eliciting growth arrest." Ann N Y Acad Sci 663: 139-153.

FRIDMAN, J. S. AND LOWE, S. W. (2003). "Control of apoptosis by p53." Oncogene 22(56): 9030-9040.

FUJiTA, H., OHUCHIDA, K., MizUMoto, K., ITABA, S., ITO, T., et al. (2010). "Gene expression levels as predictive markers of outcome in pancreatic cancer after gemcitabine-based adjuvant chemotherapy." Neoplasia 12(10): 807-817.

Fukunaga, A. K., Marsh, S., Murry, D. J., Hurley, T. D. AND MCLeOD, H. L. (2004). "Identification and analysis of single-nucleotide polymorphisms in the gemcitabine pharmacologic pathway." Pharmacogenomics J 4(5): 307-314.

Gillen, S., Schuster, T., Meyer Zum Buschenfelde, C., Friess, H. and Kleeff, J. (2010). "Preoperative/neoadjuvant therapy in pancreatic cancer: a systematic review and meta-analysis of response and resection percentages." PLoS Med 7(4): e1000267.

GiovannettI, E., Del TACCA, M., Mey, V., Funel, N., NannizzI, S., et al. (2006). "Transcription analysis of human equilibrative nucleoside transporter-1 predicts survival in pancreas cancer patients treated with gemcitabine." Cancer Res 66(7): 3928-3935.

GONG, F., SUN, L., WANG, Z., SHI, J., LI, W., et al. (2011). "The BCL2 gene is regulated by a special AT-rich sequence binding protein 1-mediated long range chromosomal interaction between the promoter and the distal element located within the 3'-UTR." Nucleic Acids Res 39(11): 4640-4652.

Greenhalf, W., Ghaneh, P., Neoptolemos, J. P., Palmer, D. H., Cox, T. F., et al. (2014). "Pancreatic cancer hENT1 expression and survival from gemcitabine in patients from the ESPAC-3 trial." $\underline{\mathrm{J} \text { Natl Cancer }}$ Inst 106(1): djt347.

Greenlee, R. T., Murray, T., Bolden, S. And Wingo, P. A. (2000). "Cancer statistics, 2000." CA Cancer J Clin 50(1): 7-33.

Grunewald, R., Abbruzzese, J. L., Tarassoff, P. And Plunkett, W. (1991). "Saturation of 2',2'difluorodeoxycytidine 5 '-triphosphate accumulation by mononuclear cells during a phase I trial of gemcitabine." Cancer Chemother Pharmacol 27(4): 258-262. 
Hahn, S. A., Schutte, M., Hoque, A. T., Moskaluk, C. A., DA CostA, L. T., et al. (1996). "DPC4, a candidate tumor suppressor gene at human chromosome 18q21.1." Science 271(5247): 350-353.

HAINAUt, P. AND HOLLSTEIN, M. (2000). "p53 and human cancer: the first ten thousand mutations." Adv Cancer Res 77: 81-137.

HeINEMANN, V., LABIANCA, R., HINKE, A. AND LoUVET, C. (2007). "Increased survival using platinum analog combined with gemcitabine as compared to single-agent gemcitabine in advanced pancreatic cancer: pooled analysis of two randomized trials, the GERCOR/GISCAD intergroup study and a German multicenter study." Ann Oncol 18(10): 1652-1659.

Heinemann, V., Xu, Y. Z., ChubB, S., Sen, A., Hertel, L. W., et al. (1992). "Cellular elimination of 2',2'difluorodeoxycytidine 5'-triphosphate: a mechanism of self-potentiation." Cancer Res 52(3): 533-539.

HILDESHEIM, J. AND FoRNACE, A. J., JR. (2002). "Gadd45a: an elusive yet attractive candidate gene in pancreatic cancer." Clin Cancer Res 8(8): 2475-2479.

Hollander, M. C., Alamo, I., Jackman, J., Wang, M. G., MCBRide, O. W., et al. (1993). "Analysis of the mammalian gadd45 gene and its response to DNA damage." J Biol Chem 268(32): 24385-24393.

Hollander, M. C. AND FornACE, A. J., JR. (2002). "Genomic instability, centrosome amplification, cell cycle checkpoints and Gadd45a." Oncogene 21(40): 6228-6233.

Hollander, M. C., Kovalsky, O., Salvador, J. M., Kim, K. E., Patterson, A. D., et al. (2001). "Dimethylbenzanthracene carcinogenesis in Gadd45a-null mice is associated with decreased DNA repair and increased mutation frequency." Cancer Res 61(6): 2487-2491.

Horil, A., NAKATSURU, S., MiYoshI, Y., ICHII, S., NAGASE, H., et al. (1992). "Frequent somatic mutations of the APC gene in human pancreatic cancer." Cancer Res 52(23): 6696-6698.

Howlader, N., Noone, A., Krapcho, M., Garshell, J., Neyman, N., et al. (2013). "SEer Cancer Statistics Review 1975-2010." National Cancer Institute, availiable from: http://seer.cancer.gov/csr/1975 2010 updated June 14, 2013.

HU, B. S., TAN, J. W., ZHU, G. H., WANG, D. F., ZHOU, X., et al. (2012). "WWOX induces apoptosis and inhibits proliferation of human hepatoma cell line SMMC-7721." World J Gastroenterol 18(23): 30203026.

HUA, H. W., JIANG, F., HUANG, Q., LIAO, Z. AND DING, G. (2015). "MicroRNA-153 promotes Wnt/betacatenin activation in hepatocellular carcinoma through suppression of WWOX." Oncotarget 6(6): 3840-3847. 
huang, P., Chubb, S., Hertel, L. W., Grindey, G. B. and Plunkett, W. (1991). "Action of 2',2'difluorodeoxycytidine on DNA synthesis." Cancer Res 51(22): 6110-6117.

InNOCENTI, F., OWZAR, K., Cox, N. L., Evans, P., KUBo, M., et al. (2012). "A genome-wide association study of overall survival in pancreatic cancer patients treated with gemcitabine in CALGB 80303." Clin Cancer Res 18(2): 577-584.

Itol, T., SOfuni, A., Fukushima, N., ItokawA, F., TsuchiyA, T., et al. (2007). "Ribonucleotide reductase subunit M2 mRNA expression in pretreatment biopsies obtained from unresectable pancreatic carcinomas." J Gastroenterol 42(5): 389-394.

IWAmoto, K., NakashiRo, K., TANaka, H., TokUzen, N. ANd Hamakawa, H. (2015). "Ribonucleotide reductase $\mathrm{M} 2$ is a promising molecular target for the treatment of oral squamous cell carcinoma." Int J Oncol 46(5): 1971-1977.

JaCobson, M. D., BuRne, J. F., KING, M. P., MiYASHITA, T., REed, J. C., et al. (1993). "Bcl-2 blocks apoptosis in cells lacking mitochondrial DNA." Nature 361(6410): 365-369.

JI, J., LIU, R., TONG, T., SONG, Y., JIN, S., et al. (2007). "Gadd45a regulates beta-catenin distribution and maintains cell-cell adhesion/contact." Oncogene 26(44): 6396-6405.

JONES, S., ZHANG, X., PARSONS, D. W., LIN, J. C., LEARY, R. J., et al. (2008). "Core signaling pathways in human pancreatic cancers revealed by global genomic analyses." Science 321(5897): 1801-1806.

JUNG, D. B., YUN, M., KIM, E. O., KIM, J., KIM, B., et al. (2015). "The heparan sulfate mimetic PG545 interferes with $\mathrm{Wnt} /$ beta-catenin signaling and significantly suppresses pancreatic tumorigenesis alone and in combination with gemcitabine." Oncotarget 6(7): 4992-5004.

JUNG, H. J., KIM, H. L., KIM, Y. J., WEON, J. I. AND SEO, Y. R. (2013). "A novel chemopreventive mechanism of selenomethionine: enhancement of APE1 enzyme activity via a Gadd45a, PCNA and APE1 protein complex that regulates p53-mediated base excision repair." Oncol Rep 30(4): 1581-1586.

KIM, R., TAN, A., LAI, K. K., JIANG, J., WANG, Y., et al. (2011). "Prognostic roles of human equilibrative transporter 1 (hENT-1) and ribonucleoside reductase subunit M1 (RRM1) in resected pancreatic cancer." Cancer 117(14): 3126-3134.

Kocabas, N. A., Aksoy, P., Pelleymounter, L. L., Moon, I., RYu, J. S., et al. (2008). "Gemcitabine pharmacogenomics: deoxycytidine kinase and cytidylate kinase gene resequencing and functional genomics." Drug Metab Dispos 36(9): 1951-1959.

LAI, I. L., ChOU, C. C., LAI, P. T., FANG, C. S., SHIRLEY, L. A., et al. (2014). "Targeting the Warburg effect with a novel glucose transporter inhibitor to overcome gemcitabine resistance in pancreatic cancer cells." Carcinogenesis 35(10): 2203-2213. 
LI, D., XIE, K., WolfF, R. AND AbBrUZZESE, J. L. (2004). "Pancreatic cancer." Lancet 363(9414): 1049-1057.

LI, G., RUAN, X., AUerbaCH, R. K., SANDhu, K. S., ZHeng, M., et al. (2012). "Extensive promoter-centered chromatin interactions provide a topological basis for transcription regulation." Cell 148(1-2): 84-98.

LI, L., Fridley, B., Kalari, K., Jenkins, G., Batzler, A., et al. (2008). "Gemcitabine and cytosine arabinoside cytotoxicity: association with lymphoblastoid cell expression." Cancer Res 68(17): 70507058.

MAREChAL, R., BACHET, J. B., MACKEY, J. R., DALBAN, C., DeMETTER, P., et al. (2012). "Levels of gemcitabine transport and metabolism proteins predict survival times of patients treated with gemcitabine for pancreatic adenocarcinoma." Gastroenterology 143(3): 664-674 e661-666.

Marechal, R., Mackey, J. R., Lal, R., Demetter, P., Peeters, M., et al. (2009). "Human equilibrative nucleoside transporter 1 and human concentrative nucleoside transporter 3 predict survival after adjuvant gemcitabine therapy in resected pancreatic adenocarcinoma." Clin Cancer Res 15(8): 29132919.

Mastrangelo, I. A., Courey, A. J., Wall, J. S., Jackson, S. P. And Hough, P. V. (1991). "DNA looping and Sp1 multimer links: a mechanism for transcriptional synergism and enhancement." Proc Natl Acad Sci USA 88(13): 5670-5674.

Meidhof, S., Brabletz, S., LehmanN, W., PrecA, B. T., Mock, K., et al. (2015). "ZeBB1-associated drug resistance in cancer cells is reversed by the class I HDAC inhibitor mocetinostat." EMBO Mol Med 7(6): 831-847.

Mercer, T. R., EdWARdS, S. L., Clark, M. B., Neph, S. J., WANG, H., et al. (2013). "DNase I-hypersensitive exons colocalize with promoters and distal regulatory elements." Nat Genet 45(8): 852-859.

MinI, E., Nobili, S., CaCiagl, B., LandinI, I. AND MazzeI, T. (2006). "Cellular pharmacology of gemcitabine." Ann Oncol 17 Suppl 5: v7-12.

MIYAKI, M. AND KUROKI, T. (2003). "Role of Smad4 (DPC4) inactivation in human cancer." Biochem Biophys Res Commun 306(4): 799-804.

Morton, J. P., TIMPSON, P., KARIM, S. A., RidgwAY, R. A., AthineOS, D., et al. (2010). "Mutant p53 drives metastasis and overcomes growth arrest/senescence in pancreatic cancer." Proc Natl Acad Sci U S A 107(1): 246-251.

Nagano, H., Tomimaru, Y., Eguchi, H., Hama, N., WadA, H., et al. (2013). "MicroRNA-29a induces resistance to gemcitabine through the $\mathrm{Wnt} /$ beta-catenin signaling pathway in pancreatic cancer cells." Int J Oncol 43(4): 1066-1072. 
NaKahiRa, S., Nakamori, S., TSUJie, M., TAKahashI, Y., OKami, J., et al. (2007). "Involvement of ribonucleotide reductase $\mathrm{M} 1$ subunit overexpression in gemcitabine resistance of human pancreatic cancer." International Journal of Cancer 120(6): 1355-1363.

Nakano, Y., TANno, S., KolzumI, K., Nishikawa, T., NakAmURA, K., et al. (2007). "Gemcitabine chemoresistance and molecular markers associated with gemcitabine transport and metabolism in human pancreatic cancer cells." Br J Cancer 96(3): 457-463.

NANDA, R. H., EL-RAYES, B., MAITHEL, S. K. AND LANDRY, J. (2015). "Neoadjuvant modified FOLFIRINOX and chemoradiation therapy for locally advanced pancreatic cancer improves resectability." J Surg Oncol.

Neoptolemos, J. P., Stocken, D. D., BAssi, C., Ghaneh, P., Cunningham, D., et al. (2010). "Adjuvant chemotherapy with fluorouracil plus folinic acid vs gemcitabine following pancreatic cancer resection: a randomized controlled trial." JAMA 304(10): 1073-1081.

O'ReILly, D. AND GREAVES, D. R. (2007). "Cell-type-specific expression of the human CD68 gene is associated with changes in Pol II phosphorylation and short-range intrachromosomal gene looping." Genomics 90(3): 407-415.

OKAZAKI, T., JAVle, M., TANAKA, M., AbBruZzeSE, J. L. AND LI, D. (2010). "Single nucleotide polymorphisms of gemcitabine metabolic genes and pancreatic cancer survival and drug toxicity." Clin Cancer Res 16(1): 320-329.

Paproski, R. J., YaO, S. Y., Favis, N., Evans, D., Young, J. D., et al. (2013). "Human concentrative nucleoside transporter 3 transfection with ultrasound and microbubbles in nucleoside transport deficient HEK293 cells greatly increases gemcitabine uptake." PLoS One 8(2): e56423.

Pluciennik, E., Nowakowska, M., Pospiech, K., Stepien, A., Wolkowicz, M., et al. (2015). "The role of WWOX tumor suppressor gene in the regulation of EMT process via regulation of CDH1-ZEB1-VIM expression in endometrial cancer." Int J Oncol 46(6): 2639-2648.

PlunKetT, W., HUANG, P. AND GANDHI, V. (1995). "Preclinical characteristics of gemcitabine." Anticancer Drugs 6 Suppl 6: 7-13.

Pomerantz, M. M., Ahmadiyeh, N., JiA, L., Herman, P., Verzl, M. P., et al. (2009). "The 8q24 cancer risk variant rs6983267 shows long-range interaction with MYC in colorectal cancer." Nat Genet 41(8): 882-884.

Rachakonda, P. S., Bauer, A. S., XIE, H., Campa, D., Rizzato, C., et al. (2013). "Somatic mutations in exocrine pancreatic tumors: association with patient survival." PLoS One 8(4): e60870.

Rejiba, S., Bigand, C., PARMentier, C. And HAJRI, A. (2009). "Gemcitabine-based chemogene therapy for pancreatic cancer using Ad-dCK::UMK GDEPT and TS/RR siRNA strategies." Neoplasia 11(7): 637-650. 
RichaRdS, R. I., ChoO, A., LEE, C. S., DAYAN, S. AND O'KeEFE, L. (2015). "WWOX, the chromosomal fragile site FRA16D spanning gene: its role in metabolism and contribution to cancer." Exp Biol Med (Maywood) 240(3): 338-344.

Ried, K., Finnis, M., Hobson, L., Mangelsdorf, M., Dayan, S., et al. (2000). "Common chromosomal fragile site FRA16D sequence: identification of the FOR gene spanning FRA16D and homozygous deletions and translocation breakpoints in cancer cells." Hum Mol Genet 9(11): 1651-1663.

ROBERT-KOCH INSTITUT (2012). "Krebs in Deutschland 2005 - 2006, Häufigkeiten und Trends: Bauchspeicheldrüse." 7. Auflage 2010(40 - 43. 3).

ROPPEL, S. (2013). "Functional Assessment of Biomarkers in Gemcitabine-Treated Pancreatic Cancer with Specific Focus on Nucleoside Transporter ENT1". Doctoral Thesis: 1-159.

Ruiz van Haperen, V. W., Veerman, G., Vermorken, J. B. and Peters, G. J. (1993). "2',2'-Difluorodeoxycytidine (gemcitabine) incorporation into RNA and DNA of tumour cell lines." Biochem Pharmacol 46(4): 762-766.

SAIF, M. W. AND KIM, R. (2007). "Role of platinum agents in the management of advanced pancreatic cancer." Expert Opin Pharmacother 8(16): 2719-2727.

Salvador, J. M., Brown-Clay, J. D. AND Fornace, A. J., JR. (2013). "Gadd45 in stress signaling, cell cycle control, and apoptosis." Adv Exp Med Biol 793: 1-19.

SANGER, F. AND COULSON, A. R. (1975). "A rapid method for determining sequences in DNA by primed synthesis with DNA polymerase." J Mol Biol 94(3): 441-448.

SChafer, A., Schomacher, L., Barreto, G., Doderlein, G. ANd Niehrs, C. (2010). "Gemcitabine functions epigenetically by inhibiting repair mediated DNA demethylation." PLoS One 5(11): e14060.

SCHOENFELDER, S., CLAY, I. AND FRASER, P. (2010). "The transcriptional interactome: gene expression in 3D." Curr Opin Genet Dev 20(2): 127-133.

SCHROCK, M. S. AND HUEBNER, K. (2015). "WWOX: a fragile tumor suppressor." Exp Biol Med (Maywood) 240(3): 296-304.

SHI, X., LIU, S., KLEEFF, J., FRIESS, H. AND BUCHLER, M. W. (2002). "Acquired resistance of pancreatic cancer cells towards 5-Fluorouracil and gemcitabine is associated with altered expression of apoptosisregulating genes." Oncology (Williston Park) 62(4): 354-362.

SHIMODA, M., KUBOtA, K., SHIMIZU, T. AND KATOH, M. (2015). "Randomized clinical trial of adjuvant chemotherapy with S-1 versus gemcitabine after pancreatic cancer resection." Br J Surg 102(7): 746754. 
ShrikHANDE, S. V., KleefF, J., ReiseR, C., WeitZ, J., Hinz, U., et al. (2007). "Pancreatic resection for M1 pancreatic ductal adenocarcinoma." Ann Surg Oncol 14(1): 118-127.

Siegel, R., Naishadham, D. AND Jemal, A. (2013). "Cancer statistics, 2013." CA Cancer J Clin 63(1): 11-30.

SMIt, V. T., Boot, A. J., SMits, A. M., Fleuren, G. J., CORnelisSe, C. J., et al. (1988). "KRAS codon 12 mutations occur very frequently in pancreatic adenocarcinomas." Nucleic Acids Res 16(16): 77737782.

SMITH, M. L., Chen, I. T., ZhAN, Q., BAE, I., Chen, C. Y., et al. (1994). "Interaction of the p53-regulated protein Gadd45 with proliferating cell nuclear antigen." Science 266(5189): 1376-1380.

SMith, M. L., Ford, J. M., Hollander, M. C., Bortnick, R. A., AMundson, S. A., et al. (2000). "p53mediated DNA repair responses to UV radiation: studies of mouse cells lacking p53, p21, and/or gadd45 genes." Mol Cell Biol 20(10): 3705-3714.

Sperti, C., Pasquali, C., Piccoli, A. and Pedrazzoli, S. (1997). "Recurrence after resection for ductal adenocarcinoma of the pancreas." World J Surg 21(2): 195-200.

Spratlin, J., SANGha, R., Glubrecht, D., Dabbagh, L., Young, J. D., et al. (2004). "The absence of human equilibrative nucleoside transporter 1 is associated with reduced survival in patients with gemcitabine-treated pancreas adenocarcinoma." Clin Cancer Res 10(20): 6956-6961.

Staley, C. A., Lee, J. E., Cleary, K. R., Abbruzzese, J. L., Fenoglio, C. J., et al. (1996). "Preoperative chemoradiation, pancreaticoduodenectomy, and intraoperative radiation therapy for adenocarcinoma of the pancreatic head." Am J Surg 171(1): 118-124; discussion 124-115.

Stoffel, E. M. (2015). "Screening in GI Cancers: The Role of Genetics." J Clin Oncol 33(16): 1721-1728.

TANAKA, M., Javle, M., Dong, X., EnG, C., AbBruzZese, J. L., et al. (2010). "Gemcitabine metabolic and transporter gene polymorphisms are associated with drug toxicity and efficacy in patients with locally advanced pancreatic cancer." Cancer 116(22): 5325-5335.

Thiery, J. P., ACloque, H., HuAng, R. Y. AND Nieto, M. A. (2009). "Epithelial-mesenchymal transitions in development and disease." Cell 139(5): 871-890.

Tokino, T. AND NaKamURA, Y. (2000). "The role of p53-target genes in human cancer." Crit Rev Oncol Hematol 33(1): 1-6.

Tuupanen, S., Turunen, M., Lehtonen, R., Hallikas, O., Vanharanta, S., et al. (2009). "The common colorectal cancer predisposition SNP rs6983267 at chromosome 8q24 confers potential to enhanced Wnt signaling." Nat Genet 41(8): 885-U837. 
UenO, H., KIYOSAWA, K. AND KANIWA, N. (2007). "Pharmacogenomics of gemcitabine: can genetic studies lead to tailor-made therapy?" Br J Cancer 97(2): 145-151.

VAcCARO, V., SPerdutI, I., VARI, S., BRIA, E., MelisI, D., et al. (2015). "Metastatic pancreatic cancer: Is there a light at the end of the tunnel?" World J Gastroenterol 21(16): 4788-4801.

VAlSeCCHI, M. E., Holdbrook, T., LeiBy, B. E., PeQuignot, E., LITTMAN, S. J., et al. (2012). "Is there a role for the quantification of RRM1 and ERCC1 expression in pancreatic ductal adenocarcinoma?" BMC Cancer 12: 104.

Van Laethem, J. L., Verslype, C., Iovanna, J. L., Michl, P., Conroy, T., et al. (2012). "New strategies and designs in pancreatic cancer research: consensus guidelines report from a European expert panel." Ann Oncol 23(3): 570-576.

Vincent, A., HeRman, J., SChUlick, R., HRUbAN, R. H. ANd Goggins, M. (2011). "Pancreatic cancer." Lancet 378(9791): 607-620.

Von Hoff, D. D., ERvin, T., ARena, F. P., Chiorean, E. G., Infante, J., et al. (2013). "Increased survival in pancreatic cancer with nab-paclitaxel plus gemcitabine." N Engl J Med 369(18): 1691-1703.

WANG, C., ZHANG, W., Fu, M., YANG, A., HUANG, H., et al. (2015). "Establishment of human pancreatic cancer gemcitabineresistant cell line with ribonucleotide reductase overexpression." Oncol Rep 33(1): 383-390.

WANG, J. P., WU, C. Y., YEH, Y. C., SHYR, Y. M., WU, Y. Y., et al. (2015). "Erlotinib is effective in pancreatic cancer with epidermal growth factor receptor mutations: a randomized, open-label, prospective trial." Oncotarget.

WANG, R., CHENG, L., XIA, J., WANG, Z., WU, Q., et al. (2014). "Gemcitabine resistance is associated with epithelial-mesenchymal transition and induction of HIF-1alpha in pancreatic cancer cells." Curr Cancer Drug Targets 14(4): 407-417.

Weissmueller, S., MAnchado, E., SABOROWSkI, M., MoRrIS, J. P. T., WAgenblast, E., et al. (2014). "Mutant p53 drives pancreatic cancer metastasis through cell-autonomous PDGF receptor beta signaling." Cell 157(2): 382-394.

WhITMARSH, A. J. AND DAVIS, R. J. (2000). "Regulation of transcription factor function by phosphorylation." Cell Mol Life Sci 57(8-9): 1172-1183.

Wolfgang, C. L., Herman, J. M., Laheru, D. A., Klein, A. P., Erdek, M. A., et al. (2013). "Recent progress in pancreatic cancer." CA Cancer J Clin 63(5): 318-348. 
Wong, A., SOO, R. A., YONG, W. P. AND INNOCENTI, F. (2009). "Clinical pharmacology and pharmacogenetics of gemcitabine." Drug Metab Rev 41(2): 77-88.

YAN, H. AND SUN, Y. (2014). "Evaluation of the mechanism of epithelial-mesenchymal transition in human ovarian cancer stem cells transfected with a WW domain-containing oxidoreductase gene." Oncol Lett 8(1): 426-430.

Zhan, Q., Antinore, M. J., Wang, X. W., CARrier, F., SMith, M. L., et al. (1999). "Association with Cdc2 and inhibition of Cdc2/Cyclin B1 kinase activity by the p53-regulated protein Gadd45." Oncogene 18(18): 2892-2900.

ZIMMER, C. (2013). "Identifizierung von Biomarkern für die Prognose der Gemcitabin-Therapie beim Pankreaskarzinom: RNA-, DNA- und Immunhistochemische-Analysen". Doctoral Thesis: 1-89. 


\section{Curriculum Vitae}

\section{PERSONAL INFORMATION:}

Name: Claudia Lüske

Date of birth: February 28 ${ }^{\text {th }}, 1986$

Place of birth: Oldenburg i.O.

\section{EDUCATION:}

$\begin{array}{ll}\text { 1992-1996: } & \text { Primary School, Molbergen } \\ \text { 1996- 1998: } & \text { Orientation stage, Molbergen } \\ \text { 1998- 2005: } & \begin{array}{l}\text { Academic High School } \\ \text { (Clemens-August-Gymnasium Cloppenburg) }\end{array} \\ \text { June 2005: } & \text { University-entrance diploma } \\ & \text { (Allgemeinbildendes Abitur, } \\ & \text { Clemens-August-Gymnasium Cloppenburg) } \\ \text { 2005 - 2008: } & \text { Studies in Environmental Science } \\ & \text { (Carl Von Ossietzky Universität Oldenburg) }\end{array}$

First University qualification: Bachelor of Science "Umweltwissenschaften"

Topic of my bachelor thesis:

(performed at ICBM (Institut für Chemie und Biologie des Meeres)-Terramare Wilhelmshaven, Department of Marine Chemistry):

"Gelöste freie Aminosäuren in Porenwässern von Wattsedimenten."

2009-2012: $\quad$ Studies in Toxicology

(Technische Universität Kaiserslautern)

Second University qualification: Master of Science "Toxikologie"

Topic of my master thesis:

(performed at Bayer Health Care AG, Wuppertal, Department of Immunotoxicology):

"Analyse der Genexpressionsveränderungen in der Rattenlunge nach Inhalation verschieden großer Nano-Partikel." 
since 08/2012:

PhD position in the Molecular Medicine program at the Institute of Clinical Pharmacology at the University Medical Center of the George August University Göttingen.

08/2012 - 12/2014: $\quad$ Scholarship of the DFG Research Training Group (GRK1034).

\section{Additional Qualifications:}

- Certificate in ICH/GCP-Good Clinical Practice

(IFS GmbH, Institut für anwendungsorientierte Forschung und klinische Studien).

- Certificate: Module „Lebensmitteltoxikologie“

(Gesellschaft für Toxikologie in der DGPT (Deutsche Gesellschaft für experimentelle und klinische Pharmakologie und Toxikologie e.V.) und dem Helmholtz Zentrum München). 


\title{
9 Appendix
}

\author{
Sequence of the pGeneClip ${ }^{\mathrm{TM}}$ Hygromycin vector used for sh-RNA (WWOX)-Transfection in section 3.10.2
}

3'GGGCGAATTGGGCCCGATATCTCTAGAGTCGACGAATTCGGATCCCTAAGGACCAGCTTCTTTGGGAGAGAACAGACGCAGGGGCGGGAGGGAAAAA GGGAGAGGCAGACGTCACTTCCCCTTGGCGGCTCTGGCAGCAGATTGGTCGGTTGAGTGGCAGAAAGGCAGACGGGGACTGGGCAAGGCACTGTCGGT GACATCACGGACAGGGCGACTTCTATGTAGATGAGGCAGCGCAGAGGCTGCTGCTTCGCCACTTGCTGCTTCACCACGAAGGAGTTCCCGTGCCCTGGGA GCGGGTTCAGGACCGCTGATCGGAAGTGAGAATCCCAGCTGTGTGTCAGGGCTGGAAAGGGCTCGGGAGTGCGCGGGGCAAGTGACCGTGTGTGTAAA GAGTGAGGCGTATGAGGCTGTGTCGGGGCAGAGGCCCAAGATCTCGCAGTCTGGAGTTTCAAAAGTAGACTGGGCGGCCGCATCGATGTTAACCTCGAG GAGCTCCCAACGCGTTGGATGCATAGCTTGAGTATTCTATAGTGTCACCTAAATAGCTTGGCGTAATCATGGTCATAGCTGTTTCCTGTGTGAAATTGTTAT CCGCTCACAATTCCACACAACATACGAGCCGGAAGCATAAAGTGTAAAGCCTGGGGTGCCTAATGAGTGAGCTAACTCACATTAATTGCGTTGCGCTCACT GCCCGCTTTCCAGTCGGGAAACCTGTCGTGCCAGCTGCATTAATGAATCGGCCAACGCGCGGGGAGAGGCGGTTTGCGTATTGGGCGCTCTTCCGCTGAT CTGCGCAGCACCATGGCCTGAAATAACCTCTGAAAGAGGAACTTGGTTAGGTACCTTCTGAGGCGGAAAGAACCAGCTGTGGAATGTGTGTCAGTTAGGG TGTGGAAAGTCCCCAGGCTCCCCAGCAGGCAGAAGTATGCAAAGCATGCATCTCAATTAGTCAGCAACCAGGTGTGGAAAGTCCCCAGGCTCCCCAGCAG GCAGAAGTATGCAAAGCATGCATCTCAATTAGTCAGCAACCATAGTCCCGCCCCTAACTCCGCCCATCCCGCCCCTAACTCCGCCCAGTTCCGCCCATTCTCC GCCCCATGGCTGACTAATTTTTTTTATTTATGCAGAGGCCGAGGCCGCCTCGGCCTCTGAGCTATTCCAGAAGTAGTGAGGAGGCTTTTTTGGAGGCCTAG GCTTTTGCAAAAAGCTTGATTCTTCTGACGCTAGCGATCGCCCGGGCCACCATGAAAAAGCCTGAACTCACCGCGACGTCTGTCGAGAAGTTTCTGATCGA AAAGTTCGACAGCGTGTCCGACCTGATGCAGCTCTCGGAGGGCGAAGAATCTCGTGCTTTCAGCTTCGATGTAGGAGGGCGTGGATATGTCCTGCGGGTA AATAGCTGCGCCGATGGTTTCTACAAAGATCGTTATGTTTATCGGCACTTTGCATCGGCCGCGCTCCCGATTCCGGAAGTGCTTGACATTGGGGAATTCAGC GAGAGCCTGACCTATTGCATCTCCCGCCGTGCACAGGGTGTCACGTTGCAAGACCTGCCTGAAACCGAACTGCCCGCTGTTCTGCAGCCGGTCGCGGAGG CCATGGATGCGATCGCTGCGGCCGATCTTAGCCAGACGAGCGGGTTCGGCCCATTCGGACCGCAAGGAATCGGTCAATACACTACATGGCGTGATTTCAT ATGCGCGATTGCTGATCCCCATGTGTATCACTGGCAAACTGTGATGGACGACACCGTCAGTGCGTCCGTCGCGCAGGCTCTCGATGAGCTGATGCTTTGGG CCGAGGACTGCCCCGAAGTCCGGCACCTCGTGCACGCGGATTTCGGCTCCAACAATGTCCTGACGGACAATGGCCGCATAACAGCGGTCATTGACTGGAG CGAGGCGATGTTCGGGGATTCCCAATACGAGGTCGCCAACATCTTCTTCTGGAGGCCGTGGTTGGCTTGTATGGAGCAGCAGACGCGCTACTTCGAGCGG AGGCATCCGGAGCTTGCAGGATCGCCGCGGCTCCGGGCGTATATGCTCCGCATTGGTCTTGACCAACTCTATCAGAGCTTGGTTGACGGCAATTTCGATGA TGCAGCTTGGGCGCAGGGTCGATGCGACGCAATCGTCCGATCCGGAGCCGGGACTGTCGGGCGTACACAAATCGCCCGCAGAAGCGCGGCCGTCTGGAC CGATGGCTGTGTAGAAGTACTCGCCGATAGTGGAAACCGACGCCCCAGCACTCGTCCGAGGGCAAAGGAATAGCTCGAGTTTAAACTCTAGAACCGGTCA TGGCCGCAATAAAATATCTTTATTTTCATTACATCTGTGTGTTGGTTTTTTGTGTGTTCGAACTAGAAGCTTGCTTCCTCGCTCACTGACTCGCTGCGCTCGGT CGTTCGGCTGCGGCGAGCGGTATCAGCTCACTCAAAGGCGGTAATACGGTTATCCACAGAATCAGGGGATAACGCAGGAAAGAACATGTGAGCAAAAGG CCAGCAAAAGGCCAGGAACCGTAAAAAGGCCGCGTTGCTGGCGTTTTTCCATAGGCTCCGCCCCCCTGACGAGCATCACAAAAATCGACGCTCAAGTCAG AGGTGGCGAAACCCGACAGGACTATAAAGATACCAGGCGTTTCCCCCTGGAAGCTCCCTCGTGCGCTCTCCTGTTCCGACCCTGCCGCTTACCGGATACCT GTCCGCCTTTCTCCCTTCGGGAAGCGTGGCGCTTTCTCATAGCTCACGCTGTAGGTATCTCAGTTCGGTGTAGGTCGTTCGCTCCAAGCTGGGCTGTGTGCA CGAACCCCCCGTTCAGCCCGACCGCTGCGCCTTATCCGGTAACTATCGTCTTGAGTCCAACCCGGTAAGACACGACTTATCGCCACTGGCAGCAGCCACTG GTAACGGGATTAGCAGAGCGAGGTATGTAGGCGGTGCTACAGAGTTCTTGAAGTGGTGGCCTAACTACGGCTACACTAGAAGAACAGTATTTGGTATCTG CGCTCTGCTGAAGCCAGTTACCTTCGGAAAAAGAGTTGGTAGCTCTTGATCCGGCAAACAAACCACCGCTGGTAGCGGTGGTTTTTTTGTTTGCAAGCAGC AGATTACGCGCAGAAAAAAAGGATCTCAAGAAGATCCTTTGATCTTTTTCTACGGGGTCTGACGCTCAGTGGAACGAAAACTCACGTTAAGGGATTTTGGTC ATGAGATTATCAAAAAGGATCTTCACCTAGATCCTTTTAAATTAAAAATGAAGTTTTAAATCAATCTAAAGTATATATGAGTAAACTTGGTCTGACAGTTACC AATGCTTAATCAGTGAGGCACCTATCTCAGCGATCTGTCTATTTCGTTCATCCATAGTTGCCTGACTCCCCGTCGTGTAGATAACTACGATACGGGAGGGCT TACCATCTGGCCCCAGTGCTGCAATGATACCGCGAGACCCACGCTCACCGGCTCCAGATTTATCAGCAATAAACCAGCCAGCCGGAAGGGCCGAGCGCAG AAGTGGTCCTGCAACTTTATCCGCCTCCATCCAGTCTATTAATTGTTGCCGGGAAGCTAGAGTAAGTAGTTCGCCAGTTAATAGTTTGCGCAACGTTGTTGC CATTGCTACAGGCATCGTGGTGTCACGCTCGTCGTTTGGTATGGCTTCATTCAGCTCCGGTTCCCAACGATCAAGGCGAGTTACATGATCCCCCATGTTGTG CAAAAAAGCGGTTAGCTCCTTCGGTCCTCCGATCGTTGTCAGAAGTAAGTTGGCCGCAGTGTTATCACTCATGGTTATGGCAGCACTGCATAATTCTCTTAC TGTCATGCCATCCGTAAGATGCTTTTCTGTGACTGGTGAGTACTCAACCAAGTCATTCTGAGAATAGTGTATGCGGCGACCGAGTTGCTCTTGCCCGGCGTC AATACGGGATAATACCGCGCCACATAGCAGAACTTTAAAAGTGCTCATCATTGGAAAACGTTCTTCGGGGCGAAAACTCTCAAGGATCTTACCGCTGTTGA GATCCAGTTCGATGTAACCCACTCGTGCACCCAACTGATCTTCAGCATCTTTTTACTTTCACCAGCGTTTTCTGGGTGAGCAAAAACAGGAAGGCAAAATGCCG CAAAAAAGGGAATAAGGGCGACACGGAAATGTTGAATACTCATACTCTTCCTTTTTCAATATTATTGAAGCATTTATCAGGGTTATTGTCTCATGAGCGGAT ACATATTTGAATGTATTTAGAAAAATAAACAAATAGGGGTTCCGCGCACATTTCCCCGAAAAGTGCCACCTGATGCGGTGTGAAATACCGCACAGATGCGT AAGGAGAAAATACCGCATCAGGAAATTGTAAGCGTTAATATTTTGTTAAAATTCGCGTTAAATTTTTGTTAAATCAGCTCATTTTTTAACCAATAGGCCGAA ATCGGCAAAATCCCTTATAAATCAAAAGAATAGACCGAGATAGGGTTGAGTGTTGTTCCAGTTTGGAACAAGAGTCCACTATTAAAGAACGTGGACTCCAA CGTCAAAGGGCGAAAAACCGTCTATCAGGGCGATGGCCCACTACGTGAACCATCACCCTAATCAAGTTTTTTGGGGTCGAGGTGCCGTAAAGCACTAAATC GGAACCCTAAAGGGAGCCCCCGATTTAGAGCTTGACGGGGAAAGCCGGCGAACGTGGCGAGAAAGGAAGGGAAGAAAGCGAAAGGAGCGGGCGCTAG GGCGCTGGCAAGTGTAGCGGTCACGCTGCGCGTAACCACCACACCCGCCGCGCTTAATGCGCCGCTACAGGGCGCGTCCATTCGCCATTCAGGCTGCGCA ACTGTTGGGAAGGGCGATCGGTGCGGGCCTCTTCGCTATTACGCCAGCTGGCGAAAGGGGGATGTGCTGCAAGGCGATTAAGTTGGGTAACGCCAGGGT TTTCCCAGTCACGACGTTGTAAAACGACGGCCAGTGAATTGTAATACGACTCACTATA 5' 